\title{
Nodal isolated tumor cells and micrometastases in early stage breast cancer
}

Citation for published version (APA):

de Boer, M. (2012). Nodal isolated tumor cells and micrometastases in early stage breast cancer.

[Doctoral Thesis, Maastricht University]. Maastricht University. https://doi.org/10.26481/dis.20120907mb

Document status and date:

Published: 01/01/2012

DOI:

10.26481/dis.20120907mb

Document Version:

Publisher's PDF, also known as Version of record

\section{Please check the document version of this publication:}

- A submitted manuscript is the version of the article upon submission and before peer-review. There can be important differences between the submitted version and the official published version of record.

People interested in the research are advised to contact the author for the final version of the publication, or visit the DOI to the publisher's website.

- The final author version and the galley proof are versions of the publication after peer review.

- The final published version features the final layout of the paper including the volume, issue and page numbers.

Link to publication

\footnotetext{
General rights rights.

- You may freely distribute the URL identifying the publication in the public portal. please follow below link for the End User Agreement:

www.umlib.nl/taverne-license

Take down policy

If you believe that this document breaches copyright please contact us at:

repository@maastrichtuniversity.nl

providing details and we will investigate your claim.
}

Copyright and moral rights for the publications made accessible in the public portal are retained by the authors and/or other copyright owners and it is a condition of accessing publications that users recognise and abide by the legal requirements associated with these

- Users may download and print one copy of any publication from the public portal for the purpose of private study or research.

- You may not further distribute the material or use it for any profit-making activity or commercial gain

If the publication is distributed under the terms of Article $25 \mathrm{fa}$ of the Dutch Copyright Act, indicated by the "Taverne" license above, 
Nodal isolated tumor cells and micrometastases in early stage breast cancer 


\section{Colofon}

The research described in this thesis was funded by the Netherlands Organization for Health Research and Development (ZonMw) (grant 945-06-509), and supported by the Dutch Breast Cancer Trialists' Group (BOOG).

Copyright (C 2012 Maaike de Boer. All rights reserved. No part of this thesis may be reproduced, stored in a retrieval system or transmitted in any form or by any means without the prior written permission of the author or from the publisher holding the copyright of the published articles.

ISBN: 978-90-9026856-9

Cover design: Karin Kuiper (www.muskunst.nl)

Lay-out: Tiny Wouters

Printed by: Ipskamp Drukkers B.V.

Publication of this thesis was financially supported by the Division of Medical Oncology of Maastricht University Medical Centre. 


\title{
Nodal isolated tumor cells and micrometastases in early stage breast cancer
}

\author{
PROEFSCHRIFT \\ ter verkrijging van de graad van doctor aan de Universiteit Maastricht, \\ op gezag van de Rector Magnificus, Prof. dr. L.L.G. Soete, \\ volgens het besluit van het College van Decanen, \\ in het openbaar te verdedigen \\ op vrijdag 7 september 2012 om 14.00 uur \\ door
}

Maaike de Boer

geboren op 4 augustus 1975

te Cuijk en Sint Agatha 
Promotor

Prof. dr. V.C.G. Tjan-Heijnen

\section{Copromotores}

Dr. P. Bult (Universitair Medisch Centrum St Radboud, Nijmegen)

Dr. E.M.M. Adang (Universitair Medisch Centrum St Radboud, Nijmegen)

\section{Beoordelingscommissie}

Prof. dr. M.F. von Meyenfeldt (voorzitter)

Prof. dr. A. zur Hausen

Prof. dr. A.L.M. Verbeek (Universitair Medisch Centrum St Radboud, Nijmegen) 


\section{Contents}

Chapter 1 Introduction and outline of the thesis 7

$\begin{array}{lll}\text { Chapter } 2 & \text { Breast cancer prognosis and occult lymph node } & 13\end{array}$ metastases, isolated tumor cells, and micrometastases J Natl Cancer Inst 2010;102:410-425

Chapter 3 Classification of small nodal metastases in the Dutch MIRROR breast cancer study

Submitted

Chapter 4 Micrometastases or isolated tumor cells and the outcome of breast cancer N Engl J Med 2009;361:653-663

Chapter 5 Prognostic impact of isolated tumor cells in breast cancer axillary nodes: single tumor cell(s) versus tumor cell cluster(s) and microanatomic location Breast Cancer Res Treat 2012;131:645-651

Chapter 6 Cost-effectiveness of adjuvant systemic therapy in low risk breast cancer patients with nodal isolated tumor cells or micrometastases

Ann Oncol 2012; Epub ahead of print

Chapter $7 \quad$ Non-sentinel lymph node metastases associated with isolated breast cancer cells in the sentinel node J Natl Cancer Inst 2008;100:1574-1580

Chapter 8 Regional recurrence in breast cancer patients with sentinel node micrometastases and isolated tumor cells

Ann Surg 2012;255:116-121

Chapter 9 Summary, general conclusions, and future perspectives

Nederlandse samenvatting

List of publications

Dankwoord

Curriculum vitae 


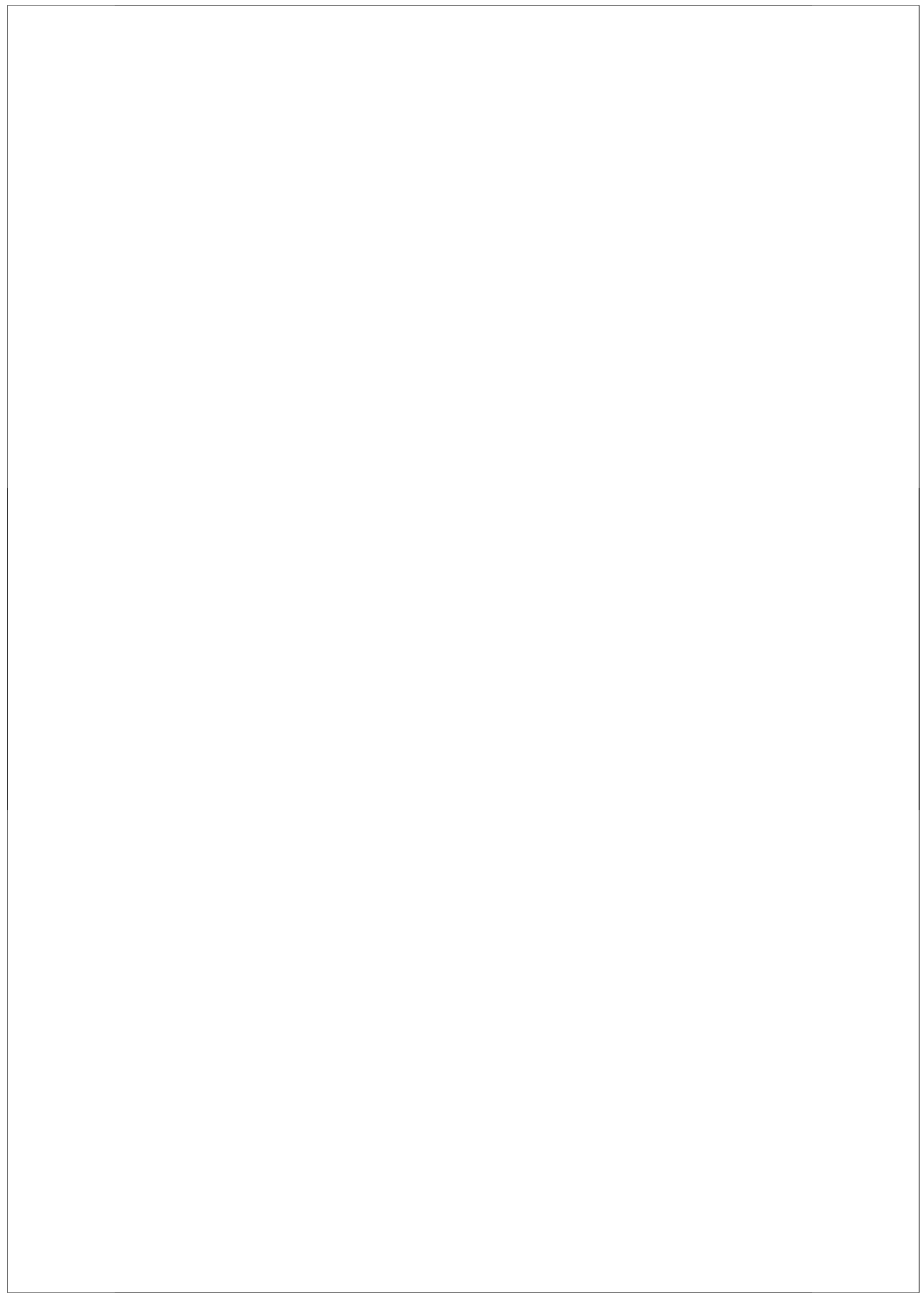




\section{Chapter 1}

Introduction and outline of the thesis 
8 Chapter 1 


\section{Introduction and outline of the thesis}

Breast cancer is a major health care problem, with a still rising incidence ${ }^{1}$. The presence of axillary lymph node metastases is the most important prognostic factor in breast cancer ${ }^{2}$. Until the nineties of the last century, every patient with breast cancer underwent an axillary lymph node dissection, in which 10 to 40 axillary lymph nodes were removed, to assess the nodal status and to remove positive lymph nodes, if present. This procedure was frequently complicated by long term morbidity, such as lymph edema, pain, numbness, and motion restriction ${ }^{3}$. With the introduction of the breast cancer screening program, the frequency of early stage, node negative breast cancer has increased ${ }^{4}$. To prevent these patients from undergoing an axillary lymph node dissection, the sentinel node procedure was introduced in the late nineties of the last century ${ }^{5}$. This procedure, in which a small number of axillary nodes are removed, is associated with a lower risk of morbidity ${ }^{3}$. The hypothesis of the sentinel node procedure supposes a spread of tumor cells from the primary tumor to the lymph nodes in the lowest level of the axilla (the sentinel lymph node(s)), before passage to other axillary lymph nodes takes place. If the sentinel node is negative, the probability of involvement of other axillary nodes (non-sentinel nodes) is assumed to be low, and a completion axillary lymph node dissection can be omitted ${ }^{6}$. If metastases are found in the sentinel lymph node, an axillary lymph node dissection is carried out to achieve a further evaluation of the nodal status, and to prevent regional recurrence in the axilla due to outgrowth of possibly remaining metastatic nodes. The concept of the sentinel node procedure was confirmed in many publications, and was adopted in daily practice quickly after introduction. Recently, a large randomized phase III study verified the safety of this procedure ${ }^{7}$.

The sentinel node is identified by preoperative lymphoscintigraphy with the use of an intra- or peritumoral injection of radioactive colloid. In addition, intraoperative, intradermal patent blue injection is used by the surgeon. The surgeon detects the sentinel node by visual inspection (patent blue) and the use of a probe (radioactivity). Usually, one to three sentinel nodes are removed. To prevent false-negative results and under treatment, the sentinel node(s) are routinely examined by the pathologist using a step-sectioning procedure, in which several levels of a lymph node are examined. Immunohistochemical staining is optionally used ${ }^{6}$. This procedure is distinct from the examination of nodes removed during an axillary lymph node dissection, as these are usually examined at only one level and without the use of immunohistochemical staining. The intensive examination of sentinel node(s) as compared to axillary lymph nodes resulted in an increased detection of small metastatic tumor deposits, including isolated tumor cells and micrometastases 8 . Before the sentinel node era, all tumor deposits of $2 \mathrm{~mm}$ or less in diameter were classified as lymph node-positive micrometastatic disease. In 2002, the Cancer Staging Manual of the American Joint Committee on Cancer $^{9}$ distinguished between isolated 
tumor cells and micrometastases. Isolated tumor cells were defined as tumor cell clusters that were not more than $0.2 \mathrm{~mm}$ in largest diameter, and were denoted as lymph node-negative $(\mathrm{pNO}[\mathrm{i}+])$. Micrometastases were defined as metastases that were larger than $0.2 \mathrm{~mm}$ up to $2 \mathrm{~mm}$ in diameter, denoted as lymph node positive $(\mathrm{pN} 1 \mathrm{mi})^{9}$. The prognostic relevance of nodal isolated tumor cells and micrometastases in patients with breast cancer has been subject of an ongoing debate for several years, and is the major topic of this thesis.

In Chapter 2, the results of all published studies on the prognostic relevance of nodal occult metastases, isolated tumor cells, and micrometastases in breast cancer in the pre-sentinel node era, and the sentinel node era are described in a systematic review and meta-analysis.

Because of insufficient evidence regarding micrometastases and prognosis, in the 2008 and earlier Dutch guidelines for treatment of breast cancer no advice was given with respect to adjuvant systemic therapy for low-risk breast cancer patients with nodal micrometastases ${ }^{10}$, and the decision was left to the individual doctor. Consequently, in the Netherlands, some patients with low risk breast cancer with micrometastases received adjuvant systemic therapy, and others did not. To evaluate the prognostic relevance of isolated tumor cells or micrometastases in the sentinel node and the role of adjuvant systemic therapy, we carried out the MIRROR (Micrometastases and Isolated tumor cells: Relevant and Robust Or Rubbish?) study. As variability in the interpretation of definitions and sizes of isolated tumor cells and micrometastases ${ }^{11}, 12$ has been described, all slides of the sentinel nodes of the patients in the MIRROR study were centrally reviewed by two breast dedicated pathologists to assure comparability of the classification of sentinel nodes. In Chapter 3 the results of a study to assess the interobserver agreement between the two reviewing pathologists are presented. In Chapter 4 the prognostic relevance of isolated tumor cells and micrometastases is described.

"Isolated tumor cells" are a heterogeneous category of nodal deposits, consisting of a single tumor cell up to tumor cell clusters. We determined the impact of extent (single cell(s) versus cell cluster(s)), size and micro-anatomic location of nodal deposit(s) on disease-free survival within the group of patients with isolated tumor cells who did not receive adjuvant systemic therapy in the MIRROR study. The results are described in Chapter 5.

To assess the cost-effectiveness of adjuvant systemic therapy in low risk breast cancer patients with isolated tumor cells or micrometastases, in Chapter 6 an economic analysis from a hospital perspective based on patient data from the MIRROR study is presented. 
The size of metastases in the sentinel node is related to the incidence of non-sentinel node metastases ${ }^{13-15}$. The chance of an additional non-sentinel node metastasis is approximately $20 \%$ among patients with micrometastases in the sentinel node $(s)^{16}$. The results of studies reporting on the chance of additional non-sentinel node metastases in the presence of isolated tumor cells in the sentinel node(s) are described in a systematic overview in Chapter 7.

In the MIRROR study, nearly $50 \%$ of patients with isolated tumor cells and approximately $15 \%$ of patients with micrometastases in the sentinel node(s) did not receive additional axillary treatment. In Chapter $\mathbf{8}$, the impact of omission of axillary treatment (axillary lymph node dissection or axillary irradiation) on the regional recurrence rate in patients with isolated tumor cells or micrometastases in the sentinel node is reported.

In Chapter 9, a summary, general conclusions, and future perspectives are described. 


\section{References}

1. Desantis C, Howlader N, Cronin KA, Jemal A. Breast cancer incidence rates in U.S. women are no longer declining. Cancer Epidemiol Biomarkers Prev 2011;20:733-739.

2. Fisher B, Bauer M, Wickerham DL, et al. Relation of number of positive axillary nodes to the prognosis of patients with primary breast cancer. An NSABP update. Cancer 1983;52:1551-1557.

3. Schrenk P, Rieger R, Shamiyeh A, Wayand W. Morbidity following sentinel lymph node biopsy versus axillary lymph node dissection for patients with breast carcinoma. Cancer 2000;88:608-614.

4. Fracheboud J, Otto SJ, van Dijck JA, Broeders MJ, Verbeek AL, De Koning HJ. Decreased rates of advanced breast cancer due to mammography screening in The Netherlands. Br J Cancer 2004; 91:861-867.

5. Giuliano AE, Kirgan DM, Guenther JM, Morton DL. Lymphatic mapping and sentinel lymphadenectomy for breast cancer. Ann Surg 1994;220:391-398.

6. Lyman GH, Giuliano AE, Somerfield MR, et al.; American Society of Clinical Oncology. American Society of Clinical Oncology guideline recommendations for sentinel lymph node biopsy in early-stage breast cancer. J Clin Oncol 2005;23:7703-7720.

7. Krag DN, Anderson SJ, Julian TB, et al. Sentinel-lymph-node resection compared with conventional axillary-lymph-node dissection in clinically node-negative patients with breast cancer: overall survival findings from the NSABP B-32 randomised phase 3 trial. Lancet Oncol 2010;11:927-933.

8. Cserni G, Amendoeira I, Apostolikas N, et al.; European Working Group for Breast Screening Pathology. Pathological work-up of sentinel lymph nodes in breast cancer. Review of current data to be considered for the formulation of guidelines. Eur J Cancer 2003;39:1654-1667.

9. Green FL, Page DL, Fleming ID. American Joint Committee on Cancer Staging Manual. $6^{\text {th }}$ ed. Philadelphia: Springer; 2002.

10. Struikmans H, Nortier JW, Rutgers EJ, et al. Guideline 'Treatment of breast cancer 2008' (revision). Ned Tijdschr Geneeskd 2008;152:2507-2511.

11. Cserni G, Amendoeira I, Apostolikas N, et al. Discrepancies in current practice of pathological evaluation of sentinel lymph nodes in breast cancer. Results of a questionnaire based survey by the European Working Group for Breast Screening Pathology. J Clin Pathol 2004;57:695-701.

12. Connolly JL. Changes and problematic areas in interpretation of the AJCC Cancer Staging Manual, 6th Edition, for breast cancer. Arch Pathol Lab Med 2006;130:287-291.

13. Yu JC, Hsu GC, Hsieh CB, Sheu LF, Chao TY. Prediction of metastasis to non-sentinel nodes by sentinel node status and primary tumor characteristics in primary breast cancer in Taiwan. World J Surg 2005; 29:813-818.

14. van Iterson, V, Leidenius M, Krogerus L, von Smitten K. Predictive factors for the status of nonsentinel nodes in breast cancer patients with tumor positive sentinel nodes. Breast Cancer Res Treat 2003;82:39-45.

15. Nos $C$, Harding-MacKean $C$, Fréneaux $P$, et al. Prediction of tumour involvement in remaining axillary lymph nodes when the sentinel node in a woman with breast cancer contains metastases. Br J Surg 2003;90:1354-1360.

16. Cserni G, Gregori D, Merletti F, et al. Meta-analysis of non-sentinel node metastases associated with micrometastatic sentinel nodes in breast cancer. Br J Surg 2004;91:1245-1252. 


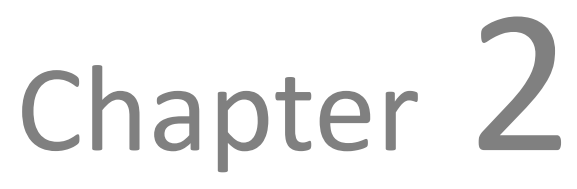

Breast cancer prognosis and occult lymph node metastases, isolated tumor cells, and micrometastases

Maaike de Boer, Jos A.A.M. van Dijck, Peter Bult, George F. Borm, Vivianne C.G. Tjan-Heijnen

J Natl Cancer Inst 2010;102:410-425 
14 Chapter 2

\section{Abstract}

\section{Background}

The prognostic relevance of isolated tumor cells and micrometastases in lymph nodes from patients with breast cancer has become a major issue since the introduction of the sentinel lymph node procedure. We conducted a systematic review of this issue.

\section{Methods}

Studies published from January 1, 1977, until August 11, 2008, were identified by use of MEDLINE, EMBASE, and the Cochrane Library. A total of 58 studies (total number of patients = 297533) were included and divided into three categories according to the method for pathological assessment of the lymph nodes: cohort studies with single-section pathological examination of axillary lymph nodes ( $n=285638$ patients), occult metastases studies with retrospective examination of negative lymph nodes by step sectioning and/or immunohistochemistry ( $n=7740$ patients), and sentinel lymph node biopsy studies with intensified work-up of the sentinel but not of the non-sentinel lymph nodes ( $n=4155$ patients). We used random-effects meta-analyses to calculate pooled estimates of the relative risks (RRs) of 5- and 10-year disease recurrence and death and the multivariably corrected pooled hazard ratio (HR) of overall survival of the cohort studies.

\section{Results}

In the cohort studies, the presence (vs the absence) of metastases of $2 \mathrm{~mm}$ or less in diameter in axillary lymph nodes was associated with poorer overall survival (pooled HR of death $=1.44$, $95 \%$ confidence interval $(\mathrm{Cl}), 1.29$ to 1.62 ). In the occult metastases studies, the presence (vs. the absence) of occult metastases was associated with poorer 5-year disease-free survival (pooled $\mathrm{RR}=1.55,95 \% \mathrm{Cl}, 1.32$ to 1.82 ) and overall survival (pooled $\mathrm{RR}=1.45,95 \% \mathrm{Cl}, 1.11$ to 1.88), although these endpoints were not consistently assessed in multivariable analyses. Sentinel lymph node biopsy studies were limited by small patient groups and short follow-up.

\section{Conclusion}

The presence (vs. the absence) of metastases of $2 \mathrm{~mm}$ or less in diameter in axillary lymph nodes detected on single-section examination was associated with poorer disease-free and overall survival. 


\section{Introduction}

Axillary lymph node status is the most important prognostic factor in breast cancer. Prognosis decreases as the number of tumor-positive lymph nodes increases ${ }^{1}$. In 1948, Saphir and Amromin ${ }^{2}$ reported that a limited number of sections, instead of many sections, taken from axillary lymph nodes were not sufficient to determine whether metastases were present or absent. They serially sectioned lymph nodes that showed no tumor in random sections and called the metastases that were so discovered "obscure" axillary lymph node metastases. Since then, the presence of tumor deposits in axillary lymph node dissection specimens that were initially assessed as negative on routine histological examination has been reported ${ }^{3-11}$. In these studies, the frequency of such occult metastases has varied widely, but their prognostic value has remained unclear. In daily clinical practice, moreover, examining all axillary lymph nodes by serial sectioning is not feasible.

This view changed soon after introduction of the sentinel lymph node procedure in the late $1990 \mathrm{~s}^{12}$. To prevent false-negative results and under treatment, the limited numbers of lymph nodes removed by the sentinel lymph node procedure are now routinely examined by use of a step-sectioning procedure, with or without immunohistochemical staining. However, as could be expected, intensive examination of sentinel lymph nodes resulted in an increased detection of small metastatic tumor deposits, including isolated tumor cells and micrometastases ${ }^{13}$, and reopened the discussion on the prognostic value of these small tumor deposits.

Before the sentinel lymph node era, all tumor deposits of $2 \mathrm{~mm}$ or less in diameter were classified as lymph node-positive micrometastatic disease. However, the Cancer Staging Manual of the American Joint Committee on Cancer (6th edition) in $2002^{14}$ distinguished between isolated tumor cells and micrometastases because of doubt about the prognostic relevance of isolated tumor cells $\mathrm{s}^{6,15-18}$. Isolated tumor cells are defined as tumor cell clusters that are not more than $0.2 \mathrm{~mm}$ in largest diameter and are denoted as lymph node negative (pNO[i+]). Micrometastases are defined as metastases that are larger than $0.2 \mathrm{~mm}$ in diameter but $2 \mathrm{~mm}$ or smaller, denoted as lymph node positive ( $\mathrm{pN} 1 \mathrm{mi}$ ).

Systematic reviews ${ }^{19,20}$ have been published on the chance of additional non-sentinel lymph node involvement. The chance of an additional non-sentinel lymph node metastasis was approximately $20 \%$ among patients with micrometastases in the sentinel lymph nodes ${ }^{19}$ and $12 \%$ among patients with isolated tumor cells in the sentinel lymph nodes ${ }^{20}$. Although several reviews ${ }^{21-31}$ have been published on the association between isolated tumor cells and micrometastases in lymph nodes and survival, none have given a complete overview of existing evidence in a systematic way. In this systematic review, we evaluated the association between occult metastases, isolated tumor cells, and micrometastases in axillary lymph nodes of patients with invasive breast cancer and disease-free and overall survival. 
16 Chapter 2

\section{Patients and methods}

\section{Literature search strategy}

We used a protocol according to guidelines for systematic reviews in health care ${ }^{32}$ to carry out this systematic review. The literature search was conducted in MEDLINE (from January 1, 1977, through August 1, 2008), EMBASE (from January 1, 1980, through August 11, 2008), and the Cochrane Library (from issue 1, January 1, 1996, through issue 3 , July 1,2008 ). The search strategy included the following key words that could be variably combined: breast cancer, (sentinel) lymph node(s), isolated tumor cell(s), micrometastases, occult metastases, prognosis, survival rate, mortality, survival analysis, cause of death, disease-free survival, recurrence, and follow-up prediction. All papers in English, German, French, and Dutch were considered. Additionally, the reference lists of selected papers were searched for additional papers.

\section{Study inclusion criteria}

The following criteria were applied to the papers that were identified by the literature search. Studies were included if patients with occult metastases, isolated tumor cells, or micrometastases in axillary lymph nodes were compared with lymph node negative patients, after a sentinel lymph node procedure and/or axillary lymph node dissection. Endpoints had to be described in terms of disease-free survival, breast cancer-specific survival, or overall survival. Studies that did not evaluate survival outcomes by life-table analyses or Kaplan-Meier methods were excluded. An exception was made for studies in patients who had undergone a sentinel lymph node procedure (ie, sentinel lymph node biopsy studies), in which survival analyses were rarely carried out because the follow-up time was short. Studies that reported on detection methods by use of molecular biology approaches (such as reverse transcriptase-polymerase chain reaction) and studies in which neoadjuvant chemotherapy was administered were excluded. If duplicate or updated studies were identified, only the more recent study was included. Only full papers that were based on original data were included.

\section{Data collection}

Two independent investigators (M. de Boer and J.A.A.M. van Dijck) extracted data to rule out potential bias or errors.

Discrepancies were resolved by consensus and if necessary by discussion with a third investigator (V.C.G. Tjan-Heijnen). The following data were extracted from the included papers: pathological assessment of removed lymph nodes; definition of isolated tumor cells, micrometastases, and occult metastases; number of patients without metastases; number of patients with lymph nodes containing isolated tumor 
cells, micrometastases, or occult metastases; included stages of disease; duration of follow-up; administration of adjuvant systemic therapy; performance of axillary lymph node dissection; definition of endpoints; disease-free, breast cancer-specific, and/or overall survival rates; and results of and factors taken into account in multivariable analyses. When data with respect to survival were not provided in text or a table of an article, they were extracted from the survival curves. Some studies did not report on exact data with respect to outcome of statistical analyses and only reported that there was no statistically significant difference in survival between the lymph node-negative and lymph node-positive group. Therefore, a complete dataset could not always be obtained for every study group evaluated in each study.

\section{Study categories}

We categorized the included studies according to the method for pathological assessment of the lymph nodes, including single or multiple sectioning with or without immunohistochemical staining. In this way, we aimed to show more clearly the differences and similarities between previous and current practice, which includes the sentinel lymph node procedure. We additionally categorized studies according to study type. The first category contained cohort studies of patients with micrometastases and/or isolated tumor cells that were detected through a singlesection histological examination without routine use of immunohistochemical staining. The second category contained occult metastases studies of patients who were lymph node negative by histological examination of axillary lymph nodes but had occult metastases (including isolated tumor cells, micrometastases, and macrometastases) by retrospective pathological examination that included step sectioning and/or immunohistochemical staining. The third category contained sentinel node biopsy studies of patients who underwent a sentinel lymph node biopsy optionally followed by an axillary lymph node dissection. In most of the sentinel lymph node biopsy studies, the sentinel lymph node(s) were evaluated by step sectioning with or without immunohistochemical staining, whereas the non-sentinel lymph nodes were evaluated in a single section that was stained with hematoxylin-eosin.

\section{Statistical analysis}

For each cohort study or occult metastases study, we calculated the 5- and 10-year relative risk (RR) of disease recurrence and/or death from any cause for the group with metastases that had a diameter of $2 \mathrm{~mm}$ or less or the group with occult metastases; the comparison group for both analyses was the lymph node-negative group. We used random-effects meta-analyses to calculate pooled estimates of the relative risks of 5- and 10-year disease recurrence and death. For some studies, the relative risks were an estimation because they had to be deduced from the KaplanMeier curves, and therefore, the standard error of the estimate could not be determined accurately. In that case, we estimated the lower and the upper boundary 
for the standard error and used the average of the two to carry out the meta-analysis. In a sensitivity analysis, we repeated the meta-analyses that were based on the standard errors that varied between the boundaries. To prevent overlap of data from studies that described subpopulations besides a total population ${ }^{7,10,33,34}$, only the total population was taken into account for calculation of the pooled estimates of the relative risks. For cohort studies that were based on overlapping selections from the Surveillance, Epidemiology, and End Results database ${ }^{35-37}$, only the largest study was used for calculation of the pooled hazard ratio $(\mathrm{HR})^{35}$. For the cohort studies that reported the results of a multivariable proportional hazard analysis, we pooled the hazard ratios of overall survival that were associated with the presence of metastases with a diameter of $2 \mathrm{~mm}$ or less by use of a random-effects approach. The heterogeneity index $\left(I^{2}\right)$ was used to evaluate inconsistency between the study results $^{38}$. We reported $95 \%$ confidence intervals (Cls). All analyses were performed in SAS (version 8.2) (SAS Institute, Cary, NC) ${ }^{39}$. All statistical tests were two-sided.

\section{Results}

\section{Literature search}

The systematic literature search yielded 953 articles. After screening of abstract and title, full texts of 129 articles were obtained and 45 articles were selected on the basis of the described selection criteria. Four articles ${ }^{40-43}$ were excluded because they were based on the same study populations as other, more recent, articles. Five additional articles ${ }^{16,17,44-46}$ were included that were identified by the manual review of references of selected articles. Consequently, 46 articles were included. Of these 46 articles, nine ${ }^{7,10,11,15,16,33,34,47,48}$ reported data on 21 populations and $37^{3-6,8,9,18,35-37,44,49-52,53-74}$ reported data on 37 populations. All populations were regarded as separate studies, resulting in the inclusion of 58 studies (with 297533 patients) for further evaluation in this systematic review. Twelve studies in 10 articles $^{34-37,44,47,49-52}$ were categorized as cohort studies (with 285638 patients); 37 studies in 27 articles ${ }^{3-11,15,16,18,33,48,53-65}$ were categorized as occult metastases studies (with 7740 patients); and nine studies in nine articles $^{66-74}$ were categorized as sentinel lymph node biopsy studies (with 4155 patients).

\section{Cohort studies}

Characteristics of the 12 cohort studies included in this review are shown in Table 1. Except for Colleoni et al. ${ }^{50}$, these studies defined micrometastases as metastases of $2 \mathrm{~mm}$ or less in diameter. No distinction was made between micrometastases and isolated tumor cells, as opposed to the current definition of micrometastases (which is tumor deposit(s) $>0.2 \mathrm{~mm}$ and $\leq 2 \mathrm{~mm}$ in size) and isolated tumor cells (which is tumor 
deposit(s) $\leq 0.2 \mathrm{~mm}$ ) in the sixth edition of the Cancer Staging Manual ${ }^{14}$. Colleoni et al. ${ }^{50}$ distinguished micrometastases (from $>0.2$ to $\leq 2 \mathrm{~mm}$ in diameter) from isolated tumor cells $(\leq 0.2 \mathrm{~mm}$ in diameter) but analyzed isolated tumor cells and micrometastases as one group. In all studies, axillary lymph node dissections were carried out without previous sentinel lymph node biopsy procedures, except in the studies of Colleoni et al. ${ }^{50}$ and Chen et al. ${ }^{35}$. In these studies, $43 \%$ and $28 \%$, respectively, of the patients had undergone a sentinel lymph node biopsy procedure that could be followed by an axillary lymph node dissection. Because most patients had undergone an axillary lymph node dissection only, we included these two studies in the cohort studies instead of in the sentinel lymph node biopsy studies. The axillary (non-sentinel) lymph nodes were examined by use of hematoxylin-eosin staining in one level without step sectioning; however, in one study ${ }^{52}$, immunohistochemical staining was used in case of doubt.

The included study populations were heterogeneous with respect to breast cancer stage, ranging from stage $\mathrm{I}^{37,47}$ to stage $\mathrm{III}^{51}$. The median follow-up in these studies was 10 years (range $=4.1-16.7$ years). Whether or not adjuvant systemic therapy had been administered was not reported in eight ${ }^{35-37,44,47,49,51}$ of 12 studies.

Disease-free survival from univariate analyses was reported in four studies ${ }^{44,47,50}$. Nine studies reported the 5-year overall survival from univariate analyses ${ }^{34,35,37,44,49-52}$, and all but two $0^{44,50}$ showed a worse 5-year overall survival in the group with metastases that were $2 \mathrm{~mm}$ or less in diameter than in the lymph node-negative group (Figure 1A) (pooled estimate for RR of death $=1.39,95 \% \mathrm{Cl}, 1.19$ to $1.62 ; I^{2}=0.38$ ). Eight cohort studies reported the 10 -year overall survival ${ }^{34-37,49,51,52}$, and all found a worse survival in the group with metastases that were $2 \mathrm{~mm}$ or less in diameter than in the lymph node-negative group (Figure 1B) (pooled estimate for RR of death $=1.21,95 \% \mathrm{Cl}, 1.13$ to $1.30 ; I^{2}=0.17$ ). The results of the sensitivity analyses were similar.

In all seven studies ${ }^{34-37,50,52}$ that carried out multivariable analyses, primary tumor size was taken into account in a model that also contained the presence of metastases that were $2 \mathrm{~mm}$ or less in diameter. Age or menopausal status was taken into account in six studies ${ }^{34-37,52}$. In three studies $35,37,50$, tumor grade and/or hormone receptor status were taken into account. One study ${ }^{37}$ carried out multivariable analysis on the prognostic impact on breast cancer-specific survival of metastases that were $2 \mathrm{~mm}$ or less in diameter. Six studies ${ }^{34-36,50,52}$ carried out multivariable analyses of the prognostic value of metastases of $2 \mathrm{~mm}$ or less in diameter on overall survival (Figure 2), five ${ }^{34-36,52}$ of which showed a negative prognostic impact on overall survival of metastases that were $2 \mathrm{~mm}$ or less in diameter (from a pooled analysis, HR of death for the presence of metastases that were $2 \mathrm{~mm}$ or less in diameter $=1.44,95 \% \mathrm{Cl}$, 1.29 to $\left.1.62 ; l^{2}=0.34\right)$. 
20 Chapter 2

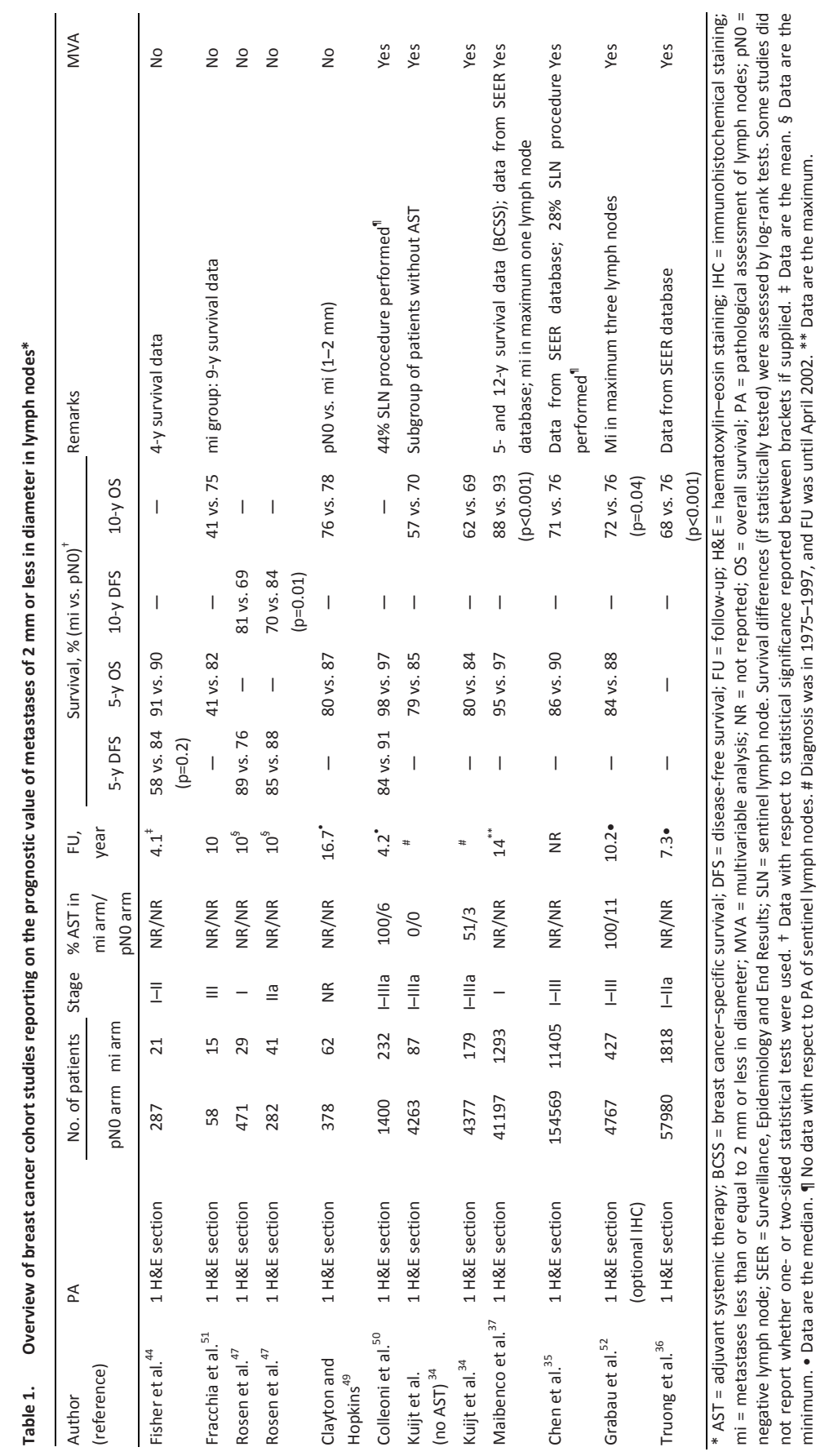


Only one study ${ }^{34}$ included a population that had been treated either with or without adjuvant systemic therapy, with separate analyses per subgroup. The presence of metastases that were $2 \mathrm{~mm}$ or less in diameter was associated with lower overall survival in the total population ( $\mathrm{HR}$ of death $=1.32,95 \% \mathrm{Cl}, 1.03$ to 1.69 ). However, in the subpopulation that had not been treated with adjuvant systemic therapy and contained $49 \%$ of the total population, the presence of metastases that were $2 \mathrm{~mm}$ or less in diameter was associated with even lower overall survival ( $H R$ of death $=1.51$, $95 \% \mathrm{Cl}, 1.11$ to 2.06$)$.
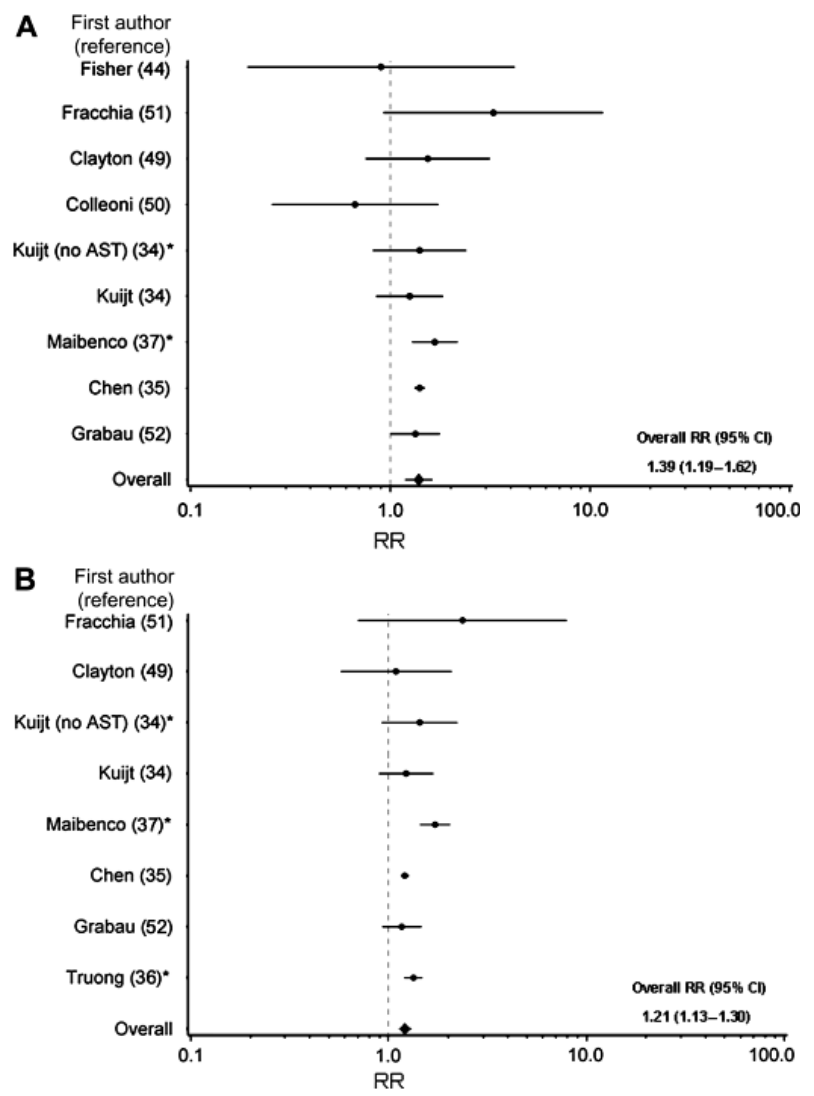

Figure 1. Cohort studies: association between risk of death after follow-up and the presence of metastases of $2 \mathrm{~mm}$ or less in diameter in axillary lymph nodes. A) A 5-year follow-up. $\left(I^{2}\right.$ for heterogeneity $=0.38$.) B) A 10 -year follow-up. $\left(I^{2}=0.17\right.$.) Each circle indicates the magnitude of the relative risk (RR), and the horizontal line through the circle indicates the $95 \%$ confidence interval $(\mathrm{Cl})$. The relative risks and their $95 \%$ confidence intervals were combined to obtain a pooled relative risk, as shown by the diamond and its $95 \%$ confidence interval. In both pooled analyses, the studies marked with an asterisk were not taken into account. The study of Kuijt et al. ${ }^{34}$ in patients without adjuvant systemic therapy (AST) was not taken into account because it was based in part on the same population as in the total population of that study. The studies of Maibenco et al. ${ }^{37}$ and Truong et al. ${ }^{36}$ were not taken into account because they were in part based on the same population as in the study of Chen et al. ${ }^{35}$. 
22 Chapter 2

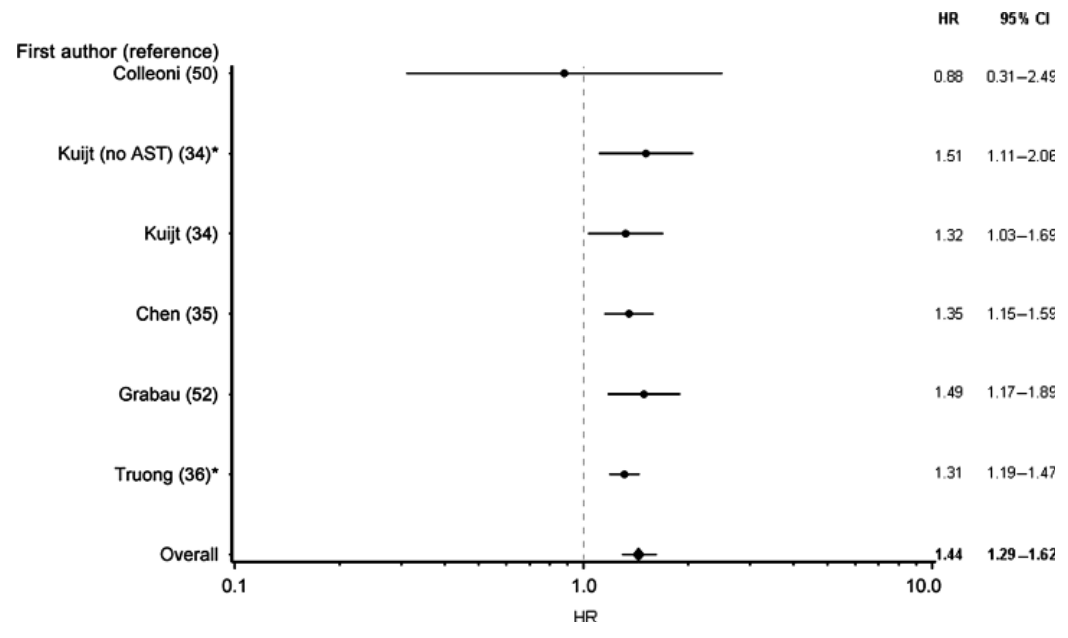

Figure 2. Cohort studies: multivariably corrected associations between overall survival (OS) and lymph nodes containing metastases of $2 \mathrm{~mm}$ or less in diameter vs lymph nodes with no metastases. $\left(I^{2}\right.$ for heterogeneity $=0.34$.) Hazard ratios (HR, circles) and $95 \%$ confidence intervals $(95 \% \mathrm{Cls}$, horizontal line through circles) were abstracted from each study and combined to obtain a pooled estimate of the association between the presence of micrometastases in lymph nodes and OS (diamond). Studies marked with an asterisk were not taken into account in the pooled analysis. The study of Truong et al. ${ }^{36}$ was not taken into account because it was based in part on the same population as that used in the study of Chen et al. ${ }^{35}$; the study of Kuijt et al. ${ }^{34}$ in patients without adjuvant systemic therapy (AST) was not taken into account because it was based in part on the same population that was analyzed in the total study group of that study.

\section{Occult metastases studies}

Characteristics of the 37 occult metastases studies ${ }^{3-11,15,16,18,33,48,53-65}$ included in this review are shown in Table 2 . The pathological assessment of the axillary lymph nodes in the occult metastases studies was very heterogeneous. In six studies ${ }^{3,15,18,57,64}$, step sectioning was carried out; in 18 studies $^{5,7,9-11,33,53,55,59-61}$, step sectioning was combined with immunohistochemical staining; and in 13 studies $^{4,6,8,16,48,54,56,58,62,63,65}$, only immunohistochemical staining was carried out. The sizes of the occult metastases were heterogeneous, ranging from single tumor cells ${ }^{10,33}$ to macrometastases that were $10 \mathrm{~mm}$ in diameter ${ }^{7}$. Breast cancer stage of the included patients was not described in 20 studies $3,7-9,11,16,18,33,55,56,60-62,65$. In 16 studies $5,6,10,15,48,53,54,57-59,63,64$, patients with stage I and/or II disease were included. Median follow-up of the occult metastases studies was 8 years (range $=3.6-24$ years). Data regarding the administration of adjuvant systemic therapy were not reported in seven studies $5,6,9,16,61,62,65$. Adjuvant systemic therapy was administered to all or some of the included patients in six studies $8,10,15,58$, and no systemic therapy was administered in 24 studies $3,4,7,11,15,16,18,33,48,53-57,59,60,63,64$. 

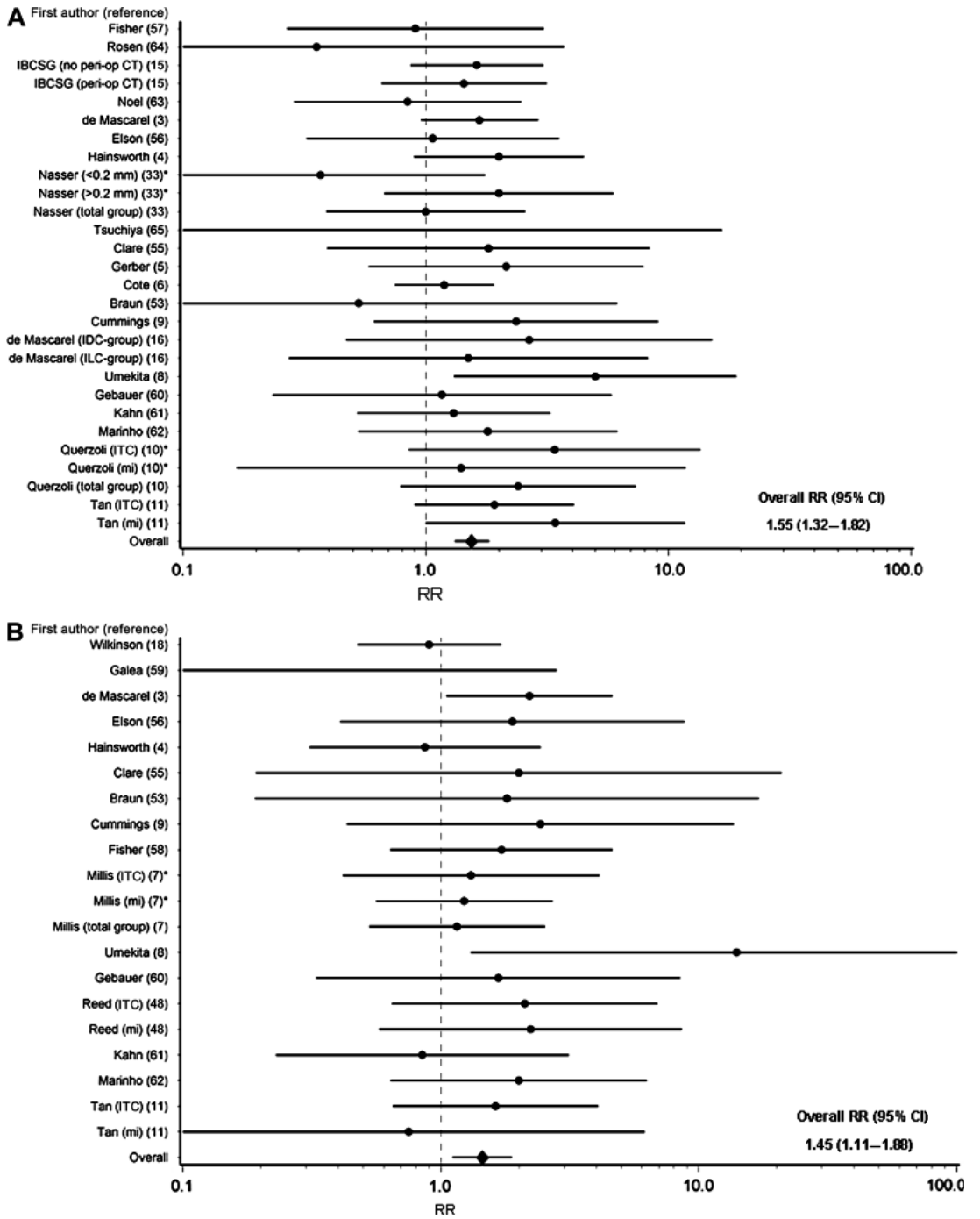

Figure 3. Occult metastases studies: associations between risk of disease recurrence or death after a 5 -year follow-up and the presence of occult metastases in axillary lymph nodes. A) Risk of disease recurrence. $\left(l^{2}\right.$ for heterogeneity $=0.15$. $)$ B) Risk of death. $\left(l^{2}=0.17\right.$. $)$ Circles indicate the relative risk (RR). The horizontal line through the circle indicates the $95 \%$ confidence interval $(\mathrm{Cl})$ of that relative risk. The relative risks and their $95 \%$ confidence intervals were combined to obtain a pooled relative risk (diamond). For both pooled analyses, the studies marked with an asterisk were not taken into account. The studies of Nasser et al. ${ }^{33}$, Querzoli et al. $^{10}$, and Millis et al. ${ }^{7}$, which describe populations with isolated tumor cells or micrometastases, were not taken into account because these populations were included in the analysis of the total group in the corresponding study. IBCSG = International Breast Cancer Study Group; IDC = invasive ductal carcinoma; ILC = invasive lobular carcinoma; ITC = isolated tumor cells of $0.2 \mathrm{~mm}$ or less in diameter; $\mathrm{mi}=$ micrometastases of greater than $0.2 \mathrm{to} 2 \mathrm{~mm}$ or less; peri-op $\mathrm{CT}$ = perioperative chemotherapy. 
24 Chapter 2

After a 5-year follow-up among the group with occult metastases, compared with the lymph node-negative group, the pooled estimates for risk of disease recurrence $(\mathrm{RR}=$ $1.55,95 \% \mathrm{Cl}, 1.32$ to $\left.1.82 ; I^{2}=0.15\right)$ (Figure $3 \mathrm{~A}$ ) and for risk of death $(\mathrm{RR}=1.45,95 \% \mathrm{Cl}$, 1.11 to $1.88 ; I^{2}=0.17$ ) (Figure $3 \mathrm{~B}$ ) were similar. In an analysis after a 10 -year follow-up that compared the same groups, the pooled estimates for risk of disease recurrence was similar to that at the 5 -year follow-up $\left(\mathrm{RR}=1.58,95 \% \mathrm{Cl}, 1.22\right.$ to $2.05 ; I^{2}=0.67$ ) (Figure $4 \mathrm{~A})$, but the risk of death was lower $\left(\mathrm{RR}=1.31,95 \% \mathrm{Cl}, 1.05\right.$ to $1.63 ; I^{2}=0.56$ ) (Figure 4B). The results of the sensitivity analyses were similar to the results above.

Separate analyses for patients with isolated tumor cells and patients with micrometastases were carried out in five studies ${ }^{7,10,11,33,48}$. All five studies found that reduced disease-free or overall survival rates were associated with micrometastases, and all but one study ${ }^{33}$ found that a reduced disease-free or overall survival rate was associated with isolated tumor cells; the comparison group for both studies was the lymph node-negative group.

The impact of occult metastases on disease-free survival was determined by multivariable analyses in only $12^{3,5,6,8,9,11,33,48,53,61,63}$ of the 37 occult metastases studies, eight ${ }^{3,5,9,11,33,53,61,63}$ of which found no negative impact. In multivariable analyses, in three ${ }^{4,11,61}$ of $\operatorname{six}^{4,8,11,48,61}$ studies on the impact of occult metastases on overall survival, occult metastases had no negative impact. Most of the studies $^{3-5,33,61,63}$ that carried out multivariable analyses on disease-free and/or overall survival and found no negative impact described the impact as "not (statistically) significant" without providing specific results. Therefore, we could not pool the results of multivariable analyses from these studies.

\section{Sentinel lymph node biopsy studies}

Characteristics of the nine sentinel lymph node biopsy studies ${ }^{66-74}$ are shown in Table 3. Eight studies ${ }^{67-74}$ processed the sentinel lymph nodes by using step sectioning and immunohistochemical staining; in one study ${ }^{66}$, only step sectioning was used. In six studies $^{66-68,70,71,73}$, no details on the breast cancer stage of included patients were reported. Median follow-up of the patients in all sentinel lymph node biopsy studies was 3 years (range $=1.2-6.1$ years). Data regarding the administration of adjuvant systemic therapy were not reported in four studies ${ }^{66,68,69,72}$. In five studies ${ }^{67,70,71,73,74}$, adjuvant systemic therapy was administered to a part of the patient population. Only one study ${ }^{74}$ carried out multivariable analyses, in which the impact of systemic therapy was taken into account. With exception of the studies of Cox et al. ${ }^{73}$ (that included 273 patients) and Gobardhan et al. ${ }^{74}$ (that included 99 patients), almost all studies were small, including up to 45 patients who had lymph nodes containing isolated tumor cells or micrometastases. Four studies carried out survival analyses: one $^{74}$ was based on final lymph node status and three ${ }^{67,70,73}$ were based on sentinel lymph node status. In all nine studies, the proportion of axillary lymph node dissection 
ranged from $0 \%$ to $100 \%$ in patients with isolated tumor cells or micrometastases and from $0 \%$ to $44 \%$ in patients with lymph node-negative disease.
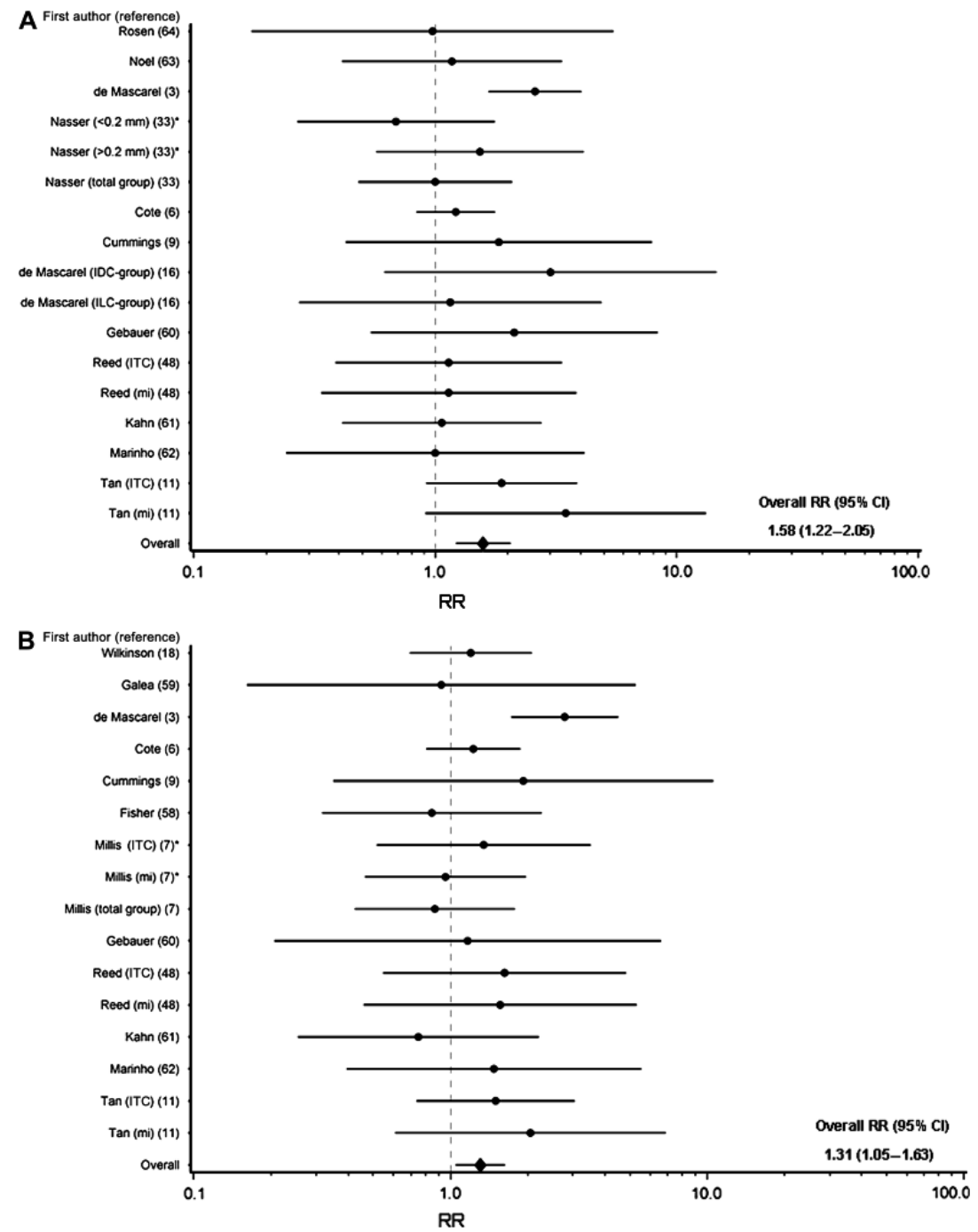

Figure 4. Occult metastases studies: association between risk of disease recurrence and death after a 10year follow-up and the presence of occult metastases in axillary lymph nodes. A) Risk of disease recurrence. $\left(I^{2}\right.$ for heterogeneity $=0.67$. $)$ B) Risk of death. $\left(I^{2}=0.56\right.$.) Circles indicate the relative risk (RR). The horizontal line through a circle indicates the $95 \%$ confidence interval $(95 \% \mathrm{Cl})$ of that relative risk. The relative risks and their $95 \%$ confidence intervals were combined to obtain a pooled relative risk (diamond). For both pooled analyses, studies marked with an asterisk were not taken into account. The studies of Nasser et al. $^{33}$ and Millis et al. ${ }^{7}$, which describe populations with isolated tumor cells or micrometastases, were not taken into account because these populations were included in the analysis of the total group of the corresponding studies. IDC = invasive ductal carcinoma; ILC = invasive lobular carcinoma; ITC = isolated tumor cells of $0.2 \mathrm{~mm}$ or less in diameter; $\mathrm{mi}=$ micrometastases of greater than 0.2 to $2 \mathrm{~mm}$ or less. 
$26 \mid$ Chapter 2

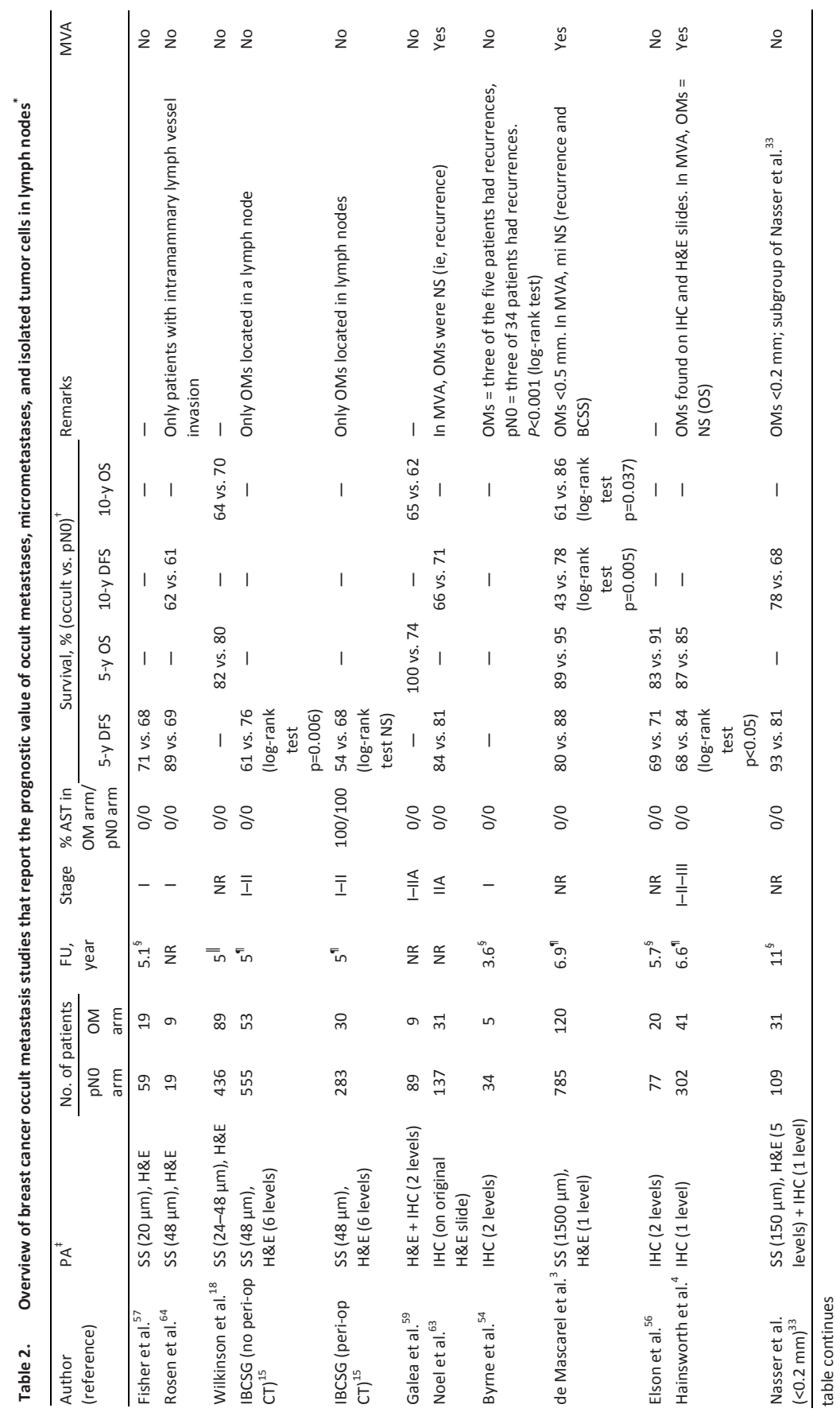




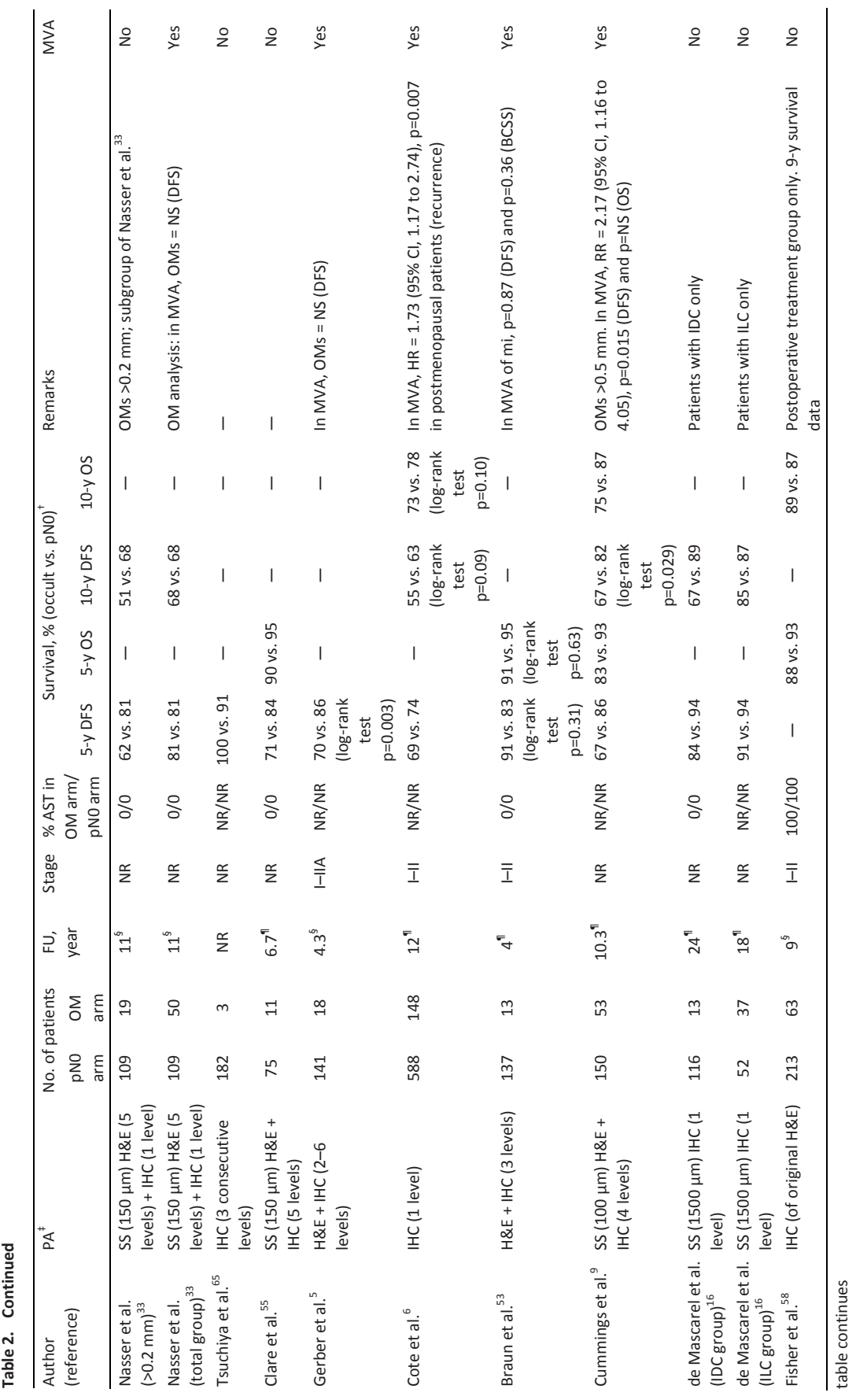




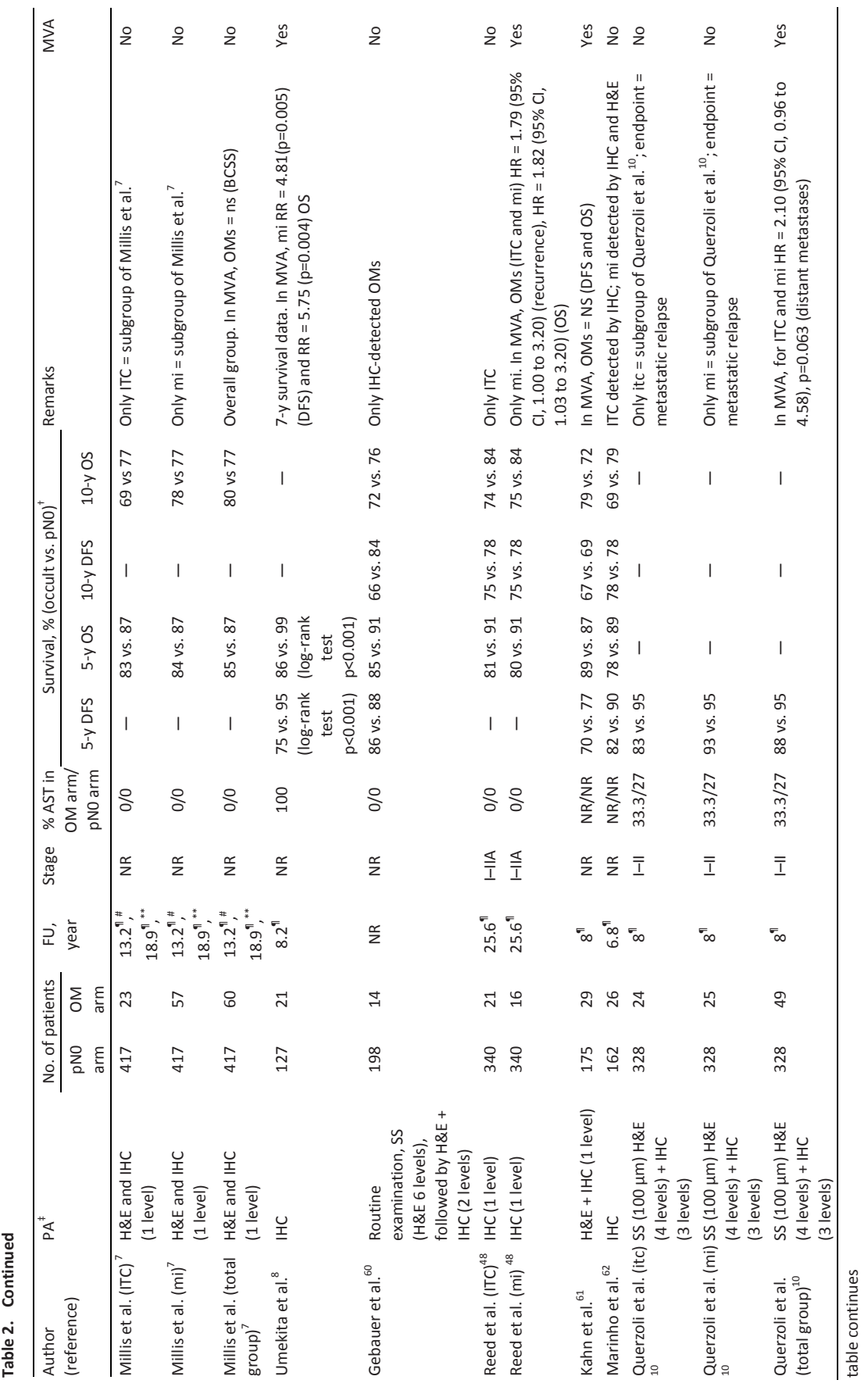


\begin{tabular}{l|l} 
Breast cancer prognosis and small lymph node metastases & 29
\end{tabular}

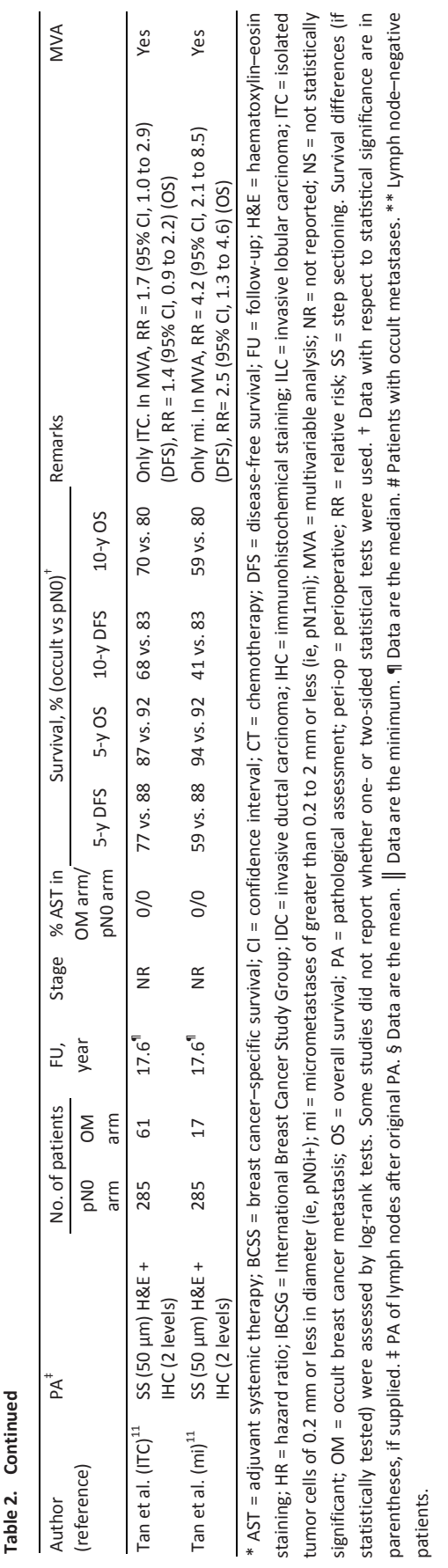




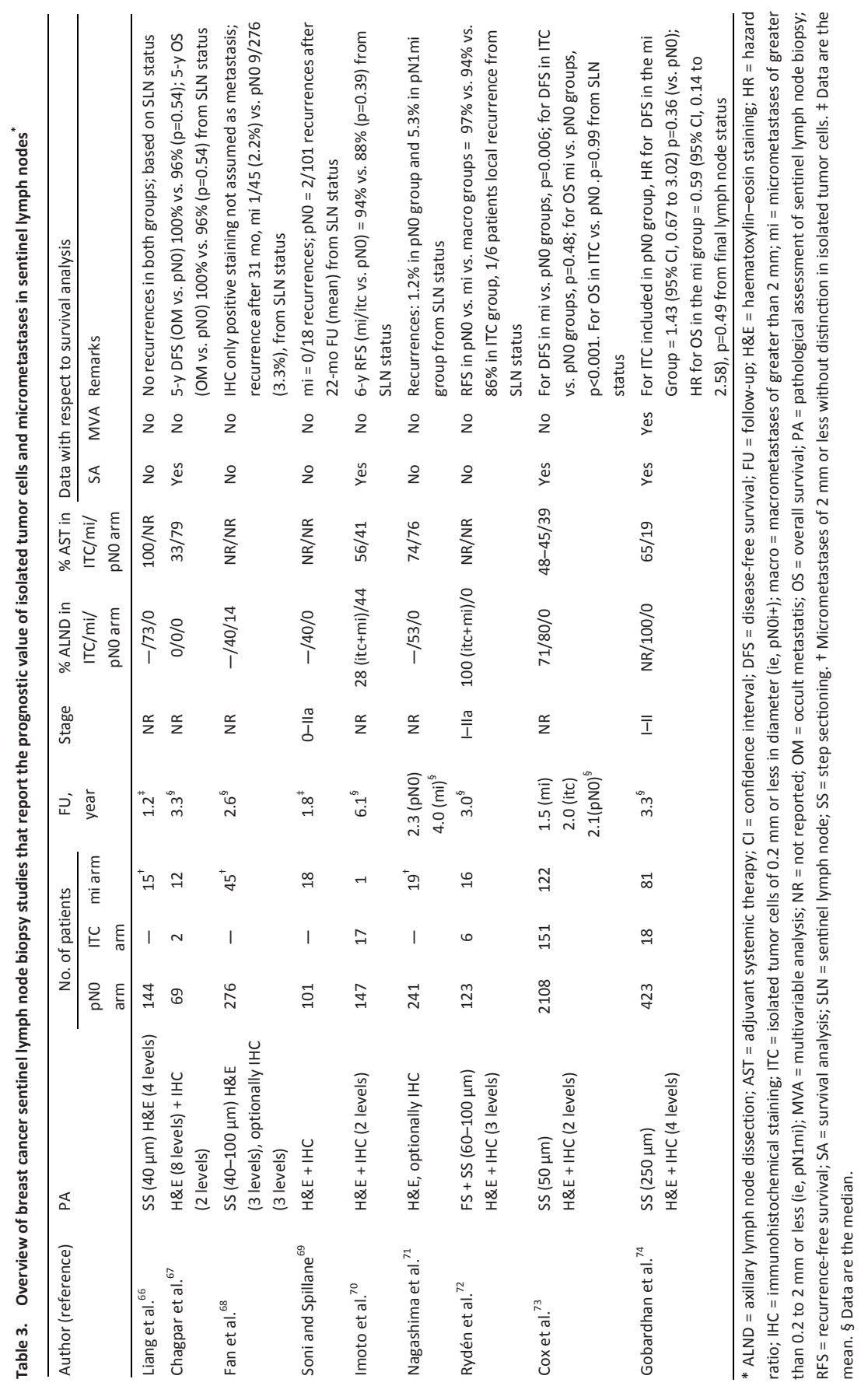


Five studies ${ }^{66-68,70,71}$ considered patients with micrometastases and isolated tumor cells as one group and found no reduced recurrence-free survival rates for these patients as compared with lymph node-negative patients, although the rates were not statistically tested in one study ${ }^{68}$. Two studies ${ }^{72,73}$ carried out separate analyses for patients with isolated tumor cells. One study ${ }^{72}$ (with 145 patients in total and six with isolated tumor cells) found a higher recurrence rate in patients with isolated tumor cells, but a survival analysis was not carried out because of small numbers of patients and events. The other larger study ${ }^{73}$ (with 2381 patients in total and 151 with isolated tumor cells) did not find a lower relapse-free survival rate for patients with isolated tumor cells.

Four studies ${ }^{69,72-74}$ assessed the prognostic impact of micrometastases (that were $>0.2 \mathrm{~mm}$ but $\leq 2 \mathrm{~mm}$ in diameter). Statistical analyses were not carried out in two studies $^{69,72}$. Two studies ${ }^{72,73}$ reported a higher recurrence rate for patients with micrometastases; however, results were based on sentinel lymph node status, and additional macrometastatic disease was found in some patients after axillary lymph node dissection. The other two studies ${ }^{69,74}$ reported no reduced survival rates for these patients. Only the data in Gobardhan et al. ${ }^{74}$ were based on final lymph node status. Although they did not find that the presence of micrometastases had a negative prognostic impact on disease-free and overall survival, they did find an increased risk of distant metastases among patients with micrometastases as final lymph node status (HR of distant metastases $=4.85,95 \% \mathrm{Cl}, 1.79$ to 13.18 ) compared with patients who were lymph node negative or who had isolated tumor cells. Random-effects meta-analyses to calculate pooled estimates of the relative risks could not be carried out because of the few studies that carried out survival analyses and because the follow-up in such studies was short.

\section{Discussion}

In this systematic review, we analyzed the association between presence of micrometastases and isolated tumor cells and outcome in 58 studies reported before August 11, 2008. These studies were categorized by the method of pathological assessment of the lymph nodes. In pooled analyses of long-term overall survival, we found that the presence of metastases of $2 \mathrm{~mm}$ or less in diameter, as detected by staining with hematoxylin-eosin in one section of each axillary lymph node, was associated with decreased overall survival, even after correction for other prognostic factors. The prognostic value of occult metastases (including isolated tumor cells, micrometastases, and macrometastases) after intensified pathological assessment of all axillary lymph nodes or of sentinel lymph nodes alone remained undetermined because of heterogeneity in methodology, small sample size, or short follow-up.

After approximately 40 years, more than 50 studies have been carried out to clarify the prognostic impact of isolated tumor cells and micrometastases in axillary lymph 
nodes in patients with breast cancer, but the issue has still not been elucidated completely. Its relevance, however, has become a major issue since the introduction of the sentinel lymph node biopsy procedure. Because the sentinel lymph node is routinely examined by use of step sectioning and immunohistochemical staining, isolated tumor cells and micrometastases are now frequently detected. Because of inconsistent findings in old studies, different policies on adjuvant systemic therapy are recommended by the American Society of Clinical Oncology, the St Gallen Breast Cancer Treatment Consensus, and the Dutch Treatment of Breast Cancer Guideline Group in patients who have otherwise favourable primary tumor characteristics ${ }^{12,75,76}$. To our knowledge, we are the first to use a systematic review to analyze the evidence that these small lymph node metastases are associated with disease-free survival and overall survival among patients with invasive breast cancer. The ultimate aim of this systematic review was to provide guidance for present practice that is based on previous studies.

The cohort studies ${ }^{34-37,44,47,49-52}$ that we analyzed in this study included almost all patients who had been diagnosed with breast cancer before the introduction of the Cancer Staging Manual in $2002^{14}$. Therefore, micrometastases were considered to be deposits of tumor cells that were $2 \mathrm{~mm}$ or less in diameter, and no distinction was made between micrometastases and isolated tumor cells ( $\leq 0.2 \mathrm{~mm}$ in diameter) and micrometastases (from $>0.2 \mathrm{~mm}$ in diameter to $\leq 2 \mathrm{~mm}$ ). In pooled analyses, the presence of metastases with a diameter of $2 \mathrm{~mm}$ or less was associated with decreased overall survival ( $\mathrm{HR}$ of death $=1.44,95 \% \mathrm{Cl}, 1.29$ to 1.62 ), after correction for other prognostic factors. These known prognostic factors were, in general, more important prognostic factors than the presence of micrometastases.

In the occult metastases studies ${ }^{3-11,15,16,18,33,48,53-65}$ that we analyzed in this study, most sample sizes of patients with occult metastases were small. In general, after 5 years of follow-up, an occult metastasis status was associated with worse survival than a lymph node-negative status (pooled $\mathrm{RR}$ of disease recurrence $=1.55,95 \% \mathrm{Cl}, 1.32$ to 1.82; and pooled RR of death $=1.45,95 \% \mathrm{Cl}, 1.11$ to 1.88 ). The occult metastases studies were heterogeneous with respect to pathological assessment, patient population, duration of follow-up, and methodology. Despite this heterogeneity, results of the studies were fairly homogenous, and the pooled estimate was inside the confidence intervals of all studies.

Multivariable analyses were carried out infrequently and did not consistently confirm the univariate results. We were not able to calculate pooled hazard ratios for the occult metastases studies because of the lack of data with respect to multivariable analyses.

The sentinel lymph node biopsy studies ${ }^{66-74}$ that we analyzed in this study could have provided evidence for or against an association between outcome and the presence of isolated tumor cells and micrometastases that are detected by use of current protocols. However, the studies in this analysis were hampered by small numbers of patients, short follow-up times, analyses that were based on sentinel lymph node 
status, and lack of multivariable analyses. The only study ${ }^{74}$ in this group of studies that carried out a multivariable analysis did not report a negative association of micrometastases (from $>0.2$ to $\leq 2 \mathrm{~mm}$ ) with disease-free and overall survival, although an almost five times higher risk for the presence of distant metastases (HR of distant metastases $=4.85,95 \% \mathrm{Cl}, 1.79$ to 13.18 ) being associated with the presence of micrometastases was reported. If the cohort studies ${ }^{35,50}$ in which sentinel lymph node biopsies were performed in a part of the patient population were taken into account in the category of sentinel lymph node biopsy studies, the presence of metastases of $2 \mathrm{~mm}$ or less in diameter in (sentinel) axillary lymph nodes was associated with lower disease-free survival ${ }^{50}$ and overall survival $\left.\right|^{35}$.

In the cohort studies, it should be noted that the axillary lymph nodes were generally processed only by use of a single section that was stained with hematoxylin-eosin. In the past, the practice in many pathology departments was to slice any lymph node in half when it was too large to fit into a cassette, and so only one half of the lymph node was examined. When a lymph node was found to be negative after hematoxylineosin staining at one level, additional step sectioning with hematoxylin-eosin staining and/or immunohistochemical staining was used. By this method, occult metastases were detected in $9 \%$ to $42 \%$ of patients ${ }^{3-11,15,16,18,33,48,53-65}$, depending on the level of detail of the work-up. The frequency of detection of small metastases increases with a more detailed work-up ${ }^{77,78}$. In sentinel lymph nodes, approximately $40 \%$ of positive lymph nodes were found to have been missed when lymph nodes are grossly bisected and then one routine histological section was examined from each lymph node half ${ }^{79}$. Therefore, in the cohort studies, the lymph node-negative groups might have contained patients with undetected (macro)metastases.

From the occult metastases studies ${ }^{3-11,15,16,18,33,48,53-65}$ and from the sentinel lymph node biopsy studies ${ }^{66-74}$, the distinct impact of systemic adjuvant therapy on survival could not be determined. In fact, the use of adjuvant systemic therapy may have obscured a true difference in survival rates in some studies because we were not able to consider this confounding parameter in the analyses. Among the cohort studies, Kuijt et al. ${ }^{34}$ found that patients with metastases of $2 \mathrm{~mm}$ or less in diameter who were not treated with adjuvant systemic therapy had a higher risk of mortality than all patients, $51 \%$ of whom had received systemic adjuvant therapy. The results of this small study underline the importance of studying the relationship of micrometastases and isolated tumor cells to prognosis among patients who have not received adjuvant systemic therapy.

This study had several limitations. Most studies did not carry out multivariable analyses because they were too small to obtain a meaningful result. Future studies on prognostic factors should be powered to obtain meaningful conclusions. It should be recognized that, in systematic reviews and pooled analyses that are based on published data, there is always the drawback of lack of individual patient data with missing information (eg, treatment information). This lack of treatment information would tend to underestimate of the risk because patients with micrometastases 
would be more likely to receive chemotherapy. In addition, biases in reported nonrandomized studies carry over to this current analysis because we have used the results of these studies in our pooled analyses. Finally, publication bias would also tend to overestimate the risk because negative studies would be less likely to be submitted for publication.

Because of non standardized pathological examinations of lymph nodes across studies, comparison of the results from cohort and occult metastases studies with studies that use the sentinel lymph node procedure and an extensive pathological examination, which is currently common practice, is difficult. Nevertheless, although the studies included in this systematic review were limited by several methodological problems, we have shown that small metastases appear to be associated with worse outcome. Ongoing or recently closed sentinel lymph node trials will hopefully provide definitive data regarding the relationship of micrometastases and isolated tumor cells to breast cancer prognosis.

Results from the International Breast Cancer Study Group 23-01 study ${ }^{80}$ should provide data to determine whether metastatic involvement of $2 \mathrm{~mm}$ or less in diameter in sentinel lymph nodes of patients with clinically lymph node-negative breast cancer is associated with prognosis. The American College of Surgeons Oncology Group Z0011 trial among patients with stage I or IIA breast cancer is evaluating the prevalence and prognostic significance of micrometastases and isolated tumor cells, as detected by immunocytochemistry, in the sentinel lymph node and in the bone marrow ${ }^{81}$. Unfortunately, this trial has been stopped because of poor accrual. The National Surgical Adjuvant Breast and Bowel Project Protocol B-32 ${ }^{82}$ is evaluating among patients who are sentinel lymph node-negative by routine pathological assessment whether a more detailed pathology investigation of sentinel lymph nodes can identify a group of patients with a potentially increased risk of systemic recurrence. The last study on this topic is the "Micrometastasis and Isolated tumor cells: Relevant and Robust Or Rubbish (MIRROR)" Trial from the Dutch Breast Cancer Trialists' Group ${ }^{83}$. A preliminary report from this study found that the presence of both isolated tumor cells and micrometastases as final lymph node status was negatively associated with disease-free survival among patients who had undergone a sentinel lymph node procedure and did not receive systemic adjuvant therapy; however, if patients with isolated tumor cells and micrometastases received systemic adjuvant therapy, disease-free survival improved.

In conclusion, since the introduction of the sentinel lymph node procedure in the late 1990s, interest has been renewed in the association of isolated tumor cells and micrometastases with prognosis. To our knowledge, we are the first to evaluate systematically the impact of these small lymph node metastases on disease-free survival and overall survival among patients with invasive breast cancer. We found in pooled analyses of long-term overall survival that the presence of metastases of $2 \mathrm{~mm}$ or less in diameter, as detected by staining with hematoxylin-eosin in one section of each axillary lymph node and without differentiation between isolated tumor cells 
and micrometastases, was negatively associated with prognosis. The independent prognostic value of occult metastases (including isolated tumor cells, micrometastases, and macrometastases) after intensive pathological assessment of all axillary lymph nodes remained undetermined. Because of non standardized pathological examination, the translation of the evidence from these older studies to the current practice of intensified examination of the sentinel lymph node but conventional examination of the non-sentinel lymph nodes is limited. In addition, studies in the sentinel lymph node era that have been published in peer-reviewed journals are hampered by small sample size and short follow-up. Therefore, results of the ongoing sentinel lymph node studies are eagerly awaited to provide data on the association of isolated tumor cells and micrometastases with prognosis and on the need for systemic adjuvant therapy.

\section{Acknowledgements}

The authors thank Wim A.J.G. Lemmens for his assistance with statistical analyses.

\section{Funding}

Netherlands Organization for Health Research and Development (ZonMw) (945-06509). 


\section{References}

1. Fisher B, Bauer M, Wickerham DL, et al. Relation of number of positive axillary nodes to the prognosis of patients with primary breast cancer. An NSABP update. Cancer 1983;52:1551-1557.

2. Saphir O, Amromin GD. Obscure axillary lymph-node metastasis in carcinoma of the breast. Cancer 1948;1:238-241.

3. de Mascarel I, Bonichon F, Coindre JM, Trojani M. Prognostic significance of breast cancer axillary lymph node micrometastases assessed by two special techniques: reevaluation with longer follow-up. Br J Cancer 1992;66:523-527.

4. Hainsworth PJ, Tjandra JJ, Stillwell RG, et al. Detection and significance of occult metastases in nodenegative breast cancer. Br J Surg 1993;80:459-463.

5. Gerber B, Krause A, Reimer T. Immunohistochemically detected lymph-node micrometastases in breast cancer and their correlation with prognostic factors. Breast J 1997;3:106-111.

6. Cote RJ, Peterson HF, Chaiwun B, et al. Role of immunohistochemical detection of lymph-node metastases in management of breast cancer. International Breast Cancer Study Group. Lancet 1999;354:896-900.

7. Millis RR, Springall R, Lee AH, Ryder K, Rytina ER, Fentiman IS. Occult axillary lymph node metastases are of no prognostic significance in breast cancer. Br J Cancer 2002;86:396-401.

8. Umekita Y, Ohi Y, Sagara Y, Yoshida H. Clinical significance of occult micrometastases in axillary lymph nodes in "node-negative" breast cancer patients. Jpn J Canc Res 2002;93:695-698.

9. Cummings MC, Walsh MD, Hohn BG, Bennett IC, Wright RG, McGuckin MA. Occult axillary lymph node metastases in breast cancer do matter: results of 10-year survival analysis. Am J Surg Pathol 2002;26:1286-1295.

10. Querzoli P, Pedriali M, Rinaldi R, et al. Axillary lymph node nanometastases are prognostic factors for disease-free survival and metastatic relapse in breast cancer patients. Clin Cancer Res 2006;12: 6696-6701.

11. Tan LK, Giri D, Hummer AJ, et al. Occult axillary node metastases in breast cancer are prognostically significant: results in 368 node-negative patients with 20-year follow-up. J Clin Oncol 2008;26: 1803-1809.

12. Lyman GH, Giuliano AE, Somerfield MR, et al; American Society of Clinical Oncology. American Society of Clinical Oncology guideline recommendations for sentinel lymph node biopsy in early-stage breast cancer. J Clin Oncol 2005;23:7703-7720.

13. Cserni G, Amendoeira I, Apostolikas N, et al; European Working Group for Breast Screening Pathology Pathological work-up of sentinel lymph nodes in breast cancer. Review of current data to be considered for the formulation of guidelines. Eur J Cancer 2003;39:1654-1667.

14. Green FL, Page DL, Fleming ID. American Joint Committee on Cancer Staging Manual. 6th ed. Philadelphia, PA: Springer; 2002.

15. International (Ludwig) Breast Cancer Study Group. Prognostic importance of occult axillary lymph node micrometastases from breast cancers. Lancet 1990;335:1565-1568.

16. de Mascarel I, MacGrogan G, Picot V, Mathoulin-Pelissier S. Prognostic significance of immunohistochemically detected breast cancer node metastases in 218 patients. $\mathrm{Br} \mathrm{J}$ Cancer 2002;87:70-74.

17. Friedman S, Bertin $\mathrm{F}$, Mouriesse $\mathrm{H}$, et al. Importance of tumor cells in axillary node sinus margins ("clandestine" metastases) discovered by serial sectioning in operable breast carcinoma. Acta Oncol 1988;27:483-487.

18. Wilkinson EJ, Hause LL, Hoffman RG, et al. Occult axillary lymph node metastases in invasive breast carcinoma: characteristics of the primary tumor and significance of the metastases. Pathol Annu 1982;17:67-91.

19. Cserni G, Gregori D, Merletti F, et al. Meta-analysis of non-sentinel node metastases associated with micrometastatic sentinel nodes in breast cancer. Br J Surg 2004;91:1245-1252.

20. van Deurzen $\mathrm{CH}$, de Boer $\mathrm{M}$, Monninkhof $\mathrm{EM}$, et al. Non-sentinel lymph node metastases associated with isolated breast cancer cells in the sentinel node. J Natl Cancer Inst 2008;100:1574-1580.

21. Dowlatshahi K, Fan M, Snider HC, Habib FA. Lymph node micrometastases from breast carcinoma: reviewing the dilemma. Cancer 1997;80:1188-1197. 
22. Gray RJ, Cox CE, Reintgen DS. Importance of missed axillary micrometastases in breast cancer patients. Breast J 2001;7:303-307.

23. Mittendorf EA, Hunt KK. Significance and management of micrometastases in patients with breast cancer. Expert Rev Anticancer Ther 2007;7:1451-1461.

24. Noguchi M. Therapeutic relevance of breast cancer micrometastases in sentinel lymph nodes. $\mathrm{Br} \mathrm{J}$ Surg 2002;89:1505-1515.

25. Quan ML, Cody HS. Missed micrometastatic disease in breast cancer. Semin Oncol 2004;31:311-317.

26. Rutgers EJ. Sentinel node biopsy: interpretation and management of patients with immunohistochemistry-positive sentinel nodes and those with micrometastases. J Clin Oncol 2008;26:698-702.

27. Sakorafas GH, Geraghty J, Pavlakis G. The clinical significance of axillary lymph node micrometastases in breast cancer. Eur J Surg Oncol 2004;30:807-816.

28. Steinhoff MM. Axillary node micrometastases: detection and biologic significance. Breast J 1999;5:325-329.

29. Tjan-Heijnen VC, Bult P, de Widt-Levert LM, Ruers TJ, Beex LV. Micro-metastases in axillary lymph nodes: an increasing classification and treatment dilemma in breast cancer due to the introduction of the sentinel lymph node procedure. Breast Cancer Res Treat 2001;70:81-88.

30. Wada N. Clinical evidence of breast cancer micrometastasis in the era of sentinel node biopsy. Int J Clin Oncol 2008;13:24-32.

31. Weaver DL. Sentinel lymph nodes and breast carcinoma: which micrometastases are clinically significant? Am J Surg Pathol 2003;27:842-845.

32. Egger M, Smith GD. In: Egger M, Smith GD, Altman D, eds. Principles and procedures for systematic reviews. Systematic Reviews in Health Care: Meta-analysis in Context. 2nd ed, Part I, chap 2. London, UK: BMJ Books; 2001:23-42.

33. Nasser IA, Lee AK, Bosari S, Saganich R, Heatley G, Silverman ML. Occult axillary lymph node metastases in "node-negative" breast carcinoma. Hum Pathol 1993;24:950-957.

34. Kuijt GP, Voogd AC, van de Poll-Franse LV, Scheijmans L, van Beek MW, Roumen RM. The prognostic significance of axillary lymph-node micrometastases in breast cancer patients. Eur J Surg Oncol 2005;31:500-505.

35. Chen SL, Hoehne FM, Giuliano AE. The prognostic significance of micrometastases in breast cancer: a SEER population-based analysis. Ann Surg Oncol 2007;14:3378-3384.

36. Truong PT, Vinh-Hung V, Cserni G, Woodward WA, Tai P, Vlastos G. The number of positive nodes and the ratio of positive to excised nodes are significant predictors of survival in women with micrometastatic node-positive breast cancer. Eur J Cancer 2008;44:1670-1677.

37. Maibenco DC, Dombi GW, Kau TY, Severson RK. Significance of micrometastases on the survival of women with T1 breast cancer. Cancer 2006;107:1234-1239.

38. Higgins JP, Thompson SG, Deeks JJ, Altman DG. Measuring inconsistency in meta-analyses. BMJ 2003;327:557-560.

39. SAS/STAT ${ }^{\circledR}$ User's Guide. Version 8.2.Cary, NC: SAS Institute Inc; 1999.

40. Hartveit F, Lilleng PK. Breast cancer: two micrometastatic variants in the axilla that differ in prognosis. Histopathology 1996;28:241-246.

41. McGuckin MA, Cummings MC, Walsh MD, Hohn BG, Bennett IC, Wright RG. Occult axillary node metastases in breast cancer: their detection and prognostic significance. Br J Cancer 1996;73:88-95.

42. Trojani M, de Mascarel I, Bonichon F, Coindre JM, Delsol G. Micrometastases to axillary lymph nodes from carcinoma of breast: detection by immunohistochemistry and prognostic significance. $\mathrm{Br} \mathrm{J}$ Cancer 1987;55:303-306.

43. Trojani M, de Mascarel I, Coindre JM, Bonichon F. Micrometastases to axillary lymph nodes from invasive lobular carcinoma of breast: detection by immunohistochemistry and prognostic significance. Br J Cancer 1987;56:838-839.

44. Fisher ER, Palekar A, Rockette H, Redmond C, Fisher B. Pathologic findings from the national surgical adjuvant breast project (protocol no. 4) V. Significance of axillary nodal micro- and macrometastases. Cancer 1978;42:2032-2038.

45. Huvos AG, Hutter RV, Berg JW. Significance of axillary macrometastases and micrometastases in mammary cancer. Ann Surg 1971;173:44-46.

46. Pickren JW. Significance of occult metastases. A study of breast cancer. Cancer 1961;14:1266-1271. 
38 Chapter 2

47. Rosen PP, Saigo PE, Braun DW, Weathers E, Fracchia AA, Kinne DW. Axillary micro- and macrometastases in breast cancer: prognostic significance of tumor size. Ann Surg 1981;194:585-591.

48. Reed W, Bohler PJ, Sandstad B, Nesland JM. Occult metastases in axillary lymph nodes as a predictor of survival in node-negative breast carcinoma with long-term follow-up. Breast J 2004;10:174-180.

49. Clayton F, Hopkins CL. Pathologic correlates of prognosis in lymph node-positive breast carcinomas. Cancer 1993;71:1780-1790.

50. Colleoni M, Rotmensz N, Peruzzotti G, et al. Size of breast cancer metastases in axillary lymph nodes: clinical relevance of minimal lymph node involvement. J Clin Oncol 2005;23:1379-1389.

51. Fracchia AA, Evans JF, Eisenberg BL. Stage III carcinoma of the breast. A detailed analysis. Ann Surg 1980;192:705-710.

52. Grabau D, Jensen MB, Rank F, Blichert-Toft M. Axillary lymph node micrometastases in invasive breast cancer: national figures on incidence and overall survival. APMIS 2007;115:828-837.

53. Braun S, Cevatli BS, Assemi C, et al. Comparative analysis of micrometastasis to the bone marrow and lymph nodes of node-negative breast cancer patients receiving no adjuvant therapy. J Clin Oncol 2001;19:1468-1475.

54. Byrne J, Horgan PG, England S, Callaghan J, Given HF. A preliminary report on the usefulness of monoclonal antibodies to CA $15-3$ and MCA in the detection of micrometastases in axillary lymph nodes draining primary breast carcinoma. Eur J Cancer 1992;28:658-660.

55. Clare SE, Sener SF, Wilkens W, Goldschmidt R, Merkel D, Winchester DJ. Prognostic significance of occult lymph node metastases in node-negative breast cancer. Ann Surg Oncol 1997;4:447-451.

56. Elson CE, Kufe D, Johnston WW. Immunohistochemical detection and significance of axillary lymph node micrometastases in breast carcinoma. A study of 97 cases. Anal Quant Cytol Histol 1993;15: 171-178.

57. Fisher ER, Swamidoss S, Lee CH, Rockette H, Redmond C, Fisher B. Detection and significance of occult axillary node metastases in patients with invasive breast cancer. Cancer 1978;42:2025-2031.

58. Fisher ER, Wang J, Bryant J, Fisher B, Mamounas E, Wolmark N. Pathobiology of preoperative chemotherapy: findings from the National Surgical Adjuvant Breast and Bowel (NSABP) protocol B-18. Cancer 2002;95:681-695.

59. Galea $\mathrm{MH}$, Athanassiou $\mathrm{E}$, Bell J, et al. Occult regional lymph node metastases from breast carcinoma: immunohistological detection with antibodies CAM 5.2 and NCRC-11. J Pathol 1991;165:221-227.

60. Gebauer G, Fehm T, Merkle E, Jaeger W, Mitze M. Micrometastases in axillary lymph nodes and bone marrow of lymph node-negative breast cancer patients-prognostic relevance after 10 years. Anticancer Res 2003;23:4319-4324.

61. Kahn HJ, Hanna WM, Chapman JA, et al. Biological significance of occult micrometastases in histologically negative axillary lymph nodes in breast cancer patients using the recent American Joint Committee on Cancer breast cancer staging system. Breast J 2006;12:294-301.

62. Marinho VF, Zagury MS, Caldeira LG, Gobbi H. Relationship between histologic features of primary breast carcinomas and axillary lymph node micrometastases: detection and prognostic significance. Appl Immunohistochem Mol Morphol 2006;14:426-431.

63. Noel P, Chauvin F, Michot JP, Catimel G, Hesch M, Groleas M. Prognostic value of lympho node micrometastases detected by immunohistochemistry. Study of 168 cases of breast cancer with a 10 year follow-up. Ann Pathol 1991;11:309-315.

64. Rosen PP, Saigo PE, Braun D-WJ, Beattie E-JJ, Kinne DW. Occult axillary lymph node metastases from breast cancers with intramammary lymphatic tumor emboli. Am J Surg Pathol 1982;6:639-641.

65. Tsuchiya A, Sugano K, Kimijima I, Abe R. Immunohistochemical evaluation of lymph node micrometastases from breast cancer. Acta Oncol 1996;35:425-428.

66. Liang WC, Sickle-Santanello BJ, Nims TA. Is a completion axillary dissection indicated for micrometastases in the sentinel lymph node? Am J Surg 2001;182:365-368.

67. Chagpar A, Middleton LP, Sahin AA, et al. Clinical outcome of patients with lymph node-negative breast carcinoma who have sentinel lymph node micrometastases detected by immunohistochemistry. Cancer 2005;103:1581-1586.

68. Fan YG, Tan YY, Wu CT, et al. The effect of sentinel node tumor burden on non-sentinel node status and recurrence rates in breast cancer. Ann Surg Oncol 2005;12:705-711.

69. Soni NK, Spillane AJ. Experience of sentinel node biopsy alone in early breast cancer without further axillary dissection in patients with negative sentinel node. ANZ J Surg 2005;75:292-299. 
70. Imoto S, Ochiai A, Okumura C, Wada N, Hasebe T. Impact of isolated tumor cells in sentinel lymph nodes detected by immunohistochemical staining. Eur J Surg Oncol 2006;32:1175-1179.

71. Nagashima T, Sakakibara M, Nakano S, et al. Sentinel node micrometastasis and distant failure in breast cancer patients. Breast Cancer 2006;13:186-191.

72. Rydén L, Chebil G, Sjostrom L, Pawlowski R, Jonsson PE. Determination of sentinel lymph node (SLN) status in primary breast cancer by prospective use of immunohistochemistry increases the rate of micrometastases and isolated tumour cells: analysis of 174 patients after SLN biopsy. Eur J Surg Oncol 2007;33:33-38

73. Cox CE, Kiluk JV, Riker Al, et al. Significance of sentinel lymph node micrometastases in human breast cancer. J Am Coll Surg 2008;206:261-268.

74. Gobardhan PD, Elias SG, Madsen EV, et al. Prognostic value of micrometastases in sentinel lymph nodes of patients with breast carcinoma: a cohort study [published online ahead of print July 24 2008]. Ann Oncol 2009;20:41-48.

75. Goldhirsch A, Glick JH, Gelber RD, Coates AS, Thurlimann B, Senn HJ. Meeting highlights: international expert consensus on the primary therapy of early breast cancer 2005. Ann Oncol 2005;16:1569-1583.

76. Struikmans H, Nortier JW, Rutgers EJ, et al. Guideline 'Treatment of breast cancer 2008' (revision) [in Dutch]. Ned Tijdschr Geneeskd 2008;152:2507-2511.

77. Bolster MJ, Bult P, Schapers RF, et al. Differences in sentinel lymph node pathology protocols lead to differences in surgical strategy in breast cancer patients. Ann Surg Oncol 2006;13:1466-1473.

78. Cserni G. Complete sectioning of axillary sentinel nodes in patients with breast cancer. Analysis of two different step sectioning and immunohistochemistry protocols in 246 patients. J Clin Pathol 2002;55:926-931.

79. Smith PA, Harlow SP, Krag DN, Weaver DL. Submission of lymph node tissue for ancillary studies decreases the accuracy of conventional breast cancer axillary node staging. Mod Pathol 1999;12: 781-785.

80. Galimberti V. International Breast Cancer Study Group Trial of sentinel node biopsy. J Clin Oncol 2006;24:210-211.

81. Olson JA Jr, McCall LM, Beitsch P, et al; American College of Surgeons Oncology Group Trials Z0010 and Z0011. Impact of immediate versus delayed axillary node dissection on surgical outcomes in breast cancer patients with positive sentinel nodes: results from American College of Surgeons Oncology Group Trials Z0010 and Z0011. J Clin Oncol 2008;26:3530-3535.

82. Harlow SP, Krag DN, Julian TB, et al. Prerandomization Surgical Training for the National Surgical Adjuvant Breast and Bowel Project (NSABP) B-32 trial: a randomized phase III clinical trial to compare sentinel node resection to conventional axillary dissection in clinically node-negative breast cancer. Ann Surg 2005;241:48-54.

83. de Boer M, van Deurzen $\mathrm{CH}$, van Dijck JA, et al. Micrometastases and Isolated tumor cells: Relevant and Robust Or Rubbish? (MIRROR): preliminary results of the MIRROR study from the Dutch breast cancer trialists' group (BOOG). Cancer Res 2009;69(2 suppl):Abstract 23. 
40 


\section{Chapter 3}

\section{Classification of small nodal metastases in the Dutch \\ MIRROR breast cancer study}

Maaike de Boer, Carolien H.M. van Deurzen, Theo de Boo, Paul J. van Diest, Peter Bult, Vivianne C.G. Tjan-Heijnen

Submitted 
42 Chapter 3

\section{Abstract}

\section{Background}

In the MIRROR study, we assessed the association of sentinel nodalsentinel node isolated tumor cells and micrometastases with breast cancer outcome. As considerable variability in the interpretation of definitions and in the assessment of size of isolated tumor cells and micrometastases had been described before, central pathology review was carried out. We assessed interobserver agreement of the classification of small tumor deposits between the two central reviewers.

\section{Methods}

The slides of more than 3000 patients were centrally reviewed and reclassified according to the sixth American Joint Committee on Cancer (AJCC) Cancer Staging Manual by two breast dedicated pathologists. The slides of 103 selected patients were assessed by both reviewers, while they were not aware of the fact that these slides were used to assess interobserver agreement.

\section{Results}

The overall agreement regarding classification as node-negative (pNO/pNO(i+)) or node-positive (pN1mi/pN1a) was $98 \%(\mathrm{k}=0.96 ; 95 \% \mathrm{Cl}, 0.90$ to 1.02). The overall agreement regarding classification in one of four categories (pNO, pNO(i+), pN1mi, or pN1a) was $83 \%(\mathrm{k}=0.75 ; 95 \% \mathrm{Cl}$, 0.65 to 0.85 ) and regarding presence versus absence of tumor deposits (pNO versus $\mathrm{pNO}(\mathrm{i}+) / \mathrm{pN} 1 \mathrm{mi} / \mathrm{pN1a}) 87 \%(\mathrm{k}=0.72 ; 95 \% \mathrm{Cl}, 0.58$ to 0.86$)$. The agreement regarding assessment of surface area of tumor deposits was not superior to assessment of diameter.

\section{Conclusions}

The assessment of small nodal involvement by two dedicated breast pathologists in the MIRROR study reached a high level of agreement, which stresses the validity of the results of the MIRROR study. Dedicated pathologists who agree beforehand on the classification of nodal deposits can achieve high levels of agreement. 


\section{Introduction}

After decades of performing axillary lymph node dissections in the treatment of primary breast cancer, the sentinel node procedure was introduced in the nineties of the last century ${ }^{1}$. If the sentinel node is negative, a lymph node dissection can be safely avoided ${ }^{2}$. To prevent false negative results and under treatment, it is recommended to extensively examine the sentinel node with the use of step sectioning, and immunohistochemical staining if the haematoxylin-eosin staining is negative ${ }^{3,4}$. This has, however, led to an increased detection rate of very small tumor deposits, such as isolated tumor cells and micrometastases ${ }^{5-7}$. Before 2002, small nodal metastases were classified as node-positive, without further distinction between isolated tumor cells and micrometastases.

In the sixth edition of the American Joint Committee on Cancer (AJCC) Cancer Staging Manual $(2002)^{8}$, single tumor cells and tumor cell clusters of up to $0.2 \mathrm{~mm}$ in largest diameter are referred to as isolated tumor cells. Isolated tumor cells are considered as node negative disease, $\mathrm{pNO}(\mathrm{i}+)$, in an attempt to prevent stage migration by the introduction of the sentinel node procedure. In contrast, metastases larger than 0.2 $\mathrm{mm}$ up to $2 \mathrm{~mm}$ are referred to as micrometastases ( $\mathrm{pN} 1 \mathrm{mi}$ ), and regarded as node positive disease. The prognostic relevance of isolated tumor cells and micrometastases was debated $^{9-14}$. In the Netherlands, we therefore conducted the nationwide MIRROR ("Micrometastases and Isolated tumor cells: Relevant and Robust Or Rubbish?) study. In this cohort study, breast cancer patients with favorable primary tumor characteristics who had undergone a sentinel node procedure were included to assess the prognostic impact of isolated tumor cells and micrometastases ${ }^{9}$. Variability in the interpretation of definitions of isolated tumor cells and micrometastases ${ }^{15}$, and in the assessment of size of these deposits has been described ${ }^{16}$. For that reason, we decided to centrally review all slides of the sentinel nodes of more than 3000 patients in the MIRROR study. We assumed that uniform classification would improve the content of the database and as a result, a higher chance of detecting a prognostic relevance if indeed present.

Therefore, the goal of the present study was to evaluate whether central pathology review of (sentinel) nodal slides in the MIRROR study was uniformly done according to the sixth AJCC Cancer Staging Manual ${ }^{8}$. We assessed interobserver agreement of selected parameters between the two central reviewers.

\section{Methods}

\section{Patients}

We identified all patients with favorable primary tumor characteristics who had undergone a sentinel node procedure before 2006, with isolated tumor cells or 
micrometastases as final nodal status from the Netherlands Cancer Registry. Patients with node-negative disease were randomly selected from the years 2000-2001. In total, central pathology review of sentinel nodes of more than 3000 patients was carried out. The review of the slides of the sentinel nodes of most patients included in the MIRROR study was carried out by two pathologists (C.H.M. van Deurzen and P. Bult), who were both experienced in the field of breast cancer and sentinel node biopsy. For the assessment of interobserver agreement the slides of 103 patients were selected. The study co-ordinator (M. de Boer) randomly selected the slides of 72 patients. In addition, the slides of 31 'false-negative' patients were selected. These were patients who had a negative sentinel node according to the original pathology report, but who had a tumor-positive sentinel node according to one of the review pathologists.

\section{Central pathology review}

The sentinel nodes of all patients were processed using step sectioning at at least 3 levels with a distance of 50 to $500 \mu \mathrm{m}$. Immunohistochemical staining was performed as a standard procedure, or performed in case no metastatic deposit was discovered on haematoxylin-eosin stained sections. All original slides from the sentinel nodes were reviewed. These slides included haematoxylin-eosin stained slides, immunohistochemically stained slides, and frozen sections. No additional sections of the sentinel node were made, and no new immunohistochemical staining was carried out. The slides were presented to the reviewing pathologists together with the original pathology report. The pathology report was provided in order to interpret how many sentinel nodes were removed during dissection, and to determine the mode of processing of the sentinel nodes. The pathologists were not aware of the fact that the slides of the patients were used to assess the interobserver agreement. At the initiation of the MIRROR study, both pathologists agreed on the assessment of size of tumor deposits according to the guidelines as reported by Cserni et al. ${ }^{17}$.

During central review, the following items were recorded: number of positive sentinel nodes, presence of single tumor cell(s) or tumor cell group(s), diameter of the largest tumor deposit, surface area of the largest tumor deposit, total surface area of tumor deposit in the slide with the largest tumor load, localization of metastasis (sinus or parenchyma), and presence of extranodal extension. The surface areas of tumor deposits with a diameter larger than $2 \mathrm{~mm}$ were not measured as these patients were excluded from the MIRROR study. Definitions of isolated tumor cells and micrometastases were used according to the sixth AJCC Cancer Staging Manual ${ }^{8}$.

The first reviewer (C.H.M. van Deurzen) carried out measurements of diameter and surface area of tumor deposits by quantitative morphometry using Research Assistant 5 (RVC B.V., Baarn, the Netherlands). The latter reviewer (P. Bult) carried out measurements of diameter of tumor deposits using a calibrated oculometer, and measurements of surface area of tumor deposits using an RGB CCD camera (AxioCam 
MRc, Zeiss, Germany). The area occupied by metastases was measured using an interactive system (KS400 image analysis system, Carl Zeiss, Germany).

\section{Study objectives}

Primary objective was the agreement in classification of nodal status according to the sixth AJCC Cancer Staging Manual $^{8}$ between two dedicated breast pathologists. Comparisons were made between node-negative $(\mathrm{pNO} / \mathrm{pNO}(\mathrm{i}+))$ and node-positive (pN1mi/pN1a) disease, between each of the four categories pN0, pNO(i+), pN1mi, $\mathrm{pN} 1 \mathrm{a}$, between presence $(\mathrm{pNO}(\mathrm{i}+) / \mathrm{pN} 1 \mathrm{mi} / \mathrm{pN} 1 \mathrm{a})$ and absence $(\mathrm{pNO})$ of tumor deposits, and between the assessment of diameter of surface area of the largest tumor deposit. Secondary objective was the agreement in assessment of diameter of surface area of the largest tumor deposit.

\section{Statistical analysis}

The interobserver agreement in classification of nodal status, and the presence or absence of tumor deposit was expressed in percentage of agreement, and analysed by $\mathrm{k}$ statistics. The following limits were used to interpret agreement based on $\mathrm{K}$ statistics: <0.00, disagreement; 0.00-0.20, slight; 0.21-0.40, fair; 0.41-0.60, moderate; $0.61-0.80$ good; $0.81-1.0$, almost perfect ${ }^{18}$. The variability in diameter and surface area of the largest tumor deposit were displayed in Bland-Altman plots ${ }^{19}$. Statistical analyses were performed using SAS (version 8.2) ${ }^{20}$.

\section{Results}

We describe the results of interobserver agreement for the overall group $(n=103)$, the randomly selected patients $(n=72)$, and the 'false-negative' patients $(n=31)$. Per patient, the slides of median 2.0 (range 1-7) sentinel nodes were available for review. According to the original pathology report of the 72 randomly selected patients, the sentinel node was negative in 28 patients, contained isolated tumor cells in 19 patients, and micrometastases in 25 patients. Of the 31 false-negative patients, 17 patients were assessed as false-negative by reviewer $A$, and 14 patients by reviewer $B$. Twenty-four patients were classified by one of the reviewers as having isolated tumor cells and 7 were classified as having micrometastases.

\section{Classification in node-negative versus node-positive ( $n=103$ )}

The agreement in the classification of sentinel node status in node-negative (pNO, pNO(i+)) versus node-positive (pN1mi, pN1a) according to the sixth AJCC Cancer Staging Manual $^{8}$ was almost perfect in the overall group $(n=103)$, the randomly selected patients $(n=72)$, and the 'false negative' patients $(n=31)(\kappa=0.96,95 \% \mathrm{Cl}, 0.90$ 
46 Chapter 3

to $1.02 ; \mathrm{k}=0.97,95 \% \mathrm{Cl}, 0.92$ to 1.03 ; and $\mathrm{k}=0.89,95 \% \mathrm{Cl}, 0.68$ to 1.10 , respectively) (Table 1).

Table 1. Agreement in assessment of sentinel lymph nodes by two breast dedicated pathologists; overall group $(n=103)$, randomly selected patients $(n=72)$, and 'false-negative' patients $(n=31)$

\begin{tabular}{|c|c|c|c|}
\hline Classification & $\mathrm{n}$ & Agreement (\%) & $\mathrm{K}(95 \% \mathrm{Cl})$ \\
\hline $\begin{array}{l}\text { Node negative ( } \mathrm{pN} 0, \mathrm{pNO}(\mathrm{i}+)) \\
\text { versus } \\
\text { node positive ( } \mathrm{pN} 1 \mathrm{mi}, \mathrm{pN} 1 \mathrm{a})^{*}\end{array}$ & & & \\
\hline overall group & 103 & 98 & $0.96(0.90-1.02)$ \\
\hline randomly selected patients & 72 & 99 & $0.97(0.92-1.03)$ \\
\hline 'false-negative' patients & 31 & 97 & $0.89(0.68-1.10)$ \\
\hline \multicolumn{4}{|l|}{ pNO versus $\mathrm{pNO}(\mathrm{i}+)$ versus } \\
\hline \multicolumn{4}{|l|}{ pN1mi versus pN1a* } \\
\hline overall group & 103 & 83 & $0.75(0.65-0.85)$ \\
\hline randomly selected patients & 72 & 94 & $0.92(0.84-1.00)$ \\
\hline 'false-negative' patients & 31 & 55 & $0.29(0.04-0.54)$ \\
\hline \multicolumn{4}{|l|}{$\begin{array}{l}\text { Presence }(\mathrm{pNO}(\mathrm{i}+), \mathrm{pN} 1 \mathrm{mi}, \mathrm{pN} 1 \mathrm{a}) \\
\text { versus } \\
\text { absence (pNO) of tumor deposit }\end{array}$} \\
\hline overall group & 103 & 87 & $0.72(0.58-0.86)$ \\
\hline randomly selected patients & 72 & 100 & $1.0(1.00-1.00)$ \\
\hline 'false-negative' patients & 31 & 58 & $-0.12(-0.27-0.03)$ \\
\hline
\end{tabular}

${ }^{*}$ According to sixth AJCC Cancer Staging Manual ${ }^{8}$

\section{Classification in $\mathrm{pNO}$ versus $\mathrm{pNO}(\mathrm{i}+)$ versus $\mathrm{pN1}$ mi versus pN1a $(\mathrm{n}=103)$}

In the overall group $(n=103)$, the agreement in classification according to the sixth AJCC Cancer Staging Manual was good ( $83 \% ; \mathrm{k}=0.75 ; 95 \% \mathrm{Cl}, 0.65$ to 0.85 ) (Table 1). In the randomly selected patients $(n=72)$, the agreement was almost perfect $(94 \%$; $\mathrm{K}=0.92 ; 95 \% \mathrm{Cl}, 0.84$ to 1.00 ) (Table 1 ). In the 'false negative' patients $(n=31)$, the overall agreement was fair ( $55 \% ; \mathrm{k}=0.29 ; 95 \% \mathrm{Cl}, 0.04$ to 0.54 ) (Table 1). Disagreement in the 'false negative' patients was determined by classification as pNO by pathologist $A$, and as pNO(i+) (tumor deposits $\leq 0.05 \mathrm{~mm}$ ) by pathologist $B(n=10)$; classification by pathologist $B$ as pNO(i+) and as pNO by pathologist $A(n=2)$; classification as pN1mi by pathologist $B$ and as pN1a by pathologist $A(n=1)$; and classification as pNO by pathologist $B$ and as pN1mi (diameter of deposit $0.22 \mathrm{~mm}$ ) by pathologist $A(n=1)$.

\section{Agreement in the assessment of presence versus absence of tumor deposit ( $n=103)$}

In the overall group ( $n=103)$, the agreement in the assessment of presence or absence of tumor deposits was good ( $87 \%$; $\mathrm{k}=0.72 ; 95 \% \mathrm{Cl}, 0.58$ to 0.86$)$ (Table 1 ). In the randomly selected patients $(n=72)$, the agreement was perfect $(100 \% ; \mathrm{k}=1.00 ; 95 \% \mathrm{Cl}$; 1.00 to 1.00$)$ (Table 1$)$. In the 'false negative' patients $(n=31)$, the agreement was poor (58\%; $\mathrm{k}=-0.12 ; 95 \% \mathrm{Cl},-0.27$ to 0.03 ) (Table 1 ). 


\section{Agreement in assessment of the diameter of the largest tumor cell deposit}

In 62 patients, both reviewers found tumor deposits in the sentinel nodes. The average diameters of the largest tumor cell deposits as measured by pathologist $A$ and $B$ were plotted against the differences in measured diameters of these 62 patients (Figure 1A). The mean difference in measured diameter was $+0.09 \mathrm{~mm}$. The limits of agreement of difference in measured diameter represented $-0.87 \mathrm{~mm}(-2 \mathrm{SD})$ and $+1.05 \mathrm{~mm}$ ( $+2 \mathrm{SD}$ ). In approximately $85 \%$ of the cases, differences were between -0.13 $\mathrm{mm}$ and $+0.28 \mathrm{~mm}$. In patients with an average diameter of the tumor deposit near $0.20 \mathrm{~mm}$, the transition between isolated tumor cells and micrometastases, the differences in diameter were small. The agreement in measurement of diameter was generally good; however, in 5 patients the differences in measured diameters were large. One point $\left(^{*}\right)$ in the upper range of Figure $1 \mathrm{~A}$ was very prominent. This point represented a case in which pathologist $A$ assessed the diameter of the tumor deposit as $0.59 \mathrm{~mm}$, and pathologist $B$ as $3.50 \mathrm{~mm}$. Pathologist A assessed the largest tumor deposit, whereas pathologist $B$ assessed the whole area of the lymph node involved by numerous scattered tumor deposits, as shown in Figure 2.
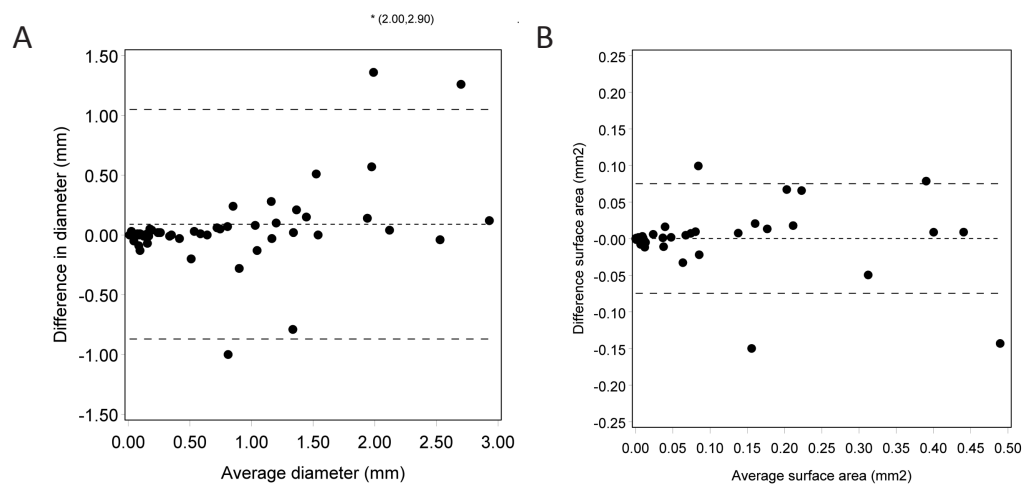

Figure 1. Panel A. Bland Altman Plot plotting the average diameter of the largest tumor deposit against difference in diameter by pathologist $A$ and $B$.

Panel B. Bland Altman Plot plotting average surface area of the largest tumor deposit against difference in surface by pathologist $A$ and $B$. 


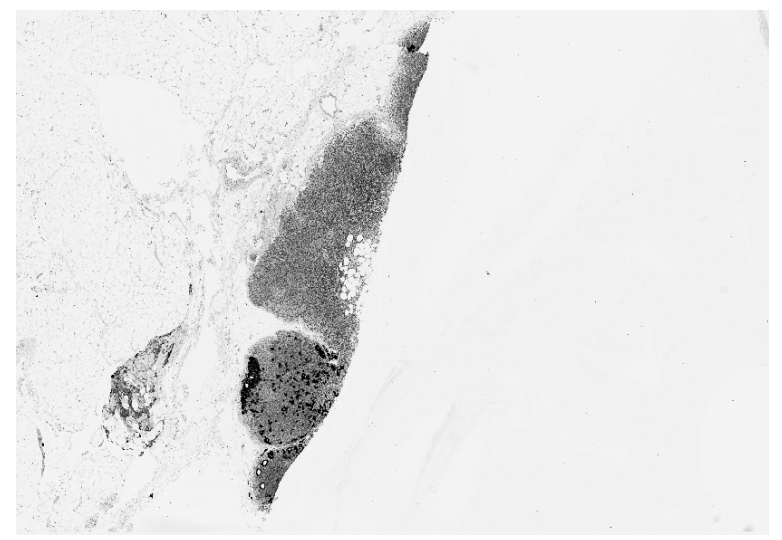

Figure 2. Example of sentinel node metastases from ductal breast carcinoma in which a large difference in interpretation was found between both reviewers. Reviewer A classified these tumor deposits as a micrometastasis of $0.59 \mathrm{~mm}$, and reviewer B classified this deposit as a macrometastasis of $3.50 \mathrm{~mm}$.

\section{Agreement in assessment of average surface area of the largest tumor deposit}

In 54 patients, both reviewers had found tumor deposits $\leq 2 \mathrm{~mm}$ in the sentinel nodes. The average surface areas of the largest tumor deposits as measured by pathologist $A$ and $B$ were plotted against the differences in measured surface area (Figure 1B). The mean difference in measured surface areas approached zero $\left(0.00026 \mathrm{~mm}^{2}\right)$. The limits of agreement of difference in measured surface area of the largest tumor deposit represented $-0.072 \mathrm{~mm}^{2}(-2 \mathrm{SD})$ and $+0.073 \mathrm{~mm}^{2}$ (+2 SD). In approximately $85 \%$ of the cases, differences were between $-0.033 \mathrm{~mm}^{2}$ and $+0.021 \mathrm{~mm}^{2}$. In cases with small average surface area of largest tumor deposit, the differences in surface area of largest tumor deposit were small. Therefore, the agreement in measurement of diameter was generally good.

\section{Discussion}

The goal of the present study was to evaluate the level of agreement of the assessment of sentinel node involvement by two dedicated breast pathologists within the scope of the MIRROR study. The two review pathologists reached a high level of agreement on classifying sentinel node status by using the sixth AJCC Cancer Staging Manual $^{8}$. Not only the agreement in nodal classification, but also the agreement in 
diameter and surface area was good, especially for smaller diameters near the transition of isolated tumor cells and micrometastases.

Recently, the final results from the MIRROR study were published ${ }^{9}$, which showed that the presence of isolated tumor cells or micrometastases in lymph nodes of women with favorable early stage breast cancer who did not receive adjuvant systemic therapy was associated with a reduced 5-year disease-free survival. The adjusted hazard ratio for disease events in patients with isolated tumor cells who did not receive systemic therapy was $1.50(95 \% \mathrm{Cl}, 1.15$ to 1.94$)$ and $1.56(95 \% \mathrm{Cl}, 1.15$ to 2.13) for patients with micrometastases, when compared to patients with nodenegative disease. This study is the largest sentinel node study regarding numbers of patients with isolated tumor cells or micrometastases with central pathology review. Obviously, a uniform pathology classification may have contributed to the outcome of the study. Therefore, this study is a major contribution to the validity of the results of the MIRROR study.

Apart from diameter ${ }^{21,22}$, surface area of tumor deposits has been reported to correlate with additional lymph node metastases in breast cancer ${ }^{22,23}$ and melanoma ${ }^{24}$. Interobserver agreement in the assessment of surface area was never evaluated before. Besides good agreement for diameter, we found a good, however not superior agreement in the assessment of the surface area of the largest tumor deposit when compared with assessment of diameter. In addition, measurement of surface area was time consuming and therefore not useful to add as an additional parameter in daily practice.

Other studies have described the interobserver agreement of the assessment of tumor deposit in the sentinel node in breast cancer. In the first study in 10 pathologists $^{25}$, the mean number of discrepant responses was 6.6 of 25 immunohistochemically stained slides, and 5 of 25 haematoxylin-eosin stained slides. In the second study in 25 pathologists $^{17}$, a $\mathrm{k}$ of 0.35 before, and a $\mathrm{k}$ of 0.45 after introduction of guidelines was reported. In the third study, 6 pathologists assessed slides of 56 mixed easy and difficult cases, resulting in a $\mathrm{k}$ of 0.58 before, and 0.95 after a training program ${ }^{26}$. In our study, the disagreements were mainly determined by 'missing' (i.e. either not seeing, or differently interpreting) single tumor cells or small tumor clusters $\leq 0.05 \mathrm{~mm}$ in the so-called 'false negative' cases. Despite inclusion of these "difficult to assess" patients in our study, the overall agreement in assessment of nodal classification according to the sixth AJCC Cancer Staging Manual was good ( $\mathrm{k}=0.75 ; 95 \% \mathrm{Cl}, 0.65$ to 0.85 ). Although methodologically different with respect to the classification of tumor deposits, the selection of cases, and the reference pathologists, the level of agreement in our study seemed at least comparable, but probably better than in the above described studies. This was probably due to a meeting at the initiation of the MIRROR study, in which the guidelines ${ }^{17}$ for the assessment of size of tumor deposits were discussed. This supports the idea that instruction and use of guidelines or checklists may be useful for improving quality of pathology assessment ${ }^{17}$. 
50 Chapter 3

The choice to define the cut-off point between isolated tumor cells and micrometastases at $0.2 \mathrm{~mm}$ diameter in the sixth AJCC Cancer Staging Manual is quite arbitrary $^{8}$. Before, others have proposed cut-off points of $0.5 \mathrm{~mm}^{27}$ and $1.3 \mathrm{~mm}^{28}$ for prognostically relevant micrometastases, based on data from their own survival analyses. In the MIRROR study, diameter was assessed to evaluate the correlation of diameter of nodal tumor deposits with prognosis to assess a cut-off point of diameter below which a tumor deposit is not related to outcome anymore ${ }^{29}$. Within the isolated tumor cell category, patients with single tumor cells had comparable survival as compared to patients with clusters of cells. However, increasing metastatic size was borderline significantly associated with reduced 5 -years disease-free survival with an adjusted hazard ratio of $1.27(95 \% \mathrm{Cl}, 1.00 \text { to } 1.61, \mathrm{p}=0.05)^{29}$. This suggests that increasing size of nodal involvement within the isolated tumor cell category is associated with reduced survival, although a cut off point for metastastic size could not be determined.

One of the most problematic areas in the interpretation of the size criterion is how to handle single cells or multiple clusters of cells ${ }^{16}$. In one of our patients, pathologist $A$ assessed the diameter of the tumor deposit as $0.59 \mathrm{~mm}$, and pathologist $B$ assessed the same deposit as $3.50 \mathrm{~mm}$ (Figure 2). The lymph node involved showed numerous tumor deposits. Pathologist A assessed the largest tumor deposit, whereas pathologist $B$ assessed the whole area of the lymph node involved by the tumor deposits. There was a difference in interpretation of the guidelines for measurement of size ${ }^{17}$, in which both pathologists had valid arguments for their choice of the diameter of the tumor deposit. Cserni et al. reported that the definition of isolated tumor cells was uniformly used by only $42 \%$, and the definition of micrometastases by $88 \%$ of the questioned pathologists in Europe ${ }^{15}$. Therefore, the European Working Group for Breast Screening Pathologists (EWGBSP) proposed criteria to differentiate between no nodal involvement, isolated tumor cells and micrometastases by using guidelines for measurement of size of clusters of cells, and other criteria, such as micro anatomic location and presence of proliferation ${ }^{17,30}$. In our study, we adhered to the approach that ignores the localization of tumor cells from the point of categorization and bases the category on the size of the largest isolated cluster in a single plane of section, provided that there is no desmoplasia ${ }^{26}$. This approach is in agreement with the AJCC Cancer Staging Manual $^{8}$, and in line with central review centres of the large prospective National Surgical Adjuvant Breast and Bowel Project B32 (NSABP-B32) ${ }^{31}$ and the American College of Surgeons Oncology Group Z0010 (ACOSOG Z0010) sentinel node trials ${ }^{32}$. This approach was shown to be better reproducible ${ }^{17,26}$ than the one suggested by the EWGBSP, but leads to higher rates of pNO(i+) due to its definitions $^{33}$, and perhaps a worse separation of a significant and a less significant type of nodal involvement ${ }^{34}$. The seventh edition of the $\mathrm{TNM}^{35}$ hopefully will improve reproducibility of staging by making some clarifications regarding the distinction between isolated tumor cells and micrometastases, and by the introduction of a maximum of 200 cells for the isolated tumor cells category, preventing large areas of 
lymph node involvement to be categorized as pNO(i+). Results based on these updated staging rules will take further years to appear.

Besides differences in interpretation, tumor deposits can be missed due to small size, variable immunohistochemical cell staining, incomplete screening of sections, and human fatigue ${ }^{36}$. The detection rate of tumor deposits in sentinel nodes can be improved by the use of computer-assisted cell detection (CACD), however, this method is expensive and time-consuming ${ }^{37,38}$. Finally, depending on the level of sampling error, a proportion of metastases will never be detected ${ }^{4,36}$.

In conclusion, we have shown that the assessment of small nodal involvement by two dedicated breast pathologists in the MIRROR study reached a high level of agreement when classifying according to the sixth AJCC Cancer Staging Manual ${ }^{8}$, which stresses the validity of the results of the MIRROR study. Furthermore, dedicated pathologists who agree beforehand on the classification of nodal deposits can achieve high levels of agreement. 


\section{References}

1. Borgstein PJ, Pijpers R, Comans EF, van Diest PJ, Boom RP, Meijer S. Sentinel lymph node biopsy in breast cancer: guidelines and pitfalls of lymphoscintigraphy and gamma probe detection. J Am Coll Surg 1998;186:275-83.

2. Lyman GH, Giuliano AE, Somerfield MR, et al; American Society of Clinical Oncology. American Society of Clinical Oncology guideline recommendations for sentinel lymph node biopsy in early-stage breast cancer. J Clin Oncol 2005;23:7703-7720.

3. Dutch Institute for Healthcare Improvement CBO. Guideline Diagnosis and Treatment of Breast Cancer. Utrecht, the Netherlands; 2008.

4. van Diest PJ. Histopathological workup of sentinel lymph nodes: how much is enough? J Clin Pathol 1999;52:871-873.

5. Bolster MJ, Bult P, Schapers RF, et al. Differences in sentinel lymph node pathology protocols lead to differences in surgical strategy in breast cancer patients. Ann Surg Oncol 2006;13:1466-1473.

6. Cserni G, Amendoeira I, Apostolikas N, et al; European Working Group for Breast Screening Pathology. Pathological work-up of sentinel lymph nodes in breast cancer. Review of current data to be considered for the formulation of guidelines. Eur J Cancer 2003;39:1654-1667.

7. van der Heiden-van der Loo M, Bezemer PD, Hennipman A, et al. Introduction of sentinel node biopsy and stage migration of breast cancer. Eur J Surg Oncol 2006;32:710-714.

8. Green F.L., Page D.L., Fleming I.D. American Joint Committee on Cancer Staging Manual. $6^{\text {th }}$ ed. Philadelphia: Springer;2002.

9. de Boer $\mathrm{M}$, van Deurzen $\mathrm{CH}$, van Dijck JA, et al. Micrometastases or isolated tumor cells and the outcome of breast cancer. N Engl J Med 2009;361:653-663.

10. de Boer M, van Dijck JA, Bult P, Borm GF, Tjan-Heijnen VC. Breast cancer prognosis and occult lymph node metastases, isolated tumor cells, and micrometastases. J Natl Cancer Inst 2010;102:410-425.

11. Hansen NM, Grube B, Ye X, et al. Impact of micrometastases in the sentinel node of patients with invasive breast cancer. J Clin Oncol 2009;27:4679-4684.

12. Truong PT, Lesperance M, Li KH, MacFarlane R, Speers CH, Chia S. Micrometastatic node-positive breast cancer: long-term outcomes and identification of high-risk subsets in a large population-based series. Ann Surg Oncol 2010;17:2138-2146.

13. van Diest PJ, de Boer M, van Deurzen $\mathrm{CH}$, Tjan-Heijnen VC. Micrometastases and isolated tumor cells in breast cancer are indeed associated with poorer outcome. J Clin Oncol 2010;28:e140-e142.

14. Weaver DL, Ashikaga T, Krag DN, et al. Effect of occult metastases on survival in node-negative breast cancer. N Engl J Med 2011;364:412-421.

15. Cserni G, Amendoeira I, Apostolikas N, et al. Discrepancies in current practice of pathological evaluation of sentinel lymph nodes in breast cancer. Results of a questionnaire based survey by the European Working Group for Breast Screening Pathology. J Clin Pathol 2004;57:695-701.

16. Connolly JL. Changes and problematic areas in interpretation of the AJCC Cancer Staging Manual, 6th Edition, for breast cancer. Arch Pathol Lab Med 2006;130:287-291.

17. Cserni G, Bianchi S, Boecker W, et al; European Working Group for Breast Screening Pathology. Improving the reproducibility of diagnosing micrometastases and isolated tumor cells. Cancer 2005;103:358-367.

18. Maclure M, Willett WC. Misinterpretation and misuse of the kappa statistic. Am J Epidem 1987;126:161-169.

19. Bland JM, Altman DG. Statistical methods for assessing agreement between two methods of clinical measurement. Lancet 1986;1:307-310.

20. SAS/STAT ${ }^{\circledR}$ User's Guide [computer program]. Version 8. Cary, NC;1999.

21. Bolster MJ, Peer PG, Bult $P$, et al. Risk factors for non-sentinel lymph node metastases in patients with breast cancer. The outcome of a multi-institutional study. Ann Surg Oncol 2007;14:181-189.

22. van Deurzen $\mathrm{CH}$, van Hillegersberg $\mathrm{R}$, Hobbelink MG, Seldenrijk CA, Koelemij R, van Diest PJ. Predictive value of tumor load in breast cancer sentinel lymph nodes for second echelon lymph node metastases. Cell Oncol 2007;29:497-505.

23. Rahusen FD, Torrenga $\mathrm{H}$, van Diest PJ, et al. Predictive factors for metastatic involvement of nonsentinel nodes in patients with breast cancer. Arch Surg 2001;136:1059-1063. 
24. Vuylsteke RJ, Borgstein PJ, van Leeuwen PA, et al. Sentinel lymph node tumor load: an independent predictor of additional lymph node involvement and survival in melanoma. Ann Surg Oncol 2005;12:440-448.

25. Roberts CA, Beitsch PD, Litz CE, et al. Interpretive disparity among pathologists in breast sentinel lymph node evaluation. Am J Surg 2003;186:324-329.

26. Turner RR, Weaver DL, Cserni G, et al. Nodal stage classification for breast carcinoma: improving interobserver reproducibility through standardized histologic criteria and image-based training. J Clin Oncol 2008;26:258-263.

27. Cummings MC, Walsh MD, Hohn BG, et al. Occult axillary lymph node metastases in breast cancer do matter: results of 10-year survival analysis. Am J Surg Pathol 2002;26:1286-1295.

28. Fisher ER, Palekar A, Rockette H, Redmond C, Fisher B. Pathologic findings from the National Surgical Adjuvant Breast Project (protocol no.4) V. Significance of axillary nodal micro- and macrometastases. Cancer 1978;42:2032-2038.

29. Vestjens JH, de Boer M, van Diest PJ, et al. Prognostic impact of isolated tumor cells in breast cancer axillary nodes: single tumor cell(s) versus tumor cel clusters and microanatomic location. Breast Cancer Res Treat 2012;131:645-651.

30. Cserni G, Sapino A, Decker T. Discriminating between micrometastases and isolated tumor cells in a regional and institutional setting. Breast 2006;15:347-354.

31. Weaver DL, Le UP, Dupuis SL, et al. Metastasis detection in sentinel lymph nodes: comparison of a limited widely spaced (NSABP protocol B-32) and a comprehensive narrowly spaced paraffin block sectioning strategy. Am J Surg Pathol 2009;33:1583-1589.

32. Olson JA Jr, McCall LM, Beitsch P, et al; American College of Surgeons Oncology Group Trials Z0010 and Z0011. Impact of immediate versus delayed axillary node dissection on surgical outcomes in breast cancer patients with positive sentinel nodes: results from American College of Surgeons Oncology Group Trials Z0010 and Z0011. J Clin Oncol 2008;26:3530-3535.

33. Cserni G, Bianchi S, Vezzosi V, et al. Variations in sentinel node isolated tumour cells/micrometastasis and non-sentinel node involvement rates according to different interpretations of the TNM definitions. Eur J Cancer 2008;44:2185-2191.

34. Cserni G. Isolated tumour cells versus micrometastases and non-sentinel node involvement in breast cancer. Eur J Surg Oncol 2009;35:897-898.

35. UICC TNM classification of malignant tumours, 7th edition. New York: John Wiley and Sons Inc.; 2009.

36. Weaver DL, Krag DN, Manna EA, et al. Comparison of pathologist-detected and automated computerassisted image analysis detected sentinel lymph node micrometastases in breast cancer. Mod Pathol 2003;16:1159-1163.

37. Mesker WE, Torrenga H, Sloos WC, et al. Supervised automated microscopy increases sensitivity and efficiency of detection of sentinel node micrometastases in patients with breast cancer. J Clin Pathol 2004;57:960-964.

38. Weaver DL, Krag DN, Manna EA, et al. Detection of occult sentinel lymph node micrometastases by immunohistochemistry in breast cancer. An NSABP protocol B-32 quality assurance study. Cancer 2006;107:661-667. 
54 


\section{Chapter 4}

\section{Micrometastases or isolated tumor cells and the outcome of breast cancer}

Maaike de Boer, Carolien H.M. van Deurzen, Jos A.A.M. van Dijck, George F. Borm, Paul J. van Diest, Eddy M.M. Adang, Johan W.R. Nortier, Emiel J.Th. Rutgers,

Caroline Seynaeve, Marian B.E. Menke-Pluymers, Peter Bult, Vivianne C.G. Tjan-Heijnen

N Engl J Med 2009;361:653-663 
56 Chapter 4

\section{Abstract}

\section{Background}

The association of isolated tumor cells and micrometastases in regional lymph nodes with the clinical outcome of breast cancer is unclear.

\section{Methods}

We identified all patients in the Netherlands who underwent a sentinel-node biopsy for breast cancer before 2006 and had breast cancer with favorable primary tumor characteristics and isolated tumor cells or micrometastases in the regional lymph nodes. Patients with nodenegative disease were randomly selected from the years 2000 and 2001. The primary end point was disease-free survival.

\section{Results}

We identified 856 patients with node-negative disease who had not received systemic adjuvant therapy (the node-negative, no-adjuvant-therapy cohort), 856 patients with isolated tumor cells or micrometastases who had not received systemic adjuvant therapy (the node-positive, noadjuvant-therapy cohort), and 995 patients with isolated tumor cells or micrometastases who had received such treatment (the node-positive, adjuvant-therapy cohort). The median followup was 5.1 years. The adjusted hazard ratio for disease events among patients with isolated tumor cells who did not receive systemic therapy, as compared with women with nodenegative disease, was 1.50 (95\% confidence interval (CI), 1.15 to 1.94); among patients with micrometastases, the adjusted hazard ratio was 1.56 (95\% Cl, 1.15 to 2.13). Among patients with isolated tumor cells or micrometastases, the adjusted hazard ratio was $0.57(95 \% \mathrm{Cl}, 0.45$ to 0.73 ) in the node-positive, adjuvant-therapy cohort, as compared with the node-positive, noadjuvant-therapy cohort.

\section{Conclusions}

Isolated tumor cells or micrometastases in regional lymph nodes were associated with a reduced 5-year rate of disease-free survival among women with favourable early-stage breast cancer who did not receive adjuvant therapy. In patients with isolated tumor cells or micrometastases who received adjuvant therapy, disease-free survival was improved. 


\section{Introduction}

The status of the axillary lymph nodes is the most important prognostic factor in breast cancer ${ }^{1}$. These nodes can be sampled by axillary lymph node dissection or sentinel-node biopsy with or without subsequent axillary lymph node dissection (these additional lymph nodes are denoted as non-sentinel nodes). Detailed examination of the sentinel node by means of serial sectioning with optional immunohistochemical staining permits the detection of small metastases or isolated tumor cells $\mathrm{s}^{2-4}$. Isolated tumor cells (staged as pNO(i+), with deposits $\leq 0.2 \mathrm{~mm}$ ) and micrometastases (staged as pN1mi, with deposits $>0.2$ to $\leq 2.0 \mathrm{~mm}$ ) have been separate categories in the American Joint Committee on Cancer (AJCC) Cancer Staging Manual since $2002^{5}$. The cut-off value of $0.2 \mathrm{~mm}$ was chosen arbitrarily.

Most studies of the association of minimal lymph node involvement with prognosis have included patients who received a diagnosis of breast cancer before the use of sentinel-node biopsy became widespread. Moreover, isolated tumor cells were seldom distinguished from micrometastases, which made their prognostic relevance debatable ${ }^{6-10}$.

The Dutch guidelines regarding the treatment of breast cancer do not recommend systemic adjuvant therapy for low-risk breast cancer with isolated tumor cells in a regional lymph node. Moreover, because of insufficient evidence concerning micrometastases and prognosis, the guidelines provide no advice with respect to systemic adjuvant therapy for low-risk breast cancer with nodal micrometastases ${ }^{11}$. Consequently, some patients with breast cancer and micrometastases in the Netherlands receive systemic adjuvant therapy, and others do not. The aim of the MIRROR (Micrometastases and Isolated tumor cells: Relevant and Robust Or Rubbish?) study was to evaluate the relationship, if any, between isolated tumor cells or micrometastases in the regional lymph nodes and clinical outcome in patients who had undergone a sentinel-node procedure and who did or did not receive systemic adjuvant therapy.

\section{Methods}

\section{Patients}

We identified women with invasive breast cancer who had undergone a sentinel-node biopsy before 2006 from the Netherlands Cancer Registry. We included consecutive patients with favorable primary tumor characteristics (i.e., tumors of $\leq 1 \mathrm{~cm}$ in diameter, irrespective of grade, or tumors $>1$ to $\leq 3 \mathrm{~cm}$, grade 1 or 2) for whom systemic adjuvant therapy was not indicated according to the Dutch guidelines, version $2002^{12}$. Among these women, we selected only patients with a final nodal status of isolated tumor cells or micrometastases detected on microscopical 
examination of the sentinel and non-sentinel lymph nodes (in patients who subsequently underwent axillary lymph node dissection). If both the sentinel node and the non-sentinel node contained metastases, the largest metastasis determined the final nodal status. According to the guidelines, axillary lymph node dissection was generally recommended if isolated tumor cells or micrometastases were detected in the sentinel node ${ }^{12}$. Table 1 lists the proportion of patients in each cohort who underwent axillary lymph node dissection.

In addition to these patients, we randomly selected a control group of 1000 patients who had breast cancer that was classified as low-risk, node-negative disease and who underwent breast surgery and a sentinel-node biopsy with or without an axillary lymph node dissection in the period from 2000 through 2001. We excluded patients who received neoadjuvant chemotherapy, had bilateral breast cancer, had a history of cancer, or had node-negative disease and received systemic adjuvant therapy. All 113 Dutch hospitals and 60 pathology laboratories participated in the study (see Table S1 of the Supplementary appendix). The review board of the Netherlands Cancer Registry approved this study. The ethics committee of Maastricht University Medical Center concluded that no informed consent was required for this retrospective, observational study.

\section{Data collection}

Registration clerks of all eight comprehensive cancer centers in the Netherlands collected data on patient and tumor characteristics, breast surgery, the sentinel-node biopsy, axillary lymph node dissection, radiotherapy, systemic adjuvant therapy, the recurrence of disease or the occurrence of another malignant condition, and death during follow-up.

\section{Pathological review}

Three pathologists who specialized in breast cancer reviewed all available original slides of the sentinel nodes and of positive nodes obtained from patients who underwent an axillary lymph node dissection. These included slides stained with hematoxylin and eosin, slides stained for immunohistochemical analysis, and frozen sections. Additional sections were not obtained, and new immunohistochemical staining was not performed. The grade of the primary tumor was assessed if it was not available from the original pathology report.

Almost all participating pathology laboratories used a protocol in which the sentinel node was serially sectioned at least every $150 \mu \mathrm{m}$ and at a minimum of three levels, with the use of keratin immunohistochemical staining if the hematoxylin and eosin staining was negative. In contrast, the non-sentinel nodes were macroscopically sectioned every 2 to $5 \mathrm{~mm}$, and one section per slice was stained with hematoxylin and eosin ${ }^{13}$. Tumor deposits were classified according to the sixth edition of the AJCC Cancer Staging Manual ${ }^{5}$. 
Table 1. Baseline patient characteristics of the patients*

\begin{tabular}{|c|c|c|c|c|c|c|}
\hline Characteristic & $\begin{array}{l}\text { All patients } \\
(\mathrm{n}=2707)\end{array}$ & $\begin{array}{c}\text { Node-negative } \\
\text { no adjuvant } \\
\text { therapy } \\
(n=856)\end{array}$ & p valuet & $\begin{array}{c}\text { Node-positive } \\
\text { no adjuvant } \\
\text { therapy } \\
(n=856)\end{array}$ & $p$ value $\neq$ & $\begin{array}{c}\text { Node-positive } \\
\text { adjuvant } \\
\text { therapy } \\
(n=995) \\
\end{array}$ \\
\hline Age at diagnosis - yr & & & $<0.001$ & & 0.76 & \\
\hline median & 57 & 59 & & 57 & & 56 \\
\hline range & $30-93$ & $30-89$ & & $32-93$ & & $31-88$ \\
\hline \multicolumn{7}{|l|}{ Tumor size - no.(\%) } \\
\hline$\leq 1 \mathrm{~cm}$ & 801 (29.6) & 346 (40.4) & 0.001 & $236(27.6)$ & 0.001 & $219(22.0)$ \\
\hline$>1$ to $\leq 2 \mathrm{~cm}$ & $1523(56.3)$ & $448(52.3)$ & & $516(60.3)$ & & $559(56.2)$ \\
\hline$>2$ to $\leq 3 \mathrm{~cm}$ & $383(14.1)$ & $62(7.2)$ & & $104(12.1)$ & & $217(21.8)$ \\
\hline \multicolumn{7}{|l|}{ Tumor grade - no.(\%) } \\
\hline 1 & $910(33.6)$ & $317(37.0)$ & 0.25 & $308(36.0)$ & 0.003 & $285(28.6)$ \\
\hline 2 & $1618(59.8)$ & 474 (55.4) & & $499(58.3)$ & & $645(64.8)$ \\
\hline 3 & $135(5.0)$ & $49(5.7)$ & & $36(4.2)$ & & $50(5.0)$ \\
\hline unknown & $44(1.6)$ & $16(1.9)$ & & $13(1.5)$ & & $15(1.5)$ \\
\hline \multicolumn{7}{|l|}{ Tumor type - no.(\%) } \\
\hline ductal & $2065(76.3)$ & $652(76.2)$ & 0.03 & $643(75.1)$ & 0.52 & $770(77.4)$ \\
\hline lobular & $293(10.8)$ & $76(8.9)$ & & $106(12.4)$ & & $111(11.2)$ \\
\hline other & 349 (12.9) & $128(14.9)$ & & $107(12.5)$ & & $114(11.5)$ \\
\hline \multicolumn{7}{|l|}{$\begin{array}{l}\text { Expression of estrogen } \\
\text { receptors, progesterone } \\
\text { receptors, or both - no.(\%) }\end{array}$} \\
\hline yes & $2468(91.2)$ & 761 (88.9) & 0.14 & 768 (89.7) & 0.001 & $939(94.4)$ \\
\hline no & $160(5.9)$ & $50(5.8)$ & & $67(7.8)$ & & $43(4.3)$ \\
\hline unknown & $79(2.9)$ & $45(5.3)$ & & $21(2.5)$ & & $13(1.3)$ \\
\hline \multicolumn{7}{|l|}{ Nodal status - no.(\%)§ } \\
\hline pNO & $856(31.6)$ & $856(100)$ & NA & - & NA & - \\
\hline pNO(i+) & $819(30.3)$ & - & NA & $513(59.9)$ & $<0.001$ & $306(30.8)$ \\
\hline pN1mi & $1032(38.1)$ & - & & $343(40.1)$ & & $689(69.2)$ \\
\hline \multicolumn{7}{|l|}{ Type of surgery - no.(\%) } \\
\hline breast-conserving & $1922(71.0)$ & 633 (73.9) & 0.07 & $599(70.0)$ & 0.77 & $690(69.3)$ \\
\hline mastectomy & $785(29.0)$ & $223(26.1)$ & & $257(30.0)$ & & $305(30.7)$ \\
\hline $\begin{array}{l}\text { No. of sentinel lymph nodes } \\
\text { removed }\end{array}$ & & & $<0.001$ & & 0.17 & \\
\hline mean & 1.9 & 1.8 & & 2.0 & & 1.9 \\
\hline range & $1-14$ & $1-9$ & & $1-14$ & & $1-9$ \\
\hline \multicolumn{7}{|l|}{$\begin{array}{l}\text { Axillary lymph node } \\
\text { dissection - no.(\%) }\end{array}$} \\
\hline no & $1370(50.6)$ & $736(86.0)$ & $<0.001$ & $389(45.4)$ & $<0.001$ & $245(24.6)$ \\
\hline yes & $1337(49.4)$ & $120(14.0)$ & & $467(54.6)$ & & $750(75.4)$ \\
\hline \multicolumn{7}{|l|}{$\begin{array}{l}\text { Axillary lymph node } \\
\text { dissection, axillary } \\
\text { irradiation, or both - no.(\%) }\end{array}$} \\
\hline no & $1218(45.0)$ & $732(85.5)$ & $<0.001$ & $333(38.9)$ & $<0.001$ & $153(15.4)$ \\
\hline yes & $1489(55.0)$ & $124(14.5)$ & & $523(61.1)$ & & $842(84.6)$ \\
\hline \multicolumn{7}{|l|}{$\begin{array}{l}\text { Systemic adjuvant therapy- } \\
\text { no.(\%) }\end{array}$} \\
\hline hormonal therapy & $627(23.2)$ & - & NA & - & NA & $627(63.0)$ \\
\hline chemotherapy & $60(2.2)$ & - & & - & & $60(6.0)$ \\
\hline both & $308(11.4)$ & - & & - & & $308(31.0)$ \\
\hline
\end{tabular}

* NA denotes not applicable; $+p$ values are for the comparison of the node-negative, no-adjuvant-therapy cohort with the node-positive, no-adjuvant-therapy cohort; $¥ p$ values are for the comparison of the node-positive, no-adjuvant-therapy cohort with the node-positive, adjuvant-therapy cohort; § Nodal status is the final nodal status after sentinel-node biopsy, with or without axillary lymph node dissection, and after central review. 
$60 \mid$ Chapter 4

\section{Cohorts}

We identified three cohorts: patients with node-negative disease who did not receive systemic adjuvant therapy (the node-negative, no-adjuvant-therapy cohort), patients with isolated tumor cells or micrometastases in the regional lymph nodes who did not receive systemic adjuvant therapy (the node-positive, no-adjuvant-therapy cohort), and patients with isolated tumor cells or micrometastases in the regional lymph nodes who received systemic adjuvant therapy (the node-positive, adjuvant-therapy cohort). Adjuvant therapy was defined as any type of hormonal therapy, chemotherapy, or both.

To determine whether an association exists between the presence or absence of isolated tumor cells or micrometastases in the regional lymph nodes and outcome, we compared the outcome for patients in the node-negative, no-adjuvant-therapy cohort with the outcome for patients in the node-positive, no-adjuvant-therapy cohort. For this latter cohort, we performed separate assessments of patients with isolated tumor cells and patients with micrometastases. To determine the effect of systemic adjuvant therapy on the outcome in patients with isolated tumor cells or micrometastases, we compared the outcomes in the cohort of patients who did not receive adjuvant therapy with the outcomes in the adjuvant-therapy cohort.

\section{End points}

The primary end point was the 5-year rate of disease-free survival. The period of disease-free survival was defined as the interval from the date of diagnosis to locoregional recurrence, distant metastases, contralateral invasive breast cancer or ductal carcinoma in situ, another malignant condition, or death from any cause, whichever occurred first. Recurrence was a composite end point defined as locoregional recurrence, distant metastases, or invasive cancer or ductal carcinoma in situ in the contralateral breast.

\section{Statistical analysis}

The chi-square test for trend was used to assess baseline differences between ordinal variables, and Student's t-test was used for continuous variables. The Kaplan-Meier method was used to estimate the 5-year rate of disease-free survival. For patients who remained alive and disease-free, data were censored at the date of the last contact.

A Cox proportional-hazards model was used to compare the cohorts and to adjust for known prognostic clinical and pathological variables. In the primary analysis, we included age at diagnosis, tumor size, tumor grade, hormone-receptor status, and form of axillary treatment (node dissection, irradiation, or both, or no axillary treatment). We did not include axillary lymph node dissection as an additional variable in the Cox proportional-hazards model when comparing the node-negative, 
no-adjuvant-therapy cohort with the node-positive, no-adjuvant-therapy cohort, since axillary lymph node dissection is not recommended in patients with a negative sentinel node ${ }^{14}$. To exclude axillary lymph node dissection as a confounder, we performed a secondary analysis in which axillary lymph node dissection was included, comparing the node-negative, no-adjuvant-therapy cohort and the node-positive, noadjuvant-therapy cohort. We did not consider hormone-receptor status when comparing the cohort of patients with isolated tumor cells or micrometastases that received adjuvant therapy with the cohort that did not receive such therapy, since hormone-receptor status partially determined whether a patient was included in the node-positive, no-adjuvant-therapy cohort or the node-positive, adjuvant-therapy cohort.

All reported $p$ values are two-sided, and confidence intervals are at the $95 \%$ level. All analyses were performed with the use of SAS software, version $8.2^{15}$.

\section{Results}

\section{Patients}

We identified 3181 women with breast cancer from the Netherlands Cancer Registry. We excluded 146 patients (4.6\%) because of incomplete or unavailable material for pathological review and 26 patients $(0.8 \%)$ because of missing baseline characteristics. After pathological review, 302 patients $(9.5 \%)$ were ineligible because of macrometastases (in 185 patients), unfavorable primary tumor characteristics (in 68 patients), noninvasive breast cancer (in 7 patients), unmeasurable size of metastasis (in 2 patients), or receipt of systemic adjuvant therapy despite favorable nodenegative disease (in 40 patients).

The final study involved 2707 women: 856 women with node-negative disease who did not receive systemic adjuvant therapy (31.6\%), 856 women with isolated tumor cells or micrometastases who did not receive adjuvant therapy (31.6\%), and 995 women with isolated tumor cells or micrometastases who received adjuvant therapy (36.8\%).

Table 1 shows the baseline characteristics of the three cohorts. In the node-positive, no-adjuvant-therapy cohort as compared with the node-negative cohort, the tumors were larger $(p<0.001)$, more patients had lobular carcinoma $(p=0.03)$, and more patients had undergone axillary lymph node dissection $(p<0.001)$. In the nodepositive, adjuvant-therapy cohort as compared with the node-positive, no-adjuvanttherapy cohort, the tumors were larger $(p<0.001)$, the differentiation grade was poorer $(p=0.003)$, more patients had micrometastases in the regional nodes $(p<0.001)$, and more patients had undergone axillary lymph node dissection $(p<0.001)$. Other differences (e.g., age at diagnosis, number of sentinel nodes removed, and 
hormone-receptor status) were small in absolute terms, though they were statistically significant (Table 1).

The median duration of follow-up was 5.1 years (range, 0.04 to 9.3). Ninety-five patients (3.5\%) were lost to follow-up within 0.04 to 5.6 years after diagnosis. At the last follow-up, 2261 patients (83.5\%) were free of disease.

The components of the composite end point of recurrence (contralateral breast cancer, locoregional recurrence, and distant metastases) all showed the same trend as that reported for the overall end point of disease recurrence (see Table S2 in the Supplementary appendix). More detailed analyses of each of the components were not possible, however, because of the small number of events.

\section{Node-negative, no-adjuvant-therapy cohort vs. node-positive, no- adjuvant-therapy cohort}

The unadjusted 5-year rate of disease-free survival in the node-positive, no-adjuvanttherapy cohort was significantly reduced as compared with that in the node-negative, no-adjuvant-therapy cohort $(76.5 \%$ vs. $85.7 \%, p<0.001)$ (Figure 1A). Patients with isolated tumor cells who did not receive adjuvant therapy had a significantly reduced 5-year rate of disease-free survival as compared with patients in the node-negative, no-adjuvant-therapy cohort ( $77.2 \%$ vs. $85.7 \%$, p<0.001) (Figure 1B), and patients with micrometastases who did not receive adjuvant therapy had a significantly reduced 5year rate of disease-free survival as compared with patients in the node-negative, noadjuvant therapy cohort ( $75.9 \%$ vs. $85.7 \%, p=0.002$ ) (Figure $1 B$ ). In the cohort of nodepositive patients who did not receive adjuvant therapy, the 5-year rate of disease-free survival was similar among patients with isolated tumor cells and those with micrometastases $(77.2 \%$ and $75.9 \%$, respectively; $p=0.77)$.

After adjustment for age at diagnosis, tumor size, tumor grade, and hormonereceptor status, there was an increased risk of events in the node positive, noadjuvant-therapy cohort as compared with the node-negative, no-adjuvant-therapy cohort (hazard ratio, 1.51; 95\% confidence interval (CI), 1.20 to 1.90) (Table 2). The hazard ratio among women with isolated tumor cells who did not receive adjuvant therapy, as compared with the node-negative, no-adjuvant-therapy cohort, was 1.50 $(95 \% \mathrm{Cl}, 1.15$ to 1.94$)$, and the hazard ratio among women with micrometastases, as compared with the node-negative women, was $1.56(95 \% \mathrm{Cl}, 1.15$ to 2.13) (Table 2). Age at diagnosis, tumor size, tumor grade, and hormone receptor status were also associated with the risk of events (Table 2). When axillary lymph node dissection was included in the model, the results were essentially the same (Table S3 in the Supplementary appendix). 


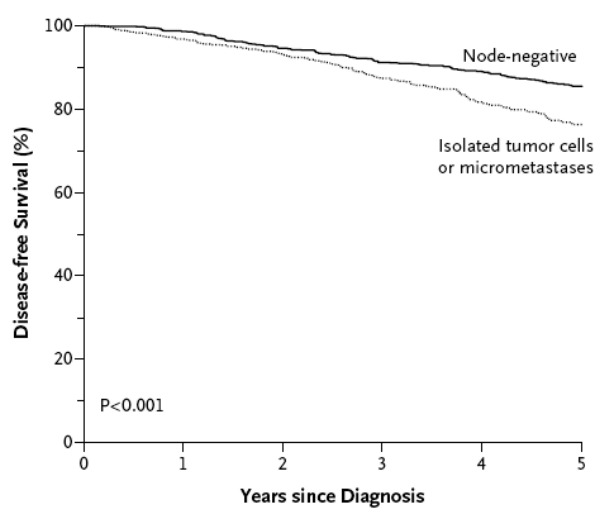

No. at Risk

\begin{tabular}{lllllll} 
Node-negative & 856 & 838 & 800 & 761 & 722 & 628 \\
$\begin{array}{c}\text { Isolated tumor } \\
\text { cells or micro- }\end{array}$ & 856 & 823 & 753 & 588 & 423 & 275 \\
\hline
\end{tabular}

cells or micro-

metastases

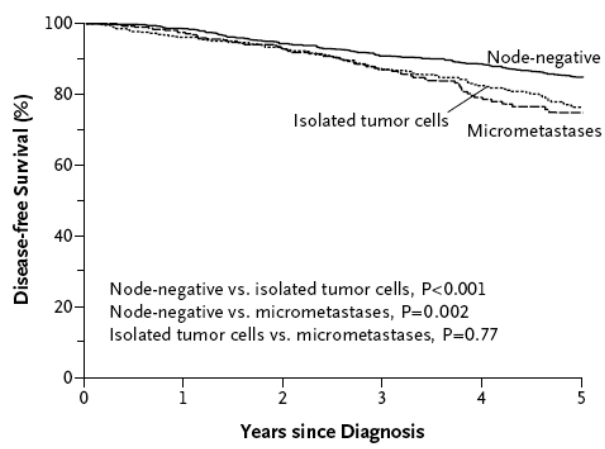

No. at Risk

\begin{tabular}{lllllll}
$\begin{array}{l}\text { Node-negative } \\
\text { Isolated tumor }\end{array}$ & 856 & 838 & 800 & 761 & 722 & 628 \\
cells & 513 & 493 & 453 & 367 & 282 & 199 \\
\hline
\end{tabular}

$\begin{array}{cccccc}\text { cells } & & & & & \\ \text { Micrometastases } 343 & 330 & 301 & 222 & 142 & 76\end{array}$

Figure 1. Disease-free survival among patients with early stage breast cancer with or without isolated tumor cells or micrometastases who did not receive systemic adjuvant therapy. Panel A shows disease-free survival among patients with node-negative disease and among patients with isolated tumor cells or micrometastases. Panel B shows disease-free survival among patients with node-negative disease, patients with isolated tumor cells, and patients with micrometastases.

No adjuvant therapy vs. adjuvant therapy among node-positive patients

The unadjusted 5-year rate of disease-free survival among women with isolated tumor cells or micrometastases who did not receive adjuvant therapy was significantly reduced as compared with the rate in the node-positive, adjuvant-therapy cohort $(76.5 \%$ vs. $86.2 \%, p<0.001)$ (Figure $2 A)$. Patients with isolated tumor cells who did not 
receive adjuvant therapy had a significantly reduced 5-year rate of disease-free survival as compared with women who did receive adjuvant therapy $(77.2 \%$ vs. $83.0 \%$, $\mathrm{p}=0.04$ ) (Figure 2B). Among women with micrometastases, the 5-year rate of diseasefree survival was significantly reduced in the no-adjuvant-therapy cohort as compared with the adjuvant-therapy cohort $(75.9 \%$ vs. $87.9 \%, p<0.001)$ (Figure $2 \mathrm{C}$ ). Within the node-positive, adjuvant-therapy cohort, the 5-year rate of disease-free survival did not differ significantly between patients with isolated tumor cells and those with micrometastases ( $83.0 \%$ and $87.9 \%$, respectively; $p=0.09)$.

Table 2. Cox proportional-hazards model of the effects of variables on events according to the presence or absence of isolated tumor cells or micrometastases

\begin{tabular}{|c|c|c|c|c|c|c|c|c|c|}
\hline \multirow[b]{2}{*}{ Variable } & \multicolumn{3}{|c|}{$\begin{array}{l}\text { Node-negative vs. isolated } \\
\text { tumor cells or } \\
\text { micrometastases, all with } \\
\text { no adjuvant therapy }\end{array}$} & \multicolumn{3}{|c|}{$\begin{array}{c}\text { Node-negative vs. isolated } \\
\text { tumor cells, both with no } \\
\text { adjuvant therapy }\end{array}$} & \multicolumn{3}{|c|}{$\begin{array}{c}\text { Node-negative vs. } \\
\text { micrometastases, both with } \\
\text { no adjuvant therapy }\end{array}$} \\
\hline & $\begin{array}{l}\text { Hazard } \\
\text { ratio for } \\
\text { events }\end{array}$ & $95 \% \mathrm{Cl}$ & $p$ value & $\begin{array}{l}\text { Hazard } \\
\text { ratio for } \\
\text { events }\end{array}$ & $95 \% \mathrm{Cl}$ & $p$ value & $\begin{array}{l}\text { Hazard } \\
\text { ratio for } \\
\text { events }\end{array}$ & $95 \% \mathrm{Cl}$ & $p$ value \\
\hline Node-negative & 1.00 & & & 1.00 & & & 1.00 & & \\
\hline $\begin{array}{l}\text { Isolated tumor cells } \\
\text { or micrometastases }\end{array}$ & 1.51 & $1.20-1.90$ & $<0.001$ & - & - & - & - & - & - \\
\hline isolated tumor cells & - & - & - & 1.50 & $1.15-1.94$ & 0.003 & - & - & - \\
\hline micrometastases & - & - & - & - & - & - & 1.56 & $1.15-2.13$ & 0.005 \\
\hline Age at diagnosis- yr* & 1.01 & $1.00-1.02$ & 0.02 & 1.02 & $1.01-1.03$ & 0.002 & 1.01 & $1.00-1.02$ & 0.17 \\
\hline Tumor size† & 1.22 & $1.02-1.46$ & 0.03 & 1.25 & $1.03-1.52$ & 0.02 & 1.20 & $0.97-1.49$ & 0.10 \\
\hline \multicolumn{10}{|l|}{ Tumor grade } \\
\hline 1 & 1.00 & & & 1.00 & & & 1.00 & & \\
\hline 2 & 1.54 & $1.19-1.99$ & 0.001 & 1.76 & $1.31-2.36$ & $<0.001$ & 1.51 & $1.10-2.08$ & 0.01 \\
\hline 3 & 2.14 & $1.27-3.60$ & 0.004 & 2.40 & $1.35-4.27$ & 0.003 & 2.31 & $1.27-4.22$ & 0.006 \\
\hline \multicolumn{10}{|l|}{$\begin{array}{l}\text { Expression of } \\
\text { estrogen receptors, } \\
\text { progesterone } \\
\text { receptors, or both }\end{array}$} \\
\hline yes & 1.00 & & & 1.00 & & & 1.00 & & \\
\hline no & 1.50 & $1.03-2.20$ & 0.04 & 1.62 & $1.06-2.46$ & 0.02 & 1.32 & $0.80-2.16$ & 0.28 \\
\hline
\end{tabular}

* Age was modeled as a continuous variable; † The hazard ratio is for a doubling of the tumor diameter

After adjustment for age at diagnosis, tumor size, tumor grade, and axillary treatment or no axillary treatment, there remained a reduced risk of events in the node-positive, adjuvant-therapy cohort as compared with the node-positive, no-adjuvant-therapy cohort (hazard ratio, $0.57 ; 95 \% \mathrm{Cl}, 0.45$ to 0.73 ) (Table 3). The hazard ratios were similar for patients with isolated tumor cells $(0.66 ; 95 \% \mathrm{Cl}, 0.46$ to 0.95$)$ and those with micrometastases $(0.50 ; 95 \% \mathrm{Cl}, 0.35$ to 0.72 ) (Table 3). Also, age at diagnosis, tumor size, tumor grade, and axillary treatment or no axillary treatment were associated with the risk of events (Table 3). 
In the node-positive, adjuvant-therapy cohort, the subgroup of patients who received chemotherapy only was small (60 patients), which limited statistical analysis according to treatment, though patients who received combined chemotherapy and endocrine treatment seemed to have the largest benefit, as compared with patients in the nodepositive, no-adjuvant-therapy cohort (adjusted hazard ratio, $0.34 ; 95 \% \mathrm{Cl}, 0.21$ to 0.55). The outcomes according to the type of adjuvant systemic therapy are shown in Tables S4 and S5 in the Supplementary appendix.

Table 3. Cox proportional-hazards model of the effect of variables on events according to whether adjuvant therapy was received

\begin{tabular}{|c|c|c|c|c|c|c|c|c|c|}
\hline \multirow[b]{2}{*}{ Variable } & \multicolumn{9}{|c|}{$\begin{array}{c}\text { Node-positive, no adjuvant Isolated tumor cells without Micrometastases without } \\
\text { therapy vs. node-positive, therapy vs. isolated tumor therapy vs. micrometastases } \\
\begin{array}{c}\text { adjuvant therapy } \\
\text { cells with therapy }\end{array}\end{array}$} \\
\hline & $\begin{array}{l}\text { Hazard } \\
\text { ratio for } \\
\text { events }\end{array}$ & $95 \% \mathrm{Cl}$ & $p$ value & $\begin{array}{l}\text { Hazard } \\
\text { ratio for } \\
\text { events }\end{array}$ & $95 \% \mathrm{Cl}$ & $\mathrm{p}$ value & $\begin{array}{l}\text { Hazard } \\
\text { ratio for } \\
\text { events }\end{array}$ & $95 \% \mathrm{Cl}$ & $p$ value \\
\hline $\begin{array}{l}\text { Node-positive, no- } \\
\text { adjuvant-therapy } \\
\text { cohort }\end{array}$ & 1.00 & & & - & - & - & - & - & - \\
\hline isolated tumor cells & - & - & - & 1.00 & & & - & - & - \\
\hline micrometastases & - & - & - & - & - & - & 1.00 & & \\
\hline $\begin{array}{l}\text { Node-positive, } \\
\text { adjuvant-therapy } \\
\text { cohort }\end{array}$ & 0.57 & $0.45-0.73$ & $<0.001$ & - & - & - & - & - & - \\
\hline isolated tumor cells & - & - & - & 0.66 & $0.46-0.95$ & 0.02 & - & - & - \\
\hline micrometastases & - & - & - & - & - & - & 0.50 & $0.35-0.72$ & $<0.001$ \\
\hline Age at diagnosis-yr* & 1.02 & $1.01-1.03$ & $<0.001$ & 1.03 & $1.02-1.05$ & $<0.001$ & 1.01 & $1.00-1.03$ & 0.08 \\
\hline Tumor size ${ }^{\dagger}$ & 1.28 & $1.05-1.57$ & 0.01 & 1.34 & $1.03-1.75$ & 0.03 & 1.19 & $0.87-1.61$ & 0.27 \\
\hline \multicolumn{10}{|l|}{ Tumor grade } \\
\hline 1 & 1.00 & & & 1.00 & & & 1.00 & & \\
\hline 2 & 1.34 & $1.03-1.75$ & 0.03 & 1.38 & $0.95-1.99$ & 0.09 & 1.28 & $0.86-1.89$ & 0.22 \\
\hline 3 & 1.83 & $0.98-3.44$ & 0.06 & 1.71 & $0.64-4.59$ & 0.28 & 1.76 & $0.77-4.04$ & 0.18 \\
\hline \multicolumn{10}{|l|}{$\begin{array}{l}\text { Axillary lymph node } \\
\text { dissection, axillary } \\
\text { irradiation, or both }\end{array}$} \\
\hline yes & 1.00 & & & 1.00 & & & 1.00 & & \\
\hline no & 1.36 & $1.06-1.76$ & 0.02 & 1.24 & $0.89-1.74$ & 0.20 & 1.63 & $1.07-2.48$ & 0.02 \\
\hline
\end{tabular}

* Age was modeled as a continuous variable; † The hazard ratio is for a doubling of the tumor diameter 
66 $\mid$ Chapter 4

A Patients with Isolated Tumor Cells or Micrometastases

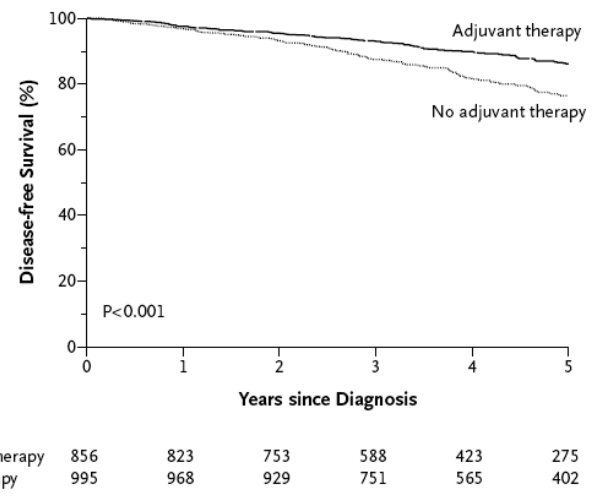

B Patients with Isolated Tumor Cells

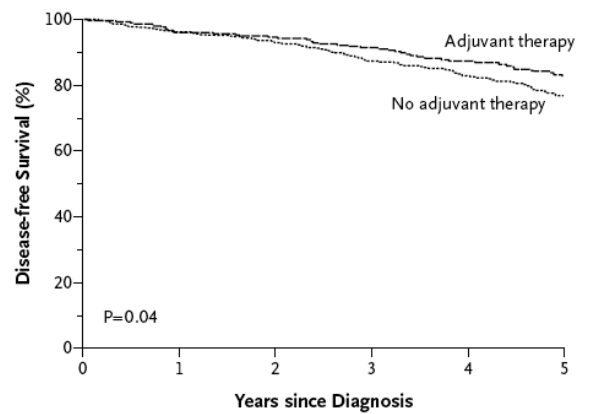

No. at Risk

$\begin{array}{lllllll}\text { No adjuvant therapy } & 513 & 493 & 453 & 367 & 282 & 199 \\ \text { Adjuvant therapy } & 306 & 293 & 285 & 249 & 199 & 148\end{array}$

Patients with Micrometastases

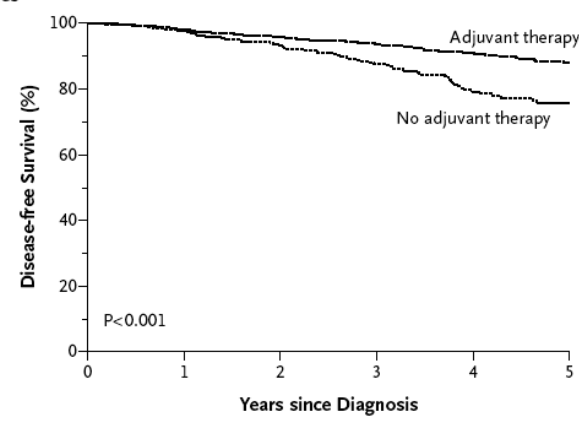

No. at Risk

$\begin{array}{llllllr}\text { No adjuvant therapy } & 343 & 330 & 301 & 222 & 142 & 76 \\ \text { Adjuvant therapy } & 689 & 675 & 644 & 502 & 366 & 254\end{array}$

Figure 2. Disease-free survival among patients with early stage breast cancer and isolated tumor cells or micrometastases who received systemic adjuvant therapy and those who did not. Panel A shows disease-free survival among all patients with isolated tumor cells or micrometastases, Panel B shows disease-free survival among patients with isolated tumor cells, and Panel C shows disease-free survival among patients with micrometastases. 


\section{Discussion}

In this study, we determined whether a relationship exists between disease-free survival and the presence of isolated tumor cells or micrometastases as the final nodal status in women with favorable primary tumor characteristics who underwent a sentinel-node biopsy. All sentinel nodes and positive non-sentinel nodes were centrally reviewed, and separate analyses of the outcomes of patients who did or did not receive systemic adjuvant therapy were performed. We found that micrometastases or isolated tumor cells in the regional lymph nodes were associated with an absolute reduction in the 5-year rate of disease-free survival of nearly 10 percentage points. Among patients who received systemic adjuvant therapy, the 5year rate of disease-free survival was significantly improved, with an absolute benefit of nearly 10 percentage points.

The presence of tumor-cell deposits in regional lymph nodes may reflect the potential of the primary tumor to metastasize. The size of the tumor deposit may not be an influence on the outcome, since patients with isolated tumor cells or micrometastases had a comparably poor 5-year rate of disease-free survival. We did not differentiate between single tumor cells (which may not have metastatic potential) ${ }^{16,17}$ and clusters of cells with an unknown potential for metastasis; this difference requires clarification. In current staging systems for breast cancer, lymph nodes containing micrometastases are classified as node-positive (pN1mi), whereas nodes containing isolated tumor cells are classified as node-negative $(\mathrm{pNO}(\mathrm{i}+))^{5,18}$. In view of our results, a re-evaluation of the current AJCC classification is warranted.

Since the introduction of the sentinel node biopsy, there has been renewed interest in the prognostic implications of the presence of isolated tumor cells and micrometastases. Most previous studies have shown reduced survival among women with occult metastases in lymph nodes, as compared with women with no nodal metastases, although the difference was not always confirmed in multivariate analyses $^{6-8,19,20}$. Large studies that included women who received a diagnosis before the sentinel-node era showed that micrometastases, defined as $2 \mathrm{~mm}$ or smaller in diameter and including isolated tumor cells, were associated with reduced overall survival $^{9,10,21-24}$. In these studies, however, the axillary nodes were examined by means of hematoxylin and eosin staining at just one level. Thus, we cannot compare these studies with ours, which involved a detailed examination of the sentinel node. The few previous studies of sentinel nodes were limited by small samples, lack of multivariate analyses, or short follow-up ${ }^{25-27}$.

A drawback of our study is that most of our patients received a diagnosis when the Dutch guidelines for management of breast cancer were conservative, advising systemic adjuvant therapy in patients with node-negative disease only if the estimated 10-year probability of overall survival was less than $80 \%{ }^{12}$. Now, because of changes in the guidelines, more patients receive systemic therapy ${ }^{11}$. Therefore, isolated tumor cells or micrometastases should have a smaller influence on disease- 
68 $\mid$ Chapter 4

free survival among patients with early-stage breast cancer. However, since chemotherapy now usually consists of potent third generation regimens, instead of the first- or second-generation regimens that were given in $69 \%$ and $29 \%$, respectively, of our patients who received chemotherapy, the impact of systemic therapy should be increased.

In this cohort study, the decision to administer systemic adjuvant therapy was at the discretion of the physician. We corrected for factors that might have influenced this decision, such as age at diagnosis, tumor size, and tumor grade. To rule out axillary lymph node dissection as a confounder, we performed an additional analysis of the node-negative, no-adjuvant-therapy cohort versus the node-positive, no-adjuvanttherapy cohort with this variable included in the model, with essentially the same outcome (Table S3 in the Supplementary appendix). No conclusion was possible regarding the effect of axillary lymph node dissection on disease-free survival and the recurrence rate in the axilla. To address that question, analyses have to be based on the sentinel node status instead of the final nodal status.

\section{Acknowledgements}

We thank Jolanda M. van Beek-Schoester for her assistance with data management and Wim A.J.G. Lemmens for his assistance with statistical analyses.

\section{Funding}

Supported by a grant from the Netherlands Organization for Health Research and Development (945-06-509) and by the Dutch Breast Cancer Trialists' Group (BOOG).

Presented in part at the San Antonio Breast Cancer Symposium, San Antonio, Texas, December 10-14, 2008. 


\section{References}

1. Fisher B, Bauer M, Wickerham DL, Redmond CK, et al. Relation of number of positive axillary nodes to the prognosis of patients with primary breast cancer: an NSABP update. Cancer 1983;52:1551-1557.

2. van der Heiden-van der Loo M, Bezemer PD, Hennipman A, et al. Introduction of sentinel node biopsy and stage migration of breast cancer. Eur J Surg Oncol 2006;32:710-714.

3. Cserni G, Amendoeira I, Apostolikas N, et al; European Working Group for Breast Screening Pathology. Pathological work-up of sentinel lymph nodes in breast cancer: review of current data to be considered for the formulation of guidelines. Eur J Cancer 2003;39:1654-1667.

4. Bolster MJ, Bult P, Schapers RF, et al. Differences in sentinel lymph node pathology protocols lead to differences in surgical strategy in breast cancer patients. Ann Surg Oncol 2006;13:1466-1473.

5. Green FL, Page DL, Fleming ID, et al. eds. AJCC cancer staging manual. 6th ed. Chicago: American Joint Commission on Cancer, 2002.

6. Cote RJ, Peterson HF, Chaiwun B, et al. Role of immunohistochemical detection of lymph-node metastases in management of breast cancer. Lancet 1999;354:896-900.

7. de Mascarel I, Bonichon F, Coindre JM, Trojani M. Prognostic significance of breast cancer axillary lymph node micrometastases assessed by two special techniques: reevaluation with longer follow-up. Br J Cancer 1992;66:523-527.

8. Tan LK, Giri D, Hummer AJ, et al. Occult axillary node metastases in breast cancer are prognostically significant: results in 368 node-negative patients with 20-year follow-up. J Clin Oncol 2008;26: 1803-1809.

9. Chen SL, Hoehne FM, Giuliano AE. The prognostic significance of micrometastases in breast cancer: a SEER population-based analysis. Ann Surg Oncol 2007;14:3378-84.

10. Colleoni M, Rotmensz N, Peruzzotti G, et al. Size of breast cancer metastases in axillary lymph nodes: clinical relevance of minimal lymph node involvement. J Clin Oncol 2005;23:1379-1389.

11. Struikmans H, Nortier JW, Rutgers EJ, et al. Guidelines 'Treatment of breast cancer 2008' (revision). Ned Tijdschr Geneeskd 2008;152:2507-2511.

12. Rutgers EJ, Nortier JW, Tuut MK, et al. Dutch Institute for Healthcare Improvement guidelines, "Treatment of breast cancer." Ned Tijdschr Geneeskd 2002;146:2144-51. (In Dutch.) [Erratum, Ned Tijdschr Geneeskd 2003;147:2612.]

13. Treatment of breast cancer: guidelines. Utrecht, the Netherlands: Dutch Institute for Healthcare Improvement (CBO) NABON, 2002. (In Dutch.)

14. Lyman GH, Giuliano AE, Somerfield MR, et al; American Society of Clinical Oncology. American Society of Clinical Oncology guideline recommendations for sentinel lymph node biopsy in early-stage breast cancer. J Clin Oncol 2005;23:7703-7720.

15. SAS/STAT user' s guide, version 8. Cary, NC: SAS Institute, 1999.

16. Bleiweiss IJ, Nagi CS, Jaffer S. Axillary sentinel lymph nodes can be falsely positive due to iatrogenic displacement and transport of benign epithelial cells in patients with breast carcinoma. J Clin Oncol 2006;24:2013-8.

17. van Deurzen $\mathrm{CH}$, Bult $\mathrm{P}$, de Boer $\mathrm{M}$, et al. Morphometry of isolated tumor cells in breast cancer sentinel lymph nodes: metastases or displacement? Am J Surg Pathol 2009;33:106-110.

18. Sobin LH, Wittekind Ch. TNM classification of malignant tumours. 6th ed. New York: Wiley-Liss, 2002.

19. Cummings MC, Walsh MD, Hohn BG, Bennett IC, Wright RG, McGuckin MA. Occult axillary lymph node metastases in breast cancer do matter: results of 10-year survival analysis. Am J Surg Pathol 2002;26:1286-95

20. Millis RR, Springall R, Lee AH, Ryder K, Rytina ER, Fentiman IS. Occult axillary lymph node metastases are of no prognostic significance in breast cancer. Br J Cancer 2002;86:396-401.

21. Grabau D, Jensen MB, Rank F, Blichert-Toft M. Axillary lymph node micrometastases in invasive breast cancer: national figures on incidence and overall survival. APMIS 2007;115:828-837.

22. Kuijt GP, Voogd AC, van de Poll-Franse LV, Scheijmans L, van Beek MW, Roumen RM. The prognostic significance of axillary lymph-node micrometastases in breast cancer patients. Eur J Surg Oncol 2005;31:500-505

23. Maibenco DC, Dombi GW, Kau TY, Severson RK. Significance of micrometastases on the survival of women with T1 breast cancer. Cancer 2006;107:1234-1239. 
70 Chapter 4

24. Truong PT, Vinh-Hung V, Cserni G, Woodward WA, Tai P, Vlastos G. The number of positive nodes and the ratio of positive to excised nodes are significant predictors of survival in women with micrometastatic node-positive breast cancer. Eur J Cancer 2008;44:1670-1677.

25. Fan YG, Tan YY, Wu CT, et al. The effect of sentinel node tumor burden on nonsentinel node status and recurrence rates in breast cancer. Ann Surg Oncol 2005;12:705-711.

26. Cox CE, Kiluk JV, Riker Al, et al. Significance of sentinel lymph node micrometastases in human breast cancer. J Am Coll Surg 2008;206:261-268.

27. Gobardhan PD, Elias SG, Madsen EV, et al. Prognostic value of micrometastases in sentinel lymph nodes of patients with breast carcinoma: a cohort study. Ann Oncol 2009;20:41-48. 
Micrometastases or isolated tumor cells and the outcome of breast cancer $\mid 71$

Supplementary appendix 
Table S1. Individuals and institutions participating in this study

Comprehensive Cancer Centre East, Nijmegen - C. Lennards; Canisius Wilhelmina Hospital, Nijmegen - C. Wauters, L. Strobbe; Radboud University Medical Centre, Nijmegen - Th. Wobbes; Maas Hospital, Boxmeer - A. Meersman; Rijnstate Hospital, Arnhem - F. van de Molengraft, R. Keus, J. Klinkenbiji; Gelderse Vallei Hospital, Ede - E. Balk, J. Kroeze; Zevenaar Hospital, Zevenaar - J. van Wijk; Slingeland Hospital, Doetinchem - E. Muller; St. Jansdal Hospital, Harderwijk - R. Tobon Morales; Comprehensive Cancer Centre Amsterdam, Amsterdam - O. Visser, W. Heijbroek-de Clerq; Academic Medical Centre, Amsterdam - M. van de Vijver, A. Kluit; IJsselmeerziekenhuizen, Lelystad - E. Neefjes-Borst, G. Algie; Onze Lieve Vrouwe Gasthuis, Amsterdam - E. Nijhuis, P. Borgstein; Flevo Hospital, Almere - M. Regoort; Medical Centre Alkmaar, Alkmaar - H.J. van Slooten, B. Langenhorst; Gemini Hospital, Den Helder - H. Tjeenk Willink; Westfries Gasthuis, Hoorn J.W. Jansen, M. Govaert; Zaans Medical Centre, Zaandam - M. Flens, J. Oomen; BovenIJ Hospital, Amsterdam - R. Klicks; Waterland Hospital, Purmerend - L. de Widt-Levert; Netherlands Cancer Institute/Antoni van Leeuwenhoek Hospital, Amsterdam - H. van Boven, J. Westerga; Slotervaart Hospital, Amsterdam - L. de Kock; Hospital Amstelland, Amstelveen - S. Veltkamp; Spaarne Hospital, Hoofddorp - J. Burggraaf, A. Tanka; Sint Lucas Andreas Hospital, Amsterdam - E. Barbé, E. Steller; Vrije Universiteit Medical Centre, Amsterdam - W. Mooi, S. Meijer; Kennemer Gasthuis, Haarlem - D. Willebrand, H. Rijna; Rode Kruis Hospital, Beverwijk - M. Hunfeld; Tergooi Hospitals, Blaricum - M. Prins, P. Bor, A. ten Tije; Tergooi Hospitals, Hilversum - J. Juttmann, S. Luykx-de Bakker; Comprehensive Cancer Centre West, Leiden - P. Krijnen, B. Jongejan; Bronovo Hospital, Den Haag - I. Koelma, J. van Esser, O. Guicherit; Diaconessenhuis, Leiden, - J. Graadt van Roggen, R. Vree, E. Planken; Rijnland Hospital, Leiderdorp - J. Calame, A. Zeilemaker, W. Molendijk; Medical Centre Haaglanden, Den Haag E. Ooms, A. Marinelli, R. Brouwer; Medical Centre Haaglanden, Leidschendam - I. Groot; 't Lange Land Hospital, Zoetermeer - B. Jas, A. Ogilvie; Groene Hart Hospital, Gouda - M. Giessen, R. Schmitz, A. van der Torren-Konze; Haga Hospital Leyenburg, Den Haag - P. Blok, W. Steup, H. Sleeboom; Haga Hospital Rode Kruis, Den Haag - J. Merkus; Leiden University Medical Centre, Leiden - V. Smit, B. Bonsing; Reinier de Graaf Groep, Delft - A. van Leeuwen, C. Marcoen, E. Maartense; Comprehensive Cancer Centre Eindhoven, Eindhoven - M. Janssen-Heijnen, A. van den Eijnden-van Rooijen; Laboratory for Pathology (PAMM), Eindhoven - M. van Beek; Catharina Hospital, Eindhoven - Y. van Riet, G. Creemers; Máxima Medical Centre, Eindhoven - O. Repelaer van Driel, M. Nijziel; Máxima Medical Centre, Veldhoven - R. Roumen, G. Vreugdenhil; Sint Anna Zorggroep, Geldrop - E. Luiten, A. Smals; Jeroen Bosch Hospital, 's Hertogenbosch - J. Broekman, W. Gelderman, J. Wissing, S. Bouwer, T. Smilde, Hospital Bernhoven, Veghel - B. Storck, N. van Diemen; Bernhoven Hospital, Oss - Y. Paquay, A. Vos; Amphia Hospital Molengracht, Breda - P. de Wit, J. Nuytinck, G. Ras; Amphia Hospital Pasteurlaan, Oosterhout - O. van West, J. van Wissen; Amphia Hospital Langendijk, Breda - A. van Gent; Sint Elizabeth Hospital, Tilburg - A. Croonen, J. Roukema, J. van Riel; Tweesteden Hospital, Tilburg - S. Brenninkmeijer, H. van Ojik; Elkerliek Hospital, Helmond - M. Tutein Nolthenius-Puylaert, B. Lemaire; VieCuri Medical Centre, Venlo - R. Schapers, P. Nijhuis, A. van der Wouw; Comprehensive Cancer Centre Rotterdam, Rotterdam - R. Damhuis, J. Paulides; Erasmus Medical Centre, Rotterdam - M. Kliffen; Medical Centre Rijnmond-Zuid Zuider, Rotterdam - S. Henzen-Logmans; Medical Centre Rijnmond-Zuid Clara, Rotterdam - H. van den Ingh, W. Meijer; Laboratory for Pathology (PATHAN), Rotterdam - J. Ruizeveld de Winter; Vlietland Hospital, Schiedam I. Mares-Engelberts; Ruwaard van Putten Hospital, Spijkenisse - R. den Toom; IJsselland Hospital, Capelle aan de IJssel - G. Tetteroo; Sint Fransiscus Hospital, Rotterdam - H. Strijdhorst; Ikazia Hospital, Rotterdam - W. Vles; Haven Hospital, Rotterdam - J. van Dam; Albert Schweitzer Hospital, Dordrecht - P. Westenend, P. Plaisier; Laboratory for Pathology Zeeland - L. de Bruijckere; Hospital Walcheren, Vlissingen - J. ten Thije; Oosterschelde Hospitals, Goes - H. de Morree; Van Weel-Bethesda Hospital, Dirksland - R. van der Hul; Hospital Zeeuw-Vlaanderen, Terneuzen - W. Mostert, K. Ongena; Hospital Lievensberg, Bergen op Zoom - V. Potters, E. Slingenberg; Franciscus Hospital, Roosendaal - H. Kemperman; Comprehensive Cancer Centre Limburg, Maastricht - J. Bruijnen, S. Adema; Maastricht University Medical Hospital, Maastricht - M. von Meyenfeldt, P. Hupperets; Maasland Hospital, Sittard - W. Vos, F. van der Ent, F. Erdkamp; Atrium Medical Centre Parkstad, Heerlen - M. Nap, J. van der Bijl, M. Pannebakker; Laurentius Hospital, Roermond - A. Willig, C. Finaly-Marais, M. den Boer; Sint Jans Gasthuis, Weert - F. Limbeek, P. den Haan; Comprehensive Cancer Centre MiddenNederland, Utrecht - M. van der Heiden-van der Loo, A. Koppejan-Rensenbrink; Sint Antonius Hospital, Nieuwegein - C. Seldenrijk, R. Koelemij, P. de Jong; Mesos Medical Centre, Utrecht - A. van Wieringen, R. Oltmans; Zuwe Hofpoort Hospital, Woerden - J. Vente, M. Verhaar-Langereis; Diakonessenhuis, Utrecht - J. van Gorp, T. van Dalen, P. Thunnissen; Meander Medical Centre, Amersfoort - E. Ahsmann, A. van Overbeeke, C. Rodenburg; University Medical Centre Utrecht, Utrecht - R. van Hilligersberg, E. van der Wall; Hospital Rivierenland, Tiel - K. Ong, C. Henkens; Comprehensive Cancer Centre North East, Enschede, Groningen - S. Siesling, M. Schaapveld, R. Otter, A. Wit; Laboratory for Pathology Oost Nederland (LPON), Enschede - M. Brinkhuis; Medisch Spectrum Twente, Enschede - W. Mastboom, W. Smit; Ziekenhuisgroep Twente Twenteborg, Almelo - D. van der Velde, R. Hoekstra; Ziekenhuisgroep Twente SMT, Hengelo - H. Heijmans, H. Dankbaar; Streekziekenhuis Koningin Beatrix, Winterswijk - F. Slootmans, P. Schiphorst; Gelre Hospitals, Apeldoorn - E. Weltevreden, J. Roussel, S. Radema; Hospital Spittaal, Zutphen - J. Ketel, O. van Dobbenburgh; Deventer Hospital, Deventer - J. Arends, H. de Vries, A. Imholz; Laboratory for Pathology (LVF), Leeuwarden - H. Eggink; Antonius Hospital, Sneek - E. Mulder, G. Woolthuis; Medical Centre Leeuwarden, Leeuwarden - C. Hoff, H. de Graaf; Hospital Nij Smellinghe, Drachten - H. van der Mijle, H. van Kamp; Hospital Talma Sionsberg, Dokkum - J. Kaspers, J. de Graaf; Hospital de Tjongerschans, Heerenveen - P. Veldman, J. de Boer; Bethesda Hospital, Hoogeveen - G. Freling, R. Haasen, J. Haasjes; Röpke-Zweers Hospital, Hardenberg M. Jagers, R. Blankenburgh; Diaconessenhuis, Meppel - L. Hanssen, H. de Korte; Isala Klinieken, Zwolle - A. Jonker, E. Pierik, J. de Graaf; Laboratory for Pathology, Winschoten - C. Schoots; Sint Lucas Hospital, Winschoten - M. Klöppner, H. Potthoff; Refaja Hospital, Stadskanaal - A. Kemper, J. Jansen; Delfzicht Hospital, Delfzijl - J. Ashruf, Z. Erjavec; Martini Hospital, Groningen - A. Groote, A. Olieman, R. de Jong; University Medical Centre Groningen, Groningen - A. Suurmeijer, J. de Vries, P. Willemse; Wilhelmina Hospital, Assen - R. Wijffels, F. Blok; Scheper Hospital, Emmen - M. van den Aardweg, E. Weernink - all in the Netherlands. 
Table S2. Number of first events after 5-year follow-up and 5-year first event rate according to cohort

\begin{tabular}{|c|c|c|c|c|c|c|c|}
\hline \multirow[b]{2}{*}{ Cohort } & \multirow[b]{2}{*}{$\begin{array}{c}\text { No. of } \\
\text { patients }\end{array}$} & \multicolumn{2}{|c|}{$\begin{array}{c}\text { Contralateral breast } \\
\text { cancer }\end{array}$} & \multicolumn{2}{|c|}{$\begin{array}{l}\text { Locoregional } \\
\text { recurrence }\end{array}$} & \multicolumn{2}{|c|}{ Distant metastases } \\
\hline & & $\begin{array}{c}\text { No. of first } \\
\text { events }\end{array}$ & $\begin{array}{c}\text { 5-year } \\
\text { first event } \\
\text { rate (\%) }\end{array}$ & $\begin{array}{c}\text { No. of first } \\
\text { events }\end{array}$ & $\begin{array}{c}\text { 5-year } \\
\text { first event } \\
\text { rate (\%) }\end{array}$ & $\begin{array}{l}\text { No. of first } \\
\text { events }\end{array}$ & $\begin{array}{c}\text { 5-year } \\
\text { first event } \\
\text { rate (\%) }\end{array}$ \\
\hline $\begin{array}{l}\text { Node-negative, no- } \\
\text { adjuvant-therapy }\end{array}$ & 856 & 21 & 2.6 & 30 & 3.7 & 23 & 2.8 \\
\hline $\begin{array}{l}\text { Node-positive, no- } \\
\text { adjuvant-therapy }\end{array}$ & 856 & 35 & 5.6 & 42 & 6.6 & 30 & 4.6 \\
\hline isolated tumor cells & 513 & 20 & 5.4 & 24 & 6.2 & 15 & 3.7 \\
\hline micrometastases & 343 & 15 & 5.9 & 18 & 6.8 & 15 & 6.3 \\
\hline $\begin{array}{l}\text { Node-positive, } \\
\text { adjuvant-therapy }\end{array}$ & 995 & 11 & 1.2 & 20 & 2.6 & 20 & 2.6 \\
\hline isolated tumor cells & 306 & 4 & 1.3 & 8 & 3.8 & 3 & 1.2 \\
\hline micrometastases & 689 & 9 & 1.2 & 12 & 1.9 & 17 & 3.2 \\
\hline All & 2707 & 67 & 2.9 & 92 & 4.1 & 73 & 3.2 \\
\hline
\end{tabular}

Table S3. Cox proportional-hazards model of the effect of variables on events according to the presence or absence of isolated tumor cells or micrometastases (axillary lymph node dissection included in the model)

\begin{tabular}{|c|c|c|c|c|c|c|c|c|c|}
\hline \multirow[b]{2}{*}{ Variable } & \multicolumn{3}{|c|}{$\begin{array}{c}\text { Node-negative vs. isolated } \\
\text { tumor cells or } \\
\text { micrometastases, all with } \\
\text { no adjuvant therapy } \\
\end{array}$} & \multicolumn{3}{|c|}{$\begin{array}{l}\text { Node-negative vs. isolated } \\
\text { tumor cells, both with no } \\
\text { adjuvant therapy }\end{array}$} & \multicolumn{3}{|c|}{$\begin{array}{c}\text { Node-negative vs. } \\
\text { micrometastases, both } \\
\text { with no adjuvant therapy }\end{array}$} \\
\hline & $\begin{array}{l}\text { Hazard } \\
\text { ratio for } \\
\text { events }\end{array}$ & $95 \% \mathrm{Cl}$ & $\begin{array}{c}\mathrm{p} \\
\text { value }\end{array}$ & $\begin{array}{l}\text { Hazard } \\
\text { ratio for } \\
\text { events }\end{array}$ & $95 \% \mathrm{Cl}$ & $\begin{array}{c}\mathrm{p} \\
\text { value }\end{array}$ & $\begin{array}{l}\text { Hazard } \\
\text { ratio for } \\
\text { events }\end{array}$ & $95 \% \mathrm{Cl}$ & $\begin{array}{c}p \\
\text { value }\end{array}$ \\
\hline Node-negative & 1.00 & & & 1.00 & & & 1.00 & & \\
\hline $\begin{array}{l}\text { Isolated tumor cells or } \\
\text { micrometastases }\end{array}$ & 1.59 & $1.24-2.04$ & $<0.001$ & - & - & - & - & - & - \\
\hline isolated tumor cells & - & - & - & 1.54 & $1.17-2.03$ & 0.002 & - & - & - \\
\hline micrometastases & - & - & - & - & - & - & 1.81 & $1.25-2.61$ & 0.002 \\
\hline Age at diagnosis- yr* & 1.01 & $1.00-1.02$ & 0.02 & 1.02 & $1.01-1.03$ & 0.002 & 1.01 & $1.00-1.02$ & 0.15 \\
\hline Tumor size† & 1.23 & $1.03-1.47$ & 0.02 & 1.26 & $1.03-1.54$ & 0.02 & 1.22 & $0.98-1.53$ & 0.08 \\
\hline \multicolumn{10}{|l|}{ Tumor grade } \\
\hline 1 & 1.00 & & & 1.00 & & & 1.00 & & \\
\hline 2 & 1.53 & $1.18-1.99$ & 0.001 & 1.75 & $1.30-2.36$ & $<0.001$ & 1.50 & $1.09-2.06$ & 0.01 \\
\hline 3 & 2.15 & $1.28-3.63$ & 0.004 & 2.41 & $1.36-4.29$ & 0.003 & 2.27 & $1.24-4.15$ & 0.008 \\
\hline \multicolumn{10}{|c|}{$\begin{array}{l}\text { Expression of estrogen } \\
\text { receptors, } \\
\text { progesterone } \\
\text { receptors, or both }\end{array}$} \\
\hline yes & 1.00 & & & 1.00 & & & 1.00 & & \\
\hline no & 1.52 & $1.04-2.23$ & 0.03 & 1.63 & $1.07-2.48$ & 0.02 & 1.34 & $0.82-2.20$ & 0.25 \\
\hline \multicolumn{10}{|l|}{$\begin{array}{l}\text { Axillary lymph node } \\
\text { dissection }\end{array}$} \\
\hline yes & 1.00 & & & 1.00 & & & 1.00 & & \\
\hline no & 1.16 & $0.89-1.51$ & 0.28 & 1.13 & $0.83-1.55$ & 0.44 & 1.31 & $0.90-1.90$ & 0.15 \\
\hline
\end{tabular}

* Age was modeled as a continuous variable; † The hazard ratio is for a doubling of the tumor diameter 
Table S4. Disease-free survival (DFS) rates according to type of systemic adjuvant therapy

\begin{tabular}{|c|c|c|c|c|c|}
\hline \multirow[b]{2}{*}{$\begin{array}{l}\text { Type of systemic } \\
\text { adjuvant therapy }\end{array}$} & \multicolumn{2}{|c|}{$\begin{array}{c}\text { Node-positive, no adjuvant } \\
\text { therapy }\end{array}$} & \multicolumn{2}{|c|}{$\begin{array}{c}\text { Node-positive, adjuvant } \\
\text { therapy }\end{array}$} & \multirow[b]{2}{*}{$\begin{array}{l}\mathrm{p} \text { value (compared } \\
\text { with no } \\
\text { chemotherapy or } \\
\text { hormonal therapy) }\end{array}$} \\
\hline & $\mathrm{n}(\%)$ & $\begin{array}{c}5 \text { year DFS rate } \\
(\%)\end{array}$ & $\mathrm{n}(\%)$ & $\begin{array}{c}5 \text { year DFS rate } \\
(\%)\end{array}$ & \\
\hline $\begin{array}{l}\text { No chemotherapy or } \\
\text { hormonal therapy }\end{array}$ & $856(100)$ & 76.5 & $0(0)$ & NA & NA \\
\hline Chemotherapy & $0(0)$ & NA & $60(6.0)$ & 83.4 & 0.41 \\
\hline Hormonal therapy & $0(0)$ & NA & $627(63.0)$ & 84.2 & 0.002 \\
\hline $\begin{array}{l}\text { Both chemotherapy } \\
\text { and hormonal } \\
\text { therapy }\end{array}$ & $0(0)$ & NA & $308(31.0)$ & 91.3 & $<0.001$ \\
\hline
\end{tabular}

Table S5. Cox proportional-hazards model of the effects of type of systemic adjuvant therapy on events

\begin{tabular}{lcc}
\hline Variable & Hazard ratio for events $(95 \% \mathrm{Cl})$ & p value \\
\hline $\begin{array}{l}\text { Node-positive, no adjuvant therapy } \\
\text { Node-positive, adjuvant therapy }\end{array}$ & 1.00 & \\
$\quad$ chemotherapy & $0.82(0.41-1.61)$ & 0.56 \\
hormonal therapy & $0.60(0.46-0.80)$ & $<0.001$ \\
both chemotherapy and hormonal therapy & $0.34(0.21-0.55)$ & $<0.001$ \\
\hline
\end{tabular}

Age at diagnosis (modeled as a continuous variable), tumor size (the hazard ratio is for a doubling of the tumor diameter), tumor grade, and axillary treatment also included as variables in the Cox proportional-hazards model. 


\section{Chapter 5}

Prognostic impact of isolated tumor cells in breast cancer axillary nodes: single tumor cell(s) versus tumor cell cluster(s) and microanatomic location

Johanna H. Vestjens, Maaike de Boer, Paul J. van Diest, Carolien H.M. van Deurzen, Jos A.A.M van Dijck, George F. Borm, Eddy M.M. Adang, Peter Bult, Vivianne C.G. Tjan-Heijnen

Breast Cancer Res Treat 2012;131:645-651 
76 Chapter 5

\section{Abstract}

\section{Background}

In breast cancer, it has been shown that $\mathrm{pNO}(\mathrm{i}+)$ and $\mathrm{pN} 1 \mathrm{mi}$ have a comparable negative impact on disease-free survival, compared with pNO. However, pNO(i+) is considered to be a heterogeneous group. We determined the effect of metastatic size and microanatomic location within the $\mathrm{pNO}(\mathrm{i}+)$ group on breast cancer recurrence.

\section{Methods}

We included all Dutch breast cancer patients diagnosed in 1998-2005 with favorable primary tumor characteristics and a final nodal status of $\mathrm{pNO}(\mathrm{i}+)$. For the present analysis only patients without adjuvant systemic therapy were eligible $(n=513)$. Presence of single tumor cells versus cell clusters, metastatic size and microanatomic location were recorded. Primary endpoint was disease-free survival. Analyses were adjusted for age at diagnosis, tumor size, tumor grade, axillary treatment and hormone receptor status.

\section{Results}

The 5-year disease-free survival of patients with single tumor cell(s) ( $n=93)$ was $78.6 \%$ and with tumor cell cluster(s) $(n=404) 77.1 \%$. The hazard ratio for disease events was $1.05 \quad(95 \%$ confidence interval ( $\mathrm{Cl}), 0.63$ to 1.76 ) for cell cluster(s) compared with single cell(s). In a Cox regression model, doubling of metastatic tumor size corresponded to a hazard ratio of 1.21 $(95 \% \mathrm{Cl}, 1.02$ to 1.43$)$. The adjusted hazard ratio was $0.90(95 \% \mathrm{Cl}, 0.54$ to 1.50$)$ for parenchymal $(n=112)$ versus sinusoidal location $(n=395)$.

\section{Conclusion}

Single tumor cells bear similar prognostic information as small tumor cell clusters, even though results do suggest that within the pNO(i+) group, increasing size of nodal involvement is associated with reduced survival. Microanatomic location does not seem to have prognostic relevance. 


\section{Introduction}

It is uniformly accepted that the axillary lymph node status is still one of the most important prognostic features in breast cancer. However, with new techniques and more aggressive treatment approaches, the landscape of primary breast cancer treatment has markedly changed, posing us for new dilemma's.

With the introduction of the sentinel node procedure, the pathologic work-up has been intensified, resulting in an increased detection frequency of small nodal metastases ${ }^{1}$. The MIRROR study is the first large cohort study in the sentinel node era with central pathology review and restaging according to the sixth AJCC Cancer Staging Manual ${ }^{2,3}$. Its results showed that the presence of isolated tumor cells, pNO(i+), as final nodal status, is an independent adverse prognostic factor as well as micrometastatic disease, $\mathrm{pN} 1(\mathrm{mi})$, and that patients with $\mathrm{pNO}(\mathrm{i}+)$ or $\mathrm{pN} 1(\mathrm{mi})$ benefitted from adjuvant systemic therapy ${ }^{2}$.

However, $\mathrm{pNO}(\mathrm{i}+)$ is a heterogeneous group ${ }^{4}$. Obviously, isolated tumor cells can be the first sign of metastasis. However, it has also been hypothesized that in some patients a few single tumor cells resemble benign or malignant cells which lack outgrowth potential, as can be found as a result of trauma ${ }^{4,5}$. In melanoma and breast cancer studies, it has been shown that microanatomic location and penetrative depth of sentinel node metastasis predicts non-sentinel node metastases ${ }^{6-10}$. Although the presence of $\mathrm{pNO}(\mathrm{i}+)$ status was associated with reduced disease-free survival in the MIRROR study, part of this category may consist of patients with merely nonsignificant (benign or malignant) epithelial cells. Therefore, we determined the effect of extent (single cells versus cell clusters), size and microanatomic location of nodal involvement on disease-free survival.

\section{Methods}

\section{Patients}

Women with invasive breast cancer, who had undergone a sentinel node biopsy between 1998 and 2005 were identified from the Netherlands Cancer Registry. Only women with favorable primary tumor characteristics according to the guidelines at that time (i.e., tumors $\leq 1 \mathrm{~cm}$ in diameter, irrespective of grade, or tumors $>1$ to $\leq 3 \mathrm{~cm}$, grade 1 or 2 ) were included. The methods and results were reported in detail by de Boer et al. ${ }^{2}$. For this present analysis, only women with a final nodal status of pNO(i+), after a sentinel node procedure with or without completion axillary lymph node dissection, and who had not undergone adjuvant systemic treatment, were selected.

\section{Pathology}

All available original slides from the sentinel nodes and of positive nodes obtained in the axillary lymph node dissection were reviewed by three pathologists (C.H.M. van 
Deurzen, P.J. van Diest, P. Bult) specialized in breast cancer. These included slides stained with hematoxylin and eosin, slides stained for immunohistochemical analysis and frozen sections. Almost all participating pathology laboratories used a protocol in which the sentinel node was serially sectioned at at least every $150 \mu \mathrm{m}$ and at a minimum of three levels, with the use of keratin immunohistochemical staining if the hematoxylin and eosin staining was negative. The non-sentinel nodes were macroscopically sectioned every $2-5 \mathrm{~mm}$ and one section per slice was stained with hematoxylin and eosin. During central review, presence of single tumor cell(s) versus tumor cell cluster(s), and the microanatomic location (sinus versus parenchyma) were recorded. In addition, metastatic size was measured by an oculometer. Classification occurred according to the sixth edition of the AJCC Cancer Staging Manual ${ }^{3}$.

\section{Statistical analysis}

The primary endpoint was disease-free survival, defined as the time from diagnosis to locoregional recurrence, distant metastases, contralateral breast cancer or ductal carcinoma in situ, other malignancy or death, whichever occurred first.

Hazard ratios for single cell(s) versus cluster(s), metastatic size and microanatomic location were estimated in multivariate models adjusted for age at diagnosis, tumor size, tumor grade, axillary treatment and hormone receptor status. In the analyses, we used a transformation and included $\log _{2}$ (metastatic size) as independent variable, because the regression coefficient of this covariate then corresponds to the hazard ratio associated with a doubling of the size. $\mathrm{P}$ values $<0.05$ were considered significant.

\section{Results}

\section{Patients}

In total 513 patients were included. The median duration of follow up was 4.2 years (range 0.2-8.8).

\section{Single tumor cell(s) versus tumor cell cluster(s)}

For this analysis, 16 patients were excluded because of missing relevant data. The baseline characteristics according to single tumor cell(s) or tumor cell cluster(s) are shown in Table 1. In patients with single tumor cell(s), axillary lymph node dissection was less often performed. Also, axillary treatment by irradiation was less often performed in this group. The median metastatic size was larger in the tumor cell cluster(s) group. Single tumor cell(s) were found more often in lobular carcinoma. The 5 -year disease-free survival in patients with single tumor cell(s) ( $n=93)$ was $78.6 \%$ and $77.1 \%$ in patients with tumor cell cluster(s) $(n=404)$. The difference was not significant $(\mathrm{p}=0.58)$ (Figure 1$)$. In a multivariate analysis, including age at diagnosis, tumor size, tumor grade, axillary treatment and hormone receptor status, the hazard ratio of 
tumor cell cluster(s) compared to single cell(s) was 1.05 (95\% confidence interval (CI), 0.63 to 1.76$)$.

Table 1. Baseline clinicopathologic characteristics of 497 study patients with invasive breast cancer with micrometastatic axillary lymph node disease

\begin{tabular}{|c|c|c|c|c|}
\hline Characteristic & $\begin{array}{c}\text { All } \\
(n=497)\end{array}$ & $\begin{array}{l}\text { Single cell(s) } \\
(\mathrm{n}=93)\end{array}$ & $\begin{array}{c}\text { Cell cluster(s) } \\
(\mathrm{n}=404)\end{array}$ & $p$ value \\
\hline Age at diagnosis (yrs) & & & & 0.59 \\
\hline median & 57 & 58 & 57 & \\
\hline range & $34-90$ & $36-89$ & $34-90$ & \\
\hline Tumor size-no. (\%) & & & & 0.98 \\
\hline$<2 \mathrm{~cm}$ & $429(87.0)$ & $81(87.1)$ & $348(87.0)$ & \\
\hline$>2$ to $\leq 3 \mathrm{~cm}$ & $64(13.0)$ & $12(12.9)$ & $52(13.0)$ & \\
\hline Tumor grade-no. (\%) & & & & 0.84 \\
\hline 1 & $188(37.8)$ & $37(39.8)$ & $151(37.4)$ & \\
\hline 2 & $281(56.5)$ & $50(53.8)$ & $231(57.2)$ & \\
\hline 3 & $19(3.8)$ & $4(4.3)$ & $15(3.7)$ & \\
\hline unknown & $9(1.8)$ & $2(2.2)$ & $7(1.7)$ & \\
\hline Tumor type-no. (\%) & & & & $<0.001$ \\
\hline ductal & $362(72.8)$ & $53(57.0)$ & $309(76.5)$ & \\
\hline lobular & $71(14.5)$ & $23(24.7)$ & 48 (11.9) & \\
\hline other & $64(13.1)$ & $17(18.3)$ & $47(11.6)$ & \\
\hline $\begin{array}{l}\text { Expression of estrogen receptors, } \\
\text { progesterone receptors, or both-no. (\%) }\end{array}$ & & & & 0.99 \\
\hline yes & $443(89.1)$ & $80(86.0)$ & $363(89.9)$ & \\
\hline no & $39(7.8)$ & $7(7.5)$ & $32(7.9)$ & \\
\hline unknown & $15(3.0)$ & $6(6.5)$ & $9(2.2)$ & \\
\hline Type of surgery-no. (\%) & & & & 0.066 \\
\hline breast-conserving & $354(71.2)$ & $59(63.4)$ & $295(73.0)$ & \\
\hline mastectomy & $143(28.7)$ & $34(36.6)$ & $109(27.0)$ & \\
\hline No. of sentinel nodes removed & & & & 0.14 \\
\hline median & 2 & 2 & 2 & \\
\hline range & $1.0-14.0$ & $1.0-14.0$ & $1.0-13.0$ & \\
\hline Metastatic size (mm) & & & & $<0.001$ \\
\hline median & 0.06 & 0.01 & 0.08 & \\
\hline range & $0.01-0.20$ & $0.01-0.04$ & $0.01-0.20$ & \\
\hline Axillary lymph node dissection-no.(\%) & & & & $<0.001$ \\
\hline no & 278 (55.9) & $68(73.1)$ & $210(52.0)$ & \\
\hline yes & $219(44.1)$ & $25(26.9)$ & $194(48.0)$ & \\
\hline $\begin{array}{l}\text { Axillary lymph-node dissection, axillary } \\
\text { irradiation or both-no.(\%) }\end{array}$ & & & & $<0.001$ \\
\hline no & $252(50.7)$ & $64(68.8)$ & $188(46.5)$ & \\
\hline yes & $245(49.3)$ & $29(31.2)$ & $216(53.5)$ & \\
\hline
\end{tabular}

\section{Metastatic size}

When including $\log _{2}$ metastatic size within the $\mathrm{pNO}(\mathrm{i}+$ ) group as a continuous variable in a Cox regression model, increasing metastatic size was significantly associated with a reduced disease-free survival with an adjusted hazard ratio of $1.21(95 \% \mathrm{Cl}, 1.00$ to 1.61) for doubling of metastatic size. 


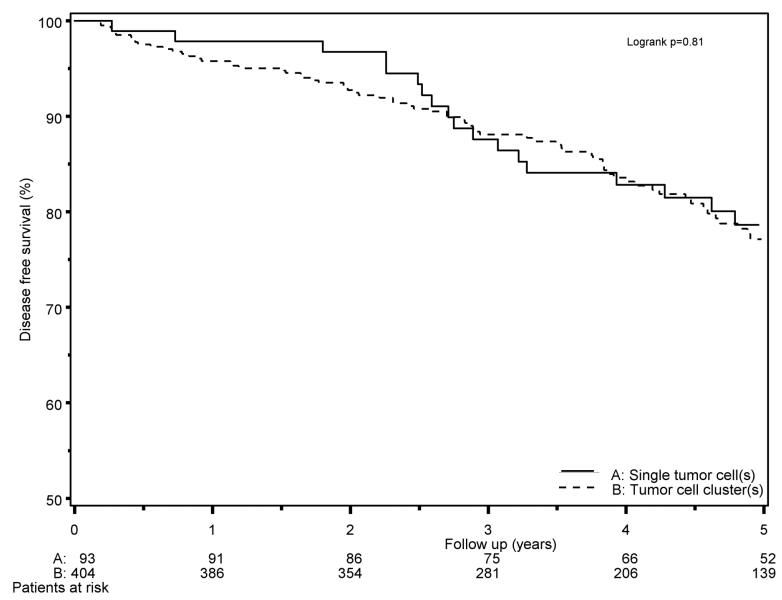

Figure 1. Disease-free survival according to disease extent, within the group of patients classified as pNO(i+).

\section{Micro-anatomic location of sentinel node metastases}

Regarding the influence of microanatomic location of sentinel node metastasis, 6 patients were excluded because of missing relevant data. The baseline characteristics are shown in Table 2. The 5-year disease-free survival was $77.6 \%$ for patients with tumor cells located only in the sinus of the sentinel node $(n=395)$, and $75.3 \%$ for patients with isolated tumor cells in the parenchyma of the sentinel node $(n=112) \quad(p=0.98$, Figure 2$)$. In multivariate analysis the adjusted hazard ratio of parenchymal location compared to sinusoidal was 0.90 ( $95 \% \mathrm{Cl}, 0.54$ to 1.50$)$.

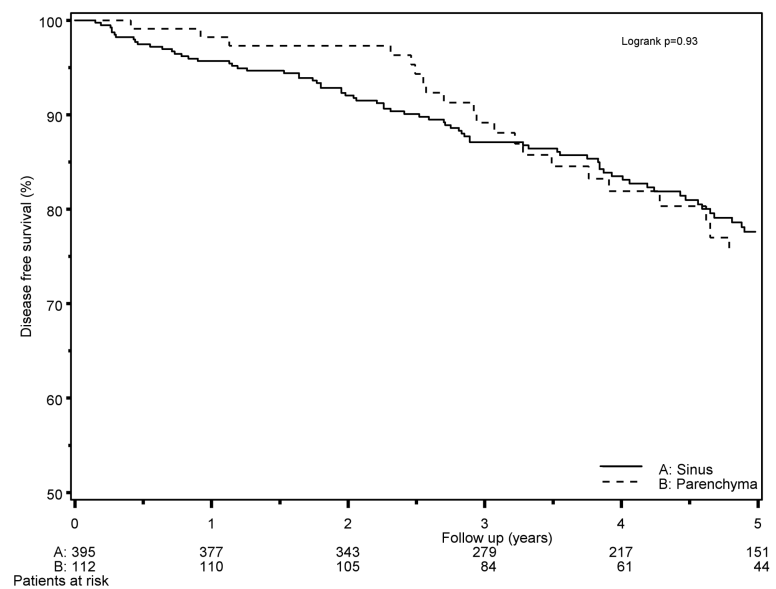

Figure 2. Disease-free survival according to micro-anatomic location, within the group of patients classified as pNO(i+). 
Table 2. Comparison of clinicopathologic features between patients with different microanatomic location of isolated tumor cells

\begin{tabular}{|c|c|c|c|c|}
\hline \multirow[t]{2}{*}{ Characteristic } & \multirow[t]{2}{*}{ All } & \multicolumn{2}{|c|}{ Microanatomic location } & \multirow[t]{2}{*}{$\mathrm{p}$ value } \\
\hline & & $\begin{array}{c}\text { Sinus } \\
(n=395)\end{array}$ & $\begin{array}{l}\text { Parenchyma } \\
(n=112)\end{array}$ & \\
\hline Age at diagnosis-yr & & & & 0.34 \\
\hline median & 57 & 57 & 57 & \\
\hline range & $34-93$ & $35-93$ & $34-89$ & \\
\hline Tumor size-no. (\%) & & & & 0.67 \\
\hline$\leq 2 \mathrm{~cm}$ & $434(86.3)$ & 336 (85.9) & $98(87.5)$ & \\
\hline$>2$ to $\leq 3 \mathrm{~cm}$ & $69(13.7)$ & $55(14.1)$ & $14(12.5)$ & \\
\hline Tumor grade-no. (\%) & & & & 0.81 \\
\hline 1 & $192(37.9)$ & $152(38.5)$ & $40(35.7)$ & \\
\hline 2 & $287(56.6)$ & $222(56.2)$ & $65(58.0)$ & \\
\hline 3 & $19(3.7)$ & $14(3.5)$ & $5(4.5)$ & \\
\hline unknown & $9(1.8)$ & $7(1.8)$ & $2(1.8)$ & \\
\hline Tumor type-no. (\%) & & & & 0.33 \\
\hline ductal & $370(73.0)$ & $293(74.2)$ & $77(68.7)$ & \\
\hline lobular & $73(14.4)$ & $52(13.2)$ & $21(18.7)$ & \\
\hline other & $64(12.6)$ & $50(12.7)$ & $14(12.5)$ & \\
\hline $\begin{array}{l}\text { Expression of estrogen receptors, } \\
\text { progesterone receptors, or both-no. (\%) }\end{array}$ & & & & 0.75 \\
\hline yes & $451(88.9)$ & 351 (88.9) & $100(89.3)$ & \\
\hline no & 40 (7.9) & $32(8.1)$ & $8(7.1)$ & \\
\hline unknown & $16(3.2)$ & $12(3.0)$ & $4(3.6)$ & \\
\hline Type of surgery-no. (\%) & & & & 0.17 \\
\hline breast-conserving & $361(71.2)$ & $287(72.7)$ & $74(66.1)$ & \\
\hline mastectomy & $146(28.8)$ & $108(27.3)$ & 38 (33.9) & \\
\hline No of sentinel nodes removed- no. & & & & 0.33 \\
\hline median & 2 & 2 & 2 & \\
\hline range & $1-14$ & $1-14$ & $1-9$ & \\
\hline Metastatic size (mm) & & & & 0.22 \\
\hline median & 0.06 & 0.06 & 0.05 & \\
\hline range & $0.01-0.20$ & $0.01-0.20$ & $0.01-0.20$ & \\
\hline Axillary lymph node dissection-no. (\%) & & & & 0.26 \\
\hline no & $286(56.4)$ & $228(57.7)$ & $58(51.8)$ & \\
\hline yes & $221(43.6)$ & $167(42.3)$ & $54(48.2)$ & \\
\hline $\begin{array}{l}\text { Axillary lymph-node dissection, axillary } \\
\text { irradiation or both-no. (\%) }\end{array}$ & & & & 0.18 \\
\hline no & $259(51.1)$ & $208(52.7)$ & $51(54.5)$ & \\
\hline yes & $248(48.9)$ & $187(47.3)$ & $61(45.5)$ & \\
\hline
\end{tabular}

\section{Discussion}

Previously, we reported that in breast cancer patients with favorable primary tumor characteristics $\mathrm{pNO}(\mathrm{i}+)$ and $\mathrm{pN} 1 \mathrm{mi}$ had a comparable negative impact on disease-free survival, compared to $\mathrm{pNO}^{2}$. However, $\mathrm{pNO}(\mathrm{i}+)$ can be regarded as a heterogeneous group, including both patients with single tumor cells and patients with tumor cell clusters, which may either be located in the sinus or in the parenchyma of the nodes. We, therefore, questioned whether there would be a differential impact on prognosis 
of size and microanatomic location of nodal metastases within the group of patients with $\mathrm{pNO}(\mathrm{i}+)$ as final nodal status. In this study, we show that within the $\mathrm{pNO}(\mathrm{i}+)$ group, patients with single tumor cells had a 5 -year disease-free survival of $78.6 \%$, not different from the 5 -year disease-free survival of $77.1 \%$ for patients with tumor cell clusters. On the other hand, we noticed that increasing metastatic size as a continuous variable was associated with a reduced disease-free survival at a hazard ratio of 1.21 (95\% Cl, 1.02 to 1.43$)$, yet indicating a small impact of size within the pNO(i+) group. Notably, the microanatomic location did not influence prognosis (adjusted hazard ratio $0.90 ; 95 \% \mathrm{Cl}, 0.54$ to 1.50 ).

The prognostic relevance of $\mathrm{pNO}(\mathrm{i}+)$ has been studied before. Five small studies including 21-61 patients from the pre-sentinel node era examined the relevance of isolated tumor cells found after step sectioning and immunohistochemical staining in lymph nodes defined as negative after hematoxylin and eosin staining ${ }^{11-15}$. In three of these, no significant adverse prognosis in the $\mathrm{pNO}(\mathrm{i}+)$ group compared to the $\mathrm{pNO}$ group was seen. However, in two of these studies, no adverse prognosis even for larger occult metastases was found at all, probably because of small number of patients evaluated ${ }^{11}$. One study reported an unadjusted hazard ratio for adverse events of $2.51(95 \% \mathrm{Cl}, 1.55$ to 4.07$)$ in the group of $\mathrm{pNO}(i+)(n=24)$ as compared to $\mathrm{pNO}$, which was also seen for patients having $\mathrm{pN} 1 \mathrm{mi}^{14}$. The adjusted hazard ratio for pNO(i+) and pN1mi combined versus pNO was $2.16(95 \% \mathrm{Cl}, 1.42$ to 3.28$)$. In another study, the adverse prognostic significance of pNO(i+) (relative risk $1.7,95 \% \mathrm{Cl}, 1.0$ to 2.7) was comparable to or larger than primary tumor size, histological grade and lymphovascular invasion ${ }^{15}$.

The prognostic effect of isolated tumor cells has also been analysed in eleven sentinel node studies, but in nine of these only 17 to 151 patients with pNO(i+) were included $^{2,16-25}$. Only four studies corrected for use of adjuvant systemic therapy in multivariate analysis ${ }^{2,19,21}$. In eight studies, the presence of isolated tumor cells did not seem to influence prognosis ${ }^{16-19,21-24}$. In one of these, however, overall survival was lower in patients who had not undergone an additional axillary lymph node dissection as compared to patients who had undergone an axillary lymph node dissection $(p=0.02)^{17}$. On the other hand, in three studies, including the two by far largest studies, the presence of isolated tumor cells did have a negative impact on breast cancer outcome $e^{2,20,25}$. In one study $(n=63)$, the 5 -year breast cancer specific survival ( $95.7 \%$ vs $98.4 \%, p=0.035$ ) was decreased and the 5 -year rate of distant metastasis $(8.1 \%$ vs $1.9 \%, p=0.001)$ was increased for patients with $\mathrm{pNO}(\mathrm{i}+)$ as compared to pNO patients, even though adjuvant systemic therapy was significantly more often administered to patients with $\mathrm{pNO}(i+)$ as final status ${ }^{20}$. The MIRROR study not only included a large group of patients $(n=2707)$, but also analyzed patients without adjuvant systemic therapy ${ }^{2}$. The 5 -year disease-free survival was significantly higher $(85.7 \%$ vs $77.2 \%)$ in patients with final stage pNO as compared to $\mathrm{pNO}(\mathrm{i}+)$ patients, all without adjuvant systemic therapy. Separate analyses showed that patients with $\mathrm{pNO}(i+)$ who had received adjuvant systemic therapy had an improved 
survival as compared to those who did not receive adjuvant systemic therapy $183.0 \%$ vs $77.2 \%)$. Similar results were seen in a recently published large prospective study including 431 patients with isolated tumor cells ${ }^{25}$. The hazard ratio of isolated tumor cell clusters versus no tumor cell clusters was 1.27 ( $95 \% \mathrm{Cl}, 1.04$ to1.54) for death.

It has been hypothesized that single tumor cells not necessarily represent metastatic disease, but merely displaced tumor cells which lack outgrowth potential, or even benign epithelial cells ${ }^{26-32}$. The first hypothesis presented is traumatic displacement of cells. It has been shown that after primary tumor biopsy, tumor cells were located in the needle tract as well as in the stroma ${ }^{26-27}$. It has also been shown that epithelial cells were found more often in the sentinel nodes after biopsy or breast massage ${ }^{28-30}$. This hypothesis was strengthened by finding epithelial cells accompanied by hemosiderin-laden macrophages and damaged erythrocytes suggesting traumatic displacement $^{31}$. A second hypothesis could be the inadequate use of cytokeratin immunohistochemistry with staining of nonepithelial cells ${ }^{33,34}$. A third hypothesis is the use of tumor cell contaminated instruments in sectioning the sentinel nodes. Furthermore, nodal entrapment of epithelial remains during embryonic development resulting in ectopic breast tissue has been suggested a possible cause for finding of $\mathrm{pNO}(\mathrm{i}+)^{32}$. Morphometric and immunohistochemical studies indeed presented clues that some of the cells may not be (vital) malignant cells ${ }^{4,5}$.

Hypothetically, breast cancer cells arrive through the afferent lymph vessel in the subcapsular sinus. The cells outgrow in the marginal sinus and into the cortical parenchyma. After extending the deeper parenchyma into the medullary sinus, further routing takes place through the efferent lymph vessel ${ }^{35}$. Exploring this hypothesis microanatomic location of tumor cells could be an indicator of relevant metastatic disease as studied in melanoma ${ }^{6-9}$. Results of breast cancer studies on microanatomic location are conflicting. In three studies, including 45-167 patients with isolated tumor cells and/or micrometastases, sinusoidal deposits, in contrast to another location, were shown to be a significant adverse prognostic factor ${ }^{13,36,37}$. However, in five other studies, including 50-136 patients, the opposite was found ${ }^{10,11,38-40}$. All these studies are heterogeneous with respect to (small) size and extent of metastatic disease. Our study shows that the hazard ratio of events was comparable for sinusoidal and parenchymal location.

Another discriminative feature could be the number of tumor cells. Isolated tumor cells can either represent truly single isolated cells or cell clusters. It can be hypothesized that the presence of only a few tumor cells might less severely affect the outcome than the presence of many tumor cells. Indeed, old studies have shown that the number of positive lymph nodes is associated with outcome, in essence also representing a measurement of nodal size involvement ${ }^{41-43}$. In our study, we showed that even within a small range of metastatic size, the number of tumor cells does matter as the prognosis declines with increasing number of cells. But of note, we have also shown that single tumor cell(s) bear similar prognostic information as tumor cell cluster(s). Notably, in our study, in the group of patients with single tumor cells, less 
84 Chapter 5

frequently axillary treatment was performed. However, adjusting for axillary treatment in multivariate analysis did not change the hazard ratio.

In daily practice, the decision to administer adjuvant systemic therapy is obviously not solely based on the lymph node involvement, because other risk factors co-influence this decision. It has been hypothesized that micro-arrays such as the Mammaprint ${ }^{\circledR}$ or Oncotype $\mathrm{DX}^{\circledR}$ assessing primary tumor characteristics might replace the information by nodal status, but so far scientific evidence shows that nodal involvement remains an independent prognosticator ${ }^{44}$.

In conclusion, microanatomic location does not seem to influence prognosis of nodal status classified as pNO(i+). Single tumor cells bear similar prognostic information as tumor cell clusters, although results suggest a small impact of size within the pNO(i+) group when analyzed as a continuous variable.

\section{Acknowledgements}

We thank Wim A.J.G. Lemmens for his assistance with statistical analyses.

\section{Funding}

This project has received funding from the Netherlands Organization for Health Research and Development (ZonMw) (945-06-509) and was supported by the Dutch Breast Cancer Trialists' Group (BOOG). 


\section{References}

1. Cserni G, Amendoeira I, Apostolikas N, et al; European Working Group for Breast Screening Pathology. Pathological work-up of sentinel lymph nodes in breast cancer. Review of current data to be considered for the formulation of guidelines. Eur J Cancer 2003;39:1654-1667.

2. de Boer $\mathrm{M}$, van Deurzen $\mathrm{CH}$, van Dijck JA, et al. Micrometastases or isolated tumor cells and the outcome of breast cancer. N Engl J Med 2009;361:653-663.

3. Green FL, Page DL, Fleming ID. AJCC cancer staging manual. 6th ed Chicago: American Joint Commission on Cancer.

4. van Deurzen $\mathrm{CH}$, Bult $\mathrm{P}$, de Boer $\mathrm{M}$, et al. Morphometry of isolated tumor cells in breast cancer sentinel lymph nodes: metastases or displacement? Am J Pathol 2009;33:106-110.

5. van Deurzen CH, de Bruin PC, Koelemij R, Hillegersberg R, van Diest PJ. Isolated tumor cells in breast cancer sentinel lymph nodes: displacement or metastases? An immunohistochemical study. Hum Pathol 2009;40:778-782.

6. Dewar DJ, Newell B, Green MA, Topping AP, Powell BW, Cook MG. The microanatomic location of metastatic melanoma in sentinel lymph nodes predicts nonsentinel lymph node involvement. J Clin Oncol 2004;22:3345-3349.

7. Reeves ME, Delgado R, Busam KJ, Brady MS, Coit DG. Prediction of non-sentinel lymph node status in melanoma. Ann Surg Oncol 2003;10:27-31.

8. Starz H, Balda BR, Krämer KU, Büchels H, Wang H. A micromorphometry-based concept for routine classification of sentinel lymph node metastases and its clinical relevance for patients with melanoma. Cancer 2001;91:2110-2121.

9. Scolyer RA, Li LX, McCarthy SW, et al. Micromorphometric features of positive sentinel lymph nodes predict involvement of nonSNs in melanoma patients. Am J Clin Pathol 2004;122:532-539.

10. van Deurzen $\mathrm{CH}$, Seldenrijk CA, Koelemij R, van Hillegersberg R, Hobbelink MG, van Diest PJ. The microanatomic location of metastatic breast cancer in sentinel lymph nodes predicts nonsentinel lymph node involvement. Ann Surg Oncol 2008;15:1309-1315.

11. Nasser IA, Lee AK, Bosari S, Saganich R, Heatley G, Silverman ML. Occult axillary lymph node metastases in "node-negative" breast carcinoma. Hum Pathol 1993;24:950-957.

12. Millis RR, Springall R, Lee AH, Ryder K, Rytina ER, Fentiman IS. Occult axillary lymph node metastases are of no prognostic significance in breast cancer. Br J Cancer 2002;86:396-401.

13. Reed W, Bøhler PJ, Sandstad B, Nesland JM. Occult metastases in axillary lymph nodes as a predictor of survival in node-negative breast carcinoma with long-term follow-up. Breast J 2004;10:174-180.

14. Querzoli P, Pedriali M, Rinaldi R, et al. Axillary lymph node nanometastases are prognostic factors for disease-free survival and metastatic relapse in breast cancer patients. Clin Cancer Res 2006;12: 6696-6701.

15. Tan LK, Giri D, Hummer AJ, et al. Occult axillary node metastases in breast cancer are prognostically significant: results in 368 node-negative patients with 20-year follow-up. J Clin Oncol 2008;26: 1803-1809.

16. Andersson $\mathrm{Y}$, Frisell J, Sylvan M, de Boniface J, Bergkvist L. Breast cancer survival in relation to the metastatic tumor burden in axillary lymph nodes. J Clin Oncol 2010;28:2868-2873.

17. Cox CE, Kiluk JV, Riker Al, et al. Significance of sentinel lymph node micrometastases in human breast cancer. J Am Coll Surg 2008;206:261-268.

18. Hansen NM, Grube B, Ye X, et al. Impact of micrometastases in the sentinel node of patients with invasive breast cancer. J Clin Oncol 2009;27:4679-4684.

19. Imoto S, Ochiai A, Okumura C, Wada N, Hasebe T. Impact of isolated tumor cells in sentinel lymph nodes detected by immunochemical staining. Eur J Surg Oncol 2006;32:1175-1179.

20. Leidenius $\mathrm{MH}$, Vironen JH, Heikkilä PS, Joensuu $\mathrm{H}$. Influence of isolated tumor cells on outcome in small, node-negative (pT1NOMO) breast cancer. Ann Surg Oncol 2010;17:254-262.

21. Maaskant AJ, van de Poll-Franse LV, Voogd AC, Coebergh JW, Tutein Nolthenius-Puylaert MC, Nieuwenhuijzen GA. Stage migration due to introduction of the sentinel node procedure: a population based study. Breast Cancer Res Treat 2009;113:173-179. 
$86 \mid$ Chapter 5

22. Montagna $\mathrm{E}$, Viale $\mathrm{G}$, Rotmensz $\mathrm{N}$, et al. Minimal axillary lymph node involvement in breast cancer has different prognostic implications according to the staging procedure. Breast Cancer Res Treat 2009;118:385-394.

23. Pugliese MS, Beatty JD, Tickman RJ, et al. Impact and outcomes of routine microstaging of sentinel lymph nodes in breast cancer: significance of $\mathrm{pNO}(\mathrm{i}+)$ and $\mathrm{pN1mi}$ categories. Ann Surg Oncol 2009;16:113-120.

24. Reed J, Rosman M, Verbanac KM, Mannie A, Cheng Z, Tafra L. Prognostic implications of isolated tumor cells and micrometastases in sentinel nodes of patients with invasive breast cancer: 10-year analysis of patients enrolled in the prospective East Carolina University / Anne Arundel Medical Center Sentinel Node Multicenter Study. J Am Coll Surg 2009;208:333-340.

25. Weaver DL, Ashikaga T, Krag DN, et al. Effects of occult metastases on survival in node-negative breast cancer. N Engl J Med 2011;364:412-421.

26. Diaz LK, Wiley EL, Venta LA. Are malignant cells displaced by large-gauge needle core biopsy of the breast? Am J Radiology 1999;173:1303-1313.

27. Hoorntje LE, Schipper ME, Kaya A, Verkooijen HM, Klinkenbijl JG, Borel Rinkes IH. Tumour cell displacement after 14G breast biopsy. Eur J Surg Oncol 2004;30:520-525.

28. Diaz NM, Cox CE, Ebert M, et al. Benign mechanical transport of breast epithelial cells to sentinel lymph nodes. Am J Surg Pathol 2004;28:1641-1645.

29. Hansen NM, Ye X, Grube BJ, Giuliano AE. Manipulation of the primary breast tumor and the incidence of SN metastases from invasive breast cancer. Arch Surg 2004;139:634-640.

30. Bleiweiss IJ, Nagi CS, Jaffer S. Axillary sentinel lymph nodes can be falsely positive due to iatrogenic displacement and transport of benign epithelial cells in patients with breast carcinoma. J Clin Oncol 2006;24:2013-2018.

31. Carter BA, Jensen RA, Simpson JF, Page DL. Benign transport of breast epithelium into axillary lymph nodes after biopsy. Am J Clin Pathol 2000;113:259-265.

32. Maiorano E, Mazzarol GM, Pruneri G, et al. Ectopic breast tissue as a possible cause of false-positive axillary sentinel lymph node biopsies. Am J Surg Pathol 2003;27:513-518.

33. $\mathrm{Xu} \mathrm{X}$, Roberts SA, Pasha TL, Zhang PJ. Undesirable cytokeratin immunoreactivity of native nonepithelial cells in sentinel lymph nodes from patients with breast carcinoma. Arch Pathol Lab Med 2000;124:1310-1313.

34. Rao RS, Taylor J, Palmer J, Jennings WC. Breast cancer pseudometastasis in a sentinel lymph node with cytokeratin-positive debris. The Breast Journal 2005;11:134-137.

35. Borgstein PJ, Meijer S, Pijpers RJ, van Diest PJ. Functional lymphatic anatomy for SN biopsy in breast cancer: echoes from the past and the periareolar blue method. Ann Surg 2000;232:81-89.

36. Masci G, Di Tommaso L, Del Prato I, et al. Sinusal localization of nodal micrometastases is a prognostic factor in breast cancer. Ann Oncol 2010;21:1228-1232.

37. Hartveit F, Lilleng PK. Breast cancer: two micrometastatic variants in the axilla that differ in prognosis. Histopathology 1996;28:241-246.

38. Cserni G. Sentinel lymph-node biopsy-based prediction of further breast cancer metastases in the axilla. Eur J Surg Oncol 2001;27:532-539.

39. Di Tommaso L, Arizzi C, Rahal D, et al. Anatomic location of breast cancer micrometastasis in sentinel lymph node predicts axillary status. Ann Surg 2006;243:706-707.

40. Li J, Rudas M, Kemmner W, et al. The location of small tumor deposits in the SLN predicts non-SLN macrometastases in breast cancer patients. Eur J Surg Oncol 2008;34:857-862.

41. Ragaz J, Olivotto IA, Spinelli JJ, et al. Locoregional radiation therapy in patients with high-risk breast cancer receiving adjuvant chemotherapy: 20-year results of the British Colombia randomized trial. J Natl Cancer Inst 2005;97:116-126.

42. Overgaard M, Hansen PS, Overgaard J, et al. Postoperative radiotherapy in high-risk premenopausal women with breast cancer who receive adjuvant chemotherapy. N Engl J Med 1997;337:949-955.

43. Overgaard M, Jensen MB, Overgaard J, et al. Postoperative radiotherapy in high risk postmenopausal breast cancer patients given adjuvant tamoxifen: Danish Breast Cancer Cooperative Group DBCG 82c randomised trial. Lancet 1999;353:1641-1648.

44. van de Vijver MJ, He YD, van't Veer LJ, et al. A gene-expression signature as a predictor of survival in breast cancer. N Engl J Med 2002;347:1999-2009. 


\section{Chapter 6}

Cost-effectiveness of adjuvant systemic therapy in low risk breast cancer patients with nodal isolated tumor cells or micrometastases

Maaike de Boer, Eddy M.M. Adang, Kirsten C.G. Van Dycke, Jos A.A.M.van Dijck, George F. Borm, Shanly C. Seferina, Carolien H.M. van Deurzen, Paul J. van Diest, Peter Bult, A. Rogier T. Donders, Vivianne C.G. Tjan-Heijnen Ann Oncol 2012; Epub ahead of print 


\section{Abstract}

\section{Background}

The cost-effectiveness of adjuvant systemic therapy in patients with low risk breast cancer and nodal isolated tumor cells or micrometastases is unknown.

\section{Patients and methods}

A cost-effectiveness analysis of adjuvant systemic therapy was performed using the costs per one percent event prevented after 5 years of follow-up as incremental cost-effectiveness ratio (ICER). Secondary objective was to establish when adjuvant systemic therapy becomes cost saving. Patients included in the MIRROR study with isolated tumor cells or micrometastases who had a complete 5-year follow-up and who either did or did not receive systemic therapy were eligible. Sensitivity analyses were carried out.

\section{Results}

In the no adjuvant therapy cohort ( $n=366), 24.9 \%$ of patients had an event within 5 years versus $16.8 \%$ of patients in the adjuvant therapy cohort $(n=483)(p<0.01)$. The ICER was $€ 363$ per one percent event prevented. Beyond 18 years after diagnosis, the extrapolated mean cumulative costs per patient in the no adjuvant therapy cohort exceeded those of the adjuvant therapy cohort.

\section{Conclusions}

In this population of breast cancer patients with isolated tumor cells or micrometastases, $€ 36300$ had to be invested to prevent one event in 5 years of follow-up. Adjuvant systemic therapy was cost saving beyond 18 years after diagnosis. 


\section{Introduction}

Breast cancer is a major public health problem ${ }^{1}$ and leads to considerable health care consumption ${ }^{2}$. The use of adjuvant systemic therapy has greatly improved diseasefree and overall survival in patients with early breast cancer ${ }^{3}$. The efficacy of adjuvant systemic therapies is clearly related to prognosis: patients with high risk of recurrence benefit most of adjuvant systemic therapy. The cost-effectiveness of various adjuvant systemic therapy regimens have been reported in node-positive $e^{4-7}$ and node-negative breast cancer patients ${ }^{5}$.

Recently, we have reported the results of the Dutch MIRROR (Micrometastases or Isolated tumor cells: Relevant and Robust Or Rubbish?) study, in which (sentinel) nodal isolated tumor cells and micrometastases in patients with early stage breast cancer and favorable primary tumor characteristics who did not receive adjuvant systemic therapy were associated with poorer disease-free survival as compared to node-negative patients. In patients with isolated tumor cells or micrometastases who received adjuvant systemic therapy, disease-free survival was improved ${ }^{8}$.

The cost-effectiveness of administering adjuvant systemic therapy to patients with isolated tumor cells or micrometastases has never been assessed before. We present an economic analysis based on patient data derived from the MIRROR study to assess the cost-effectiveness of adjuvant systemic therapy in this patient population.

\section{Patients and Methods}

\section{Objectives}

The primary objective was to determine the incremental cost-effectiveness ratio (ICER) of administration of adjuvant systemic therapy in breast cancer patients with isolated tumor cells or micrometastases as final nodal status. The ICER was expressed as costs per one percent event prevented after 5-year follow-up. Secondary objective was to determine the time frame necessary for the administration of adjuvant systemic therapy to become cost saving (break-even point).

\section{Patients}

Details of the patient and tumor characteristics in the MIRROR study have been reported elsewhere ${ }^{8}$. In short, all patients $(n=2707)$ in the Netherlands who had a sentinel node biopsy before 2006, with isolated tumor cells or micrometastases as final nodal status after central pathology revision and favorable characteristics of the primary tumor, were included, as well as a control group of node negative patients. For the present analysis, only patients with isolated tumor cells or micrometastases who had a complete follow-up, defined as minimal follow-up of 5 years, or deceased within 5 years were eligible. 
$90 \mid$ Chapter 6

\section{Effects}

An event was defined as either local, regional, or distant recurrence, contralateral invasive breast cancer, or ductal carcinoma in situ, another malignancy, death from any cause. The event rate per cohort was defined as the percentage events after 5 years of follow-up for the primary objective and as time to event for the secondary objective.

\section{Costs}

\section{Volumes}

Volume data on types of surgery (breast surgery, sentinel node biopsy, and optionally axillary lymph node dissection), application of radiotherapy, administration (type and duration) of adjuvant systemic therapy, and on frequency and type of recurrence of disease were derived from patients in the no adjuvant and adjuvant therapy cohort. In addition, we used data from other sources to assess the frequency of adverse events of sentinel node biopsy, axillary lymph node dissection ${ }^{9-11}$, and adjuvant systemic therapy $^{12-14}$. The Dutch Guidelines for Treatment of Breast Cancer were used to determine the cost parameters for uncomplicated follow-up and the treatment of local, regional, and contralateral recurrences ${ }^{15}$. The mean costs of diagnosis and treatment of metastatic breast cancer from 2004 to 2009 were derived from a random selection of 50 patients not included in this study treated in a university hospital that also provides a regional function. All cost data, except the costs of diagnosis and treatment of metastatic breast cancer, were based on samples of patients with complete follow-up in the no adjuvant and adjuvant therapy cohort. The mean costs of diagnosis and treatment of metastatic breast cancer were added to these costs as a constant to those patients that developed metastatic breast cancer in the respective cohorts.

\section{Cost prices}

Table S1 in the Supplementary appendix shows the unit cost price and their sources. In accordance with national guidelines for cost calculation in health care, we added $35 \%$ overhead cost to cost of personnel ${ }^{17}$. We calculated full cost prices from date of diagnosis up to five years after diagnosis for every treatment delivered for primary breast cancer, follow-up, and local, regional, contralateral, or distant recurrence of disease. All costs were converted to 2008 Euros using the Dutch consumer price index ${ }^{20}$.

\section{Cost and effect analyses}

Costs were discounted to present values at $3 \%$. Cost differences between both cohorts were explored by linear regression. First, a linear regression model was fitted to the raw data without taking into account potential confounding. Second, a 
regression model taking into account potential confounders (age, nodal status, log tumor size, tumor grade, and axillary treatment) was fitted to the data. Event rates after 5 years of follow-up were analyzed in a similar way with a generalized linear model (binomial family) using an identity link.

To assess the secondary objective, we analyzed the expected disease-free survival with a parametric regression model using the set of confounders described above and assuming a log-logistic distribution for the disease-free survival times. The costs up to break-even were assessed using the mean costs of follow-up with adding the expected event rates per cohort, derived from the parametric regression model multiplied by the mean costs of an event.

\section{Cost-effectiveness analysis}

We carried out a cost-effectiveness analysis from an inpatient perspective. The sample for this analysis was bootstrapped $(n=1000)$ to derive a fairly normal distribution of the ICER. The $95 \%$ confidence interval $(95 \% \mathrm{Cl})$ of the ICER(s) was estimated using the percentile method. Finally, cost-effectiveness acceptability curves (CEACS) were derived enabling to evaluate efficiency exploring a range of thresholds (willingness to pay for one percent event prevented in 5 years) ${ }^{21}$. The CEAC shows how many of all bootstrap replications, expressed as the probability (y-axis), result in ICERs lower than or equal to a certain willingness to pay for one percent event prevented (x-axis). For an increasing willingness to pay for one percent event prevented in 5 years, the probability that adjuvant systemic therapy becomes costeffective increases according to the shape of the acceptability curve.

\section{Sensitivity analyses}

One way sensitivity analyses were performed on the status of the follow-up: a pessimistic scenario on complete and incomplete follow-up, an optimistic scenario on complete follow-up or incomplete follow-up and the occurrence of an event within 5 years; and two scenarios in which the discount rates were varied between $0 \%$ and $6 \%$. These sensitivity analyses were displayed as CEACs. One additional deterministic scenario was carried out in which patients receiving chemotherapy in the base-case analysis received a third generation chemotherapy regimen (six cycles of docetaxel, doxorubicin and cyclophosphamide (TAC)) instead of a first or second-generation regimen, taking into account additional costs and effectiveness ${ }^{22}$.

\section{Results}

\section{Patients}

Complete follow-up up to 5 years after diagnosis was available for 366 of 856 patients $(43 \%)$ in the no adjuvant therapy cohort, and for 483 of 995 patients $(49 \%)$ in the 
92 Chapter 6

adjuvant therapy cohort of the MIRROR study. The characteristics of the patients with complete follow-up in the no adjuvant therapy cohort $(n=366)$ and the adjuvant therapy cohort $(n=483)$ are shown in Table 1.

Table 1. Characteristics of patients in the no adjuvant therapy cohort and the adjuvant therapy cohort

\begin{tabular}{|c|c|c|c|}
\hline Characteristic & $\begin{array}{c}\text { No adjuvant therapy } \\
\text { cohort } \\
(\mathrm{n}=366) \\
\mathrm{n}(\%)\end{array}$ & $p$ value & $\begin{array}{c}\text { Adjuvant therapy } \\
\text { cohort } \\
(n=483), \\
n(\%)\end{array}$ \\
\hline Years of age (median (range)) & $57(32-89)$ & $p=0.58$ & $57(31-88)$ \\
\hline \multicolumn{4}{|l|}{ Tumor size ) } \\
\hline$\leq 1 \mathrm{~cm}$ & $100(27)$ & \multirow[t]{3}{*}{$p=0.02$} & $99(23)$ \\
\hline $1-2 \mathrm{~cm}$ & $214(59)$ & & $290(59)$ \\
\hline $2-3 \mathrm{~cm}$ & $52(14)$ & & $94(17)$ \\
\hline \multicolumn{4}{|l|}{ Tumor grade } \\
\hline 1 & $133(37)$ & \multirow[t]{4}{*}{$p=0.02$} & $134(28)$ \\
\hline 2 & $213(60)$ & & $325(68)$ \\
\hline 3 & $12(3)$ & & $17(4)$ \\
\hline unknown & $8(0)$ & & $7(0)$ \\
\hline \multicolumn{4}{|l|}{ ER/PgR statusboth } \\
\hline ER+ and/or PgR+ & $322(91)$ & \multirow[t]{3}{*}{$p=0.02$} & $450(95)$ \\
\hline ER- and PgR- & $31(9)$ & & $23(5)$ \\
\hline unknown & $13(0)$ & & $10(0)$ \\
\hline \multicolumn{4}{|l|}{ Final nodal status (revised) } \\
\hline $\mathrm{pNO}(\mathrm{i}+)$ & $259(71)$ & \multirow{2}{*}{$p<0.01$} & $183(38)$ \\
\hline pN1mi & $107(29)$ & & $300(62)$ \\
\hline \multicolumn{4}{|l|}{ ALND and/or Al } \\
\hline no ALND and/or Al & $193(53)$ & \multirow{2}{*}{$p<0.01$} & $80(17)$ \\
\hline ALND and/or $\mathrm{Al}$ & $173(47)$ & & $403(83)$ \\
\hline \multicolumn{4}{|l|}{ Systemic adjuvant therapy } \\
\hline hormonal therapy & - & & $316(65)$ \\
\hline chemotherapy & - & NA & $40(8)$ \\
\hline both & - & & $127(26)$ \\
\hline
\end{tabular}

Al, axillary irradiation; ALND, axillary lymph node dissection; ER, estrogen receptor; NA, non applicable; PgR, progesterone receptor.

\section{Effects}

Of patients with a complete follow-up, $24.9 \%$ had an event within 5 years in the no adjuvant therapy cohort, and $16.8 \%$ of patients in the adjuvant therapy cohort. The difference in event rates between the cohorts was $8.1 \%(95 \% \mathrm{Cl}, 2.6 \%$ to $13.6 \%)$. After correction for confounders, the difference in events between the cohorts was $8.0 \%$ (95\% $\mathrm{Cl}, 2.4 \%$ to $13.6 \%)$.

\section{Costs}

From a random selection of 50 patients with metastatic breast cancer, 46 patients had a follow-up of at least 1 year, and 27 patients had a follow-up of at least 2 years and 
could be included in the analysis of costs. The mean costs of diagnosis and treatment of metastatic breast cancer for the first year after diagnosis of metastatic disease were $€ 19156$ ( $n=46 ; 95 \% \mathrm{Cl}, € 11589$ to $€ 26722$ ). The mean costs of treatment for the second year after diagnosis of metastatic disease were $€ 15622$ ( $n=27 ; 95 \% \mathrm{Cl}$, €9260 to $€ 21985$ ). These costs were assigned to the patients with metastatic disease in the present study.

Figure 1 shows the mean categorized cumulative costs per patient in the no adjuvant and the adjuvant therapy cohort. After the first year of diagnosis, the additional costs per patient comprised adjuvant systemic therapy (endocrine treatment) in the adjuvant therapy cohort and costs due to recurrence of disease and follow-up in both cohorts. The estimated mean total costs after 5 years of follow-up were $€ 15119$ (95\% $\mathrm{Cl}, € 14034$ to $€ 16205)$ for the patients in the no adjuvant therapy cohort, and €18059 ( $95 \% \mathrm{Cl}, € 17277$ to $€ 18840$ ) for the patients in the adjuvant therapy cohort, resulting in a difference of $€ 2939$ ( $95 \% \mathrm{Cl}, € 1638$ to $€ 4241)$. After correction for confounders, the difference in mean total costs remained significant, however, smaller (€1852 (95\% $\mathrm{Cl}, € 459$ to $€ 3245)$ ). Table 2 shows the difference in mean total costs and the difference in the costs of primary treatment of breast cancer, systemic adjuvant therapy, follow-up, and recurrence of disease per patient between the adjuvant therapy cohort and the no adjuvant therapy cohort after 5 years of follow-up. The difference in total mean costs per patient between both cohorts could be attributed to higher costs for primary surgical, radiotherapeutic, and adjuvant systemic treatment and lower costs for recurrence of disease in the adjuvant therapy cohort.

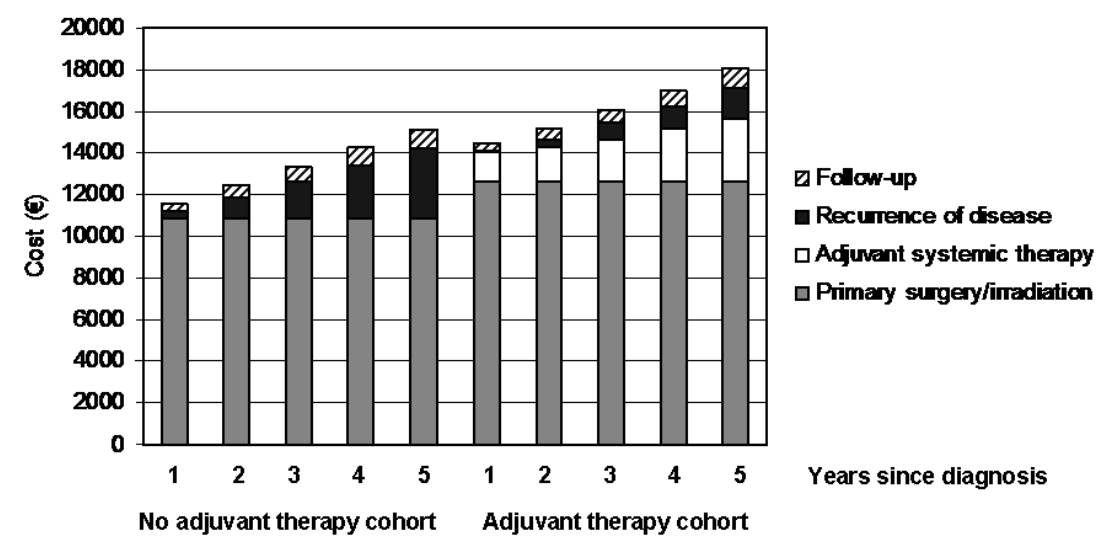

Figure 1. Mean cumulative costs per patient in the no adjuvant and the adjuvant therapy cohort, classified by type of costs. 
Table 2. Difference in mean costs per patient between the adjuvant therapy cohort and the no adjuvant therapy cohort after 5 years of follow-up

\begin{tabular}{lcc}
\hline & $\begin{array}{c}\text { Differences in mean costs per patient } \\
\text { (adjuvant therapy cohort minus no adjuvant } \\
\text { therapy cohort) }\end{array}$ & 95\% Cl of difference \\
\hline Total costs & $€ 2939$ & $€ 1603$ to $€ 4275$ \\
Primary treatment $^{\mathrm{a}}$ & $€ 1725$ & $€ 1180$ to $€ 2268$ \\
AST $^{\mathrm{b}}$ & $€ 3008$ & $€ 2669$ to $€ 3348$ \\
Follow-up $_{\text {Recurrence of disease }}$ & $-€ 9$ & $-€ 31$ to $€ 14$ \\
\end{tabular}

primary treatment $=$ surgery and optionally irradiation ${ }^{\mathrm{b}} \mathrm{AST}=$ chemotherapy and/or endocrine therapy

AST, adjuvant systemic therapy; $\mathrm{Cl}$, confidence interval

\section{Cost-effectiveness}

The base-case scenario showed an ICER of $€ 363$ per one percent event prevented in 5 years $(95 \% \mathrm{Cl},-€ 1422$ to $€ 4159)$. The base-case CEAC is displayed in Figure 2 . The willingness to pay for one percent event prevented in 5 years, given an $80 \%$ probability that adjuvant systemic therapy becomes cost-effective, approached $€ 1000$.

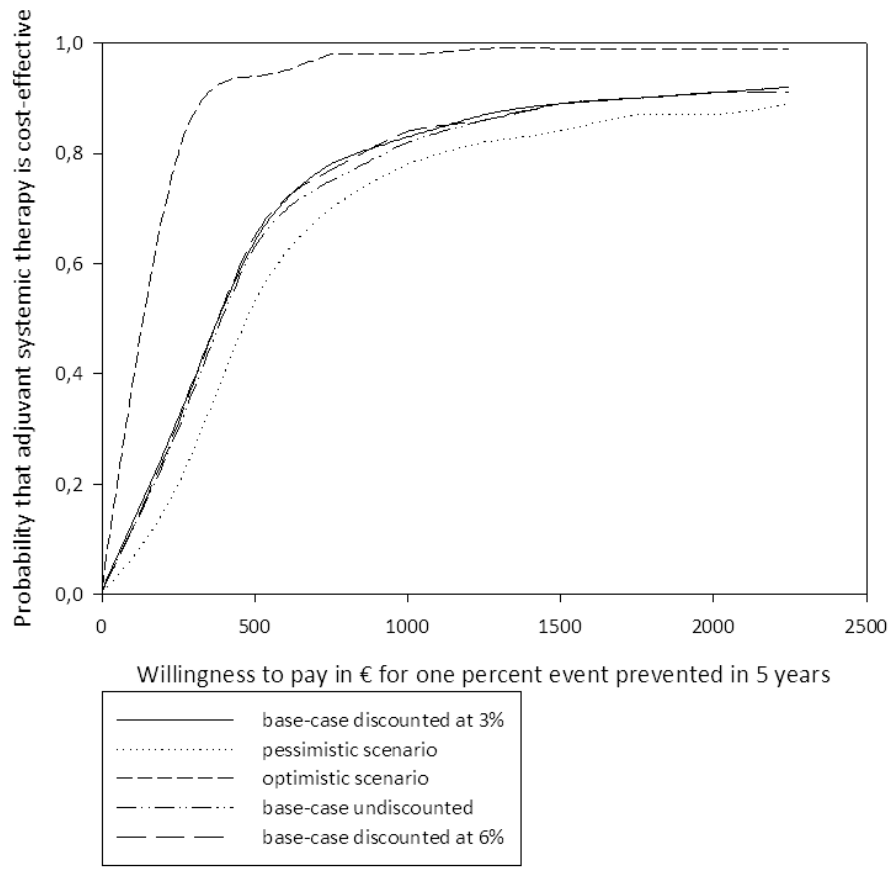

Figure 2. Cost-effectiveness acceptability curves for the base case scenario and the scenarios in the sensitivity analyses. 


\section{The break-even point for adjuvant systemic therapy}

The mean costs for recurrence of disease were $€ 16809$ in the no adjuvant therapy cohort and €11627 in the adjuvant therapy cohort. The mean costs of follow-up in the fifth year after diagnosis were $€ 128$. Figure 3 shows the extrapolated cumulative mean costs per patient up to 20 years after diagnosis in both cohorts, using the extrapolated event rate. Around 18 years after diagnosis, the extrapolated mean cumulative costs per patient were almost equal in the no adjuvant therapy cohort (€22652) as compared to the adjuvant therapy cohort (€22694) and consequently, the no adjuvant systemic therapy and the adjuvant systemic therapy strategy approach break-even. Beyond 18 years after diagnosis adjuvant systemic therapy becomes the dominant strategy, i.e. cost saving and more effective.

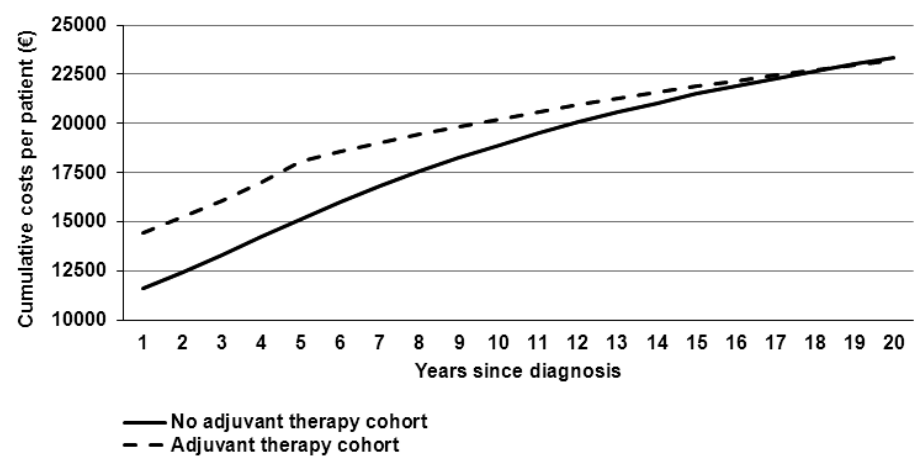

Figure 3. Extrapolated cumulative mean costs per patient up to 20 years after diagnosis in the no adjuvant and adjuvant therapy cohort.

\section{Sensitivity analyses}

Sensitivity analyses resulted in ICERs ranging from $€ 129$ to $€ 478$ for one percent event prevented. Figure 2 shows the CEACs for the different scenarios. Varying the discount rate did not alter the results in any way. The optimistic scenario showed that the willingness to pay for one percent event prevented in 5 years with a 95\% probability that adjuvant systemic therapy became cost-effective approached €500; the pessimistic scenario resulted in a willingness to pay for one percent event prevented in 5 years with a $80 \%$ probability that adjuvant systemic therapy became costeffective that approached $€ 1200$. The deterministic established scenario, the administration of 6 cycles of TAC, resulted in an ICER of $€ 743$ per one percent event prevented. 


\section{Discussion}

The MIRROR-study has shown that disease-free survival was decreased in patients with isolated tumor cells or micrometastases as compared to node-negative patients and significantly improved in patients with isolated tumor cells or micrometastases who received adjuvant systemic therapy ${ }^{8}$. The present study assessed whether the administration of adjuvant systemic therapy in patients with early stage breast cancer and lymph nodes containing isolated tumor cells or micrometastases is cost-effective. The ICER was $€ 363$ per one percent event prevented after 5 years of follow-up. An alternative interpretation is that to prevent one event in 5 years in the study population, $€ 36300$ has to be invested extra. However, in breast cancer, disease recurrence frequently occurs more than 10 years after diagnosis ${ }^{23}$. To assess whether and when administering adjuvant systemic therapy would break-even and consequently would become cost saving, we extrapolated our outcome to a longer time horizon. We showed that around 18 years after diagnosis, the expected mean costs in both cohorts were approaching break-even; beyond 18 years the administration of adjuvant systemic therapy in patients with isolated tumor cells or micrometastases was expected to become dominant, resulting in both prevention of events and saving of costs. The mean age of patients in this study was 57 years. The life expectancy of a 55-year-old healthy woman in the Netherlands is 29 years $^{24}$. Therefore, the administration of adjuvant systemic therapy becomes cost saving far before a substantial part of the patients without disease recurrence in this study are expected to die.

This study is a nationwide cohort study in an unselected patient population, reflecting daily clinical practice. Due to the costs of systemic treatment and the more frequent axillary treatment in the adjuvant therapy cohort, the mean costs per patient were higher as compared to the no adjuvant therapy cohort. After correction for confounders, the difference between both cohorts was smaller, but remained significant. In the sensitivity analyses, discounting of costs had negligible effect on the cost-effectiveness. In our cohort study, the average follow-up duration was 5 years. In the cost-effectiveness analysis we primarily assessed costs for patients who had a follow-up of at least 5 years. In the scenario where patients with incomplete follow-up were also included, the result was less cost-effective. These patients were included more recently in the study and more frequently received second instead of first generation chemotherapy regimens and both chemo- and hormonal therapy instead of hormonal therapy only. As the guidelines for adjuvant systemic therapy have become more liberal nowadays ${ }^{15,25}$, this scenario better reflects daily practice. The deterministic scenario, in which a third generation chemotherapy regimen (TAC) was applied, resulted in the most unfavorable cost-effectiveness of all scenarios. This was mainly due to more than six times higher costs of adjuvant systemic therapy (Table S1 in the Supplementary appendix) and 'only' 1.25 times more effectiveness ${ }^{22}$ in the adjuvant therapy cohort. Like in node-positive patients ${ }^{26}$, recently, this regimen also 
showed to be more effective than second generation regimens in node negative patients $^{27}$. Probably, in the near future all breast cancer patients who need adjuvant chemotherapy will receive a third generation regimen, and therefore, this scenario might reflect future practice. In this study, 59\% of patients on endocrine therapy received tamoxifen for 5 years. Currently, this therapy will mostly consist of 2-3 years of tamoxifen, followed by 2-3 years of a more expensive (Table S1 in the Supplementary appendix) but more effective ${ }^{28}$ aromatase-inhibitor. This will change the cost-effectiveness of adjuvant systemic therapy in the current era. In addition, trastuzumab is currently used as adjuvant targeted therapy in patients with HER2 positive breast cancer who are candidates for adjuvant chemotherapy ${ }^{29}$. This effective but expensive drug will change the cost-effectiveness of adjuvant systemic therapy in HER2 positive breast cancer patients even more.

In various breast cancer patient populations, cost-effectiveness and cost-utility studies have been carried out. Messori et al. ${ }^{4}$ and Kievit et al. ${ }^{30}$ studied first-generation chemotherapy regimens in node positive and in both node negative and positive patients, respectively, resulting in ICERs of US\$447 and €4837 per life year gained, the last study including also endocrine therapy. Recently, the cost-utility of third versus second generation chemotherapy regimens were analyzed in node positive patients ${ }^{6,7,31-33}$, resulting in ICERs of $€ 2631 /$ QALY (quality-adjusted life year) ${ }^{31}$ up to GBP20432/QALY ${ }^{6}$. Adjuvant systemic therapy is less cost-effective in patients with lower risk of disease recurrence, illustrated by Kattlove et al. ${ }^{5}$, who showed that an investment of $\$ 50000$ was necessary to save one life in 10 years in node negative patients who received cyclophosphamide, methotrexate and 5-fluorouracil (CMF) polychemotherapy versus no chemotherapy, versus an investment of $\$ 23000$ in node positive breast cancer patients. These economic analyses are difficult to compare, as the included patients' risk profiles and the timeframes for costs and effects vary, different endpoints have been used, and sensitivity analyses and discounting have not always been carried out. In patients with nodal isolated tumor cells or micrometastases, cost-effectiveness or cost-utility analyses have never been reported. In the Netherlands, treatment of serious diseases is considered cost-effective if costs of treatment do not exceed $€ 80000$ per $Q A L Y^{34}$. In our study, we did not have data with respect to quality of life (QoL) of the included patients. However, QALY is not a very common parameter in economic analyses of adjuvant systemic therapy in breast cancer, as the impact of adjuvant systemic therapy on QOL is transient and minor compared to patients' adaptation and coping after diagnosis and surgery ${ }^{35}$. Moreover, recurrence of disease is associated with decrease in QoL, which we have taken into account by using the percentage of events prevented as effect parameter. Finally, QoL is less important as administering adjuvant systemic therapy was not only expected to be more effective but also cost saving beyond 18 years of follow-up.

This study was carried out in the Netherlands. As health care policies and costs of treatment might vary, the exact results of this cost-effectiveness analysis may be difficult to extrapolate to other countries. However, as adjuvant systemic therapy was 
98 Chapter 6

expected to become cost saving beyond 18 years of follow-up, it seems reasonable to assume that in the long run adjuvant therapy becomes cost saving in all Western countries. This study was carried out from an inpatient perspective. Therefore, costs for extramural care were not taken into account. Especially in metastatic disease, these costs can be considerable, accounting for almost $15 \%$ of total costs of metastatic disease ${ }^{36}$. If extramural costs would have been taken into account, the administration of adjuvant systemic therapy was expected to become more costeffective, as more patients in the no adjuvant therapy cohort had distant metastatic disease.

In conclusion, we carried out a cost-effectiveness analysis within a large nationwide cohort study to assess the cost-effectiveness of administering adjuvant systemic therapy to patients with nodal isolated tumor cells or micrometastases. To prevent one event in 5 years in this population of early breast cancer patients, $€ 36300$ had to be invested to be considered cost-effective. Beyond 18 years after diagnosis, the administration of adjuvant systemic therapy in this population was cost saving.

\section{Acknowledgements}

We thank Jolanda M. van Beek-Schoester for her assistance with data management and Wim A.J.G. Lemmens for his assistance with statistical analyses.

\section{Funding}

Netherlands Organization for Health Research and Development (ZonMw) (945-06509) and the Dutch Breast Cancer Trialists' Group (BOOG).

This study was presented in part at the American Society of Clinical Oncology Annual Meeting 2010 (poster, \#614), Chicago, IL, June 4-8, 2010. 


\section{References}

1. Parkin DM, Bray F, Ferlay J, Pisani P. Global cancer statistics, 2002. CA Cancer J Clin 2005;55:74-108.

2. Broekx S, Den Hond E, Torfs R, et al. The costs of breast cancer prior to and following diagnosis. Eur J Health Econ 2011;12:311-7.

3. Early Breast Cancer Trialists' Collaborative Group (EBCTCG). Effects of chemotherapy and hormonal therapy for early breast cancer on recurrence and 15-year survival: an overview of the randomised trials. Lancet 2005;365:1687-1717.

4. Messori A, Becagli P, Trippoli S, Tendi E. Cost-effectiveness of adjuvant chemotherapy with cyclophosphamide+methotrexate+fluorouracil in patients with node-positive breast cancer. Eur J Clin Pharmacol 1996;51:111-116.

5. Kattlove H, Liberati A, Keeler E, Brook RH. Benefits and costs of screening and treatment for early breast cancer. Development of a basic benefit package. JAMA 1995;273:142-148.

6. Wolowacz SE, Cameron DA, Tate HC, Bagust A. Docetaxel in combination with doxorubicin and cyclophosphamide as adjuvant treatment for early node-positive breast cancer: a cost-effectiveness and cost-utility analysis. J Clin Oncol 2008;26:925-933.

7. Marino $\mathrm{P}$, Siani $\mathrm{C}$, Roché $\mathrm{H}$, et al. Cost-effectiveness of adjuvant docetaxel for node-positive breast cancer patients: results of the PACS 01 economic study. Ann Oncol 2010;21:1448-1454.

8. de Boer $\mathrm{M}$, van Deurzen $\mathrm{CH}$, van Dijck JA, et al. Micrometastases or isolated tumor cells and the outcome of breast cancer. N Engl J Med 2009;361:653-663.

9. McLaughlin SA, Wright MJ, Morris KT, et al. Prevalence of lymphedema in women with breast cancer 5 years after sentinel lymph node biopsy or axillary dissection: objective measurements. J Clin Oncol 2008;26:5213-5219.

10. Lucci A, McCall LM, Beitsch PD, et al; American College of Surgeons Oncology Group. Surgical complications associated with sentinel lymph node dissection (SLND) plus axillary lymph node dissection compared with SLND alone in the American College of Surgeons Oncology Group Trial Z0011. J Clin Oncol 2007;25:3657-3663.

11. Langer I, Guller U, Berclaz G, et al. Morbidity of sentinel lymph node biopsy (SLN) alone versus SLN and completion axillary lymph node dissection after breast cancer surgery: a prospective Swiss multicenter study on 659 patients. Ann Surg 2007;245:452-461.

12. von Minckwitz G, Kümmel S, Vogel P, et al; German Breast Group. Neoadjuvant vinorelbinecapecitabine versus docetaxel-doxorubicin-cyclophosphamide in early nonresponsive breast cancer: phase III randomized GeparTrio trial. J Natl Cancer Inst 2008;100:542-551.

13. Martín M, Lluch A, Seguí MA, et al. Toxicity and health-related quality of life in breast cancer patients receiving adjuvant docetaxel, doxorubicin, cyclophosphamide (TAC) or 5-fluorouracil, doxorubicin and cyclophosphamide (FAC): impact of adding primary prophylactic granulocyte-colony stimulating factor to the TAC regimen. Ann Oncol 2006;17:1205-1212.

14. Aapro MS, Cameron DA, Pettengell R, et al; European Organisation for Research and Treatment of Cancer (EORTC) Granulocyte Colony-Stimulating Factor (G-CSF) Guidelines Working Party. EORTC guidelines for the use of granulocyte-colony stimulating factor to reduce the incidence of chemotherapy-induced febrile neutropenia in adult patients with lymphomas and solid tumours. Eur J Cancer 2006;42:2433-2453.

15. Struikmans H, Nortier JW, Rutgers EJ, et al. Guideline 'Treatment of breast cancer 2008' (revision). Ned Tijdschr Geneeskd 2008;152:2507-2511.

16. Dutch Health Care Insurance Board. Diagnostic Compass, Amstelveen, the Netherlands: Dutch Health Care Insurance Board 2003.

17. Oostenbrink JB, Bouwmans CAM, Koopmanschap MA, Rutten FFH. Manual for cost analysis, methods and guidelines prices in health care economic evaluations, Amstelveen, the Netherlands: College voor Zorgverzekeringen (CVZ) 2004

18. Health Care Insurance Board. Cost of Medicine. www.medicijnkosten.nl (9 April 2009, date last accessed).

19. Dutch Healthcare Authority. Tariffs in Health Care. http://ctg.bit-ic.nl/Nzatarieven/top.do (9 April 2009, date last accessed). 
$100 \mid$ Chapter 6

20. Statistics Netherlands. Consumer Price Indices. http://statline.cbs.nl/StatWeb/publication/?DM= SLEN\&PA $=71905 E N G \& D 1=0 \& D 2=0,10,20,30,40,50,60,63,70,80,90,100-I \& L A=E N \& V W=T \quad(12 \quad$ May 2011, date last accessed).

21. O'Brien BJ, Briggs AH: Analysis of uncertainty in health care cost-effectiveness studies: an introduction to statistical issues and methods. Stat Methods Med Res 2002;11:455-468.

22. Peto R. The worldwide overview: new results for systemic adjuvant therapies. Presented at the San Antonio Breast Cancer Symposium. San Antonio, TX, December 13-16,2007.

23. Demicheli R, Abbattista A, Miceli R, Valagussa P, Bonadonna G. Time distribution of the recurrence risk for breast cancer patients undergoing mastectomy: further support about the concept of tumor dormancy. Breast Cancer Res Treat 1996;41:177-185.

24. Statistics Netherlands. Remaining (Healthy) Life Expectancy. http://www.cbs.nl/en-GB/menu/ themas/gezondheid-welzijn/cijfers/extra/resterende-gezonde-levensverwachting.htm? Languageswitch=on (12 May 2011, date last accessed).

25. Rutgers EJ, Nortier JW, Tuut MK, et al. Dutch Institute for Healthcare Improvement guideline, "Treatment of breast cancer". Ned Tijdschr Geneeskd 2002;146:2144-2151.

26. Martin M, Pienkowski T, Mackey J, et al; Breast Cancer International Research Group 001 Investigators. Adjuvant docetaxel for node-positive breast cancer. N Engl J Med 2005;352:2302-2313.

27. Martín M, Seguí MA, Antón A, et al; GEICAM 9805 Investigators. Adjuvant docetaxel for high-risk, node-negative breast cancer. N Engl J Med 2010;363:2200-2210.

28. Coombes RC, Kilburn LS, Snowdon CF, et al; Intergroup Exemestane Study. Survival and safety of exemestane versus tamoxifen after 2-3 years' tamoxifen treatment (Intergroup Exemestane Study): a randomised controlled trial. Lancet 2007;369:559-570.

29. Smith I, Procter M, Gelber RD, et al; HERA study team. 2-year follow-up of trastuzumab after adjuvant chemotherapy in HER2-positive breast cancer: a randomised controlled trial. Lancet 2007;369:29-36.

30. Kievit W, Bolster MJ, van der Wilt GJ, et al. Cost-effectiveness of new guidelines for adjuvant systemic therapy for patients with primary breast cancer. Ann Oncol 2005;16:1874-1881.

31. Martin-Jimenez $M$, Rodriguez-Lescure A, Ruiz-Borrego $M$, et al: Cost-effectiveness analysis of docetaxel (Taxotere) vs. 5-fluorouracil in combined therapy in the initial phases of breast cancer. Clin Transl Oncol 2009;11:41-47.

32. Au HJ, Golmohammadi K, Younis T, et al. Cost-effectiveness analysis of adjuvant docetaxel, doxorubicin, and cyclophosphamide (TAC) for node-positive breast cancer: modeling the downstream effects. Breast Cancer Res Treat 2009;114:579-587.

33. Younis T, Rayson D, Sellon M, Skedgel C. Adjuvant chemotherapy for breast cancer: a cost-utility analysis of FEC-D vs. FEC 100. Breast Cancer Res Treat 2008;111:261-267.

34. Raad voor de Volksgezondheid en Zorg (RVZ) (Council for Public Health and Health Care). Sensible and Durable Care. Zoetermeer, the Netherlands: Raad voor de Volksgezondheid en Zorg (Council for Public Health and Health Care) 2006.

35. Hürny C, Bernhard J, Coates AS, et al. International Breast Cancer Study Group. Impact of adjuvant therapy on quality of life in women with node-positive operable breast cancer. Lancet. 1996;347: 1279-1284. Erratum in Lancet 1997;350:298.

36. Dahlberg L, Lundkvist J, Lindman $\mathrm{H}$. Health care costs for treatment of disseminated breast cancer. Eur J Cancer 2009;45:1987-1991. 
Cost-effectiveness of adjuvant systemic therapy 101

Supplementary appendix 
Table S1. Unit cost prices and sources

\begin{tabular}{|c|c|c|c|}
\hline Cost parameter & Volume & $\begin{array}{l}\text { Cost price } 2008 \\
(€)\end{array}$ & $\begin{array}{c}\text { Source } \\
\text { (reference) }\end{array}$ \\
\hline \multicolumn{4}{|l|}{ Breast biopsy } \\
\hline general hospital & 1 biopsy & 60 & (16) \\
\hline university hospital & 1 biopsy & 108 & (16) \\
\hline Pathologic assessment biopsy & 1 biopsy & 37 & (16) \\
\hline Mammography & 1 mammography & 75 & (16) \\
\hline Ultrasound breast & 1 ultrasound & 70 & (16) \\
\hline \multicolumn{4}{|l|}{ Visit outpatient department } \\
\hline general hospital & 1 visit & 60 & (17) \\
\hline university hospital & 1 visit & 108 & (17) \\
\hline Ultrasound liver & 1 ultrasound & 73 & (16) \\
\hline Bone scintigraphy & 1 scan & 175 & (16) \\
\hline Chest $X$-ray & $1 \mathrm{X}$-ray & 47 & (16) \\
\hline $\begin{array}{l}\text { SN procedure (including nuclear medicine } \\
\text { and pathologic assessment) }\end{array}$ & 1 procedure & 297 up to $965^{*}$ & $(16)$ \\
\hline \multicolumn{4}{|c|}{$\begin{array}{l}\text { Breast and axillary surgery (including pathologic assessment and treatment of complications (seroma, } \\
\text { wound infection, lymphedema)) }\end{array}$} \\
\hline \multicolumn{4}{|c|}{ Breast-conserving + SN procedure } \\
\hline general hospital & 1 procedure & 1965 & $(17-18)$ \\
\hline university hospital & 1 procedure & 1979 & \\
\hline \multicolumn{4}{|l|}{ Mastectomy + SN procedure } \\
\hline general hospital & 1 procedure & 2269 & \\
\hline university hospital & 1 procedure & 2284 & \\
\hline \multicolumn{4}{|l|}{ Breast-conserving + SN procedure + ALND } \\
\hline general hospital & 1 procedure & 3149 & \\
\hline university hospital & 1 procedure & 3190 & \\
\hline \multicolumn{4}{|l|}{ Mastectomy + SN procedure + ALND } \\
\hline general hospital & 1 procedure & 3453 & \\
\hline university hospital & 1 procedure & 3495 & \\
\hline \multicolumn{4}{|l|}{ SN procedure } \\
\hline general hospital & 1 procedure & 635 & \\
\hline university hospital & 1 procedure & 649 & \\
\hline \multicolumn{4}{|l|}{ ALND } \\
\hline general hospital & 1 procedure & 2075 & \\
\hline university hospital & 1 procedure & 2117 & \\
\hline \multicolumn{4}{|l|}{ Days of hospitalization } \\
\hline general hospital & 1 day & 407 & (17) \\
\hline university hospital & 1 day & 514 & (17) \\
\hline \multirow{2}{*}{\multicolumn{4}{|c|}{$\begin{array}{l}\text { Course of chemotherapy (including costs of treatment of febrile neutropenia, costs of preparation and } \\
\text { administration, blood tests) } \\
\text { CMF }\end{array}$}} \\
\hline & & & \\
\hline general hospital & 1 course & 431 & $(16-18)$ \\
\hline university hospital & 1 course & 536 & \\
\hline \multicolumn{4}{|l|}{ AC } \\
\hline general hospital & 1 course & 635 & \\
\hline university hospital & 1 course & 761 & \\
\hline \multicolumn{4}{|l|}{ FEC } \\
\hline general hospital & 1 course & 368 & \\
\hline university hospital & 1 course & 422 & \\
\hline
\end{tabular}

table continues 
Table S1. (to be continued)

\begin{tabular}{|c|c|c|c|}
\hline Cost parameter & Volume & $\begin{array}{c}\text { Cost price } 2008 \\
(€)\end{array}$ & $\begin{array}{c}\text { Source } \\
\text { (reference) }\end{array}$ \\
\hline \multicolumn{4}{|l|}{ TAC (including G-CSF) } \\
\hline general hospital & 1 course & 3104 & $(16-18)$ \\
\hline university hospital & 1 course & 3192 & \\
\hline \multicolumn{4}{|l|}{ Endocrine therapy } \\
\hline Tamoxifen & 1 year & 66 & (18) \\
\hline LHRH agonist & 1 year & 2504 & $(18)$ \\
\hline $\begin{array}{l}\text { Aromatase-inhibitors (including DEXA- } \\
\text { scans and bisphosphonates) }\end{array}$ & 1 year & 1567 & $(16,18)$ \\
\hline \multicolumn{4}{|l|}{ Radiotherapy } \\
\hline $\begin{array}{l}\text { Radiotherapy after breast conserving } \\
\text { surgery }\end{array}$ & cost per course & 8020 & $(18,19)$ \\
\hline Axillary radiotherapy (instead of ALND) & cost per course & 7076 & \\
\hline $\begin{array}{l}\text { Radiotherapy for local or regional } \\
\text { recurrence }\end{array}$ & cost per course & 8020 & \\
\hline Radiotherapy for bone metastases & cost per course & 1685 & \\
\hline Radiotherapy for brain metastases & cost per course & 1685 & \\
\hline \multicolumn{4}{|c|}{ Uncomplicated follow-up (outpatient visits, mammography) +} \\
\hline \multicolumn{4}{|c|}{ 1st year } \\
\hline general hospital & cost per year & 326 & $(16,17,19)$ \\
\hline university hospital & cost per year & 516 & \\
\hline \multicolumn{4}{|l|}{ 2nd year } \\
\hline general hospital & cost per year & 206 & \\
\hline university hospital & cost per year & 300 & \\
\hline \multicolumn{4}{|l|}{ after 2 nd year } \\
\hline general hospital & cost per year & 148 & \\
\hline university hospital & cost per year & 198 & \\
\hline \multicolumn{4}{|l|}{ Diagnosis and treatment of local recurrence } \\
\hline general hospital & 1 recurrence & 6207 to 10024 & $(16-19)$ \\
\hline university hospital & 1 recurrence & 6527 to 11204 & \\
\hline \multicolumn{4}{|c|}{ Diagnosis and treatment of regional recurrence } \\
\hline general hospital & 1 recurrence & 11876 to 17156 & $(16-19)$ \\
\hline university hospital & 1 recurrence & 12277 to 18336 & \\
\hline \multicolumn{4}{|c|}{ Diagnosis and treatment of contralateral breast cancer } \\
\hline general hospital & 1 recurrence & 11508 to 16102 & $(16-19)$ \\
\hline university hospital & 1 recurrence & 12415 to 17138 & \\
\hline \multicolumn{4}{|c|}{ Diagnosis and treatment of metastatic breast cancer } \\
\hline first year & 1 recurrence & 19156 & $(16-19)$ \\
\hline second year & 1 recurrence & 15622 & \\
\hline \multicolumn{4}{|c|}{$\begin{array}{l}\text { *depending on number of sentinel nodes, and use of immunohistochemistry (IHC); tassuming } 5 \% \text { of patients require MRI } \\
\text { in addition to mammography; SN = sentinel node; ALND = axillary lymph node dissection; CMF = cyclophosphamide, } \\
\text { methotrexate and 5-fluorouracil; AC = doxorubicin, cyclophosphamide; FEC = 5-fluorouracil, epirubicin, cyclophosphamide; } \\
\text { TAC = docetaxel, doxorubicin, cyclophosphamide; G-CSF = granulocyte-colony stimulating factor; LHRH = luteinizing- } \\
\text { hormone-releasing hormone; DEXA = dual energy } x \text {-ray absorptiometry; LVEF = left ventricular ejection fraction; ECG = } \\
\text { electrocardiogram }\end{array}$} \\
\hline
\end{tabular}


104 


\section{Chapter

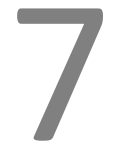

Non-sentinel lymph node metastases associated with isolated breast cancer cells in the sentinel node

Carolien H.M. van Deurzen, Maaike de Boer, Evelyn M. Monninkhof, Peter Bult, Elsken van der Wall, Vivianne C.G. Tjan-Heijnen, Paul J. van Diest

J Natl Cancer Inst 2008;100:1574-1580 


\section{Abstract}

\section{Background}

There are many reports on the frequency of non-sentinel lymph node involvement when isolated tumor cells are found in the sentinel node, but results and recommendations for the use of an axillary lymph node dissection differ among studies. This systematic review was conducted to give an overview of this issue and to provide recommendations for the use of an axillary lymph node dissection in these patients.

\section{Methods}

We searched Medline, Embase, and Cochrane databases from January 1, 2002, through November 27, 2007, for articles on patients with invasive breast cancer who had isolated tumor cells in the sentinel lymph node (according to the sixth edition of the Cancer Staging Manual of the American Joint Committee on Cancer) and who also underwent axillary lymph node dissection.

\section{Results and Conclusion}

Of 411 selected articles, 29 (including 836 patients) were included in this review. These 29 studies were heterogeneous, reporting a wide range of non-sentinel lymph node involvement (defined as the presence of isolated tumor cells or micro- or macrometastases) associated with isolated tumor cells in the sentinel lymph node, with an overall pooled risk for such involvement of $12.3 \%$ (95\% Cl, $9.5 \%$ to $15.7 \%)$. This pooled risk estimate was marginally higher than the risk of a false-negative sentinel lymph node biopsy examination (ie, $7 \%-8 \%$ ) but marginally lower than the risk of non-sentinel lymph node metastases in patients with micrometastases (ie, approximately $20 \%$ ) who are currently eligible for an axillary lymph node dissection. Because 36 (64\%) of the 56 patients with isolated tumor cells in their sentinel lymph node also had nonsentinel lymph node macrometastases, those patients with isolated tumor cells in the sentinel lymph node without other indications for adjuvant systemic therapy might be candidates for axillary lymph node dissection. 


\section{Introduction}

Axillary lymph node status is one of the most important prognostic factors for breast cancer patients ${ }^{1}$. A sentinel lymph node biopsy examination is a safe and accurate initial staging method for lymph nodes of patients with early-stage breast cancer and has largely replaced axillary lymph node dissection as the preferred staging method ${ }^{2}$. Selective targeting of the sentinel lymph node with enhanced pathological analysis (ie, step sectioning and immunohistochemistry) has led to an increased rate of identifying positive lymph nodes ${ }^{3,4}$. However, the clinical significance of small groups of metastatic cells in lymph nodes is unclear.

The sixth edition of the Cancer Staging Manual of the American Joint Committee on Cancer (AJCC), which was first published in 2002, distinguishes between isolated tumor cells (clusters with diameters of $\leq 0.2 \mathrm{~mm}$ ) and micrometastases (tumor cell clusters of $>0.2$ but $\leq 2 \mathrm{~mm}$ ) on the basis of cluster size, reflecting the increased use of the sentinel lymph node biopsy method for lymph node staging. According to the first publication $^{5}$, the category no regional lymph node metastases (pNO) was given an additional description "i" (pNO(i+)) for metastatic cells visible by immunohistochemistry only. That is, $\mathrm{pNO}(\mathrm{i}+)$ indicated that lymph node metastases were not detected on haematoxylin-eosin-stained lymph node sections but were detected by immunohistochemistry and that each tumor cluster had a diameter of no more than $0.2 \mathrm{~mm}$. These definitions were clarified in the 2003 revision $^{6}$, so that the i description referred to the presence $(i+)$ or absence ( $i-$ ) of isolated tumor cells (clusters with diameters of $\leq 0.2 \mathrm{~mm}$ ) regardless of detection method. These patients have been assigned to the NO group for staging and treatment purposes because "the unknown benefits of providing treatment for these small lesions would not overweigh the morbidity caused by the treatment itself" ${ }^{7}$.

Although there is agreement that patients whose sentinel lymph node contain microand/or macrometastases (ie, those in the N1 category) should be subjected to axillary lymph node dissection, controversy exists as to whether there is a benefit associated with axillary lymph node dissection for patients whose sentinel lymph node contains isolated tumor cells. Several studies ${ }^{8-10}$ report an association between the size of metastases in the sentinel lymph node and non-sentinel lymph node involvement. Before the introduction of the current definition of isolated tumor cells, such groups of metastatic cells were included in the micrometastases category (pN1a) and thus usually integrated into the group of metastases detected by immunohistochemistry only. A meta-analysis by Cserni et al. ${ }^{11}$ reported an overall risk of non-sentinel lymph node involvement of $9 \%$, when sentinel lymph node metastases were detectable by immunohistochemistry only. Since the introduction of the current definition of isolated tumor cells, a growing number of studies ${ }^{12-14}$ have assessed the detection rate of non-sentinel lymph node metastases in patients who have isolated tumor cells in their sentinel lymph node, but the results and recommendations from these studies for the use of axillary lymph node dissection have varied. This systematic review was 
conducted to give an overview of these results and provide recommendations regarding the role of an axillary lymph node dissection in patients with isolated tumor cells in their sentinel lymph node.

\section{Patients and methods}

\section{Literature search strategy}

The electronic databases of Medline, Embase, and Cochrane were searched from January 1, 2002, through November 27, 2007, by use of variations of free text and controlled terms for breast cancer and sentinel lymph node and non-sentinel lymph node involvement. The year 2002 was selected because the sixth edition of the AJCC Cancer Staging Manual was published this year. Articles published in English, German, French, or Dutch were considered. Two reviewers (C.H.M. van Deurzen and M. de Boer) independently evaluated titles and abstracts of the identified papers. The full text of potentially relevant articles was then reviewed.

\section{Study inclusion criteria}

To be included in this review, studies had to meet three inclusion criteria. First, patients had to have invasive breast cancer. Second, patients must have had a sentinel lymph node biopsy procedure followed by an axillary lymph node dissection. Third, isolated tumor cells had to be classified according to the sixth edition of the AJCC Cancer Staging Manual (tumor cell clusters with a diameter of $\leq 0.2 \mathrm{~mm}$ ). Studies were excluded that reported on a sentinel lymph node biopsy procedure after neoadjuvant chemotherapy, microinvasive breast cancer, or sentinel lymph node tumor deposits without size definition according to the sixth edition of the AJCC Cancer Staging Manual.

\section{Data extraction and statistical analysis}

Data extraction was carried out independently by two reviewers (C.H.M. van Deurzen and M. de Boer). Any disagreement was resolved by consensus. Data were extracted by use of standardized data extraction forms. We documented sample size, inclusion and exclusion criteria, primary tumor characteristics, definition of isolated tumor cells, sentinel lymph node biopsy protocol (blue dye and/or colloid and the injection site), processing methods for sentinel lymph nodes and non-sentinel lymph nodes, level of axillary lymph node dissection, and number of patients with isolated tumor cells in their sentinel lymph node and with non-sentinel lymph node metastases. The AJCC classification of non-sentinel lymph node metastases, including isolated tumor cells (cell clusters with diameters of $\leq 0.2 \mathrm{~mm}$ ), micrometastases (tumor cell clusters $>0.2$ but $\leq 2 \mathrm{~mm}$ ), and macrometastases (tumor cell clusters $>2 \mathrm{~mm}$ ), was also recorded. In some instances, corresponding authors were contacted for additional information. 
We calculated $95 \%$ confidence intervals (Cls) for the risks of non-sentinel lymph node involvement within the studies by use of the Rothman spreadsheet ${ }^{15}$. A randomeffects meta-analysis with an exact likelihood approach was used to calculate pooled risk estimates of non-sentinel lymph node involvement and 95\% confidence intervals ${ }^{16}$. The extent to which one or more study characteristics explained betweenstudy heterogeneity was explored by use of metaregression analysis ${ }^{17}$. The following variables were considered: the number of levels of the sentinel lymph node or nonsentinel lymph nodes that were stained with haematoxylin-eosin and/or by immunohistochemistry. Systematic differences between small and large studies were assessed by use of a funnel $\operatorname{plot}^{18}$. Statistical analyses were performed with SAS version 9.1. All statistical tests were two-sided.

\section{Results}

The initial electronic search identified 411 potentially relevant articles of which we screened the title and abstract. After that screening, the full texts of 144 articles were obtained. After full text review and exclusion of overlapping series, 29 articles that met the inclusion and exclusion criteria for this study were identified and used for data extraction. The main characteristics and results of these studies are summarized in Table 1. These studies were heterogeneous regarding study design, size, inclusion criteria for sentinel lymph node biopsy examination, sentinel lymph node biopsy technique, and histopathological work-up. Overall, these 29 studies included 836 patients, of whom 108 had non-sentinel lymph node involvement.

Sentinel lymph nodes were usually identified by use of blue dye in combination with radioactive colloid that was injected peritumorally. The detection rate of non-sentinel lymph node metastases ranged from $0 \%$ through $27 \%$, with a pooled risk for nonsentinel lymph node metastases of $12.3 \%$ (95\% Cl, 9.5\% to $15.7 \%)$. Data on the size of non-sentinel lymph node metastases and whether such metastases were considered in the treatment of the patient were scarce. In 10 of the 17 studies with non-sentinel lymph node involvement, information was available on the type of metastases that was classified according to the sixth edition of the AJCC Cancer Staging Manual. The pooled risk of non-sentinel lymph node macrometastases, after a positive sentinel lymph node was found, in these studies was $63.5 \%$ (95\% Cl, $38.1 \%$ to $83.1 \%$ ). The funnel plot did not indicate systematic differences in the frequency of non-sentinel lymph node metastases between large studies and smaller studies (Figure 1). However, the range of non-sentinel lymph node metastases $(5 \%-19 \%)$ in larger studies (ie, those with $>30$ patients) was smaller than the range $(0 \%-27 \%)$ in smaller studies (ie, those with $<30$ patients). 


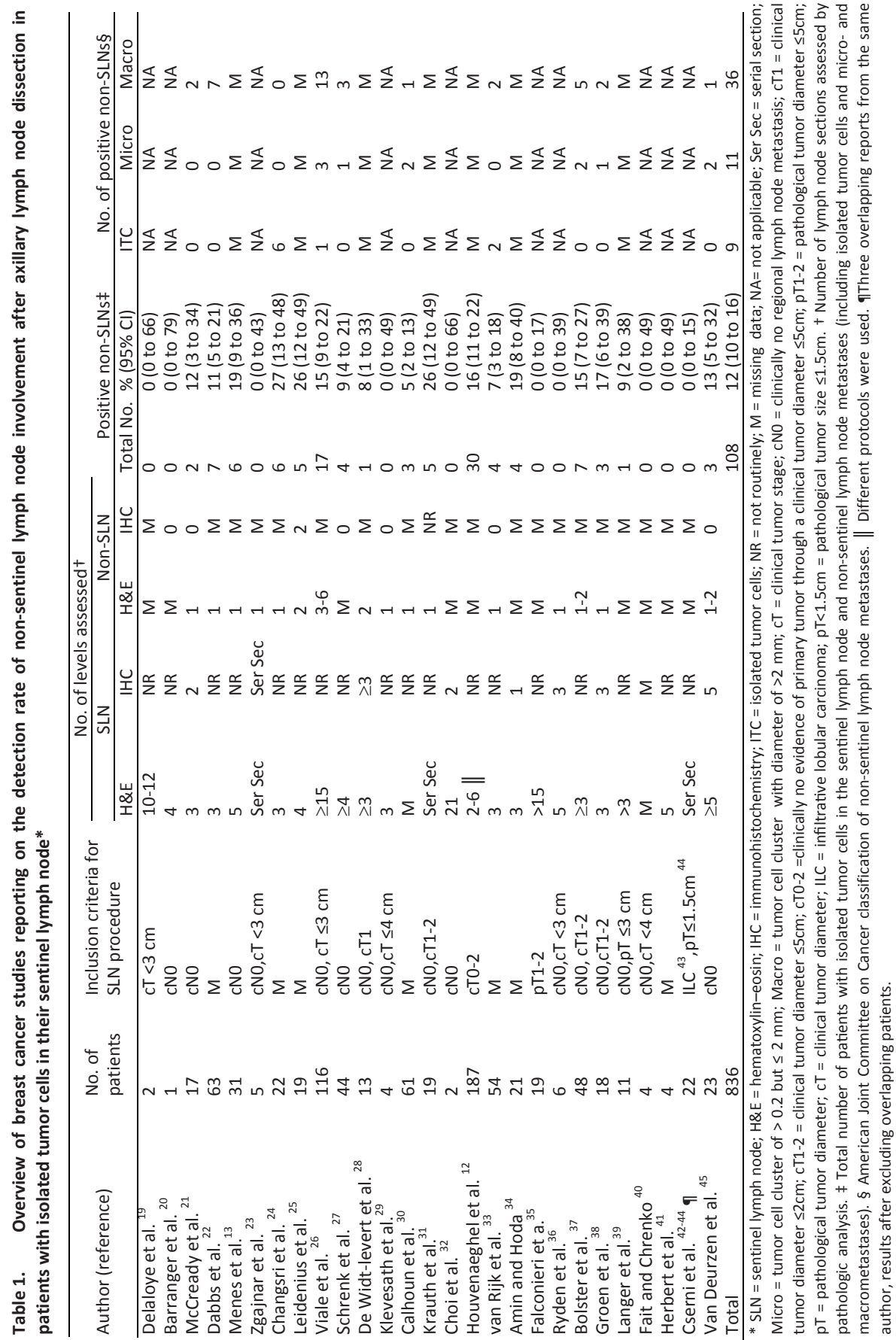




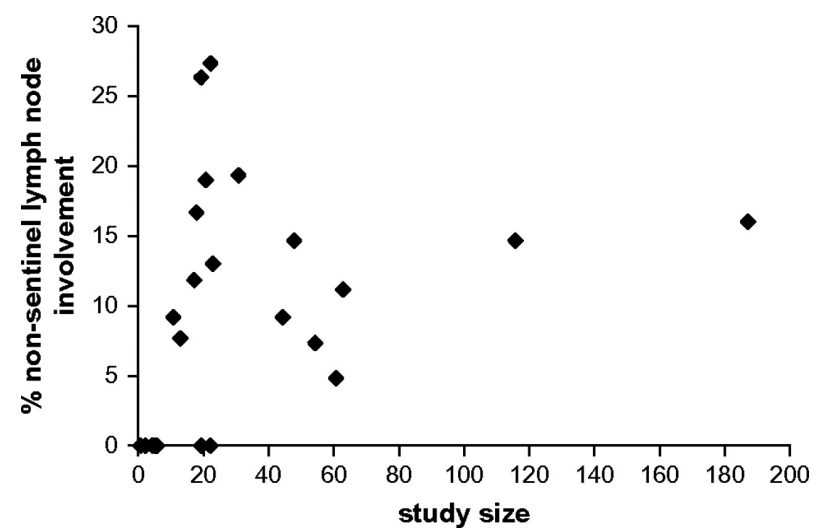

Figure 1. Funnel plot. The 29 studies on non-sentinel lymph node involvement associated with isolated breast cancer cells in the sentinel node were analyzed (see Table 1 for these studies). The study size (defined as the number of patients included with isolated tumor cells in the sentinel node and who also underwent axillary lymph node dissection) is plotted on the horizontal axis, and the percentage of these patients with non-sentinel lymph node metastases is plotted on the vertical axis. Each point represents a published study.

Metaregression analysis revealed that the number of assessed levels of the sentinel lymph node or non-sentinel lymph nodes stained with haematoxylin-eosin and/or immunohistochemistry (ie, defined as the number of lymph node sections assessed by pathological analysis) did not contribute substantially to between-study heterogeneity in non-sentinel lymph node involvement. Because the included articles did not further specify clinicopathologic features of patients with a sentinel lymph node containing isolated tumor cells, we could not formulate recommendations for the use of axillary lymph node dissection for patients with sentinel lymph node involvement.

\section{Discussion}

In this systematic literature review, we have summarized the available studies reporting on the risk of non-sentinel lymph node involvement after isolated tumor cells were found in the sentinel lymph node. The overall incidence of non-sentinel lymph node involvement ranged from $0 \%$ to $27 \%$. The pooled overall risk of nonsentinel lymph node involvement was $12.3 \%(95 \% \mathrm{Cl}, 9.5 \%$ to $15.7 \%)$, and $63.5 \%(95 \%$ $\mathrm{Cl}, 38.1 \%$ to $83.1 \%$ ) of non-sentinel lymph node metastases were macrometastases. This study had several limitations. First, the studies included in the analysis did not specify the clinicopathologic details of those patients with isolated tumor cells and non-sentinel lymph node involvement. Therefore, with the currently available data, 
we cannot generate recommendations for the use of an axillary lymph node dissection in subgroups of patients with isolated tumor cells in the sentinel lymph node. Second, many of the included studies in this analysis did not further classify non-sentinel lymph node metastases (ie, isolated tumor cells or micro- or macrometastases). Therefore, the risk calculation for macrometastases in the nonsentinel lymph node was based on a relatively small number of studies.

The large range of non-sentinel lymph node involvement may stem partially from differences in study design, inclusion criteria for a sentinel lymph node biopsy procedure in this study, sentinel lymph node biopsy technique, and/or the processing and interpretation of metastatic deposits. First, included studies may be limited, in part, by their retrospective design because not all patients with a sentinel lymph node containing isolated tumor cells may have undergone an axillary lymph node dissection. The subgroup of patients with a sentinel lymph node containing isolated tumor cells who underwent an axillary lymph node dissection may have been selected because they appeared to have more aggressive primary disease. Second, exclusion criteria for sentinel lymph node biopsy procedure differed by the largest included clinical tumor diameter (ie, 3 or $5 \mathrm{~cm}$ ). Third, the sentinel lymph node biopsy protocol differed by the type of substance injected (colloid and/or blue dye) and injection site (subdermal, peritumoral, or periareolar), although the influence of these variables was probably minimal. Fourth, the included studies used different protocols for sentinel lymph node and non-sentinel lymph node analyses, with a wide range in the number of slides, depth of section intervals, and use of immunohistochemistry. The detection rate of isolated tumor cells in the sentinel lymph node decreased with less extensive pathological work-up (ie, analysis of a low number of lymph node sections or a lack of routine use of immunohistochemistry) and some sentinel lymph nodes classified as having isolated tumor cells may, in fact, have had micrometastases at deeper levels; these variations would be expected to affect the risk and type of nonsentinel lymph node involvement observed. The risk of non-sentinel lymph node involvement was affected by the size of sentinel lymph node metastases; the larger the metastasis in the sentinel lymph node, the higher the risk of non-sentinel lymph node involvement. Because pathological sampling involves assessment of a fraction of the lymph node volume only, there may be discordance between the detected sentinel lymph node metastatic size and its true size. In this systematic review, however, the number of assessed levels (defined as the number of lymph node sections assessed by pathological analysis) of the sentinel lymph node and nonsentinel lymph nodes stained with haematoxylin-eosin and by use of immunohistochemistry could not explain the between-study heterogeneity. Nonsentinel lymph nodes are generally examined less extensively without the routine use of immunohistochemistry, and this practice may underestimate the actual risk of small non-sentinel lymph node metastases after isolated tumor cells are found in the sentinel lymph node. The use of immunohistochemistry in the work-up of nonsentinel lymph nodes increases the detection rate of (small) non-sentinel lymph node 
metastases ${ }^{46}$, so omitting immunohistochemistry for non-sentinel lymph nodes is likely to result in a relatively high percentage of non-sentinel lymph node macrometastases. However, Changsri et al. ${ }^{24}$ reported only on isolated tumor cells in non-sentinel lymph nodes, by examining a single section of the non-sentinel lymph node by haematoxylin-eosin only. In their study, all patients with isolated tumor cells in their sentinel lymph node also had isolated tumor cells in their non-sentinel lymph nodes. They concluded that additional metastases in non-sentinel lymph nodes of patients with isolated tumor cells in the sentinel lymph node should also be of a small size, which is in contrast with the results of this systematic review. Finally, the heterogeneity of the results of these studies could be due to various interpretations of the current definition of isolated tumor cells, which do not permit a reproducible distinction between micrometastases and isolated tumor cell ${ }^{47-49}$.

In, to our knowledge, the largest study of isolated tumor cells in the sentinel lymph node followed by axillary lymph node dissection $(n=187)$, Houvenaeghel et al. ${ }^{12}$ reported a $16 \%$ rate of non-sentinel lymph nodes involvement. This retrospective multicenter study reported no statistically significant difference in the risk of nonsentinel lymph node involvement between sentinel lymph nodes that contained isolated tumor cells (16\%) and those that contained micrometastases (14.3\%). However, they reported a $9.9 \%$ detection rate of non-sentinel lymph node involvement in a large group $(n=212)$ of sentinel lymph nodes containing micrometastases that had an unknown diameter (which also included isolated tumor cells). No mention was made as to whether additional non-sentinel lymph node metastases were associated with therapeutic decision making. They found that the only proposed subgroups of patients for whom axillary lymph node dissection could be avoided were patients with a small primary tumor (pT1a or pT1b) or with pT1 tubular, colloidal, or medullary tumors, with a risk for non-sentinel lymph node involvement of $5 \%$ or less. In the second largest study $(n=116)$, Viale et al. ${ }^{14}$ reported non-sentinel lymph node involvement in $15 \%$ of patients whose sentinel lymph node contained isolated tumor cells; this non-sentinel lymph node involvement was further classified as isolated tumor cells $(6 \%)$ or micrometastasis $(18 \%)$ or macrometastasis $(76 \%)$. They included clinically lymph node-negative patients with early breast cancer (breast tumor diameter of $\leq 3 \mathrm{~cm}$ ). The $6.7 \%$ difference in the detection rate of non-sentinel lymph node involvement between sentinel lymph nodes containing isolated tumor cells $(14.7 \%)$ and micrometastases $(21.4 \%)$ was not statistically significant. The identification of these non-sentinel lymph node metastases, which were mostly macrometastases, affected further systemic therapy in most patients whose sentinel lymph node contained isolated tumor cells or micrometastases. They concluded that the current categories, which were introduced by the sixth edition of the AJCC Cancer Staging Manual, cannot safely be adopted to tailor axillary surgical treatment for patients undergoing a sentinel lymph node biopsy procedure. A predictive model that was based on features associated with non-sentinel lymph node involvement could not identify a subgroup of patients with less than $13 \%$ non-sentinel lymph node 
involvement. From these results, Viale et al. recommended axillary lymph node dissection if there was any evidence of sentinel lymph node involvement in all settings except clinical trials. However, it must be emphasized that their assessment of the sentinel lymph node (by frozen sections and without routine immunohistochemistry) was likely to have decreased the detection rate of isolated tumor cells in the sentinel lymph node, which would, therefore, affect the detectable rate of non-sentinel lymph node involvement.

The decision of whether or not to proceed with an axillary lymph node dissection after finding isolated tumor cells in the sentinel lymph node was based on the risk of the procedure itself and on the risk and clinical significance of leaving residual disease in the axilla. The size of metastatic tumor material in the sentinel lymph node was one of the strongest predictors of non-sentinel lymph node involvement, although other characteristics (increased tumor size, more than one positive sentinel lymph node, and lymphovascular invasion in the primary tumor) also have statistically significant predictive value ${ }^{50}$. From the studies included in this systematic review, the pooled risk of non-sentinel lymph node involvement among patients whose sentinel lymph node contained isolated tumor cells was approximately $12.3 \%$, which is only marginally lower than the risk of non-sentinel lymph node involvement in patients with sentinel lymph node micrometastases (ie, approximately $20 \%$ ) $^{11,14,51}$ who are currently eligible for axillary lymph node dissection. It could therefore be argued that patients whose sentinel lymph node contained isolated tumor cells should also undergo an axillary lymph node dissection. However, this risk of non-sentinel lymph node involvement in patients with isolated tumor cells in the sentinel node is only marginally higher than the risk of a false-negative sentinel lymph node biopsy examination $(7 \%-8 \%)^{52,53}$, and we do not advocate axillary lymph node dissection for patients with sentinel lymph node-negative breast cancer. In addition, the clinical significance of residual axillary disease when axillary lymph node dissection is not performed is unclear. The risk of axillary recurrence if residual disease is present is probably low, and whether axillary lymph node dissection provides a survival benefit for sentinel lymph node-positive patients is not clear. Several studies ${ }^{54-56}$, although limited by size and follow-up time, reported a very low rate of axillary recurrence in patients with a positive sentinel lymph node who did not undergo axillary lymph node dissection. This result may be due to selection of low-risk patients, limited outgrowth potential of residual tumor, or the effects of local radiotherapy. Furthermore, most breast cancer patients receive adjuvant systemic therapy when their primary tumor has unfavorable characteristics, and such therapy may also eradicate residual lymph node metastases. With regard to local control, a wait-and-see policy may therefore be acceptable when the sentinel lymph node contains isolated tumor cells. However, a substantial proportion (approximately 64\%) of non-sentinel lymph node metastases identified in patients with sentinel lymph nodes containing isolated tumor cells are macro-metastases, which require adjuvant systemic therapy. Failure to detect these non-sentinel lymph node macrometastases by omitting axillary lymph node dissection could thus result in 
undertreatment of those patients whose sentinel lymph node contains isolated tumor cells but whose primary tumor characteristics do not indicate the need for adjuvant therapy.

In conclusion, results on isolated tumor cells in the sentinel lymph node are somewhat controversial, and there is still doubt about the need for axillary lymph node dissection after finding isolated tumor cells in the sentinel lymph node. A wait-and-see policy is probably acceptable for most patients whose sentinel lymph node contains isolated tumor cells. However, for patients with a sentinel lymph node that contains isolated tumor cells, axillary lymph node dissection could be used if the indication for adjuvant systemic therapy is influenced by finding macrometastases on full lymph node staging. In this respect, the risk of non-sentinel lymph node involvement also depends on other risk factors (ie, primary tumor size and the presence of lymphovascular invasion). Molecular profiling of metastatic deposits, which could be distinct from the primary tumor ${ }^{57}$, could be used to further select patients who might benefit from axillary lymph node dissection. Findings from large ongoing clinical trials, such as the International Breast Cancer Study Group 2301 trial, which has randomly assigned sentinel lymph node-positive patients to axillary lymph node dissection or surveillance, may provide greater clinical evidence regarding policies on axillary lymph node dissection after the identification of a positive sentinel lymph node. 


\section{References}

1. Fisher ER, Anderson S, Redmond C, Fisher B. Pathologic findings from the National Surgical Adjuvant Breast Project protocol B-06: 10-year pathologic and clinical prognostic discriminants. Cancer 1993;71:2507-2514.

2. Veronesi U, Paganelli G, Viale G, et al. A randomized comparison of sentinel-node biopsy with routine axillary dissection in breast cancer. N Engl J Med 2003;349:546-553.

3. van der Heiden-van der Loo M, Bezemer PD, Hennipman A, et al. Introduction of sentinel node biopsy and stage migration of breast cancer. Eur J Surg Oncol 2006;32:710-714.

4. Cserni G, Amendoeira I, Apostolikas N, et al; European Working Group for Breast Screening Pathology. Pathological work-up of sentinel lymph nodes in breast cancer. Review of current data to be considered for the formulation of guidelines. Eur J Cancer 2003;39:1654-1667.

5. Singletary SE, Greene FL. Revision of breast cancer staging: the 6th edition of the TNM Classification. Semin Surg Oncol 2003;21:53-59.

6. Singletary SE, Greene FL, Sobin LH. Classification of isolated tumor cells: clarification of the 6th edition of the American Joint Committee on Cancer Staging Manual. Cancer 2003;98:2740-1.

7. Singletary SE, Allred C, Ashley $\mathrm{P}$, et al. Revision of the American Joint Committee on Cancer staging system for breast cancer. J Clin Oncol 2002;20:3628-3636.

8. van Iterson V, Leidenius M, Krogerus L, von Smitten K. Predictive factors for the status of non-sentinel nodes in breast cancer patients with tumor positive sentinel nodes. Breast Cancer Res Treat 2003;82:39-45.

9. Nos C, Harding-MacKean C, Fréneaux P, et al. Prediction of tumor involvement in remaining axillary lymph nodes when the sentinel node in a woman with breast cancer contains metastases. Br J Surg 2003;90:1354-1360.

10. Yu JC, Hsu GC, Hsieh CB, Sheu LF, Chao TY. Prediction of metastasis to non-sentinel nodes by sentinel node status and primary tumor characteristics in primary breast cancer in Taiwan. World J Surg 2005;29:813-818.

11. Cserni G, Gregori D, Merletti F, et al. Meta-analysis of non-sentinel node metastases associated with micrometastatic sentinel nodes in breast cancer. Br J Surg 2004;91:1245-1252.

12. Houvenaeghel G, Nos C, Mignotte H, et al; Groupe des Chirurgiens de la Federation des Centres de Lutte Contre le Cancer. Micrometastases in sentinel lymph node in a multicentric study: predictive factors of nonsentinel lymph node involvement - Groupe des Chirurgiens de la Federation des Centres de Lutte Contre le Cancer. J Clin Oncol 2006;24:1814-1822.

13. Menes TS, Tartter PI, Mizrachi H, Constantino J, Estabrook A, Smith SR. Breast cancer patients with $\mathrm{pNO}(\mathrm{i}+)$ and $\mathrm{pN} 1(\mathrm{mi})$ sentinel nodes have high rate of nonsentinel node metastases. J Am Coll Surg 2005;200:323-327

14. Viale G, Maiorano E, Pruneri G, et al. Predicting the risk for additional axillary metastases in patients with breast carcinoma and positive sentinel lymph node biopsy. Ann Surg 2005;241:319-325.

15. Rothman KJ. Epidemiology. An Introduction. New York:Oxford University Press;2002 .

16. Hamza TH, van Houwelingen HC, Stijnen T. The binomial distribution of meta-analysis was preferred to model within-study variability. J Clin Epidemiol 2008;61:41-51.

17. Greenland S. Quantitative methods in the review of epidemiologic literature. Epidemiol Rev 1987;9: $1-30$.

18. Sterne JAC, Egger M, Davey Smith G. Investigating and dealing with publication and other biases. In: Egger M, Davey Smith G, Altman DG, eds. Systematic Reviews in Health Care. Meta-analysis in Context. London:BMJ Publishing Group;2001:189-208

19. Delaloye JF, Monod JF, Friedli A, et al. Un reseau pour la recherche du ganglion sentinelle du cancer du sein. [Network for sentinel lymph node research in breast cancer] Rev Med Suisse Romande 2003;123:299-302.

20. Barranger E, Grahek D, Antoine M, Montravers F, Talbot JN, Uzan S. Evaluation of fluorodeoxyglucose positron emission tomography in the detection of axillary lymph node metastases in patients with early-stage breast cancer. Ann Surg Oncol 2003;10:622-627. 
21. McCready DR, Yong WS, Ng AK, Miller N, Done S, Youngson B. Influence of the new AJCC breast cancer staging system on sentinel lymph node positivity and false-negative rates. J Natl Cancer Inst 2004;96:873-875.

22. Dabbs DJ, Fung M, Landsittel D, McManus K, Johnson R. Sentinel lymph node micrometastasis as a predictor of axillary tumor burden. Breast J 2004;10:101-105.

23. Zgajnar J, Besic N, Podkrajsek M, Hertl K, Frkovic-Grazio S, Hocevar M. Minimal risk of macrometastases in the non-sentinel axillary lymph nodes in breast cancer patients with micrometastatic sentinel lymph nodes and preoperatively ultrasonically uninvolved axillary lymph nodes. Eur J Cancer 2005;41:244-248.

24. Changsri C, Prakash S, Sandweiss L, Bosew S. Prediction of additional axillary metastasis of breast cancer following sentinel lymph node surgery. Breast J 2004;10:392-397.

25. Leidenius $\mathrm{MH}$, Vironen JH, Riihelä MS, et al. The prevalence of non-sentinel node metastases in breast cancer patients with sentinel node micrometastases. Eur J Surg Oncol 2005;31:13-18.

26. Viale G, Maiorano E, Pruneri G, et al. Predicting the risk for additional axillary metastases in patients with breast carcinoma and positive sentinel lymph node biopsy. Ann Surg 2005;241:319-325.

27. Schrenk $P$, Konstantiniuk $P$, Wölfl $S$, et al. Prediction of non-sentinel lymph node status in breast cancer with a micrometastatic sentinel node. Br J Surg 2005;92:707-713.

28. de Widt-Levert L, Tjan-Heijnen V, Bult P, Ruers T, Wobbes T. Stage migration in breast cancer: surgical decisions concerning isolated tumour cells and micro-metastases in the sentinel lymph node. Eur J Surg Oncol 2003;29:216-220.

29. Klevesath MB, Bobrow LG, Pinder SE, Purushotham AD. The value of immunohistochemistry in sentinel lymph node histopathology in breast cancer. Br J Cancer 2005;92:2201-2205.

30. Calhoun KE, Hansen NM, Turner RR, Giuliano AE. Nonsentinel node metastases in breast cancer patients with isolated tumor cells in the sentinel node: implications for completion axillary node dissection. Am J Surg 2005;190:588-591.

31. Krauth JS, Charitansky H, Isaac S, Bobin JY. Clinical implications of axillary sentinel lymph node 'micrometastases' in breast cancer. Eur J Surg Oncol 2006;32:400-404.

32. Choi YJ, Yun HR, Yoo KE, et al. Intraoperative examination of sentinel lymph nodes by ultrarapid immunohistochemistry in breast cancer. Jpn J Clin Oncol 2006;36:489-493.

33. van Rijk MC, Peterse JL, Nieweg OE, Oldenburg HS, Rutgers EJ, Kroon BB. Additional axillary metastases and stage migration in breast cancer patients with micrometastases or submicrometastases in sentinel lymph nodes. Cancer 2006;107:467-471.

34. Amin BD, Hoda SA. Minimal metastatic disease in sentinel lymph nodes in breast carcinoma: some modest proposals to refine criteria for "isolated tumor cells. Adv Anat Pathol 2006;13:185-189.

35. Falconieri G, Pizzolitto S, Gentile G. Comprehensive examination of sentinel lymph node in breast cancer: a solution without a problem? Int J Surg Pathol 2006;14:1-8.

36. Rydén L, Chebil G, Sjöström L, Pawlowski R, Jönsson PE. Determination of sentinel lymph node (SLN) status in primary breast cancer by prospective use of immunohistochemistry increases the rate of micrometastases and isolated tumor cells: analysis of 174 patients after SLN biopsy. Eur J Surg Oncol 2007;33:33-38

37. Bolster MJ, Peer PG, Bult $P$, et al. Risk factors for non-sentinel lymph node metastases in patients with breast cancer. The outcome of a multi-institutional study. Ann Surg Oncol 2007;14:181-189.

38. Groen RS, Oosterhuis AW, Boers JE. Pathologic examination of sentinel lymph nodes in breast cancer by a single haematoxylin-eosin slide versus serial sectioning and immunocytokeratin staining: clinical implications. Breast Cancer Res Treat 2007;105:1-5.

39. Langer I, Guller U, Berclaz G, et al. Morbidity of sentinel lymph node biopsy (SLN) alone versus SLN and completion axillary lymph node dissection after breast cancer surgery: a prospective Swiss multicenter study on 659 patients. Ann Surg 2007;245:452-461.

40. Fait V, Chrenko V. Sentinel node biopsy in breast cancer: short time results show appropriate regional control. Neoplasma 2007;54:256-261.

41. Herbert GS, Sohn VY, Brown TA. The impact of nodal isolated tumor cells on survival of breast cancer patients. Am J Surg 2007;193:571-573.

42. Cserni G, Burzykowski T, Vinh-Hung V, et al. Axillary sentinel node and tumor-related factors associated with non-sentinel node involvement in breast cancer. Jpn J Clin Oncol 2004;34:519-524. 
43. Cserni G, Bianchi S, Vezzosi V, et al. The value of cytokeratin immunohistochemistry in the evaluation of axillary sentinel lymph nodes in patients with lobular breast carcinoma. J Clin Pathol 2006;59: 518-522.

44. Cserni G, Bianchi S, Vezzosi V, et al. Sentinel lymph node biopsy in staging small (up to $15 \mathrm{~mm}$ ) breast carcinomas. Results from a European multi-institutional study. Pathol Oncol Res 2007;13:5-14.

45. van Deurzen $\mathrm{CH}$, van Hillegersberg $\mathrm{R}$, Hobbelink MG, Seldenrijk CA, Koelemij R, van Diest PJ. Predictive value of tumor load in breast cancer sentinel lymph nodes for second echelon lymph node metastases. Cell Oncol 2007;29:497-505.

46. Chu KU, Turner RR, Hansen NM, Brennan MB, Giuliano AE. Sentinel node metastasis in patients with breast carcinoma accurately predicts immunohistochemically detectable nonsentinel node metastasis. Ann Surg Oncol 1999;6:756-761.

47. Cserni G, Bianchi S, Boecker W, et al; European Working Group for Breast Screening Pathology. Improving the reproducibility of diagnosing micrometastases and isolated tumor cells. Cancer 2005;103:358-367.

48. Turner RR, Weaver DL, Cserni G, et al. Nodal stage classifi cation for breast carcinoma: improving interobserver reproducibility through standardized histologic criteria and image-based training. J Clin Oncol 2008;26:258-263.

49. Cserni G, Amendoeira I, Apostolikas N, et al. Discrepancies in current practice of pathological evaluation of sentinel lymph nodes in breast cancer. Results of a questionnaire based survey by the European Working Group for Breast Screening Pathology. J Clin Pathol 2004;57:695-701.

50. Degnim AC, Griffith KA, Sabel MS, et al. Clinicopathologic features of metastasis in nonsentinel lymph nodes of breast carcinoma patients. Cancer 2003;98:2307-2315.

51. Wada N, Imoto S. Clinical evidence of breast cancer micrometastasis in the era of sentinel node biopsy. Int J Clin Oncol 2008;13:24-32.

52. Lyman GH, Giuliano AE, Somerfield MR, et al; American Society of Clinical Oncology. American Society of Clinical Oncology guideline recommendations for sentinel lymph node biopsy in early-stage breast cancer. J Clin Oncol 2005;23:7703-7720.

53. Goyal A, Newcombe RG, Chhabra A, Mansel RE; ALMANAC Trialists Group. on behalf of the ALMANAC-Trialists-Group. Factors affecting failed localisation and false-negative rates of sentinel node biopsy in breast cancer-results of the ALMANAC validation phase. Breast Cancer Res Treat 2006;99:203-208.

54. Guenther JM, Hansen NM, DiFronzo LA, et al. Axillary dissection is not required for all patients with breast cancer and positive sentinel nodes. Arch Surg 2003;138:52-56.

55. Langer I, Marti WR, Guller U, et al. Axillary recurrence rate in breast cancer patients with negative sentinel lymph node (SLN) or SLN micro-metastases: prospective analysis of 150 patients after SLN biopsy. Ann Surg 2005;241:152-158.

56. Hwang RF, Gonzalez-Angulo AM, Yi M, et al. Low locoregional failure rates in selected breast cancer patients with tumor-positive sentinel lymph nodes who do not undergo completion axillary dissection. Cancer 2007;110:723-730.

57. Vecchi $\mathrm{M}$, Confalonieri $\mathrm{S}$, Nuciforo $\mathrm{P}$, et al. Breast cancer metastases are molecularly distinct from their primary tumors. Oncogene 2008;15:2148-2158. 


\section{Chapter 8}

Regional recurrence in breast cancer patients with sentinel node micrometastases and isolated tumor cells

Manon J. Pepels, Maaike de Boer, Peter Bult, Jos A.A.M. van Dijck,

Carolien H.M. van Deurzen, Marian B.E. Menke-Pluymers, Paul J. van Diest, George F. Borm, Vivianne C.G. Tjan-Heijnen

Ann Surg 2012;255:116-121 
120 Chapter 8

\section{Abstract}

\section{Objective}

The impact of axillary treatment in daily practice on 5-year regional recurrence rate in breast cancer patients with isolated tumor cells or micrometastases in the sentinel node.

\section{Background}

Axillary dissection is recommended in patients with tumor-positive sentinel nodes. But, in recent studies, regional recurrence rates seemed low if dissection was omitted.

\section{Methods}

We identified all patients in the Netherlands with invasive breast cancer who had a sentinel node biopsy before 2006, favorable primary tumor characteristics, and node-negative disease, isolated tumor cells or micrometastases as final nodal status. The primary endpoint was regional recurrence rate. To investigate differences in recurrence rates between patients with and without axillary treatment, a proportional hazard regression was carried out correcting for potential confounders.

\section{Results}

In total, 857 patients with node-negative disease, 795 patients with isolated tumor cells, and 1028 patients with micrometastases in the sentinel node were included. Without axillary treatment, the 5-year regional recurrence rates were $2.3 \%, 2.0 \%$ and $5.6 \%$, respectively. Compared with patients who underwent axillary treatment, the adjusted hazard ratio for regional recurrence in patients who underwent a sentinel node procedure only was $1.08(95 \%$ $\mathrm{Cl}, 0.23$ to 4.98 ) for node-negative disease, 2.39 (95\% Cl 0.67 to 8.48 ) for isolated tumor cells, and $4.39(95 \% \mathrm{Cl}, 1.46$ to 13.24) for micrometastases. Doubling of tumor size, grade 3 and negative hormone receptor status were also significantly associated with recurrence.

\section{Conclusion}

Not performing axillary treatment in patients with sentinel node micrometastases is associated with an increased 5-year regional recurrence rate. Axillary treatment is recommended in patients with sentinel node micrometastases and unfavorable tumor characteristics. 


\section{Introduction}

The axillary lymph node status is the most important prognostic factor in patients with breast cancer ${ }^{1}$. Since the late 1990s, the sentinel lymph node procedure was introduced in clinically node negative early breast cancer. The sentinel node is the first lymph node or nodes draining the primary tumor site. If the sentinel node is negative, the probability of additional involved non-sentinel nodes is assumed to be 5 to $10 \%$, and the remaining axillary nodes do not need to be explored ${ }^{2}$. To prevent falsenegative results, the sentinel node is intensively examined with the use of step sectioning and/or immunohistochemical staining, with an increased detection rate of small nodal metastases. Since 2002, isolated tumor cells (pNO(i+), deposits $\leq 0.2 \mathrm{~mm}$ ) and micrometastases ( $\mathrm{pN} 1 \mathrm{mi}$, deposits $>0.2-\leq 2 \mathrm{~mm}$ ) are defined as separate categories in the American Joint Committee on Cancer (AJCC) Cancer Staging Manual ${ }^{3}$. One pivotal question, to justify the intensified work-up of the sentinel node, is whether these small nodal metastases are of prognostic relevance. A recent systematic review on studies from the pre-sentinel node era showed that the presence of metastases $2 \mathrm{~mm}$ or less in diameter in axillary lymph nodes was associated with poorer overall survival ${ }^{4}$. In addition, we demonstrated in the Dutch MIRROR (Micrometastases and Isolated tumor cells: Relevant and Robust or Rubbish?) cohort study that isolated tumor cells and micrometastases detected after a sentinel node procedure were also of significant prognostic relevance in patients not receiving adjuvant systemic therapy ${ }^{5}$. Furthermore, we showed that prognosis was improved in patients who received adjuvant systemic therapy.

A second relevant question is whether the detection of sentinel node isolated tumor cells or micrometastases warrants further axillary treatment. All patients in the MIRROR study underwent a sentinel node biopsy, in some followed by a completion axillary lymph node dissection or axillary irradiation. Nearly $50 \%$ of patients with isolated tumor cells in the sentinel nodes and approximately $15 \%$ of patients with micrometastases had not received additional axillary treatment. In $8 \%$ of patients with isolated tumor cells or micrometastases, axillary treatment consisted of axillary irradiation only.

The primary goal of the current analysis of the MIRROR cohort study was to determine the impact of axillary treatment (axillary lymph node dissection or axillary irradiation) on 5-year regional recurrence rate in patients with isolated tumor cells or micrometastases in the sentinel node. Secondary aims were to determine the efficacy of axillary irradiation compared to axillary lymph node dissection, and to examine other factors predictive for regional recurrence. 


\section{Methods}

\section{Patients}

Patient characteristics were largely described previously ${ }^{5}$. In summary, we identified all female patients who underwent surgery for early-stage breast cancer, irrespective of type of histology, and who had undergone a sentinel node biopsy between 1997 and 2005 from the Netherlands Cancer Registry. We included patients with favorable primary tumor characteristics according to the Dutch guidelines, version 2002, that is, tumor size of $1 \mathrm{~cm}$ or smaller, irrespective of grade, or tumor size 1-3 cm and grade 1 or $2^{6}$. Of these, we selected patients with isolated tumor cells or micrometastases as final nodal status after sentinel node biopsy and optionally additional axillary treatment (dissection or irradiation). All patients with sentinel node or non-sentinel node macrometastases were excluded. Furthermore, we randomly selected a control group of patients with node-negative disease who underwent a sentinel node procedure in the year 2000 or 2001. All 113 Dutch hospitals and 60 pathology laboratories participated in the study (see Table S1 of the Supplementary appendix). The Review Board of the Netherlands Cancer Registry approved this study.

\section{Data collection}

Registration clerks of all $(n=8)$ comprehensive cancer centers in the Netherlands collected data with respect to patient and tumor characteristics, breast surgery, sentinel node procedure, axillary lymph node dissection, axillary irradiation, adjuvant systemic therapy, and regional recurrences during follow-up.

\section{Pathology Review}

Three pathologists who are specialized in breast pathology (C.H.M. van Deurzen, P.J. van Diest, and P. Bult) reviewed all available original slides of the sentinel nodes and positive non-sentinel nodes. These slides included haematoxylin-eosin stained slides, slides stained for immunohistochemistry, and frozen sections. Neither additional sections nor new immunohistochemical stains were performed. Grade of the primary tumor was assessed, if not available from the original pathology report.

As previously reported, almost all participating pathology laboratories used a protocol in which the sentinel node was step-sectioned at least at every $150 \mu \mathrm{m}$ and at a minimum of three levels, using keratin immunohistochemical staining if the haematoxylin-eosin stain was negative. In contrast, the non-sentinel nodes were macroscopically sectioned every 2-5 mm, with one haematoxylin-eosin stained section per slice ${ }^{5}$. Tumor deposits were classified according to the sixth AJCC Cancer Staging Manual ${ }^{3}$. 
Table 1. Baseline characteristics of $\mathbf{2 6 8 0}$ patients with early stage breast cancer according to axillary lymph node status

\begin{tabular}{|c|c|c|c|c|c|c|}
\hline \multirow[b]{2}{*}{ Characteristic } & \multicolumn{2}{|c|}{$\mathrm{NO}(\mathrm{i}-)(\mathrm{sn})$} & \multicolumn{2}{|c|}{$\mathrm{NO}(\mathrm{i}+)(\mathrm{sn})$} & \multicolumn{2}{|c|}{$\mathrm{N} 1(\mathrm{mi})(\mathrm{sn})$} \\
\hline & $\begin{array}{c}\text { No axillary } \\
\text { treatment } \\
(n=732)\end{array}$ & $\begin{array}{c}\text { Axillary } \\
\text { treatment } \\
(n=125)\end{array}$ & $\begin{array}{c}\text { No axillary } \\
\text { treatment } \\
(n=345)\end{array}$ & $\begin{array}{c}\text { Axillary } \\
\text { treatment } \\
(n=450)\end{array}$ & $\begin{array}{c}\text { No axillary } \\
\text { treatment } \\
(n=141)\end{array}$ & $\begin{array}{c}\text { Axillary } \\
\text { treatment } \\
(\mathrm{n}=887)\end{array}$ \\
\hline \multicolumn{7}{|c|}{$\begin{array}{l}\text { No. of sentinel lymph nodes } \\
\text { removed }\end{array}$} \\
\hline median & 2 & 1 & 2 & 2 & 2 & 2 \\
\hline interquartile range & 1,2 & 1,2 & 1,3 & 1,2 & 1,3 & 1,3 \\
\hline \multicolumn{7}{|l|}{ Age at diagnosis - year } \\
\hline median & 59 & 61 & 58 & 57 & 59 & 56 \\
\hline range & $30-89$ & $34-87$ & $34-93$ & $31-89$ & $36-88$ & $32-89$ \\
\hline \multicolumn{7}{|l|}{ Tumor size-no. (\%) } \\
\hline$\leq 1 \mathrm{~cm}$ & $310(42)$ & $37(30)$ & $91(27)$ & $125(28)$ & $34(24)$ & $197(22)$ \\
\hline$>1$ to $\leq 2 \mathrm{~cm}$ & $375(51)$ & $73(58)$ & $201(58)$ & $239(53)$ & $80(57)$ & $539(61)$ \\
\hline$>2$ to $\leq 3 \mathrm{~cm}$ & $47(7)$ & $15(12)$ & $53(15)$ & $86(19)$ & 27 (19) & $151(17)$ \\
\hline \multicolumn{7}{|l|}{ Tumor grade-no. (\%) } \\
\hline 1 & $264(37)$ & $54(44)$ & $117(35)$ & $137(31)$ & $41(30)$ & $287(33)$ \\
\hline 2 & $408(57)$ & $66(53)$ & $211(62)$ & $283(64)$ & $93(67)$ & $543(62)$ \\
\hline 3 & $45(6)$ & $4(3)$ & $11(3)$ & $22(5)$ & $5(3)$ & $45(5)$ \\
\hline \multicolumn{7}{|c|}{$\begin{array}{l}\text { Hormone receptor status- } \\
\text { no. }(\%)\end{array}$} \\
\hline negative & $42(6)$ & $9(8)$ & $22(7)$ & $33(7)$ & $11(8)$ & $41(5)$ \\
\hline positive & $661(94)$ & $100(92)$ & $311(93)$ & 407 (93) & $130(92)$ & $834(95)$ \\
\hline \multicolumn{7}{|l|}{$\begin{array}{l}\text { Type of breast surgery- } \\
\text { no. (\%) }\end{array}$} \\
\hline mastectomy & $167(23)$ & $57(46)$ & $109(32)$ & $140(31)$ & $40(28)$ & $267(30)$ \\
\hline breast conserving & $565(77)$ & $68(54$ & $236(68)$ & 310 (69) & $101(72)$ & $620(70)$ \\
\hline \multicolumn{7}{|l|}{$\begin{array}{l}\text { Radiation of the breast- } \\
\text { no. (\%) }\end{array}$} \\
\hline no & $185(25)$ & $59(47)$ & $118(34)$ & $136(30)$ & $48(34)$ & $270(30)$ \\
\hline yes & $547(75)$ & $66(53)$ & $227(66)$ & $314(70)$ & $93(66$ & $617(70)$ \\
\hline \multicolumn{7}{|c|}{$\begin{array}{l}\text { Adjuvant systemic therapy- } \\
\text { no (\%) }\end{array}$} \\
\hline no systemic therapy & $732(100)$ & $125(100)$ & $260(75)$ & $239(53)$ & $73(52)$ & $283(32)$ \\
\hline chemotherapy & $0(0)$ & $0(0)$ & $4(1)$ & $14(3)$ & $3(2)$ & $32(3)$ \\
\hline hormonal therapy & $0(0)$ & $0(0)$ & $67(20)$ & $143(32)$ & $53(38)$ & 349 (39) \\
\hline both & $0(0)$ & $0(0)$ & $14(4)$ & $54(12)$ & $12(8)$ & $223(25)$ \\
\hline
\end{tabular}

\section{Cohorts}

For this present analysis, patients were categorized by their sentinel node status and by axillary treatment. We identified three cohorts. Cohort I consisted of patients with node-negative disease; cohort II consisted of patients with sentinel node isolated tumor cells; and cohort III consisted of patients with sentinel node micrometastases. All cohorts were divided into two subgroups consisting of patients with no axillary treatment, or axillary treatment consisting of axillary lymph node dissection or axillary irradiation. The choice of axillary treatment was at the discretion of the physician and the patient at that time. 


\section{Endpoints}

To determine whether an association existed between lymph node status, axillary treatment, and regional recurrence, we compared the regional recurrence rate for each cohort in the subgroups with and without axillary treatment. The primary endpoint was the 5-year regional recurrence rate, involving axilla and infra- and supraclavicular sites. The time to regional recurrence was defined as the interval from the date of diagnosis to regional recurrence. If a patient had a local recurrence or a contralateral breast cancer (before a regional recurrence), the follow-up continued to assess the time of the first regional recurrence. That is, regional recurrence was not always a first event for the patient. If the patient had a combined local and regional recurrence, the primary endpoint was reached, as was also the case if a combined distant and regional recurrence was diagnosed. Also, if a regional recurrence was unexpectedly detected at surgery of a local recurrence, this was coded as a regional recurrence. Secondary aims were to determine the efficacy of axillary irradiation compared to completion axillary lymph node dissection with regard to regional recurrence rate and to examine other patient, tumor, and treatment-related factors predictive for regional recurrence.

\section{Statistical analysis}

To assess the primary and secondary goals, we used Cox proportional-hazards regression to evaluate the differences in occurrence of regional recurrences between axillary treated and untreated patients, adjusted for known prognostic clinical and pathological variables. These included age at diagnosis, histological grade, hormone receptor status, adjuvant systemic therapy breast irradiation and $\log _{2}$ tumor size. We used a $\log _{2}$ transformation, because the corresponding coefficient in the Cox model will then correspond to the hazard ratio associated with a doubling of the tumor size, which makes the interpretation of the hazard ratio easier. In an additional analysis, we included date of biopsy in the model to investigate a possible change in recurrence rate over the 1997-2005 period. Two-sided 95\% confidence intervals (Cls) were calculated.

\section{Results}

\section{Patients}

We identified 2707 women with early-stage breast cancer who were potentially eligible. For the present study, we excluded 27 patients $(0.08 \%)$ who received both axillary lymph node dissection and axillary irradiation, leaving 2680 women for analyses: 857 patients with node-negative disease, 795 patients with isolated tumor cells, and 1028 patients with micrometastases in the sentinel node. Of patients with a 
negative sentinel node, 732 patients (85\%) received no axillary therapy; the remaining 125 patients (15\%) underwent an axillary lymph node dissection during the sentinel node learning phase of a surgeon. Of patients with isolated tumor cells in the sentinel node, 345 patients $(43 \%)$ received no additional axillary therapy, 396 patients $(50 \%)$ underwent axillary lymph node dissection, and 54 patients $(7 \%)$ received axillary irradiation. Of patients with micrometastases in the sentinel node, 141 patients (14\%) received no further axillary therapy, 793 patients (77\%) underwent axillary lymph node dissection, and 94 patients $(9 \%)$ received axillary irradiation.

Table 1 shows the baseline characteristics of the three nodal status cohorts. In the node-negative cohort, compared to the patient group without additional axillary treatment, patients with axillary treatment had significantly larger primary tumor size, had more frequently undergone mastectomy instead of breast conserving therapy, and had less frequently undergone irradiation of the breast. In both the sentinel node isolated tumor cells cohort and the sentinel node micrometastases cohort, compared to the patients without additional axillary treatment, patients with axillary treatment more frequently received adjuvant systemic therapy.

The median duration of follow-up was 5.1 years (range, 0.04 to 9.3). Ninety-five (3.5\%) patients were lost to follow-up 0.04 to 5.6 years after diagnosis. At the last date of follow-up $97.5 \%$ were free of regional recurrence. Regional recurrence was in $91 \%$ of patients the first recurrence, and in $52 \%$ of patients the only presenting recurrence.

\section{No axillary treatment vs. axillary treatment in patients with negative sentinel nodes}

In patients with negative sentinel nodes, the 5-year regional recurrence rate was $2.3 \%$ in patients without axillary treatment, and $1.6 \%$ in patients with axillary treatment (Figure 1A). After adjustment for age, tumor size, histological grade, hormone receptor status, adjuvant systemic therapy and irradiation of the breast, there was no difference in risk of regional recurrence in the no axillary treatment group versus the axillary treatment group (hazard ratio 1.08; $95 \%$ confidence interval (CI), 0.23 to 4.98 ) (Table 2).

\section{No axillary treatment vs. axillary treatment for sentinel node isolated tumor cells}

In patients with isolated tumor cells in the sentinel node, the 5-year regional recurrence rate was $2.0 \%$ in patients without axillary treatment, and $0.9 \%$ in patients with axillary treatment (Figure 1B). The adjusted hazard ratio for regional recurrence among women who did not receive further axillary treatment was $2.39(95 \% \mathrm{Cl}, 0.67$ to 8.48) (Table 2) as compared to women who did receive axillary treatment. 


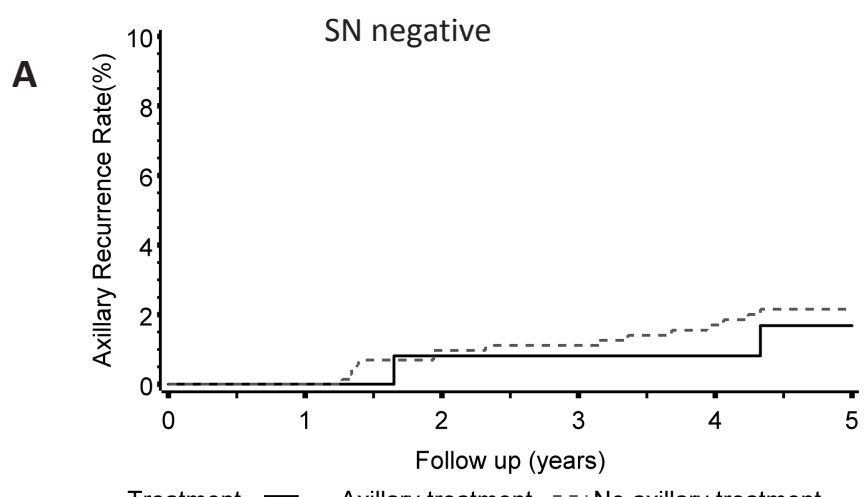

Treatment - Axillary treatment - No axillary treatment

$\mathrm{SN}$ isolated tumor cells

B

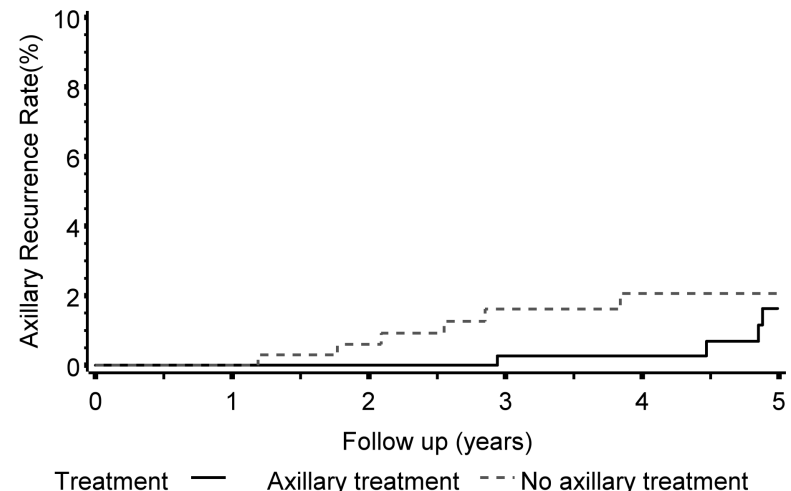

$\mathrm{SN}$ micrometastases

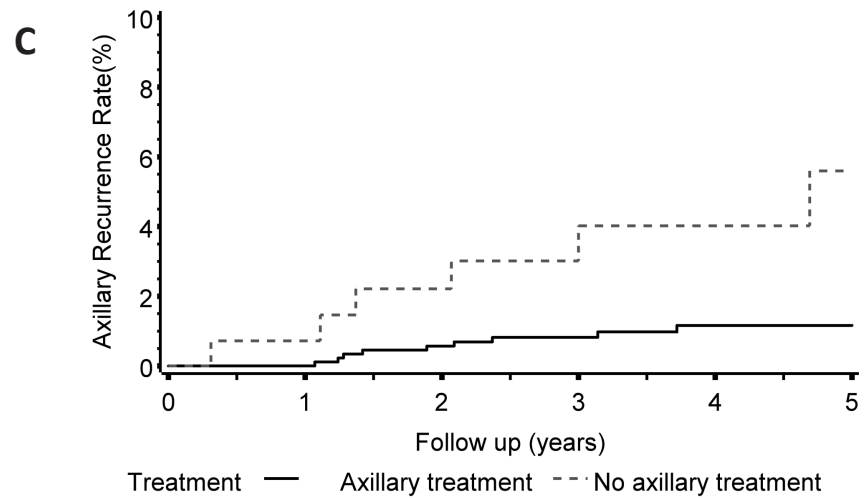

Figure 1. Axillary recurrence rates among patients with early breast cancer with node-negative disease (Panel A), with sentinel node (SN) isolated tumor cells (Panel B), and with sentinel node micrometastases (Panel C), who did or did not receive axillary treatment. 
No axillary treatment vs. axillary treatment for sentinel node micrometastases

In patients with micrometastases in the sentinel node, the 5-year regional recurrence rate was $5.6 \%$ if no axillary treatment was carried out (Figure $1 \mathrm{C}$ ), $1.0 \%$ in case of completion axillary lymph node dissection, and $0 \%$ in case of axillary irradiation. In these patients, omission of axillary treatment resulted in a significantly increased hazard ratio for regional recurrence of 4.39 (95\% Cl, 1.46 to 13.24) (Table 2), as compared to patients with axillary treatment, after adjustment for age, tumor size, histological grade, hormone receptor status, adjuvant systemic therapy and irradiation of the breast.

\section{Efficacy of axillary irradiation compared to axillary lymph node dissection}

None of the 54 patients with sentinel node isolated tumor cells and none of the 94 patients with sentinel node micrometastases treated with axillary irradiation had a regional recurrence at 5-year follow-up. In contrast, 1.0\% of 396 patients with sentinel node isolated tumor cells and $1.1 \%$ of 793 patients with sentinel node micrometastases treated with axillary lymph node dissection had a regional recurrence. However, due to low numbers we were not able to assess hazard ratios for regional recurrence rates in case of axillary irradiation as compared to axillary lymph node dissection.

\section{Other risk factors associated with regional recurrence in patients with sentinel node micrometastases not receiving additional axillary treatment}

In patients with micrometastases in the sentinel node, doubling of tumor size (hazard ratio, 7.91; $95 \% \mathrm{Cl}$ 1.36-45.91), histological grade 3 (hazard ratio, 25.05; 95\% Cl, 1.26 to 497.18 ) and negative hormone receptor status (hazard ratio, $4.96 ; 95 \% \mathrm{Cl}, 1.48$ to 16.62) were significantly associated with regional recurrences. No adjuvant systemic therapy (hazard ratio $1.36 ; 95 \% \mathrm{Cl}, 0.47$ to 3.99 ) and breast irradiation (hazard ratio $1.01 ; 95 \% \mathrm{Cl}, 0.36$ to 2.88 ) were not significantly associated with regional recurrences (Table 2). 
Table 2. Cox proportional-hazards model of the effect of variables on regional recurrences in patients with negative sentinel nodes, patients with sentinel node isolated tumor cells, and patients with sentinel node micrometastases

\begin{tabular}{lcccccc}
\hline & \multicolumn{2}{c}{$\mathrm{NO}(\mathrm{i}-)(\mathrm{sn})$} & \multicolumn{2}{c}{$\mathrm{NO}(\mathrm{i}+)(\mathrm{sn})$} & \multicolumn{2}{c}{$\mathrm{N} 1(\mathrm{mi})(\mathrm{sn})$} \\
\cline { 2 - 7 } Variable & \multicolumn{2}{c}{ Hazard } & & Hazard & \multicolumn{3}{c}{ Hazard } \\
ratio & $95 \% \mathrm{Cl}$ & ratio & $95 \% \mathrm{Cl}$ & ratio & $95 \% \mathrm{Cl}$ \\
\hline No axillary treatment & 1.08 & $0.23-4.98$ & 2.39 & $0.67-8.48$ & 4.39 & $1.46-13.24$ \\
Young age at diagnosis (per year) & 1.08 & $1.02-1.12$ & 1.06 & $1.00-1.12$ & 1.05 & $1.00-1.10$ \\
Doubling of tumor diameter & 1.22 & $0.48-3.05$ & 3.80 & $0.74-19.42$ & 7.91 & $1.36-45.91$ \\
Histological grade 2 vs 1 & $\mathrm{NE}$ & & 1.60 & $0.32-7.96$ & 4.90 & $0.63-38.33$ \\
Histological grade 3 vs 1 & $\mathrm{NE}$ & & $\mathrm{NE}$ & & 25.05 & $1.26-497.18$ \\
Negative hormone receptor & 1.23 & $0.35-4.39$ & 5.92 & $1.52-23.00$ & 4.96 & $1.48-16.62$ \\
status & & & & & \\
No adjuvant systemic therapy & $\mathrm{NE}$ & & 1.03 & $0.28-3.85$ & 1.36 & $0.47-3.99$ \\
No breast irradiation & 1.96 & $0.73-5.29$ & 1.54 & $0.44-5.39$ & 1.01 & $0.36-2.88$ \\
\hline
\end{tabular}

$\mathrm{NE}=$ not estimable

\section{Discussion}

In the MIRROR study, we evaluated whether omitting axillary treatment in patients with early breast cancer having no tumor cells, isolated tumor cells or micrometastases in their sentinel nodes was associated with regional recurrence. This study was based on a nationwide Dutch cohort study, reflecting daily clinical practice, in 2680 patients in which central pathology review of all sentinel nodes was carried out. Compared with patients who underwent axillary treatment, the adjusted hazard ratio for regional recurrence in patients who underwent only a sentinel node procedure was $1.08(95 \% \mathrm{Cl}$ 0.23-4.98) for node-negative disease, 2.39 (95\% Cl, 0,67 to 8,48$)$ for patients with isolated tumor cells in the sentinel node(s), and 4.39 (95\% $\mathrm{Cl}, 1,46$ to 13.24$)$ for patients with micrometastases in the sentinel node(s). The efficacy of axillary irradiation compared with axillary lymph node dissection could not be assessed due to low numbers. In patients with micrometastases in the sentinel node, doubling of tumor size, histological grade 3, and negative hormone receptor status were significantly associated with regional recurrences.

To deal with confounders, we corrected for factors that might have influenced the decision to carry out additional axillary treatment, which was at the discretion of the physician and the patient at that time. These factors were age at diagnosis, tumor size, histological grade, hormone receptor status, irradiation of the breast and use of adjuvant systemic therapy. Previous investigators have highlighted the importance of the learning curve in the sentinel node procedure. For that reason, we also carried out an exploratory analysis with the year of diagnosis as additional covariate, but this did not change the results (data not further shown). Notably, omission of axillary treatment in the presence of sentinel node isolated tumor cells or micrometastases was increasingly the case in the more recent years of the cohort study. 
As can be expected, the risk of regional recurrence in our cohort was associated with risk factors known for non-sentinel node involvement ${ }^{7}$, except for lymph vessel invasion, which was not assessed in our study. Unfortunately, we were not able to develop a predictive model to identify patients who are more at risk to develop a recurrence, but, obviously by taking both sentinel node and primary tumor characteristics into account one can individualize treatment recommendations. Based on the results obtained in the Cox-proportional hazards model, one can consider omission of axillary treatment in patients with sentinel node micrometastases who have small, low grade, hormone receptor positive tumors. In remaining patients, the (small) increased risk of recurrence without axillary treatment should be offset against the increased risk of shoulder and arm morbidity if a level I-II axillary lymph node dissection is performed.

In sentinel node negative disease, we did not observe an increased risk of regional recurrence if axillary treatment was omitted, which is in agreement with results seen in randomized trials ${ }^{8-11}$. The relevance of isolated tumor cells with respect to the risk of regional recurrence is considered to be of uncertain significance, not supporting routine use of axillary treatment, in contrast to recommendations in sentinel node micrometastases, according to American Society of Clinical Oncology (ASCO) guidelines ${ }^{2}$. We have noticed differences in daily practice between hospitals within the Netherlands. We showed that half of the patients with isolated tumor cells in the sentinel node did not undergo additional axillary treatment, whereas $15 \%$ of patients with sentinel node micrometastases did not receive further axillary treatment. Recently, a survey among ASCO members revealed that in the USA axillary lymph node dissection for sentinel node micrometastases was routinely recommended by only $23 \%$ of surgeons, $23 \%$ of medical oncologists and $15 \%$ of radiation oncologists ${ }^{12}$. Radiation oncologists were more likely than medical oncologists or surgeons to consider axillary radiation instead of axillary lymph node dissection for sentinel node micrometastases.

In single centre and multi centre series, regional recurrence rates in sentinel node positive patients without axillary treatment seemed not worse as compared to results in sentinel node negative patients not receiving additional axillary treatment ${ }^{13}$. However, these low recurrence rates in sentinel node positive patients may partly be explained by underreporting to cancer registries ${ }^{14}$, patient selection ${ }^{15}$, the classification of isolated tumor cells as "micrometastases"14,16-20, and use of axillary irradiation $^{21}$. Of note, the Memorial Sloan-Kettering Cancer Center (MSKCC) reported that in patients identified with a positive sentinel node by haematoxylin-eosin examination who did not undergo completion axillary lymph node dissection, the axillary recurrence rate was $5 \%$ at a median follow-up of only 23 months, even though these were highly selected patients ${ }^{15}$.

Recently, the results from the American College of Surgeons Oncology Group (ACOSOG) trial Z0011 were published ${ }^{22,23}$. In this study, patients with one or two haematoxylin-eosin positive sentinel nodes were randomized between axillary lymph 
node dissection (38\% micrometastases) or no further treatment of the axilla $(45 \%$ micrometastases). In sharp contrast to our study and the observations in the MSKCC trial, only $0.9 \%$ regional recurrences with sentinel node alone as compared to $0.5 \%$ with axillary lymph node dissection were reported after a median follow up of 6.3 years. Important to note, in our study only $48 \%$ of patients with sentinel node micrometastases and none of the patients with node-negative disease, who did not undergo axillary treatment, had received adjuvant systemic therapy whereas in the ACOSOG Z0011 study $97 \%$ of patients who had not undergone axillary treatment had received adjuvant systemic therapy. In our study, omission of systemic therapy resulted in a non-significant increase of number of regional recurrences, comparable with evidence from the literature ${ }^{24}$. This non-significant increase was seen, even though the majority of patients who had received systemic therapy had only received endocrine therapy. Therefore, if omission of axillary treatment is considered, the use of adjuvant systemic therapy should be considered. In particular, this is relevant in countries using conservative adjuvant systemic therapy guidelines.

Further, only patients who were treated with breast-conserving therapy were included in the Z0011 trial. Previously, it was shown that with opposing tangential field irradiation as part of breast-conserving therapy "only" $55 \%$ of level I and II nodes received an adequate irradiation dose ${ }^{25}$. Yet, this inadequate dose may have a potential role on regional recurrence rate. The randomized NSABP B-06 study showed a regional recurrence rate of $4.5 \%$ after breast radiotherapy compared to $7.2 \%$ in the absence of breast radiotherapy ${ }^{26}$. In another trial, $4 \%$ of patients receiving whole breast radiotherapy had an axillary recurrence versus $14 \%$ in patients in whom local fields were used $^{27}$. These findings suggest that the nodes at greatest risk of involvement in early-stage breast cancer patients treated with breast-conserving treatment are often included in standard breast tangential fields. This may have had major implications for the outcome of the Z0011 trial ${ }^{22,23}$. So, for implementation in daily practice, it is important to stress that the excellent results of the Z0011 trial may only be applicable for women who have low-volume nodal disease, receiving adjuvant systemic therapy and breast conserving treatment with tangential irradiation fields. In the MIRROR study, a number of patients with isolated tumor cells or micrometastases in the sentinel node received axillary irradiation instead of axillary surgery. In none of the 54 patients with isolated tumor cells in the sentinel node and the 94 patients with sentinel node micrometastases who were treated with axillary irradiation, regional recurrences occurred. The absence of regional recurrences in patients treated with axillary irradiation is challenging with respect to the current recommendation of axillary lymph node dissection in node positive patients, including those with micrometastases ${ }^{2}$. Unfortunately, we were not able to perform any meaningful statistical analysis on the differential impact of type of axillary treatment, as the number of patients in our cohort study treated with axillary irradiation was quite small. An ongoing prospective study on this topic is the European After Mapping the Axilla: Radiotherapy Or Surgery?, trial $^{28}$. 
The most important issue is, of course, not the occurrence of a relapse, but whether this relapse is associated with poorer survival. In a meta-analysis before the sentinel node-era, it was shown that omission of axillary lymph node dissection in clinically node-negative patients was associated with reduction in overall survival of about $5 \%$ after 5 to 10 years of follow-up ${ }^{29}$. However, in these older studies relatively few patients had T1 tumors, the percentage of patients with pathologically tumor-positive lymph nodes was quite high, and essentially none of the patients were treated with systemic therapy, in contrast to current practice. The Early Breast Cancer Trialists' Collaborative Group found that variations in local treatment had a definite, although moderate effect on breast cancer mortality by 15 years $^{24}$. Recently, it was reported that with increased use of adjuvant systemic therapy this ratio changed from 4:1 to $2: 1$, that is for every two locoregional recurrences avoided, about one breast cancer death over the next 15 years is prevented ${ }^{30}$. The 5-year overall survival in the Z0011 study was not different for patients who underwent nodal dissection or only a sentinel node procedure, as could be expected from the observed comparable regional recurrence rates in these selected patients ${ }^{22,23}$. However, we showed that uncontrolled omission of axillary treatment resulted in an increased recurrence rate. These different findings stress the importance of first identifying the patients in whom a new strategy can safely be used, before it is broadly implemented in routine daily practice.

In conclusion, we found that omitting axillary treatment in patients with sentinel node micrometastases resulted in a significantly increased 5-year regional recurrence rate of 5.6\% with an adjusted hazard ratio of 4.39 (95\% Cl 1.46-13.24). However, regional recurrence was also strongly associated with tumor size, grade and hormone receptor status. Use of systemic therapy and breast irradiation as part of breast conserving therapy may reduce the risk of recurrence. For an individual patient, all these factors have to be taken into account to offer the most optimal, personalized, treatment strategy.

\section{Acknowledgements}

The authors thank the Netherlands Cancer Registry for making this study possible, Jolanda M. van Beek-Schoester for her assistance with data management, Wim A.J.G. Lemmens for his assistance with statistical analyses, and Eddy M.M. Adang for his assistance with critical analyses. 


\section{References}

1. Fisher B, Bauer M, Wickerham DL, et al. Relation of number of positive axillary nodes to the prognosis of patients with primary breast cancer. An NSABP update. Cancer 1983:52:1551-1557.

2. Lyman GH, Giuliano AE, Somerfield MR, et al; American Society of Clinical Oncology. American Society of Clinical Oncology guideline recommendations for sentinel lymph node biopsy in early-stage breast cancer. J Clin Oncol 2005:23:7703-7720.

3. Green FL, Page DL, Fleming ID, et al. American Joint Committee on Cancer Staging Manual.6th ed. Philadelphia, PA: Springer; 2002.

4. de Boer M, van Dijck JA, Bult P, Borm GF, Tjan-Heijnen VC. Breast cancer prognosis and occult lymph node metastases, isolated tumor cells, and micrometastases. J Natl Cancer Inst 2010:102:410-425.

5. de Boer $\mathrm{M}$, van Deurzen $\mathrm{CH}$, van Dijck JA, et al. Micrometastases or isolated tumor cells and the outcome of breast cancer. N Engl J Med 2009:361:653-663.

6. Rutgers EJ, Nortier JW, Tuut MK, et al; Nationaal Borstkanker Overleg Nederland; Kwaliteitsinstituut voor de Gezondheidszorg. Dutch Institute for Healthcare Improvement guidelines, "Treatment of breast cancer". Ned Tijdschr Geneeskd 2002:146:2144-2151.

7. Van Zee KJ, Kattan MW. Validating a predictive model for presence of additional disease in the nonsentinel lymph nodes of a woman with sentinel node positive breast cancer. Ann Surg Oncol 2007:14:2177-2178.

8. Krag DN, Anderson SJ, Julian TB, et al. Sentinel-lymph-node resection compared with conventional axillary-lymph-node dissection in clinically node-negative patients with breast cancer: overall survival findings from the NSABP B-32 randomised phase 3 trial. Lancet Oncol 2010:11:927-933.

9. Veronesi U, Paganelli G, Viale G, et al. Sentinel-lymph-node biopsy as a staging procedure in breast cancer: update of a randomised controlled study. Lancet Oncol 2006:7:983-990.

10. Canavese G, Catturich A, Vecchio C, et al. Sentinel node biopsy compared with complete axillary dissection for staging early breast cancer with clinically negative lymph nodes: results of randomized trial. Ann Oncol 2009:20:1001-1007.

11. Zavagno G, De Salvo GL, Scalco G, et al; GIVOM Trialists. A Randomized clinical trial on sentinel lymph node biopsy versus axillary lymph node dissection in breast cancer: results of the Sentinella/GIVOM trial. Ann Surg 2008:247:207-213.

12. Wasif $\mathrm{N}, \mathrm{Ye} X$, Giuliano AE. Survey of ASCO members on management of sentinel node micrometastases in breast cancer: variation in treatment recommendations according to specialty. Ann Surg Oncol 2009:16:2442-2449.

13. Pepels MJ, Vestjens JH, de Boer M, et al. Safety of avoiding routine use of axillary dissection in early stage breast cancer: a systematic review. Breast Cancer Res Treat 2011;125:301-313

14. Bilimoria KY, Bentrem DJ, Hansen NM, et al. Comparison of sentinel lymph node biopsy alone and completion axillary lymph node dissection for node-positive breast cancer. J Clin Oncol 2009:27: 2946-2953.

15. Park J, Fey JV, Naik AM, Borgen PI, Van Zee KJ, Cody HS 3rd. A declining rate of completion axillary dissection in sentinel lymph node-positive breast cancer patients is associated with the use of a multivariate nomogram. Ann Surg 2007:245:462-468.

16. Bulte CS, van der Heiden-van der Loo M, Hennipman A. Axillary recurrence rate after tumour negative and micrometastatic positive sentinel node procedures in breast cancer patients, a population based multicenter study. Eur J Surg Oncol 2009:35:25-31.

17. Langer I, Marti WR, Guller U, et al M. Axillary recurrence rate in breast cancer patients with negative sentinel lymph node (SLN) or SLN micrometastases: prospective analysis of 150 patients after SLN biopsy. Ann Surg 2005:241:152-158.

18. Jeruss JS, Winchester DJ, Sener SF, et al. Axillary recurrence after sentinel node biopsy. Ann Surg Oncol 2005:12:34-40.

19. Fant JS, Grant MD, Knox SM, et al. Preliminary outcome analysis in patients with breast cancer and a positive sentinel lymph node who declined axillary dissection. Ann Surg Oncol 2003:10:126-130.

20. Guenther JM, Hansen NM, DiFronzo LA, et al. Axillary dissection is not required for all patients with breast cancer and positive sentinel nodes. Arch Surg 2003:138:52-56. 
21. Hwang RF, Gonzalez-Angulo AM, Yi M, et al. Low locoregional failure rates in selected breast cancer patients with tumor-positive sentinel lymph nodes who do not undergo completion axillary dissection. Cancer 2007:110:723-730.

22. Giuliano AE, McCall L, Beitsch $\mathrm{P}$, et al. Locoregional Recurrence after sentinel lymph node dissection with or without axillary dissection in patients with sentinel lymph node metastases. The ACOSOG Z0011 randomized trial. Ann Surg 2010:252:426-432.

23. Giuliano $A E, M c C a l l ~ L, B e i t s c h ~ P$, et al. Locoregional recurrence after sentinel lymph node dissection with or without axillary dissection in patients with sentinel lymph node metastases: the American College of Surgeons Oncology Group Z0011 randomized trial. Ann Surg 2010:252:426-432.

24. Early Breast Cancer Trialists' Collaborative Group (EBCTCG).Effects of chemotherapy and hormonal therapy for early breast cancer on recurrence and 15-year survival: an overview of the randomised trials. Lancet 2005:365:1687-1717.

25. Reed DR, Lindsley SK, Mann GN, et al. Axillary lymph node dose with tangential breast irradiation. Int J Rad Oncology Biol. Phys 2005:61:358-364.

26. Fisher B, Redmond C, Poisson R, et al. Eight-year resuls of a randomized clinical trial comparing total mastectomy and lumpectomy with or without irradiation in the treatment of breast cancer. N Engl J Med 1989:320:822-828.

27. Ribeiro GG, Dunn G, Swindell R, Harris M, Banerjee SS. Conservation of the breast using two different radiotherapy techniques: interim report of a clinical trial. Clin Oncol 1990:2:27-34.

28. Straver ME, Meijnen P, van Tienhoven G, et al. Role of axillary clearance after a tumor-positive sentinel node in the administration of adjuvant therapy in early breast cancer. J Clin Oncol 2010:28:731-737

29. Orr RK. The impact of prophylactic axillary node dissection on breast cancer survival-a Bayesian metaanalysis. Ann Surg Oncol 1999:6:109-116.

30. Harris JR, Morrow M. How the '4:1 ratio' will likely change with increasingly effective systemic therapy San Antonio Breast Cancer Symposium. San Antonio, TX, 2009, MS3-2. 
134 Chapter 8 
Regional recurrence in breast cancer 135

Supplementary appendix 
Table S1. Individuals and institutions participating in this study

Comprehensive Cancer Centre East, Nijmegen - C. Lennards; Canisius Wilhelmina Hospital, Nijmegen - C. Wauters, L. Strobbe; Radboud University Medical Centre, Nijmegen - Th. Wobbes; Maas Hospital, Boxmeer - A. Meersman; Rijnstate Hospital, Arnhem - F. van de Molengraft, R. Keus, J. Klinkenbijl; Gelderse Vallei Hospital, Ede - E. Balk, J. Kroeze; Zevenaar Hospital, Zevenaar - J. van Wijk; Slingeland Hospital, Doetinchem - E. Muller; St. Jansdal Hospital, Harderwijk - R. Tobon Morales; Comprehensive Cancer Centre Amsterdam, Amsterdam - O. Visser, W. Heijbroek-de Clerq; Academic Medical Centre, Amsterdam - M. van de Vijver, A. Kluit; IJsselmeerziekenhuizen, Lelystad - E. Neefjes-Borst, G. Algie; Onze Lieve Vrouwe Gasthuis, Amsterdam - E. Nijhuis, P. Borgstein; Flevo Hospital, Almere - M. Regoort; Medical Centre Alkmaar, Alkmaar - H.J. van Slooten, B. Langenhorst; Gemini Hospital, Den Helder - H. Tjeenk Willink; Westfries Gasthuis, Hoorn J.W. Jansen, M. Govaert; Zaans Medical Centre, Zaandam - M. Flens, J. Oomen; BovenIJ Hospital, Amsterdam - R. Klicks; Waterland Hospital, Purmerend - L. de Widt-Levert; Netherlands Cancer Institute/Antoni van Leeuwenhoek Hospital, Amsterdam - H. van Boven, J. Westerga; Slotervaart Hospital, Amsterdam - L. de Kock; Hospital Amstelland, Amstelveen - S. Veltkamp; Spaarne Hospital, Hoofddorp - J. Burggraaf, A. Tanka; Sint Lucas Andreas Hospital, Amsterdam - E. Barbé, E. Steller; Vrije Universiteit Medical Centre, Amsterdam - W. Mooi, S. Meijer; Kennemer Gasthuis, Haarlem - D. Willebrand, H. Rijna; Rode Kruis Hospital, Beverwijk - M. Hunfeld; Tergooi Hospitals, Blaricum - M. Prins, P. Bor, A. ten Tije; Tergoo Hospitals, Hilversum - J. Juttmann, S. Luykx-de Bakker; Comprehensive Cancer Centre West, Leiden - P. Krijnen, B. Jongejan; Bronovo Hospital, Den Haag - I. Koelma, J. van Esser, O. Guicherit; Diaconessenhuis, Leiden, - J. Graadt van Roggen, R. Vree, E. Planken; Rijnland Hospital, Leiderdorp - J. Calame, A. Zeilemaker, W. Molendijk; Medical Centre Haaglanden, Den Haag E. Ooms, A. Marinelli, R. Brouwer; Medical Centre Haaglanden, Leidschendam - I. Groot; 't Lange Land Hospital, Zoetermeer - B. Jas, A. Ogilvie; Groene Hart Hospital, Gouda - M. Giessen, R. Schmitz, A. van der Torren-Konze; Haga Hospital Leyenburg, Den Haag - P. Blok, W. Steup, H. Sleeboom; Haga Hospital Rode Kruis, Den Haag - J. Merkus; Leiden University Medical Centre, Leiden - V. Smit, B. Bonsing; Reinier de Graaf Groep, Delft - A. van Leeuwen, C. Marcoen, E. Maartense; Comprehensive Cancer Centre Eindhoven, Eindhoven - M. Janssen-Heijnen, A. van den Eijnden-van Rooijen; Laboratory for Pathology (PAMM), Eindhoven - M. van Beek; Catharina Hospital, Eindhoven - Y. van Riet, G. Creemers; Máxima Medical Centre, Eindhoven - O. Repelaer van Driel, M. Nijziel; Máxima Medical Centre, Veldhoven - R. Roumen, G. Vreugdenhil; Sint Anna Zorggroep, Geldrop - E. Luiten, A. Smals; Jeroen Bosch Hospital, `s Hertogenbosch - J. Broekman, W. Gelderman, J. Wissing, S. Bouwer, T. Smilde, Hospital Bernhoven, Veghel - B. Storck, N. van Diemen; Bernhoven Hospital, Oss - Y. Paquay, A. Vos; Amphia Hospital Molengracht, Breda - P. de Wit, J. Nuytinck, G. Ras; Amphia Hospital Pasteurlaan, Oosterhout - O. van West, J. van Wissen; Amphia Hospital Langendijk, Breda - A. van Gent; Sint Elizabeth Hospital, Tilburg - A. Croonen, J. Roukema, J. van Riel; Tweesteden Hospital, Tilburg - S. Brenninkmeijer, H. van Ojik; Elkerliek Hospital, Helmond - M. Tutein Nolthenius-Puylaert, B. Lemaire; VieCuri Medical Centre, Venlo - R. Schapers, P. Nijhuis, A. van der Wouw; Comprehensive Cancer Centre Rotterdam, Rotterdam - R. Damhuis, J. Paulides; Erasmus Medical Centre, Rotterdam - M. Kliffen; Medical Centre Rijnmond-Zuid Zuider, Rotterdam - S. Henzen-Logmans; Medical Centre Rijnmond-Zuid Clara, Rotterdam - H. van den Ingh, W. Meijer; Laboratory for Pathology (PATHAN), Rotterdam - J. Ruizeveld de Winter; Vlietland Hospital, Schiedam I. Mares-Engelberts; Ruwaard van Putten Hospital, Spijkenisse - R. den Toom; IJsselland Hospital, Capelle aan de IJssel - G. Tetteroo; Sint Fransiscus Hospital, Rotterdam - H. Strijdhorst; Ikazia Hospital, Rotterdam - W. Vles; Haven Hospital, Rotterdam - J. van Dam; Albert Schweitzer Hospital, Dordrecht - P. Westenend, P. Plaisier; Laboratory for Pathology Zeeland - L. de Bruijckere; Hospital Walcheren, Vlissingen - J. ten Thije; Oosterschelde Hospitals, Goes - H. de Morree; Van Weel-Bethesda Hospital, Dirksland - R. van der Hul; Hospital Zeeuw-Vlaanderen, Terneuzen - W. Mostert, K. Ongena; Hospital Lievensberg, Bergen op Zoom - V. Potters, E. Slingenberg; Franciscus Hospital, Roosendaal - H. Kemperman Comprehensive Cancer Centre Limburg, Maastricht - J. Bruijnen, S. Adema; Maastricht University Medical Hospital, Maastricht - M. von Meyenfeldt, P. Hupperets; Maasland Hospital, Sittard - W. Vos, F. van der Ent, F. Erdkamp; Atrium Medical Centre Parkstad, Heerlen - M. Nap, J. van der Bijl, M. Pannebakker; Laurentius Hospital, Roermond - A. Willig, C. Finaly-Marais, M. den Boer; Sint Jans Gasthuis, Weert - F. Limbeek, P. den Haan; Comprehensive Cancer Centre MiddenNederland, Utrecht - M. van der Heiden-van der Loo, A. Koppejan-Rensenbrink; Sint Antonius Hospital, Nieuwegein - C. Seldenrijk, R. Koelemij, P. de Jong; Mesos Medical Centre, Utrecht - A. van Wieringen, R. Oltmans; Zuwe Hofpoort Hospital, Woerden - J. Vente, M. Verhaar-Langereis; Diakonessenhuis, Utrecht - J. van Gorp, T. van Dalen, P. Thunnissen; Meander Medical Centre, Amersfoort - E. Ahsmann, A. van Overbeeke, C. Rodenburg; University Medical Centre Utrecht, Utrecht - R. van Hilligersberg, E. van der Wall; Hospital Rivierenland, Tiel - K. Ong, C. Henkens; Comprehensive Cancer Centre North East, Enschede, Groningen - S. Siesling, M. Schaapveld, R. Otter, A. Wit; Laboratory for Pathology Oost Nederland (LPON), Enschede - M. Brinkhuis; Medisch Spectrum Twente, Enschede - W. Mastboom, W. Smit; Ziekenhuisgroep Twente Twenteborg, Almelo - D. van der Velde, R. Hoekstra; Ziekenhuisgroep Twente SMT, Hengelo - H. Heijmans, H. Dankbaar; Streekziekenhuis Koningin Beatrix, Winterswijk - F. Slootmans, P. Schiphorst; Gelre Hospitals, Apeldoorn - E. Weltevreden, J. Roussel, S. Radema; Hospital Spittaal, Zutphen - J. Ketel, O. van Dobbenburgh; Deventer Hospital, Deventer - J. Arends, H. de Vries, A. Imholz; Laboratory for Pathology (LVF), Leeuwarden - H. Eggink; Antonius Hospital, Sneek - E. Mulder, G. Woolthuis; Medical Centre Leeuwarden, Leeuwarden - C. Hoff, H. de Graaf; Hospital Nij Smellinghe, Drachten - H. van der Mijle, H. van Kamp; Hospital Talma Sionsberg, Dokkum - J. Kaspers, J. de Graaf; Hospital de Tjongerschans, Heerenveen - P. Veldman, J. de Boer; Bethesda Hospital, Hoogeveen - G. Freling, R. Haasen, J. Haasjes; Röpke-Zweers Hospital, Hardenberg M. Jagers, R. Blankenburgh; Diaconessenhuis, Meppel - L. Hanssen, H. de Korte; Isala Klinieken, Zwolle - A. Jonker, E. Pierik, J. de Graaf; Laboratory for Pathology, Winschoten - C. Schoots; Sint Lucas Hospital, Winschoten - M. Klöppner, H. Potthoff; Refaja Hospital, Stadskanaal - A. Kemper, J. Jansen; Delfzicht Hospital, Delfzijl - J. Ashruf, Z. Erjavec; Martini Hospital, Groningen - A. Groote, A. Olieman, R. de Jong; University Medical Centre Groningen, Groningen - A. Suurmeijer, J. de Vries, P. Willemse; Wilhelmina Hospital, Assen - R. Wijffels, F. Blok; Scheper Hospital, Emmen - M. van den Aardweg, E. Weernink - all in the Netherlands. 


\section{Chapter 9}

Summary, general conclusions, and future perspectives 
138 Chapter 9 


\section{Summary, general conclusions, and future perspectives}

Breast cancer is a major health care problem. The presence of axillary lymph node metastases is the most important prognostic factor in breast cancer. Since the nineties of the last century, the sentinel lymph node procedure has been introduced, replacing routine axillary lymph node dissection in patients with clinically nodenegative disease. The intensive examination of sentinel nodes resulted in an increased detection of small metastatic tumor deposits, including isolated tumor cells and micrometastases. Since then, the prognostic relevance of these small deposits has become an issue, and is the major topic of this thesis.

In Chapter 1, a general introduction and outline of the thesis is presented.

The aims of the studies presented were to review studies with respect to the prognostic relevance of occult metastases, isolated tumor cells, and micrometastases; to describe the interobserver agreement between two breast dedicated pathologists in classification of small nodal deposits; to investigate the prognostic relevance of nodal isolated tumor cells and micrometastases; to describe the economic impact of administration of adjuvant systemic therapy to low risk breast cancer patients with small nodal metastases; to review the literature with respect to the frequency of nonsentinel node metastases when the sentinel node contains isolated tumor cells; and to assess the regional recurrence rate in patients with sentinel nodal isolated tumor cells or micrometastases who did not receive additional axillary treatment.

In Chapter 2, we present a systematic review and meta-analysis of 58 studies regarding the prognostic relevance of isolated tumor cells and micrometastases in lymph nodes from patients with breast cancer. These studies were divided into three categories. From the cohort studies, we conclude that the presence of metastases 2 $\mathrm{mm}$ or less in diameter in axillary lymph nodes was associated with poorer overall survival (pooled hazard ratio of death $=1.44,95 \%$ confidence interval $(\mathrm{Cl}), 1.29$ to 1.62). In the occult metastases studies, the presence of occult metastases (isolated tumor cells, micrometastases, and macrometastases, only detected after intensive pathological assessment of initially negative nodes) was associated with poorer 5-year disease-free survival (pooled relative risk $(R R)=1.55,95 \% \mathrm{Cl}, 1.32$ to 1.82 ) and overall survival (pooled $\mathrm{RR}=1.45,95 \% \mathrm{Cl}, 1.11$ to 1.88). However, the independent prognostic value of occult metastases remained undetermined, because these endpoints were not consistently assessed in multivariable analyses. The translation of evidence from these older studies to the current sentinel node era is limited. The sentinel lymph node biopsy studies published so far were hampered by small patient groups and short follow-up. Therefore, we conclude that the results of ongoing sentinel lymph node studies have to be awaited to provide data on the prognostic relevance of isolated tumor cells and micrometastases in the sentinel node era. 
In Chapter 3, we describe the results of the study that assessed the agreement in classification of small nodal deposits between two breast dedicated pathologists, who reviewed all sentinel nodes of patients included in the MIRROR (Micrometastases and Isolated tumor cells: Relevant and Robust Or Rubbish?) study. In this side study of the MIRROR study, one hundred three sentinel nodes were classified by both central review pathologists. The pathologists reached a high level of agreement in classifying sentinel nodal status according to the sixth AJCC Cancer Staging Manual. Not only agreement in nodal classification, but also agreement in diameter and surface area was good, especially for smaller diameters near the transition of isolated tumor cells and micrometastases. A meeting at the initiation of the study, in which guidelines for the assessment of size of tumor deposits were discussed, probably contributed to the high level of agreement. We conclude that the results described in this chapter stress the validity of the results of the MIRROR study, which are described in Chapter 4.

In Chapter 4 we report the main results of the MIRROR study, in which the prognostic relevance of isolated tumor cells or micrometastases in regional lymph nodes, and the role of adjuvant systemic therapy were evaluated. In this nationwide cohort study, we identified all patients with favorable primary tumor characteristics who had undergone a sentinel node procedure before 2006, with isolated tumor cells or micrometastases as final nodal status. A control group of patients with node-negative disease who did not receive systemic therapy was randomly selected from the years 2000-2001. Central pathology review of all sentinel nodes and all positive non-sentinel nodes was carried out. The primary endpoint was disease-free survival. Median follow-up was 5.1 years. In patients not receiving adjuvant systemic therapy $(n=856)$, the adjusted hazard ratio for disease-recurrence was $1.50(95 \% \mathrm{Cl}, 1.15$ to 1.94$)$ for patients with isolated tumor cells, and $1.56(95 \% \mathrm{Cl}, 1.15$ to 2.13$)$ for patients with micrometastases, both as compared to patients with node-negative disease $(n=856)$. In patients with isolated tumor cells or micrometastases, the adjusted hazard ratio was $0.57(95 \% \mathrm{Cl}, 0.45$ to 0.73$)$ for patients receiving ( $n=995)$ as compared to patients not receiving adjuvant systemic therapy $(n=856)$. Therefore, we conclude that compared to node-negative disease both the presence of isolated tumor cells and micrometastases in regional lymph nodes had a negative prognostic impact on 5-year disease-free survival in favorable early stage breast cancer patients who did not receive adjuvant systemic therapy. In patients with isolated tumor cells or micrometastases who received adjuvant systemic therapy, disease-free survival was improved.

The impact of extent, size, and microanatomic location of nodal involvement on disease-free survival within the group of patients with isolated tumor cells is described in Chapter 5. In this study, we included all patients from the MIRROR study who had isolated tumor cells and who did not receive adjuvant systemic therapy $(n=513)$. We determined the effect of single tumor cell(s) versus tumor cell cluster(s), 
metastatic size and microanatomic location on 5-year disease-free survival. The hazard ratio for disease events was $1.05(95 \% \mathrm{Cl}, 0.63$ to 1.76$)$ for patients with tumor cell cluster(s) ( $n=404)$ as compared to patients with single cell(s) ( $n=93)$. In a Cox regression model, doubling of metastatic size corresponded to a hazard ratio of 1.21 (95\% Cl, 1.02 to 1.43$)$. The adjusted hazard ratio for disease events was $0.90(95 \% \mathrm{Cl}$, 0.54 to 1.50$)$ for patients with parenchymal $(n=112)$ versus patients with sinusoidal location ( $n=395)$. We conclude that the presence of single tumor cell(s) has the same prognostic relevance as the presence of tumor cell cluster(s), even though the results suggest that within the category of isolated tumor cells increasing size of nodal involvement is associated with reduced survival. Microanatomic location does not have prognostic relevance.

To determine the cost-effectiveness of administering adjuvant systemic therapy in patients with early stage breast cancer and isolated tumor cells or micrometastases, an economic analysis based on patient data derived from the MIRROR study is described in Chapter 6. Patients with isolated tumor cells or micrometastases who had a complete 5-year follow-up and who either did or did not receive systemic therapy were eligible. Primary objective was the incremental cost-effectiveness ratio (ICER), which was expressed as costs per one percent event prevented after 5 years of follow-up. Secondary objective was to establish when adjuvant systemic therapy would become cost saving. The analyses were carried out from a hospital perspective. The total mean costs per patient from diagnosis up to 5 years after diagnosis were $€ 2939$ (95\% Cl, €1638 - €4241) higher in the adjuvant therapy cohort ( $n=366)$ as compared to the no-adjuvant therapy cohort $(n=483)$, resulting in an ICER of $€ 363$ per one percent event prevented. Beyond 18 years after diagnosis, the extrapolated mean cumulative costs per patient in the no-adjuvant therapy cohort exceeded those of the adjuvant therapy cohort due to increasing costs of breast cancer related events in patients who had not received adjuvant systemic therapy. We conclude that in this population of breast cancer patients with isolated tumor cells or micrometastases, $€ 36300$ had to be invested to prevent one event in 5 years of follow-up. Beyond 18 years of follow-up, adjuvant systemic therapy becomes cost-saving.

To analyze the frequency of non-sentinel node metastases when the sentinel node contains isolated tumor cells, a systematic review on this subject is presented in Chapter 7. Twenty-nine studies were included, with an overall pooled risk of nonsentinel node involvement of $12.3 \%$ ( $95 \% \mathrm{Cl}, 9.5 \%$ to $15.7 \%)$. Of note, $64 \%$ of these metastases were macrometastases. Although the pooled risk estimate of non-sentinel node involvement is slightly higher than the reported risk of non-sentinel-node involvement in patients with a negative sentinel node, we conclude that in patients with sentinel nodal isolated tumor cells an axillary lymph node dissection should not routinely be carried out. In patients with isolated tumor cells with other risk factors 
for non-sentinel node metastases, who are not treated with adjuvant systemic therapy, axillary lymph node dissection should be considered.

In Chapter 8, the impact of omission of axillary treatment (axillary lymph node dissection or axillary irradiation) on the regional recurrence rate in patients with isolated tumor cells or micrometastases in the sentinel node is reported. The adjusted hazard ratio for regional recurrence in patients who underwent a sentinel node procedure only was 1.08 ( $95 \% \mathrm{Cl}, 0.23$ to 4.98$)$ for node-negative patients; 2.39 (95\% $\mathrm{Cl}, 0.67$ to 8.48 ) for patients with isolated tumor cells; and 4.39 (95\% Cl, 1.46 to 13.24) for patients with micrometastases in their sentinel nodes, all as compared to patients who had undergone axillary treatment. Doubling of tumor size, differentiation grade 3 , and a negative hormone receptor status were significantly associated with regional recurrence. We conclude that omission of axillary treatment in patients with sentinel nodal micrometastases is associated with an increased 5 -year regional recurrence rate.

\section{Conclusions and future perspectives}

In this thesis, we describe several aspects of isolated tumor cells and micrometastases: their prognostic relevance, the (difficulties in) pathologic classification of these small deposits, the cost-effectiveness of adjuvant systemic therapy in patients with these nodal metastases, their association with non-sentinel node metastases and regional recurrence when additional axillary treatment is omitted.

Most of the chapters in this thesis are derived from data from the MIRROR study. This observational study is a reflection of daily practice in patients with nodal isolated tumor cells or micrometastases who were treated in all Dutch hospitals before 2006. In this study, we showed the prognostic relevance of isolated tumor cells and micrometastases. It is the largest study in the sentinel node era with separate analyses for patients with and without adjuvant systemic therapy. Other studies on this topic in the sentinel node era are smaller, and included patients who received adjuvant systemic therapy, which is a serious confounding factor. We showed that survival improved in patients with isolated tumor cells or micrometastases who received adjuvant systemic therapy. However, our study was carried out in an era in which guidelines for the use of adjuvant systemic therapy were conservative. In the Netherlands, the indications for adjuvant systemic therapy based on primary tumor characteristics have been broadened over the years. If the patients in the MIRROR study would have been treated nowadays, about half of the patients would have received adjuvant systemic therapy based on their primary tumor characteristics. The additional information of the presence of isolated tumor cells or micrometastases in the sentinel node(s) would therefore not have altered adjuvant systemic treatment 
decisions in these patients. In the early stage breast cancer patients who currently still would not receive adjuvant systemic therapy if solely based on the primary tumor characteristics, it is uncertain whether the presence of isolated tumor cells or micrometastases would increase the risk of recurrence of disease in such a way that adjuvant systemic therapy would still be justified. In the present situation, the increased efficacy of systemic therapies should be taken into account in decisionmaking regarding this therapy. Further evidence from prospective, randomized studies regarding the prognostic relevance of isolated tumor cells and micrometastases and the role of adjuvant systemic therapy cannot be expected as these studies will neither be ethical nor feasible to perform. When data from the MIRROR study have become more mature, the effect of small nodal metastases on overall survival will be determined.

We showed that the chance of additional non-sentinel node metastases was $12 \%$ (of which $64 \%$ were macrometastases) when isolated tumor cells were present in the sentinel node. Comparable with other studies ${ }^{1-4}$, the regional recurrence rate after omission of axillary treatment was very low. Therefore, axillary lymph node dissection is currently not recommended any more in case isolated tumor cells are demonstrated in the sentinel node ${ }^{5}$. However, if a patient has no indication for adjuvant systemic therapy based on primary tumor characteristics, an axillary lymph node dissection should be considered as this may alter treatment decisions when macrometastases are present in non-sentinel nodes. The use of non-sentinel node prediction models may help to identify patients at high risk of non-sentinel node metastases. We are currently investigating which model to predict the chance of nonsentinel node metastases performs best in patients with small sentinel nodal involvement.

The 5-year risk of regional recurrence was 5.6\% when micrometastases were present in sentinel node(s) and axillary lymph node dissection was omitted. These results contradict the results of the recent American College of Surgeons Oncology Group (ACOSOG) Z0011 trial, in which patients with early stage breast cancer and positive sentinel nodes were randomized between axillary lymph node dissection and no axillary lymph node dissection ${ }^{6}$. These patients all underwent lumpectomy and breast irradiation, had a maximum of 2 positive sentinel nodes, and received adjuvant systemic therapy. After a median follow-up of 6.3 years, the regional recurrence rate was extremely low, and comparable in both groups. No difference was found in disease-free and overall survival. In patients meeting the inclusion criteria of the latter study, omission of axillary treatment can be considered according to the recently updated Dutch guidelines for diagnosis and treatment of breast cancer ${ }^{5}$. The difference in regional recurrence rates in this study as compared to our study might be explained by the fact that the MIRROR study was an observational study in which axillary lymph node dissection was omitted in unselected patients, including those 
who underwent mastectomy without breast irradiation, and who did not receive adjuvant systemic therapy. These different results stress the importance of first identifying the patients in whom a new strategy can safely be used, before it is broadly implemented in routine daily practice. Because it is unknown whether omission of axillary treatment is safe in patients with sentinel nodal (micro)metastases who undergo mastectomy, future studies should evaluate this strategy. In the MIRROR study, a small proportion of patients with isolated tumor cells or micrometastases in their sentinel nodes underwent axillary irradiation instead of axillary lymph node dissection. Because of low numbers we were not able to assess the safety of axillary irradiation instead of axillary lymph node dissection. It is not yet clear to what extent axillary irradiation can replace axillary dissection after a positive sentinel node biopsy. The results of a recently closed large randomized trial will answer this question?

To assure comparability of the sentinel nodal classification of both reviewing pathologists in the MIRROR study, we assessed their interobserver agreement, which showed high agreement. However, we have observed differences in classification of small nodal deposits between the local pathologists and the review pathologists. We are currently investigating whether these differences have had impact on treatment decisions and survival. One of the problems of classification is the variability in interpretation of definitions of isolated tumor cells or micrometastases, and the assessment of size of these nodal deposits. To improve the classification of small nodal deposits, the seventh edition of the TNM contains clarifications regarding the distinction between isolated tumor cells and micrometastases ${ }^{8}$. Hopefully, these clarifications will further improve the reproducibility of staging. Based on the results described in this thesis, pathology protocols for assessment of sentinel nodes should be aimed at detecting micrometastases, at least for those patients not eligible for systemic therapy based on primary tumor characteristics. This can be achieved using a protocol that includes step sectioning at 5 levels with an interval of $250 \mu \mathrm{m}$ with H\&E staining and immunohistochemistry when the first level H\&E section is negative ${ }^{9}$. Uniformity of protocols to assess the sentinel nodal status and regular quality control of assessment of breast specimens and axillary lymph nodes are warranted to guarantee good quality breast cancer care and high quality studies on this subject. We are currently evaluating the uniformity of the protocols for assessment of sentinel nodes used by pathology laboratories throughout the Netherlands.

Currently, traditional prognostic factors such as nodal status, age, estrogen receptor status, tumor size and grade are being used to assess the risk of recurrence and the benefit of adjuvant systemic therapy. To improve the risk estimation and selection of patients who will benefit from adjuvant systemic therapy, gene expression profiling of the primary tumor is developed. In retrospective studies, gene expression profiling performed better than traditional prognostic factors in discrimination of patients at 
low or high risk of recurrent disease ${ }^{10,11}$. However, nodal status remained an independent prognostic factor in these studies. The results of prospective trials have to be awaited to assess the value of these techniques in predicting response to systemic therapy, and to determine their position in relation to traditional prognostic factors. The results of these studies might bring us new dilemmas. What is the role of the axillary nodal status in clinically node negative patients? Can sentinel node biopsy be omitted in patients with a poor prognosis signature because they will receive adjuvant systemic therapy? And should a sentinel node biopsy be carried out in patients with a good prognosis signature? Future studies should define the role of axillary staging when using gene expression profiling techniques.

In conclusion, we have shown that isolated tumor cells and micrometastases are prognostically relevant, although their presence will infrequently alter adjuvant systemic therapy decisions nowadays. With respect to additional axillary treatment, the presence of micrometastases is relevant, especially in those patients undergoing mastectomy. Therefore, pathology protocols for processing of sentinel nodes should be aimed to detect micrometastases, at least in patients not eligible for systemic therapy based on primary tumor characteristics. Future studies should be aimed at the impact of small nodal involvement on overall survival, and the influence of central pathology review on classification and treatment decisions. In addition, the safety of omission of axillary lymph node dissection in patients with (micro)metastases who undergo mastectomy, and the role of axillary irradiation need to be evaluated. Finally, the role of axillary surgery in the era of gene expression profiling needs evaluation. The ultimate goal should be personalized medicine, in which axillary surgery and its morbidity should be limited as much as possible, without jeopardizing safety. However, until that time the evaluation of axillary nodal status through a sentinel node biopsy will remain important in diagnosis and treatment decisions in patients with clinically node negative breast cancer. 
$146 \mid$ Chapter 9

\section{References}

1. Pugliese MS, Karam AK, Hsu M, et al. Predictors of completion axillary lymph node dissection in patients with immunohistochemical metastases to the sentinel lymph node in breast cancer. Ann Surg Oncol 2010;17:1063-1068.

2. Cox CE, Kiluk JV, Riker Al, et al. Significance of sentinel lymph node micrometastases in human breast cancer. J Am Coll Surg 2008;206:261-268.

3. Calhoun KE, Hansen NM, Turner RR, Giuliano AE. Nonsentinel node metastases in breast cancer patients with isolated tumor cells in the sentinel node: implications for completion axillary node dissection. Am J Surg 2005;190:588-591.

4. Jeruss JS, Winchester DJ, Sener SF, et al. Axillary recurrence after sentinel node biopsy. Ann Surg Oncol 2005;12:34-40.

5. Updated Dutch guidelines of diagnosis and trreatment of breast cancer. National Breast Cancer Organization of the Netherlands; www.oncoline.nl (2012). (In Dutch.)

6. Giuliano $\mathrm{AE}$, Hunt $\mathrm{KK}$, Ballman $\mathrm{KV}$, et al. Axillary dissection vs no axillary dissection in women with invasive breast cancer and sentinel node metastasis: a randomized clinical trial. JAMA 2011;305: 569-575.

7. Straver ME, Meijnen P, van Tienhoven G, et al. Role of axillary clearance after a tumor-positive sentinel node in the administration of adjuvant therapy in early breast cancer. J Clin Oncol 2010;28:731-737.

8. UICC TNM classification of malignant tumours, 7th edition. 7th edition ed. New York: John Wiley and Sons Inc.; 2009.

9. Van Diest PJ, van Deurzen CHM, Cserni G, et al. Pathology issues related to SN procedures and increased detection of micrometastases and isolated tumor cells. Breast Dis 2010;31:65-81.

10. Mook S, Schmidt MK, Viale G, et al. The 70-gene prognosis-signature predicts disease outcome in breast cancer patients with 1-3 positive lymph nodes in an independent validation study. Breast Cancer Res Treat 2009;116:295-302.

11. Mook S, Knauer M, Bueno-de-Mesquita JM, et al. Metastatic potential of T1 breast cancer can be predicted by the 70-gene MammaPrint signature. Ann Surg Oncol 2010;17:1406-1413. 
Samenvatting 
148 


\section{Samenvatting}

Jaarlijks wordt in Nederland bij 12.000 vrouwen de diagnose borstkanker gesteld. De prognose van borstkanker wordt onder meer negatief beïnvloed door de aanwezigheid van uitzaaiingen in de lymfeklieren in de oksel. Tot ruim 10 jaar geleden werden de oksellymfeklieren bij elke patiënt met borstkanker operatief verwijderd, door middel van een zogeheten okselklierdissectie. Een complicatie van deze ingreep is het ontstaan van lymfoedeem in de arm, pijn, gevoelloosheid of een bewegingsbeperking van de arm en schouder.

Om de kans op bovengenoemde complicaties te verminderen werd de schildwachtklierprocedure eind jaren negentig van de vorige eeuw ingevoerd. Tijdens deze procedure wordt een blauwe en radioactieve vloeistof ingespoten rond de tumor in de borst. De lymfe vanuit de tumor verkleurt hierdoor blauw en wordt radioactief. Deze lymfe komt uit op één of meerdere klieren in de oksel, de zogenaamde schildwachtklieren. Vanuit daar verspreidt de lymfe zich verder naar andere klieren in de oksel. De schildwachtklieren worden door de chirurg geïdentificeerd door hun blauwe verkleuring en de aanwezigheid van radioactiviteit. Deze klier(en) worden verwijderd en door de patholoog intensief onderzocht op de aanwezigheid van uitzaaiingen. Als er geen uitzaaiingen worden gevonden in de schildwachtklieren is de kans op uitzaaiingen in de achtergebleven okselklieren heel klein. Daarom hoeven deze klieren niet meer verwijderd te worden en is de kans op een van de boven genoemde complicaties veel kleiner.

De verwijderde schildwachtklieren worden veel intensiever onderzocht op de aanwezigheid van uitzaaiingen dan de oksellymfeklieren die tijdens een okselklierdissectie worden verwijderd. Er worden meerdere plakjes (coupes) gesneden van een lymfeklier en er wordt een speciale (immunohistochemische) kleuring toegepast waarmee heel kleine uitzaaiingen eenvoudiger herkend kunnen worden. Door het gebruik van deze technieken worden er vaker kleine uitzaaiingen in schildwachtklieren gevonden. Deze kleine uitzaaiingen worden geïsoleerde tumorcellen (kleiner of gelijk aan 0,2 $\mathrm{mm}$ ) of micrometastasen $(0,2-2 \mathrm{~mm}$ ) genoemd. In dit proefschrift worden de resultaten beschreven van onderzoek naar de invloed van deze kleine uitzaaiingen op de prognose van borstkanker.

In hoofdstuk 1 wordt een inleiding gegeven op het proefschrift en wordt beschreven welke onderwerpen in de verschillende hoofdstukken aan bod komen.

In hoofdstuk 2 geven we een overzicht van studies die eerder werden verricht naar de invloed van geïsoleerde tumorcellen en micrometastasen op de prognose van borstkanker. In dit overzicht werden de studies verdeeld in drie categorieën. De eerste categorie bestond uit cohort studies, dat wil zeggen studies gebaseerd op 
gegevens uit verschillende kankerregistraties. Wanneer de resultaten van deze studies bij elkaar werden genomen bleek dat de aanwezigheid van metastasen van $2 \mathrm{~mm}$ of kleiner in oksellymfeklieren leidde tot een kleinere kans op overleving dan wanneer er geen uitzaaiingen in de oksellymfeklieren aanwezig waren. Dit verschil bleef bestaan wanneer er werd gecorrigeerd voor verschillen in kenmerken van patiënten zoals leeftijd, tumortype en behandeling. De tweede categorie bestond uit studies naar occulte metastasen, dat wil zeggen metastasen die pas werden gevonden na uitgebreid aanvullend onderzoek van lymfklieren die in eerste instantie geen metastasen leken te bevatten. Uit analyse van de resultaten van deze studies bleek dat de aanwezigheid van occulte metastasen leidde tot een grotere kans op terugkeer van ziekte of overlijden. In deze studies konden we echter de invloed van occulte metastasen op de prognose onafhankelijk van de andere patiëntkenmerken niet bepalen. De derde categorie bestond uit studies naar de invloed van geïsoleerde tumorcellen en micrometastasen in het huidige tijdperk waarin de schildwachtklierprocedure wordt uitgevoerd. Omdat deze techniek vrij recent werd ingevoerd, waren vrijwel alle studies klein en was de tijd dat patiënten na diagnose vervolgd werden kort. Daarom konden we geen uitspraak doen over de invloed van geïsoleerde tumorcellen en micrometastasen in schildwachtklieren op de prognose van borstkanker. We concluderen dat de resultaten van grote studies in het schildwachtkliertijdperk moeten worden afgewacht om meer duidelijkheid te krijgen over de invloed van deze kleine uitzaaiingen op de prognose.

In het kader van de MIRROR (Micrometastases or Isolated tumor cells: Relevant and Robust Or Rubbish?)-studie die in hoofdstuk 4 wordt besproken, beoordeelden 2 ervaren pathologen de schildwachtklieren van meer dan 3000 patiënten opnieuw op de aanwezigheid van uitzaaiingen. In hoofdstuk 3 beschrijven we de resultaten van onderzoek waarbij we 103 schildwachtklieren van patiënten in de MIRROR-studie door beide pathologen afzonderlijk lieten beoordelen op de aanwezigheid van uitzaaiingen. Het doel was de overeenstemming in beoordeling te onderzoeken. Deze overeenstemming bleek niet alleen goed wanneer de klieren werden geclassificeerd volgens de internationaal geldende criteria, maar ook wanneer de gemeten diameters of de gemeten oppervlakken van de uitzaaiingen werden vergeleken. Mogelijk was de overeenstemming in de beoordeling van de schildwachtklieren zo goed, omdat we voor aanvang van de MIRROR-studie een bijeenkomst met de pathologen hadden georganiseerd waarin de richtlijnen voor beoordeling van kleine lymfklieruitzaaiingen besproken werden. De resultaten van dit onderzoek zijn een bevestiging van de betrouwbaarheid van de resultaten van de MIRROR-studie.

In hoofdstuk 4 worden de belangrijkste resultaten van de MIRROR-studie beschreven. In deze studie onderzochten we de invloed van geïsoleerde tumorcellen en micrometastasen in lymfeklieren op de prognose van patiënten met borstkanker die een schildwachtklierprocedure hadden ondergaan. In de tijd dat de MIRROR-studie 
werd opgezet was er discussie over de invloed van geïsoleerde tumorcellen of micrometastasen op de prognose van borstkanker. De richtlijn voor behandeling van borstkanker die destijds gold, liet de keuze voor het al dan niet geven van adjuvante systeemtherapie (chemotherapie en/of hormoontherapie) om die reden over aan de individuele behandelaar. De helft van de Nederlandse borstkankerbehandelaars behandelden patiënten met geïsoleerde tumorcellen of micrometastasen met adjuvante systeemtherapie, omdat zij van mening waren dat de aanwezigheid van deze kleine uitzaaiingen de prognose ongunstig beïnvloedde. De andere helft van de Nederlandse borstkankerbehandelaars waren niet van mening dat deze kleine uitzaaiingen de prognose negatief beïnvloedde en adviseerden patiënten daarom geen adjuvante systeemtherapie. Van deze bijzondere situatie, waarbij een groep patiënten op twee verschillende manieren wordt behandeld, hebben wij in de MIRROR-studie gebruik gemaakt. Uit de gegevensbanken van alle integrale kankercentra in Nederland werden de anonieme gegevens verkregen van alle patiënten bij wie vóór 2006 de diagnose borstkanker was gesteld en bij wie een schildwachtklierprocedure was uitgevoerd. Alleen patiënten die borstkanker hadden in een vroeg stadium, waarbij er vanwege de tumor in de borst geen nabehandeling met adjuvante systeemtherapie noodzakelijk was, werden in de studie geïncludeerd. Vervolgens werden er drie groepen samengesteld: één controle groep van patiënten zonder lymfklieruitzaaiingen bij wie de diagnose in 2000 of 2001 werd gesteld, één groep van patiënten bij wie geïsoleerde tumorcellen of micrometastasen in de lymfeklieren waren gevonden en die geen behandeling met adjuvante systeemtherapie hadden ondergaan, en één groep van patiënten bij wie geïsoleerde tumorcellen of micrometastasen in de lymfeklieren waren gevonden en die wel een behandeling met adjuvante systeemtherapie hadden ondergaan. Alle schildwachtklieren en positieve niet-schildwachtklieren van deze patiënten werden, zoals eerder beschreven, opnieuw beoordeeld. Het doel van deze studie was de overleving zonder dat de ziekte was teruggekomen te bepalen voor de drie patiëntengroepen. De patiënten in de studie werden gemiddeld vervolgd tot 5,1 jaar na de diagnose. Vergeleken met de controle groep zonder lymfklieruitzaaiingen hadden meer patiënten met geïsoleerde tumorcellen of micrometastasen die geen behandeling met adjuvante systeemtherapie hadden ondergaan de ziekte teruggekregen. De slechtere prognose werd veroorzaakt door de aanwezigheid van geïsoleerde tumorcellen of micrometastasen. De negatieve invloed van geïsoleerde tumorcellen was net zo groot als die van micrometastasen. Vergeleken met de groep patiënten met kleine lymfklieruitzaaiingen die géén adjuvante systeemtherapie hadden ondergaan, hadden minder patiënten in de groep met kleine uitzaaiingen mét adjuvante systeemtherapie de ziekte teruggekregen. We concluderen dat geïsoleerde tumorcellen en/of micrometastasen in lymfklieren een vergelijkbaar, negatief effect hebben op de kans op terugkeer van ziekte. De kans op terugkeer van ziekte is kleiner bij patiënten met geïsoleerde tumorcellen of micrometastasen in lymfklieren die adjuvante systeemtherapie hadden ondergaan. 
De invloed van de uitgebreidheid, de lokalisatie en de grootte van kleine uitzaaiingen in een lymfklier op de kans op terugkeer van ziekte werd verder onderzocht in de groep patiënten met geïsoleerde tumorcellen, die geen adjuvante systeemtherapie hadden ondergaan. In hoofdstuk 5 beschrijven we hiervan de resultaten. De kans op terugkeer van ziekte in de groep van patiënten die één of meerdere losse tumorcellen in hun lymfklieren hadden was vergelijkbaar met de kans op terugkeer van ziekte in de groep patiënten die één of meerdere groepjes van tumorcellen in hun lymfklieren hadden. De kans op terugkeer van ziekte was vergelijkbaar bij uitzaaiingen in de lymfebaantjes van de lymfklier ten opzichte van uitzaaiingen in het lymfklierweefsel zelf. Het risico op terugkeer van ziekte nam toe als de grootte van de uitzaaiing in de lymfklier verdubbelde.

In hoofdstuk 6 beschrijven we een onderzoek waarbij we analyseren of het kosteneffectief is om adjuvante systeemtherapie te geven aan patiënten met geïsoleerde tumorcellen of micrometastasen in hun lymfklieren. Het doel van de studie was om te bepalen hoeveel extra kosten er moeten worden gemaakt in de groep patiënten die adjuvante systeemtherapie krijgt om terugkeer van ziekte te voorkomen. Een tweede doel was om te bepalen wanneer het geven van adjuvante systeemtherapie kostenbesparend zou kunnen worden. De gemiddelde kosten per patiënt vanaf diagnose tot 5 jaar na diagnose bedroegen $€ 15119$ in de groep patiënten met geïsoleerde tumorcellen of micrometastasen die geen adjuvante systeemtherapie ondergingen en $€ 18059$ in de groep patiënten met geïsoleerde tumorcellen of micrometastasen die wel adjuvante systeemtherapie ondergingen. Om bij één patiënt terugkeer van ziekte te voorkomen moet $€ 36300$ worden geïnvesteerd. Wanneer de kosten en de effecten op terugkeer van ziekte in de toekomst worden geschat, blijkt dat 18 jaar na de diagnose de kosten in de patiëntengroep zonder adjuvante systeemtherapie die van de patiëntengroep met adjuvante systeemtherapie overstijgen. Op dat moment wordt het geven van adjuvante systeemtherapie aan patiënten met geïsoleerde tumorcellen of micrometastasen dus zelfs kostenbesparend.

In hoofdstuk $\mathbf{7}$ geven we een overzicht van de literatuur die is gepubliceerd over de kans op uitzaaiingen in de achtergebleven okselklieren (die kunnen worden verwijderd bij een okselklierdissectie) wanneer er geïsoleerde tumorcellen worden gevonden in de schildwachtklier. We beschrijven 29 studies, waarbij de gemiddelde kans op uitzaaiingen in achtergebleven okselklieren $12,3 \%$ was wanneer er geïsoleerde tumorcellen aanwezig waren in de schildwachtklier. In $64 \%$ van de gevallen werden er in deze klieren macrometastasen (uitzaaiingen groter dan $2 \mathrm{~mm}$ ) gevonden. Omdat de kans op uitzaaiingen in de achtergebleven okselklieren bij geïsoleerde tumorcellen in de schildwachtklieren maar net iets groter was dan wanneer er geen uitzaaiingen in de schildwachtklieren zouden zijn gevonden, 
concluderen we dat - net als wanneer er geen uitzaaiingen in de schildwachtklieren worden gevonden - er bij geïsoleerde tumorcellen in de schildwachtklier geen okselklierdissectie hoeft te worden uitgevoerd. Een uitzondering kan worden gemaakt voor patiënten die geen adjuvante systeemtherapie krijgen vanwege de gunstige kenmerken van de tumor in de borst en waarbij het vinden van uitzaaiingen in achtergebleven okselklieren aanleiding zou zijn om een patiënt toch adjuvante systeemtherapie te geven.

Een deel van de patiënten met geïsoleerde tumorcellen of micrometastasen in de MIRROR-studie onderging na de schildwachtklierprocedure geen aanvullende okselklierdissectie. In hoofdstuk 8 beschrijven we het effect hiervan op de kans op het optreden van een regionaal recidief, dat wil zeggen terugkeer van ziekte in de oksel. De kans op een regionaal recidief bij patiënten met een negatieve schildwachtklier die geen okselklierdissectie ondergingen was net zo groot als bij patiënten met een negatieve schildwachtklier die wel een okselklierdissectie ondergingen. Dit gold ook voor patiënten met geïsoleerde tumorcellen in de schildwachtklier. Voor patiënten met micrometastasen in de schildwachtklier die geen okselklierdissectie ondergingen was er echter wel een grotere kans op regionaal recidief. Een regionaal recidief trad binnen 5 jaar op bij $5.6 \%$ van de patiënten met micrometastasen die geen okselklierdissectie ondergingen en bij $1 \%$ van de patiënten met micrometastasen die wel een okselklierdissectie ondergingen. Patiënten met een grotere of agressievere tumor in de borst of een tumor die niet hormoongevoelig was bleken een grotere kans te hebben op een regionaal recidief.

In hoofdstuk 9 worden de resultaten samengevat, worden conclusies getrokken en wordt vooruitgeblikt op de toekomst. We hebben in dit proefschrift laten zien dat geïsoleerde tumorcellen en micrometastasen prognostisch van belang zijn. In de huidige praktijk zal hun aanwezigheid het besluit om wel of geen adjuvante systeemtherapie te adviseren niet vaak beïnvloeden, omdat tegenwoordig al bij kleinere borsttumoren dan in de tijd van de MIRROR-studie adjuvante systeemtherapie wordt geadviseerd. Recent werd een onderzoek gepubliceerd waarin patiënten met (micro)metastasen in maximaal 2 schildwachtklieren waren geloot tussen het uitvoeren of het achterwege laten van een okselklierdissectie. Deze patiënten hadden allemaal een borstsparende operatie en aanvullende borstbestraling ondergaan en bijna allemaal een behandeling met adjuvante systeemtherapie ondergaan. De kans op een regionaal recidief en terugkeer van ziekte was vergelijkbaar in beide groepen. Deze resultaten staan in contrast met ons onderzoek, waarin we vonden dat de kans op regionaal recidief veel groter is bij patiënten met micrometastasen in de schildwachtklier die geen okselklierdissectie hadden ondergaan. Het verschil wordt mogelijk verklaard doordat een deel van de patiënten in ons onderzoek een borstamputatie ondergingen zonder aanvullende bestraling en dat een deel van de patiënten geen adjuvante systeemtherapie 
ondergingen. We vinden dan ook dat bij patiënten die geen borstsparende operatie ondergaan en bij wie micrometastasen worden gevonden in de schildwachtklieren een okselklierdissectie niet achterwege gelaten mag worden. Nieuw onderzoek is nodig om te bepalen of een okselklierdissectie ook veilig achterwege gelaten kan worden als er een borstamputatie wordt uitgevoerd. Omdat de aanwezigheid van micrometastasen invloed kan hebben op beleidsbeslissingen, met name omtrent het uitvoeren van een okselklierdissectie, moet de bewerking van een schildwachtklier gericht zijn op het kunnen vinden van micrometastasen. Dit kan worden bewerkstelligd met een protocol waarbij de schildwachtklier op 5 niveaus wordt aangesneden met een tussenruimte van $250 \mu \mathrm{m}$ en het toepassen van een immunohistochemische kleuring als het eerste niveau met een normale kleuring geen metastasen laat zien. Tegenwoordig wordt veel onderzoek gedaan naar het gebruik van genexpressieprofielen om een betere inschatting te kunnen maken van het risico op terugkeer van ziekte en het effect van adjuvante systeemtherapie voor een individuele patiënt. Wanneer deze profielen in de dagelijkse praktijk gebruikt gaan worden, zullen we de rol van de okselklier status en de rol van chirurgie van de oksel opnieuw moeten onderzoeken. Het uiteindelijke doel is om te komen tot zorg op maat, waarbij chirurgie in de oksel zo beperkt mogelijk verricht wordt zonder in te boeten op de veiligheid voor een patiënt. Tot die tijd blijft het evalueren van de aanwezigheid van uitzaaiingen in de okselklieren door middel van een schildwachtklierprocedure een hoeksteen van de diagnose en behandeling van patiënten met vroeg stadium borstkanker. 
156 


\section{List of publications}

P.W.J. van Dongen, M. de Boer, W.A.J.G. Lemmens, G.B. Theron. Hypermobility and peripartum pelvic pain syndrome in pregnant South African women. Eur J Obstet Gynecol Reprod Biol 1999;84:77-82.

M. de Boer, M.T.J.M. Mol, M.J.J.T. Bogman, J.M.D. Galama, R.A.P. Raymakers. Chronic active Epstein-Barr virus infection in an adult with no detectable immune deficiency. Neth J Med 2003;61:376-382.

I.M.E. Desar, M. de Boer, C.P.M. Bens, J.A. Jacobs, J.W. Mouton, A.S.M. Dofferhoff, C.H.W. Klaassen. Rapid and reliable identification of Streptococcus anginosus group isolates to the species level by real-time PCR and melting curve analysis. J Microbiol Methods 2008;75:372-374.

C.H.M. van Deurzen, M. de Boer, E.M. Monninkhof, P. Bult, E. van der Wall, V.C.G. Tjan-Heijnen, P.J. van Diest. Non-sentinel lymph node metastases associated with isolated breast cancer cells in the sentinel node. J Natl Cancer Inst 2008;100:15741580.

C.H.M. van Deurzen, P. Bult, M. de Boer, R. Koelemij, R. van Hillegersberg, V.C.G. TjanHeijnen, M.G. Hobbelink, P.C. de Bruin, P.J. van Diest. Morphometry of isolated tumor cells in breast cancer sentinel lymph nodes; metastases or displacement? Am J Surg Pathol 2009;33:106-110.

M. de Boer, C.H.M. van Deurzen, J.A.A.M van Dijck, G.F. Borm, P.J. van Diest, E.M.M. Adang, J.W.R. Nortier, E.J.Th. Rutgers, C. Seynaeve, M.B.E. Menke-Pluymers, P. Bult, V.C.G. Tjan-Heijnen. Micrometastases or isolated tumor cells and the outcome of breast cancer. N Engl J Med 2009;361:653-663.

V.C.G. Tjan-Heijnen, M. de Boer. Minimal lymph node involvement and outcome of breast cancer. The results of the Dutch MIRROR study. Discov Med 2009;8:137-139.

P.J. van Diest, M. de Boer, C.H.M. van Deurzen, V.C.G. Tjan-Heijnen. Micrometastases and isolated tumor cells in breast cancer are indeed associated with poorer outcome. J Clin Oncol 2010;28:e140; author reply e141-142.

M. de Boer, J.A.A.M. van Dijck, P. Bult, G.F. Borm, V.C.G. Tjan-Heijnen. Breast cancer Prognosis and occult lymph node metastases, isolated tumor cells, and micrometastases. J Natl Cancer Inst 2010;102:410-425. 
M.J.A.E. Pepels, J.H.M.J. Vestjens, M. de Boer, M. Smidt, P.J. van Diest, G.F. Borm, V.C.G. Tjan-Heijnen. Safety of avoiding routine use of axillary dissection in early stage breast cancer: a systematic review. Breast Cancer Res Treat 2011;125:301-313.

J.H.M.J. Vestjens, M. de Boer, P.J. van Diest, C.H.M. van Deurzen, J.A.A.M. van Dijck, G.F. Borm, E.M.M. Adang, P. Bult, V.C.G. Tjan-Heijnen. Prognostic impact of isolated tumor cells in breast cancer axillary nodes: single tumor cell(s) versus tumor cell cluster(s) and microanatomic location. Breast Cancer Res Treat 2012;131:645-651.

M.J.A.E. Pepels, M. de Boer, P. Bult, J.A.A.M. van Dijck, C.H.M. van Deurzen, M.B.E. Menke-Pluymers, P.J. van Diest, G.F. Borm, V.C.G. Tjan-Heijnen. Regional recurrence in breast cancer patients with sentinel node micrometastases and isolated tumor cells. Ann Surg 2012;255:116-121.

M. de Boer, E.M.M. Adang, K.C.G. Van Dycke, J.A.A.M. van Dijck, G.F. Borm, S.C. Seferina, C.H.M. van Deurzen, P.J. van Diest, P. Bult, A.R.T. Donders, V.C.G. TjanHeijnen. Cost-effectiveness of adjuvant systemic therapy in low-risk breast cancer patients with nodal isolated tumor cells or micrometastases. Ann Oncol 2012; Epub ahead of print.

J.H.M.J. Vestjens, M.J.A.E. Pepels, M. de Boer, G.F. Borm, C.H.M. van Deurzen, P.J. van Diest, J.A.A.M. van Dijck, E.M.M. Adang, J.W.R. Nortier, E.J.Th. Rutgers, C. Seynaeve, M.B.E. Menke-Pluymers, P. Bult, V.C.G. Tjan-Heijnen. Relevant impact of central pathology review on nodal classification in individual breast cancer patients. Ann Oncol 2012; Epub ahead of print. 
160 


\section{Dankwoord}

De kracht van de MIRROR-studie die wordt beschreven in dit proefschrift ligt in de deelname van alle integrale kankercentra en alle Nederlandse ziekenhuizen en laboratoria voor pathologie. Daardoor is dit onderzoek een reflectie geworden van de dagelijkse Nederlandse praktijk met betrekking tot de behandeling en de prognose van borstkankerpatiënten met geïsoleerde tumorcellen of micrometastasen in okselklieren na een schildwachtklierprocedure. Ik wil daarom alle pathologen, chirurgen en internist-oncologen bedanken voor hun belangeloze medewerking aan dit onderzoek. Door ondersteuning van de Borstkanker Onderzoek Groep (BOOG) was er een breed draagvlak voor deze studie. Door financiële ondersteuning van ZonMw hebben wij dit project kunnen uitvoeren. Daarnaast hebben vele anderen bijgedragen aan het tot stand komen van dit proefschrift, waarvoor ik hen hartelijk wil bedanken. Een aantal van hen wil ik in het bijzonder noemen.

Prof. dr. V.C.G. Tjan-Heijnen, beste Vivianne, ik voel me bevoorrecht dat ik met jou aan dit grootse project heb mogen werken. De combinatie van visie, daadkracht en zorgzaamheid maken jou tot een fantastische promotor. Je gaf me alle ruimte om invulling te geven aan het project en was nabij als het nodig was. Ik verheug me op onze samenwerking in Maastricht!

Mijn copromotor, dr. P. Bult, beste Peter, zelden heb ik iemand ontmoet met zoveel passie voor zijn vak als jij. Je laat je niet van de wijs brengen en hebt oog voor detail. Dat de revisie van alle schildwachtklieren zo'n klus zou zijn, wisten we van tevoren (gelukkig) niet. Jouw enorme bijdrage hieraan is van cruciaal belang geweest voor het slagen van de MIRROR-studie.

Mijn copromotor, dr. E.M.M. Adang, beste Eddy, jij hebt me wegwijs gemaakt in de wereld van de gezondheidseconomie. Jouw betrokkenheid bij het project en jouw kritische, zinvolle bijdragen waren vanaf het begin groot. Je toegankelijkheid en je oog voor de mens achter de promovenda waardeer ik zeer.

De projectgroep van de MIRROR-studie is belangrijk geweest voor de voortgang van de studie en de resultaten die we hebben geboekt. Onze besprekingen waren nooit saai en altijd zinvol. Prof. dr. P.J. van Diest, beste Paul, op jouw ontwapenende, charmante wijze heb je veel bijgedragen aan dit project. Jij hebt me geleerd te denken in mogelijkheden in plaats van onmogelijkheden. Dr. J.A.A.M. van Dijck, beste Jos, bedankt voor onze samenwerking op het IKO en voor je epidemiologische input in het project. Dr. C.H.M. van Deurzen, beste Carolien, duizend maal dank voor een essentieel onderdeel van het project: de revisie van een onbeschrijfelijke hoeveelheid coupes. Fijn dat we elkaar tegen blijven komen. Prof. dr. G.F. Borm, beste George, bedankt voor je efficiënte en krachtige statistische bijdragen aan het project. 
Dr. Th. de Boo, beste Theo, bedankt voor je bijdrage aan het interobserver-project. Dr. A.R.T. Donders, beste Rogier, bedankt voor je bijdrage aan de kosteneffectiviteitsanalyse. Dr. Caroline Seynaeve, dr. Marian Menke-Pluijmers, prof. dr. Hans Nortier, prof. dr. Emiel Rutgers, bedankt voor jullie kritische input. Manon Pepels en Hanneke Vestjens, fijn dat jullie het stokje overnemen!

Alle integrale kankercentra (thans IKNL en IKZ) wil ik bedanken voor hun deelname aan dit onderzoek. Door dit onderzoek is het belang en de hoge kwaliteit van de Nederlandse kankerregistratie mij nog duidelijker geworden. In het bijzonder wil ik bedanken Otto Visser, Michael Schaapveld, Marlies Janssen-Landheer, Pieta Krijnen, Wilma Kloosterman, Margriet van der Heijden, Mirian Brink, Gitty Jaanen-van der Sanden, Mariska Janssen-Heijnen, Anke Willemse, Johan Bruijnen, Miranda Dirx, Sabine Siesling, Marloes Elferink, Della Kleinjan, Ronald Damhuis en Ardine Reedijk. Daarnaast wil ik alle registratiemedewerkers bedanken die voor deze studie duizenden CRF's op zeer zorgvuldige wijze hebben ingevuld.

Het voormalige Integraal Kankercentrum Oost (IKO) (thans IKNL, locatie Nijmegen) heeft een bijzondere plaats in het onderzoek en in mijn hart gekregen. Mijn hele onderzoekstijd heb ik op het IKO doorgebracht. Het was als een warm bad om bij jullie te mogen werken en het is fijn dat ik met een aantal van jullie nog regelmatig contact heb. Christianne Lennards, ik wil je bedanken voor de ruimte, letterlijk en figuurlijk, en de begeleiding die je me hebt gegeven om het onderzoek optimaal te kunnen uitvoeren. Marjorie de Kok, de pilot van de MIRROR-studie hebben we in de IKO-regio uitgevoerd. Bedankt voor je inwijding in de wereld van de kankerregistratie en je bijdrage bij de uitvoering van de studie in de IKO-regio. Jolanda van Beek-Schoester, wat zou er van de studie terecht zijn gekomen zonder jou? Bedankt voor het lezen van duizenden PA-verslagen, invullen van CRF's, data-invoer en de landelijke coördinatie van registratie van alle CRF's. Katja Aben, bedankt voor je input en de 3-jarige cursus "Hoe leer ik een dokter omgaan met Excel, Access en SPSS". Bianca Schalk en Trienika Hidding-Luth, bedankt voor jullie hulp bij een scala aan programmeerklussen. Monique de Groot, Gerty Lummen, Kees Ebben, Jeannette Schraa en Marina Janssen, bedankt voor jullie registraties en feedback bij de pilot van de studie in de IKO-regio. Ingrid Derksen, Jenny Sperwer, Roos Putinela, Gerdy Beekhof en Ronald Snippe, bedankt voor jullie secretariële ondersteuning.

Wim Lemmens, beste Wim, op zeer vakkundige wijze heb jij alle data verwerkt en geanalyseerd. Meer dan eens was je mijn steun en toeverlaat. Veel dank voor alles.

Alle secretaresses en archiefmedewerkers van de laboratoria voor pathologie wil ik bedanken. Duizenden pathologie-verslagen moesten worden geanonimiseerd, en tienduizenden coupes moesten uit de archieven worden opgezocht en (op soms zeer creatieve wijze) verpakt en verzonden worden. 
Margrethe Schlooz, Rosemarie Jansen, Egbert Schretlen, Dominic Schinagl, Rob Simons, Jos van Loenhout, Kirsten Van Dycke, Harry van Montvoort, Liesbeth Boersma, Shanly Seferina, Anja Timmer-Bonte, Wietske Kievit, Anita Botterweck, Henk Huizenga, Peter Eijkhout, Wilma Stienen en Sam Stijns: veel dank voor jullie bijdrage aan de kosteneffectiviteitsanalyse.

Lilian Wishaupt, veel dank voor je secretariële ondersteuning.

Prof. dr. J.W.M. van der Meer, prof. dr. P.M.J. Stuyt, prof. dr. J. de Graaf en dr. C.P. Bleeker-Rovers, beste Jos, Paul, Jacqueline en Chantal, bedankt voor de mogelijkheid die jullie hebben geboden om dit onderzoek te combineren met mijn opleiding tot internist.

Prof. dr. W.T.A. van der Graaf, prof. dr. C.J.A. Punt en dr. J.N.H. Timmer-Bonte, beste Winette, Kees en Anja, bedankt voor jullie belangrijke bijdragen aan mijn opleiding tot medisch oncoloog. Door jullie flexibiliteit kon ik mijn opleiding combineren met het afronden van dit proefschrift. Alle oncologen, fellows, onderzoekers, (research)verpleegkundigen, doktersassistentes en ondersteunend personeel van de afdeling Medische Oncologie in het UMC St Radboud: heel veel dank voor de fijne samenwerking.

Yvonne Grijzen, lieve Yvonne, mijn schoonzus, jij ontwierp voor mij een prachtige database die van onschatbare waarde is gebleken. Veel dank voor alles.

Marieke Bolster, lieve Marieke, al bijna 19 jaar delen wij lief en leed, en sinds 6 jaar ook onze promotor. Ik vind het fijn dat jij vandaag naast me staat.

Joke en Henk Grijzen, mijn lieve schoonouders, jullie staan altijd voor ons klaar. Bedankt voor jullie onuitputtelijke steun en interesse.

Bart en Pieter, mijn broers waar ik zo trots op ben, onze vriendschap is heel belangrijk voor mij. Pieter, fijn dat jij mijn paranimf wil zijn.

Mijn ouders, lieve papa en mama, met en door jullie onvoorwaardelijke liefde ben ik geworden wie ik ben. Jullie lieten mij m'n dromen najagen zonder me echt los te laten. Fijn dat jullie er zijn.

Lieve Brecht en Madelief, jullie zijn mijn grote geluk!

Allerliefste Frank, tijdens dit promotietraject beleefden wij samen de hoogtepunten en dieptepunten uit ons leven. Het heeft ons geleerd hoe krachtig onze liefde is. 
164 
166 


\section{Curriculum vitae}

Maaike de Boer werd geboren op 4 augustus 1975 te Cuijk en Sint Agatha. In 1993 behaalde zij het VWO diploma aan het Merletcollege in Cuijk. Vanaf 1993 studeerde zij Gezondheidswetenschappen aan de Katholieke Universiteit Nijmegen (thans: Radboud Universiteit Nijmegen), waar zij in 1994 haar propedeuse behaalde. Vanaf 1994 studeerde zij Geneeskunde aan dezelfde universiteit. In 1997 verbleef zij gedurende drie maanden voor een stage in het Deborah Retief Memorial Hospital in Mochudi, Botswana. In 2000 volgde zij haar afsluitend co-assistentschap in het Holy Family Hospital in Berekum, Ghana.

$\mathrm{Na}$ het behalen van haar artsexamen (cum laude) in mei 2000 was zij werkzaam als arts-assistent op de afdeling Interne Geneeskunde van het Canisius Wilhelmina Ziekenhuis te Nijmegen, alwaar zij in augustus 2001 startte met haar opleiding tot internist (opleider: dr. R.W. de Koning, later dr. A.S.M. Dofferhoff). In januari 2005 zette zij haar opleiding voort in het Universitair Medisch Centrum (UMC) St Radboud te Nijmegen (opleiders: prof. dr. J.W.M. van der Meer, prof. dr. P.M.J. Stuyt, prof. dr. J. de Graaf, dr. C.P. Bleeker-Rovers). Vanaf januari 2006 tot en met augustus 2009 werkte zij aan het onderzoek beschreven in dit proefschrift onder begeleiding van prof. dr. V.C.G. Tjan-Heijnen (Maastricht Universitair Medisch Centrum, afdeling Interne Geneeskunde, onderafdeling Medische Oncologie), dr. P. Bult (UMC St Radboud, afdeling Pathologie) en dr. E.M.M. Adang (UMC St Radboud, afdeling Epidemiologie, Biostatistiek en HTA). In 2011 ontving zij voor dit onderzoek de Henny C. Dirven Prijs. In september 2009 startte zij binnen de opleiding Interne Geneeskunde met het aandachtsgebied Medische Oncologie in het UMC St Radboud (opleider: prof. dr. W.T.A. van der Graaf, later dr. J.N.H. Timmer-Bonte). In januari 2010 vond registratie als internist plaats. In februari 2012 volgde registratie als internistoncoloog. Vanaf oktober 2012 zal zij werkzaam zijn als internist-oncoloog in het Maastricht Universitair Medisch Centrum.

Maaike de Boer is getrouwd met Frank Grijzen. Zij hebben twee dochters, Brecht (2008) en Madelief (2011). 
168 